\title{
A Comparative Study
}

of Emerging Vehicle Technology Assessments

Final Report

February 2011

Funding provided by:

U.S. Department of Energy

Vehicle Technologies Program
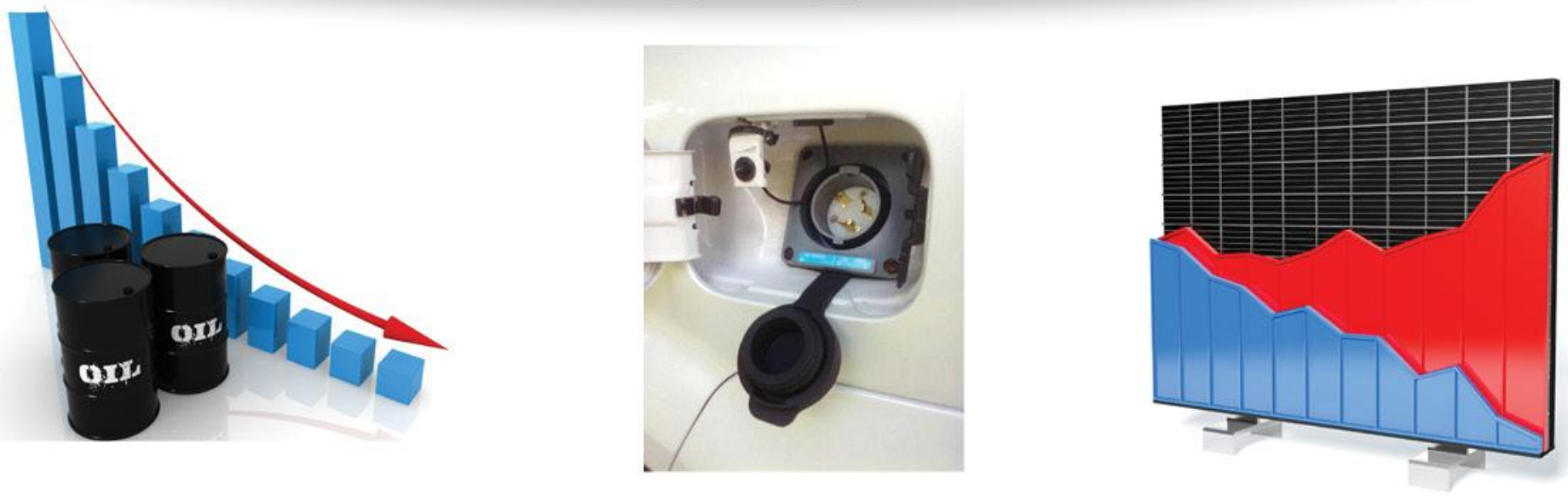


\section{DOCUMENT AVAILABILITY}

Reports produced after January 1, 1996, are generally available free via the U.S. Department of Energy (DOE) Information Bridge:

Web site: http://www.osti.gov/bridge

Reports produced before January 1, 1996, may be purchased by members of the public from the following source:

National Technical Information Service

5285 Port Royal Road

Springfield, VA 22161

Telephone: 703-605-6000 (1-800-553-6847)

TDD: 703-487-4639

Fax: 703-605-6900

E-mail: info@ntis.fedworld.gov

Web site: http://www.ntis.gov/support/ordernowabout.htm

Reports are available to DOE employees, DOE contractors, Energy Technology Data Exchange (ETDE)

representatives, and International Nuclear Information System (INIS) representatives from the following source:

Office of Scientific and Technical Information

P.O. Box 62

Oak Ridge, TN 37831

Telephone: 865-576-8401

Fax: 865-576-5728

E-mail: reports@adonis.osti.gov

Web site: http://www.osti.gov/contact.html

This report was prepared as an account of work sponsored by an agency of the United States Government. Neither the United States government nor any agency thereof, nor any of their employees, makes any warranty, express or implied, or assumes any legal liability or responsibility for the accuracy, completeness, or usefulness of any information, apparatus, product, or process disclosed, or represents that its use would not infringe privately owned rights. Reference herein to any specific commercial product, process, or service by trade name, trademark, manufacturer, or otherwise, does not necessarily constitute or imply its endorsement, recommendation, or favoring by the United States Government or any agency thereof. The views and opinions of authors expressed herein do not necessarily state or reflect those of the United States Government or any agency thereof. 


\title{
A Comparative Study \\ Of Emerging Vehicle Technology Assessments
}

\author{
Final Report
}

February 2011

OAK RIDGE NATIONAL LABORATORY

Oak Ridge, Tennessee 37831 managed by UT-BATTELLE, LLC

for the

U.S. DEPARTMENT OF ENERGY

under contract No. DE-AC05-00OR22725 
This page intentionally left blank. 


\section{Acknowledgements}

"A Comparative Study of Emerging Vehicle Technology Assessments" is a collaborative effort between Sentech, Inc., Oak Ridge National Laboratory (ORNL) and the U.S. Department of Energy (DOE). Funding for this report was provided by the DOE Vehicle Technologies Program. The following individuals from these organizations are among those who contributed to the preparation of this document or provided insight throughout the duration of this study:

Sentech, Inc. / SRA International
Julia Blackburn*
Jonathan Ford*
Gannate Khowailed*
Lawrence Markel
Dr. Ralph McGill
Karen Sikes*
Dick Ziegler

${ }^{*}$ Co-authors
ORNL

Bob DeVault

Stan Hadley

Dr. David E. Smith

DOE

Dave Anderson

Philip Patterson

Lee Slezak

Jacob Ward 
This page intentionally left blank. 


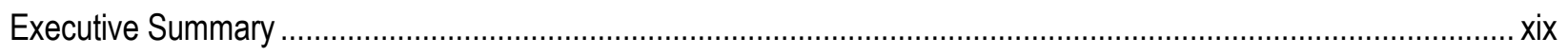

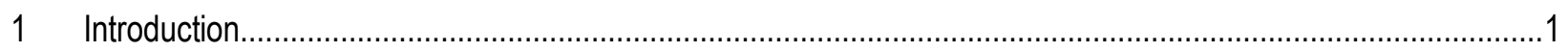

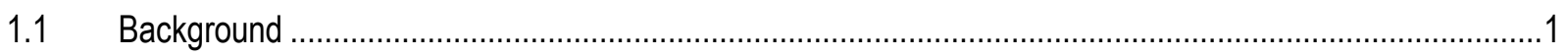

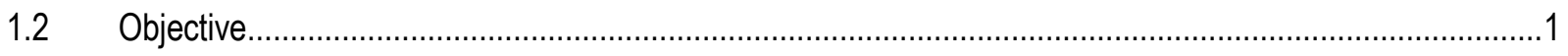

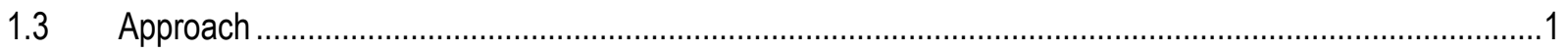

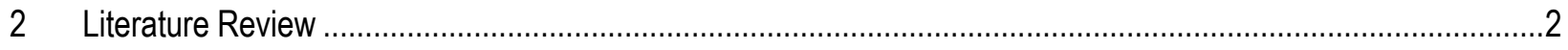

2.1 Massachusetts Institute of Technology (MIT) - "On the Road in 2035" Publication Date: 2008 Referred to

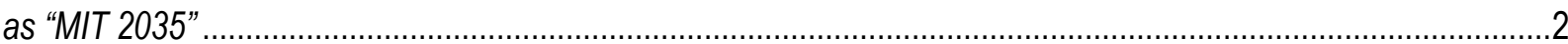

2.2 MIT - "Prospects for Plug-In Hybrid Electric Vehicles in the United States and Japan: A General Equilibrium Analysis" Publication Date: 2009 Referred to as "MIT Prop"...........................................................

2.3 Argonne National Laboratory (ANL) - "Impact of Component Size on Plug-In Hybrid Energy Consumption Using Global Optimization" Publication Date: 2008 Referred to as "ANL CS" .......................................................

2.4 ANL- "Impact of Real World Drive Cycles on PHEV Fuel Efficiency and Cost for Different Powertrain and Battery Characteristics" Publication Date: 2009 Referred to as "ANL EVS".

2.5 ANL - "Multi-Path Transportation Future Study: Vehicle Characterization and Scenario Analyses"

Publication Date: 2009 Referred to as "ANL MPT".

2.6 ANL - "Well-to-Wheels Analysis of Energy Use and Greenhouse Gas Emissions of Plug-in Hybrid Electric Vehicles" Publication Date: 2010 Referred to as "ANL WTW".

2.7 SENTECH, Inc. / ORNL - "Plug-in Hybrid Electric Vehicle Market Introduction Study" Publication Date:

2010 Referred to as "SENTECH/ORNL MIS"

2.8 SENTECH, Inc. / ORNL - "Plug-In Hybrid Electric Vehicle Value Proposition Study" Publication Date: 2010 Referred to as "SENTECH/ORNL VP".

2.9 ORNL - "Impact of Plug-in Hybrid Vehicles on the Electric Grid" Publication Date: 2006 Referred to as "ORNL Impact"...

2.10 Pacific Northwest National Laboratory (PNNL) - "Impacts Assessment of Plug-In Hybrid Vehicles on Electric Utilities and Regional U.S. Power Grids" Publication Date: 2007 Referred to as "PNNL Impact".

2.11 PNNL - "Plug-in Hybrid Electric Vehicle Annual Market Penetration Scenarios" Publication Date: 2008 Referred to as "PNNL MPS".

2.12 NREL - "Battery Requirements and Cost-Benefit Analysis for Plug-In Hybrid Vehicles" Presentation Date: 2007 Referred to as "NREL CBA".

2.13 NREL - "Using GPS Travel Data to Assess the Real World Driving Energy Use of Plug-in Hybrid Electric Vehicles" Publication Date: 2007 Referred to as "NREL GPS".

2.14 Electrification Coalition - "Electrification Roadmap: Revolutionizing Transportation and Achieving Energy Security" Publication Date: 2009 Referred to as "EC". 
2.15 U.S. Energy Information Administration (EIA) - "Annual Energy Outlook" Publication Date: 2010 Referred to as $A E O$...

2.16 EPRI/NRDC - "Environmental Assessment of Plug-In Hybrid Electric Vehicles, Volume 1: Nationwide Greenhouse Gas Emissions" Publication Date: 2007 Referred to as "EPRI"......

2.17 EPA - "Analysis of the Transportation Sector: Greenhouse Gas and Oil Reduction Scenarios" Publication Date: 2010 Referred to as "EPA".

2.18 National Research Council (NRC) - "Transitions to Alternative Transportation Technologies" Publication

Date: 2010 Referred to as "NRC".

2.19 Roland Berger - "Powertrain 2020 Li-ion Batteries - The Next Bubble Ahead?" Publication Date: 2010

Referred to as "Roland Berger".

2.20 Deloitte - "Gaining Traction: A customer view of electric vehicle mass adoption in the U.S. automotive market" Publication Date: 2010 Referred to as "Deloitte"......

2.21 Deutsche Bank - "Electric Cars: Plugged In" Publication Date: 2008 Referred to as "Deutsche Bank"....24

2.22 The Boston Consulting Group (BCG) - "The Comeback of the Electric Car" Publication Date: 2010

Referred to as "BCG".

2.23 UMTRI - "Market Models for Predicting PHEV Adoption and Diffusion" Publication Date: 2009 Referred to as "UMTRI".

2.24 Carnegie Mellon University (CMU) - "Life Cycle Assessment of Greenhouse Gas Emissions from Plug-in

Hybrid Vehicles: Implications for Policy" Publication Date: 2008 Referred to as "CMU". .26

2.25 California Cars Initiative (CalCars) - "Displacement of Petroleum \& $\mathrm{CO}_{2}$ Reductions from Super-Optimistic Business-as-Usual Mass Production of Light Vehicle PHEVs" Publication Date: 2009 Referred to as "CalCars"...28

2.26 University of Vermont (UVM) Transportation Center - "Plug-In Hybrid Vehicles and the Vermont Grid: A Scoping Analysis" Publication Date: 2008 Referred to as "UVM"...

2.27 JD Power and Associates -"Drive Green 2020: More Hope Than Reality?" Publication Date: 2010

Referred to as "JD Power".

2.28 University of California-Davis - "Plug-In Hybrid Vehicle GHG Impacts in California: Integrating ConsumerInformed Recharge Profiles with an Electricity-Dispatch Model" Publication Date: 2010 Referred to as "UCD" .....30

2.29 RAND Corporation - "Environmental, Security, and Economic Issues of Electricity as a Transportation Fuel" Publication Date: 2010 Referred to as "RAND".

2.30 The Institute of Electrical and Electronics Engineers (IEEE) - "A Review of Results from Plug-in Hybrid Electric Vehicle Impact Studies" Publication Date: 2009 Referred to as "IEEE"......

2.31 Toronto Atmospheric Fund - "Plug-In Hybrids: Prospects and Progress" Publication Date: 2007 Referred to as "TAF".

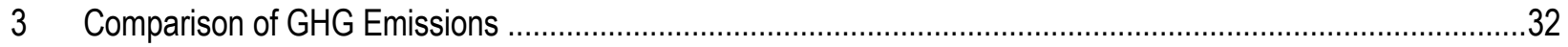

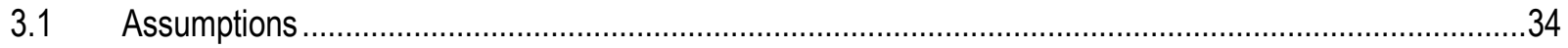

3.2 GHG Emissions Trends among Reports ......................................................................................... 40

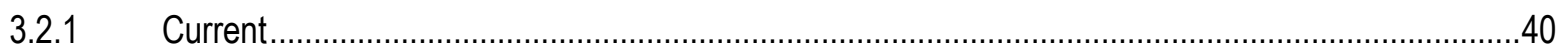




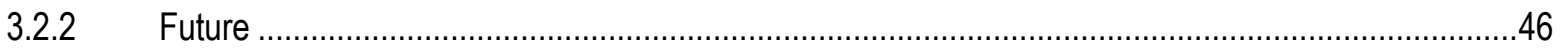

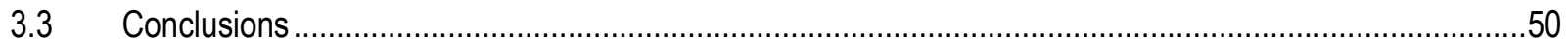

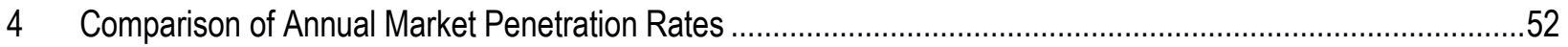

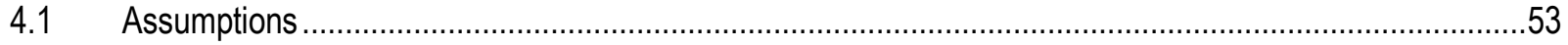

4.2 Annual Market Penetration Rates - Trends among Studies ................................................................62

4.2.1 PHEV Annual Market Penetration Scenarios................................................................................62

4.2.2 BEV and HEV Annual Market Penetration ............................................................................... 72

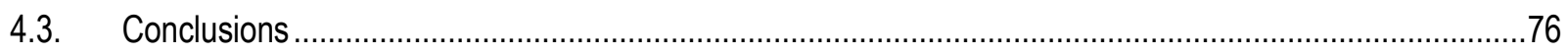

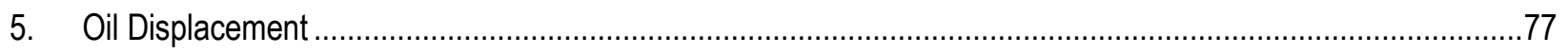

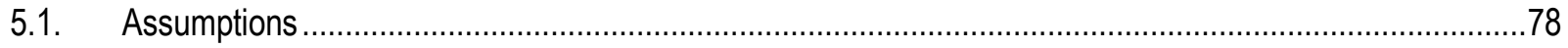

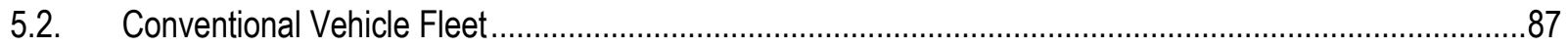

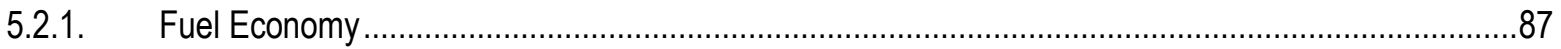

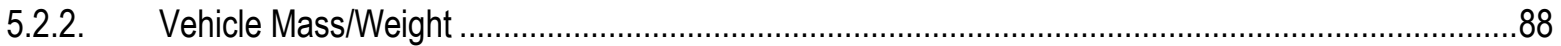

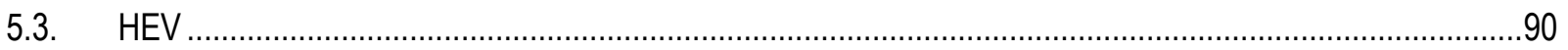

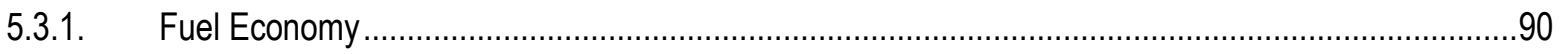

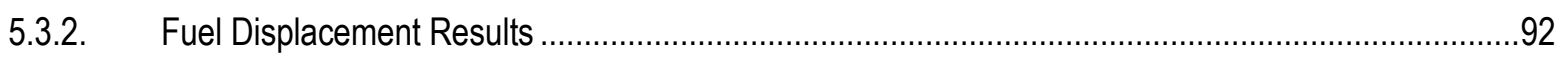

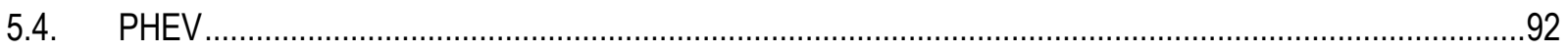

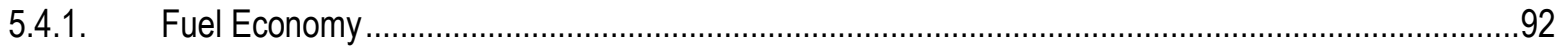

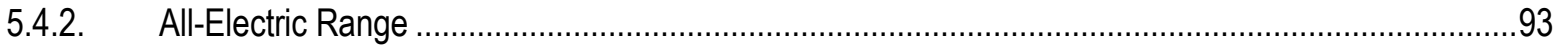

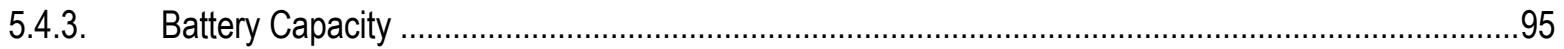

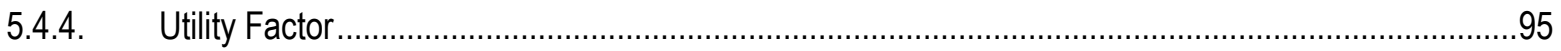

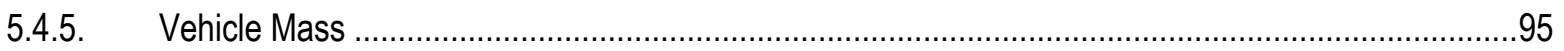

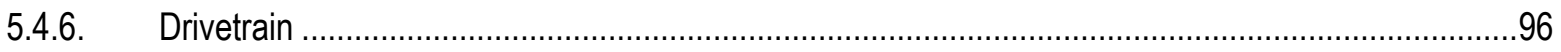

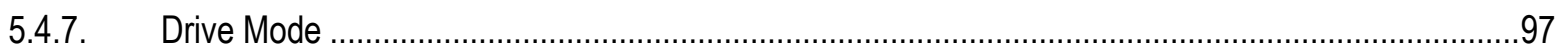

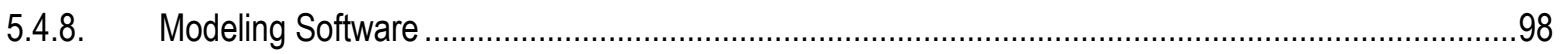

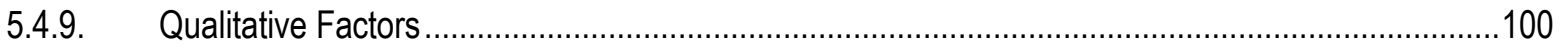

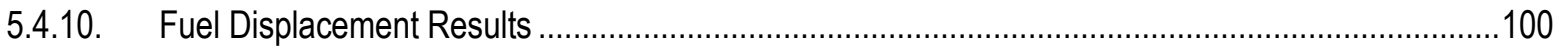

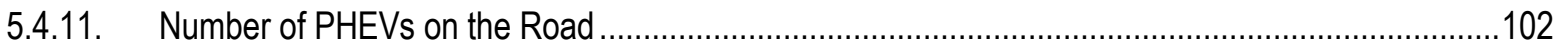

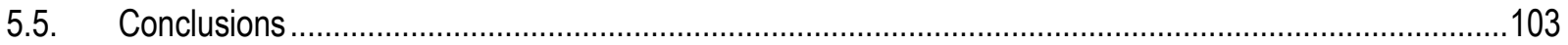

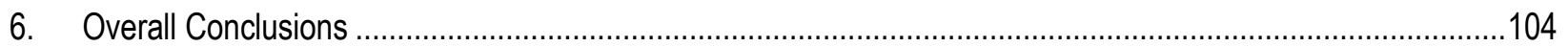

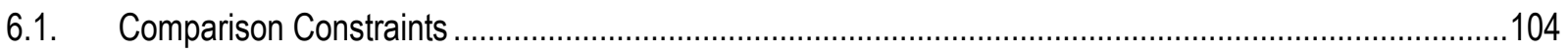

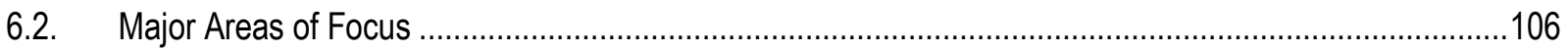

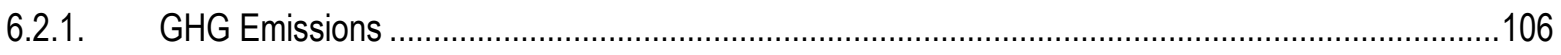




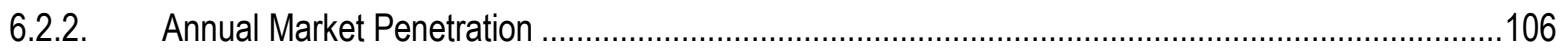

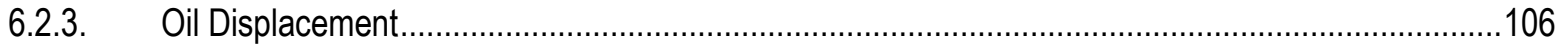

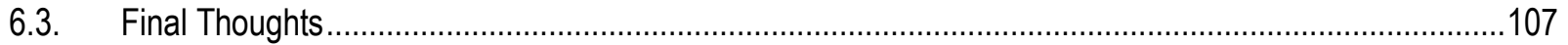

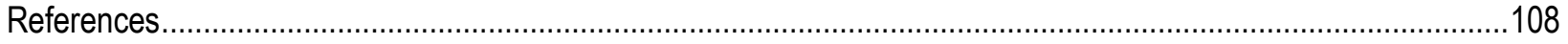

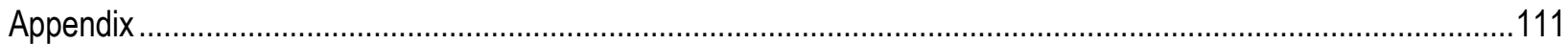




\section{List of Figures}

Figure 1: GHG Emission Projections from MIT 2035

Figure 2: WTW GHG emissions data for the year 2010 included in ANL CS .....................................................5

Figure 3: Trend of gasoline displacement with available battery power .............................................................

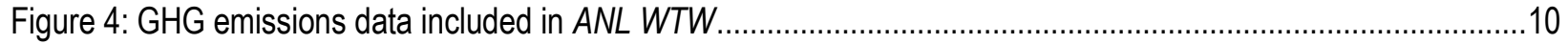

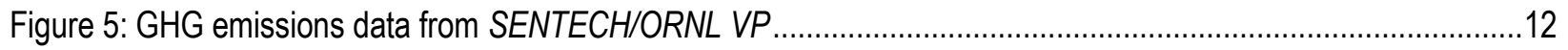

Figure 6: Selected GHG emissions data from the Electrification Coalition..............................................................18

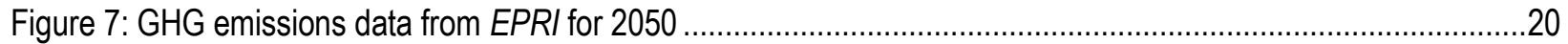

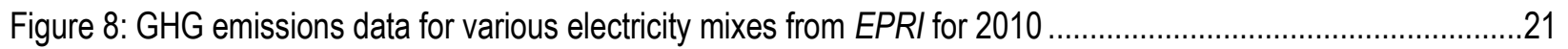

Figure 9: GHG emissions data for all scenarios in CMU using gasoline .............................................................27

Figure 10: GHG emissions data for all scenarios in CMU using cellulosic E85 ……...........................................27

Figure 11: Fleet fuel consumption savings as a function of PHEV sales, provided in CalCars ................................28

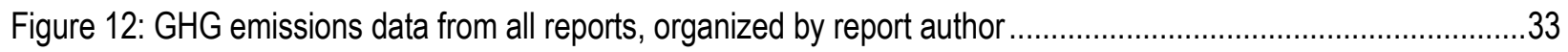

Figure 13: GHG emissions for current-day conventional vehicle ................................................................... 40

Figure 14: GHG emissions for current PHEVs using an average electricity generation mix and fuel blend...............41

Figure 15: Emissions for current PHEV30s using various electricity mixes and average fuel blend..........................42

Figure 16: GHG emissions for current PHEV30s using various electricity mixes, assuming an average fuel blend,

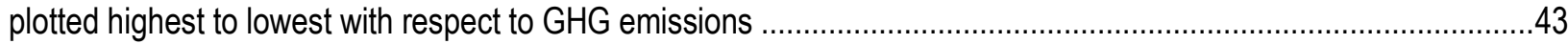

Figure 17: Emissions for current PHEV30s with various fuel blends powered by an "average" electricity generation

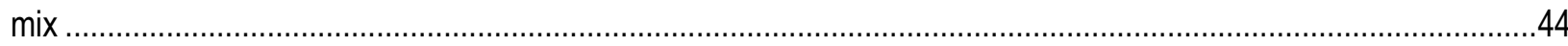

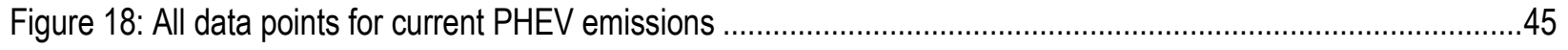

Figure 19: GHG emissions for future conventional vehicles using an average fuel blend .....................................46

Figure 20: GHG emissions for future PHEV30s using an average electricity mix and average fuel blend.................47

Figure 21: Future PHEV GHG emissions using various electricity generation mixes and an average fuel blend ........48

Figure 22: Future PHEV30 GHG emissions using various fuel blends and an "average" electricity generation mix....49

Figure 23: Future PHEV GHG emissions, including all electricity mixes and fuel blends .49

Figure 24: GHG emissions data for all vehicles and all senarios, plotted from highest to lowest with respect to GHG emissions

Figure 25: PHEV annual market penetration scenarios 2012 - 2050 by percentage of total annual sales.

Figure 26: PHEV annual market penetration scenarios spanning 2012 - 2050 (after connecting the single data points within the same study) .64

Figure 27: PHEV annual market penetration rates from 2012 - 2050 in terms of unit sales .65 
Figure 28: PHEV annual market penetration scenarios for 2050 and the concentration of scenarios

Figure 29: Timeline of publications of PHEV annual market penetration studies.

Figure 30: Polynomial trend for studies' publication year......

Figure 31: HEV annual market penetration projections from 2012 to 2050

Figure 32: HEV annual market penetration spanning 2012- 2050 (After Connecting the Data Points for Each

Scenario). . .73

Figure 33: BEV annual I market penetration scenarios 2012-2050 .74

Figure 34: BEV / PHEV annual market penetration scenarios for 2012 to 2050 .......................................................75

Figure 35: HEV/PHEV annual market penetration from 2012 to 2050

Figure 36: Projected conventional vehicle fuel economy out to 2050 with the current and 2016 CAFE standards marked.

Figure 37: Graph of the fuel economy values used for conventional vehicles, broken down by study......... .88

Figure 38: Variation in conventional vehicle fuel economy with mass .90

Figure 39: Gasoline displacement plotted with vehicle fuel economy .91

Figure 40: Vehicle fuel economy as a function of mass. . .91

Figure 41: PHEV fuel economy by study

Figure 42: Percent gasoline displaced by one PHEV compared to a single conventional vehicle as a function of its AER.

Figure 43: Gasoline displaced per PHEV as a function of VMT.

Figure 44: Correlation between battery power and fuel displacement from ANL EVS

Figure 45: SENTECH/ORNL VP provides information to calculate fuel economy for three different vehicle masses

and three different vehicle types . .96

Figure 46: Gasoline displacement as a function of AER and drivetrain configuration..... .97

Figure 47: Gasoline displacement with respect to the modeling software implemented in the analysis . .99

Figure 48: PHEV gasoline displacement per thousand miles driven per vehicle relative to a conventional vehicle...100 Figure 49: Annual oil displacement for per vehicle, broken down by publication relative to a conventional vehicle ..101 Figure 50: Oil displacement per thousand VMT. 102

Figure 51: Comparison Constraints 105 


\section{List of Tables}

Table 1: Vehicle market penetration rates included in MIT's "On the Road in 2035" ...............................................2

Table 2: PHEV annual market penetration rates projected in MIT Prop ................................................................

Table 3: ANL EVS fuel use data for PHEVs in real-world drive cycles .............................................................

Table 4: ANL EVS PHEV categories and corresponding AER values .................................................................

Table 5: ANL EVS fuel consumption by vehicle configuration ...........................................................................

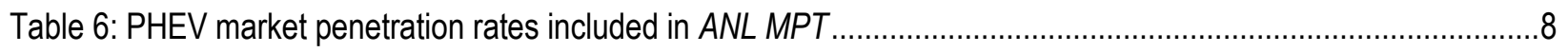

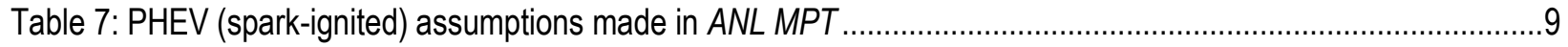

Table 8: PHEV market penetration from SENTECH/ORNL MIS ..........................................................................11

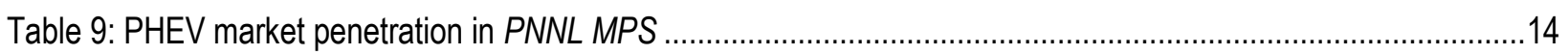

Table 10: NREL defines the effectiveness of electric vehicle technology to displace petroleum depending on driving

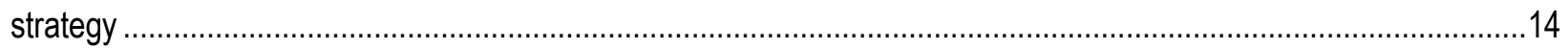

Table 11: Fuel economy and consumption for NREL's vehicle simulations .........................................................15

Table 12: Vehicle specifications for NREL's simulations using real-world driving data in NREL GPS ......................16

Table 13: Comparison of fuel economy results from GPS driving data compared to fuel economies calculated using EPA's standard test cycles.

Table 14: NREL comparison of the results calculated from the drive cycle GPS data for the AER of the PHEV20 and PHEV40.

Table 15: Annual PEV annual market penetration milestones from the Electrification Coalition's report. . .17

Table 16: Vehicle penetration rates projected in the Annual Energy Outlook 2010 ..................................................18

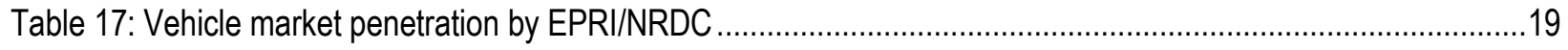

Table 18: Range of utility factors analyzed by EPRI/NRDC for each PHEV AER ...............................................20

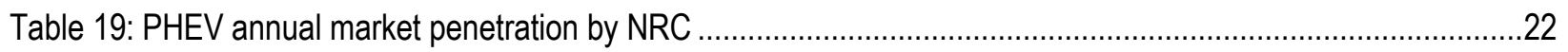

Table 20: Vehicle market penetration rate projections in Roland Berger's high scenario .....................................23

Table 21: Market penetration forecasts for electric vehicle technologies in Deloitte .............................................23

Table 22: Projected annual market penetration for electric vehicle technologies in Deutsche Bank ..........................24

Table 23: Projected annual market penetration rates for electric vehicle technologies in BCG ............................25

Table 24: Annual market penetration projections for PHEVs in UMTRI based on specific models ............................26

Table 25: PHEV annual market penetration rates provided by the Consideration Purchase Model ..........................26

Table 26: Predicted gasoline displacement for the state of Vermont with respect to the size of its PHEV fleet..........29

Table 27: Key assumptions used to guide analysis in the most relevant reports found ..........................................35

Table 28: Detailed assumptions for the "PHEV Value Proposition Study" written by SENTECH/ORNL .....................36 
Table 29: Detailed assumptions for the "Electrification Roadmap" published by the Electrification Coalition .36

Table 30: Detailed assumptions for MIT's "On the Road in 2035" .37

Table 31: Detailed assumptions for ANL's "WTW Analysis of Energy Use and GHG Emissions of PHEVs................37

Table 32: Detailed assumptions for ANL's “Impact of Component Size on PHEV Energy Consumption” ...................38

Table 33: Detailed assumptions for EPRI/NRDC's "Environmental Assessment of PHEVs, Volume 1" .....................38

Table 34: Detailed assumptions for EPA's "Analysis of the Transportation Sector" ...................................................39

Table 35: Detailed assumptions for CMU's "Life Cycle Assessment of GHG Emissions from PHEVs: Implication of

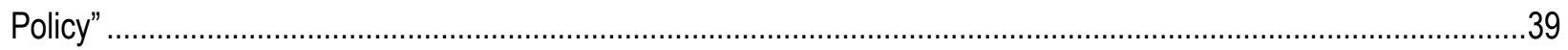

Table 36: Assumptions overview for PHEV market penetration rates ................................................................54

Table 37: Detailed assumptions regarding vehicle economics ...........................................................................55

Table 38: Detail assumptions for "Gaining Traction: A customer view of electric vehicle mass adoption in the U.S.

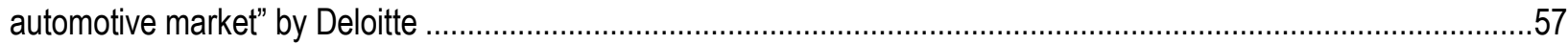

Table 39: Detailed assumptions for "The Comeback of the Electric Car?" by BCG .................................................57

Table 40: Detailed Assumptions for "On the Road in 2035" by MIT ....................................................................58

Table 41: Detailed assumptions for "Market Models for Predicting PHEV Adoption and Diffusion" by UMTRI............58

Table 42: Detailed assumptions for "Plug-In Hybrid Electric Vehicle Annual Market Penetration Scenarios" by PNNL

Table 43: Detailed assumptions for "Electric Cars: Plugged In" by Deutsche Bank ..............................................59

Table 44: Detailed assumptions for "PHEV Market Introduction Study" by SENTECH/ORNL .................................60

Table 45: Detailed assumptions for "Prospects for Plug-in Hybrid Electric Vehicles in the United States and Japan: A

General Equilibrium Analysis" by MIT (1 of 2 sets)..... 60

Table 46: Detailed assumptions for "Prospects for Plug-in Hybrid Electric Vehicles in the United States and Japan: A General Equilibrium Analysis" by MIT (2 of 2 sets) .61

Table 47: Detailed assumptions for "Multi-Path Transportation Futures Study: Vehicle Characterization and Scenario Analyses" by ANL. 61

Table 48: Assumptions supporting the highest PHEV penetration scenarios as of $2050 .$. .67

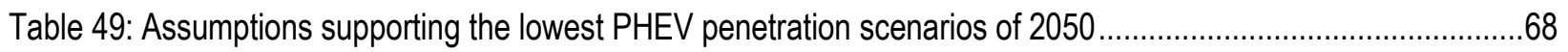

Table 50: PHEV annual market penetration studies and simulation models............................................................71

Table 51: Oil displacement estimates from different reports ................................................................................78

Table 52: Chart of main studies and their corresponding assumptions.................................................................80

Table 53: Detailed assumptions for "On the Road in 2035" written by MIT ............................................................81

Table 54: Detailed assumptions for "Prospects for PHEVs in the United States and Japan: A General Equilibrium Analysis" by MIT ..... 
Table 55: Detailed assumptions for the "WTW Analysis of Energy Use and GHG Emissions of PHEVs" written by ANL

Table 56: Detailed assumptions for "Multi-Path Transportation Futures Study: Vehicle Characterization and Scenario Analyses" written by ANL

Table 57: Detailed assumptions for "Impact of Real World Drive Cycles on PHEV Fuel Efficiency and Cost" written by ANL.

Table 58: Detailed assumptions for the "PHEV Value Proposition Study" written by SENTECH/ORNL .83

Table 59: Detailed assumptions for "Using GPS Travel Data to Assess the Real World Driving Energy Use of PHEVs" written by NREL

Table 60: Detailed assumptions for "Battery Requirements and Cost-Benefit Analysis of Plug-in Hybrid Vehicles" prepared by NREL .84

Table 61: Detailed assumptions for the "Electrification Roadmap" written by the Electrification Coalition

Table 62: Detailed assumptions for "Environmental Assessment of Plug-in Hybrid Electric Vehicles, Volume 1" written by EPRI/NRDC

Table 63: Detailed assumptions for the "Displacement of Petroleum and $\mathrm{CO}_{2}$ Reductions from Super-Optimistic

Business-as-Usual Mass Production of Light Vehicle PHEVs" written by the CalCars

Table 64: Detailed assumptions for "Plug-in Hybrid Vehicles and the Vermont Grid: A Scoping Analysis" written by the UVM

Table 65: Listing of the types of mass/weight values provided from the reports examined in this chapter...... .89

Table 66: Annual gasoline displacement by a single HEV from different reports. .92

Table 67: List of PHEV drivetrain configurations where defined .97

Table 68: Choice of driving strategy selected for each report .98

Table 69: List of various modeling programs used to calculate oil displacement. .99 
This page intentionally left blank. 


\begin{tabular}{|c|c|}
\hline & approximately \\
\hline ADVISOR & ADvanced Vehlcle SimulatOR \\
\hline AER & all-electric range \\
\hline ANL & Argonne National Laboratory \\
\hline ATLAS & Advanced Transportation Limited Analysis Spreadsheet \\
\hline bbl & barrel \\
\hline BCG & The Boston Consulting Group \\
\hline BEV & battery electric vehicle \\
\hline CAFE & Corporate Average Fuel Economy \\
\hline CD & charge depleting \\
\hline CMU & Carnegie Mellon University \\
\hline $\mathrm{CO}_{2}$ & carbon dioxide \\
\hline CC & carbon capture \\
\hline CS & charge sustaining \\
\hline CV & conventional vehicle \\
\hline DB & Deutsche Bank \\
\hline DOE & U.S. Department of Energy \\
\hline ECAR & East Central Area Reliability Coordination Agreement \\
\hline EIA & U.S. Energy Information Administration \\
\hline EMFAC & The EMission FACtors model \\
\hline EPA & U.S. Environmental Protection Agency \\
\hline EPPA & The MIT Emissions Predictions and Policy Analysis model \\
\hline EPRI & Electric Power Research Institute \\
\hline EV & electric vehicle \\
\hline GEV & grid-enabled vehicle \\
\hline GHG & greenhouse gas \\
\hline GPS & global positioning system \\
\hline GREET & Greenhouse Gases, Regulated Emissions, and Energy Use in Transportation Model \\
\hline GT & gas turbine \\
\hline GTAP & Global Trade Analysis Project \\
\hline $\mathrm{H} 2$ & "hydrogen technology success" scenario \\
\hline HEV & hybrid electric vehicle \\
\hline HWFET & EPA Highway Fuel Economy Driving Schedule \\
\hline ICE & internal combustion engine \\
\hline $\mathrm{K}$ & 1,000 \\
\hline LA92 & EPA "Unified" Dynamometer Driving Schedule \\
\hline LDV & light duty vehicle \\
\hline LR & literature review \\
\hline M & "Mixed" scenario \\
\hline $\mathrm{MA}^{3} \mathrm{~T}$ & Market Acceptance of Advanced Automotive Technologies Model \\
\hline MIS & Market Introduction Study \\
\hline MIT & Massachusetts Institute of Technology \\
\hline MKP & markup \\
\hline $\mathrm{mpg}$ & miles per gallon \\
\hline
\end{tabular}




$\begin{array}{ll}\text { NEMS } & \text { National Energy Modeling System } \\ \text { NERC } & \text { North American Electric Reliability Corporation } \\ \text { NESSIE } & \text { National Electric System Simulation Integrated Evaluator } \\ \text { NHTSA } & \text { National Highway Traffic Safety Administration } \\ \text { NRC } & \text { National Research Council } \\ \text { NRDC } & \text { Natural Resources Defense Council } \\ \text { NREL } & \text { National Renewable Energy Laboratory } \\ \text { ORNL } & \text { Oak Ridge National Laboratory } \\ \text { PG } & \text { program goals } \\ \text { PHEV } & \text { plug-in hybrid electric vehicle } \\ \text { PHEVxx } & \text { PHEV with an AER of "xx" miles } \\ \text { PNNL } & \text { Pacific Northwest National Laboratory } \\ \text { Ppm } & \text { parts per million } \\ \text { PSAT } & \text { Powertrain System Analysis Toolkit } \\ \text { PTW } & \text { pump-to-wheels } \\ \text { RE-EV } & \text { range extended electric vehicle } \\ \text { SC } & \text { southern California } \\ \text { SOC } & \text { state of charge } \\ \text { SUV } & \text { sport utility vehicle } \\ \text { UDDS } & \text { EPA Urban Dynamometer Driving Schedule } \\ \text { UF } & \text { utility factor } \\ \text { U.S. CCSP } & \text { U.S. Climate Change Science Program } \\ \text { UMTRI } & \text { University of Michigan Transportation Research Institute } \\ \text { UVM } & \text { University of Vermont } \\ \text { VMT } & \text { vehicle miles traveled } \\ \text { VAMMP } & \text { Virtual AutoMotive MarketPlace Model } \\ \text { VP Study } & \text { Value Proposition Study } \\ \text { WTW } & \text { well-to-wheels } \\ & \end{array}$




\section{INTRODUCTION}

Numerous organizations have published reports in recent years that investigate the ever changing world of electric vehicle (EV) technologies and their potential effects on society. Specifically, projections have been made on greenhouse gas (GHG) emissions associated with these vehicles and how they compare to conventional vehicles or hybrid electric vehicles (HEVs). Similar projections have been made on the volumes of oil that these vehicles can displace by consuming large amounts of grid electricity instead of petroleum-based fuels. Finally, the projected rate that these new vehicle fleets will enter the market varies significantly among organizations.

New ideas, technologies, and possibilities are introduced often, and projected values are likely to be refined as industry announcements continue to be made. As a result, over time, a multitude of projections for GHG emissions, oil displacement, and market penetration associated with various EV technologies has resulted in a wide range of possible future outcomes. This leaves the reader with two key questions:

1) Why does such a collective range in projected values exist in these reports?

2) What assumptions have the greatest impact on the outcomes presented in these reports?

Since it is impractical for an average reader to review and interpret all the various vehicle technology reports published to date, Sentech Inc. and the Oak Ridge National Laboratory have conducted a comparative study to make these interpretations. The primary objective of this comparative study is to present a snapshot of all major projections made on GHG emissions, oil displacement, or market penetration rates of EV technologies. From the extensive data found in relevant publications, the key assumptions that drive each report's analysis are identified and "apples-to-apples" comparisons between all major report conclusions are attempted.

The general approach that was taken in this comparative study is comprised of six primary steps:

- $\quad$ Search Relevant Literature. An extensive search of recent analyses that address the environmental impacts, market penetration rates, and oil displacement potential of various EV technologies was conducted

- $\quad$ Consolidate Studies. Upon completion of the literature search, a list of analyses that have sufficient data for comparison and that should be included in the study was compiled.

- Identify Key Assumptions. Disparity in conclusions very likely originates from disparity in simple assumptions. In order to compare "apples-to-apples," key assumptions were identified in each study to provide the basis for comparing analyses.

- Extract Information. Each selected report was reviewed, and information on key assumptions and data points was extracted.

- Overlay Data Points. Visual representations of the comprehensive conclusions were prepared to identify general trends and outliers.

- Draw Final Conclusions. Once all comparisons are made to the greatest possible extent, the final conclusions were draw on what major factors lead to the variation in results among studies.

\section{LITERATURE REVIEW}

Thirty-one reports were identified as relevant to the topics investigated in this comparative study. The following table identifies which reports were used in the comparison of GHG emissions, market penetration rates, and oil displacement in this study. 


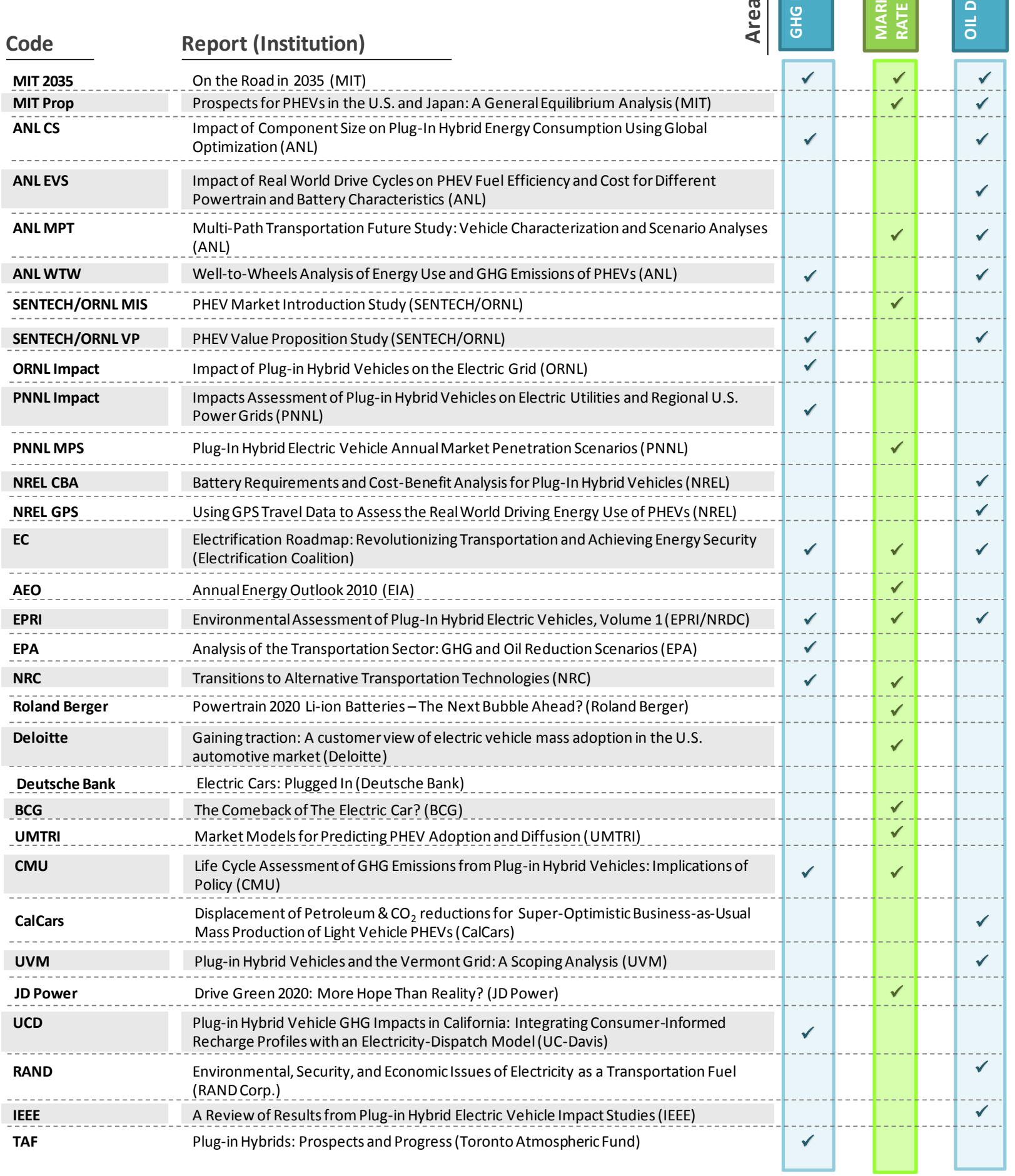




\section{EXECUTIVE SUMMARY}

\section{GHG EMISSIONS}

The numerous publications that contain $\mathrm{GHG}$ emissions projections for electric vehicle technologies result in an overwhelming amount of emissions data. The GHG emissions data are reported in a variety of ways, including those for the transportation sector as a whole, the lifetime $\mathrm{GHG}$ emissions for individual technologies, and the reductions in GHG emissions compared to a baseline. The findings from reports used in this comparative study cover a wide range of years, scenarios, and technologies, and the values vary from 17 to 450 grams of carbon dioxide equivalent per mile $\left(\mathrm{g} \mathrm{CO}_{2} \mathrm{e} / \mathrm{mile}\right)$ per vehicle.

To compare data from multiple studies, the key assumptions in each report must first be identified, broken down, and compared side by side. The table below matches the relevant reports with key assumptions for GHG emissions.

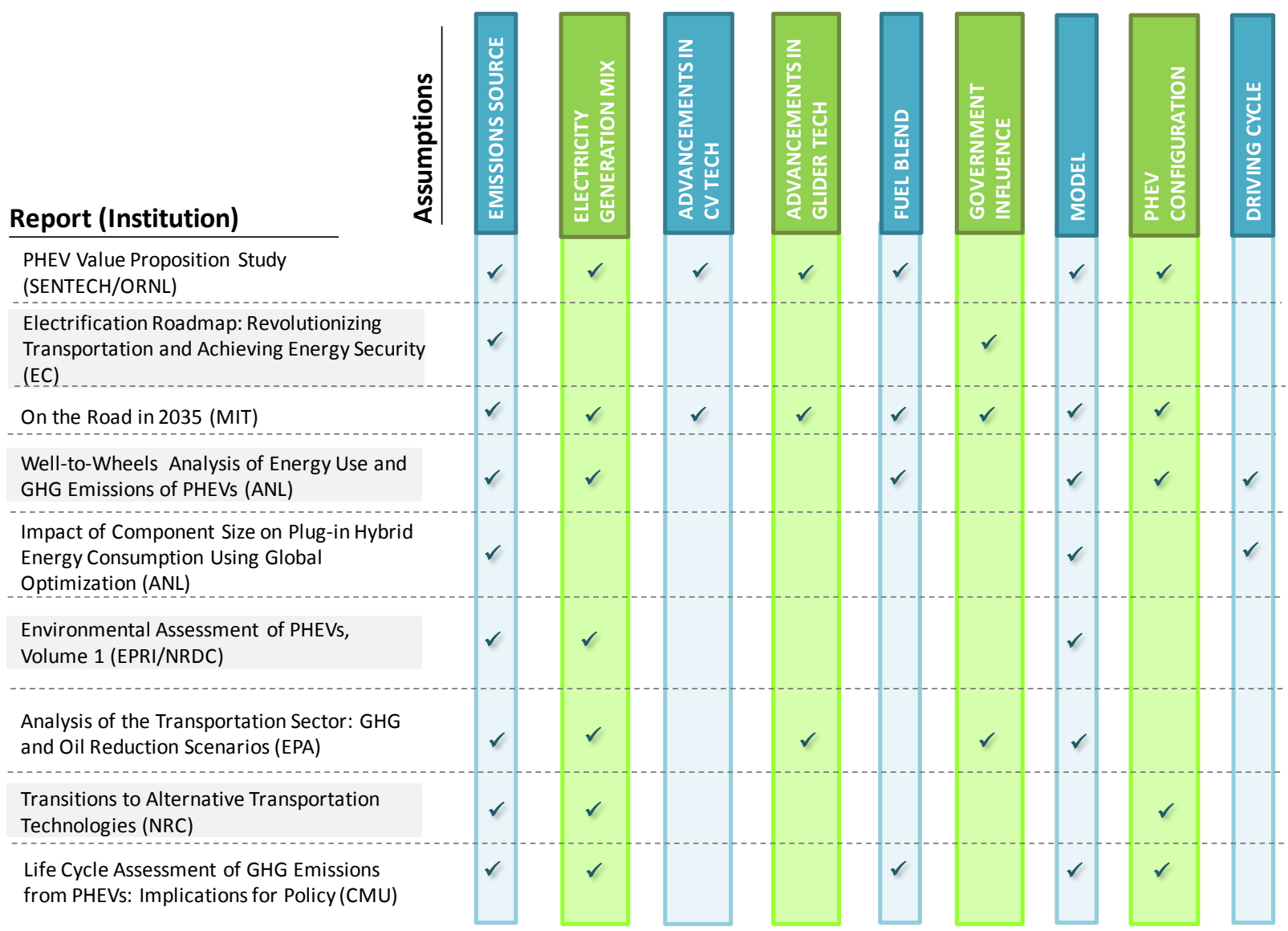

Now that the assumptions from each report have been identified, comparisons of data can begin between similar scenarios. Although all assumptions play a role in arriving at each study's results, three major sets of assumptions were found to lead to meaningful comparisons. These are Baseline Conditions, Varying Electricity Generation Mixes, and Varying Fuel Blends. While the full report provides extensive data on a variety of vehicle types (categorized by "current" or "future"), only future projections for plug-in hybrid electric vehicles (PHEV) are highlighted in this executive summary. 
The comparison of Baseline Conditions for all future PHEV emissions can be made using an "average" electricity generation mix, gasoline (E10) as fuel, and a similar all-electric range (AER) within 10 miles. This comparison can be seen in the figure below. Three of the four data points in this figure are very similar at approximately $180 \mathrm{~g} \mathrm{CO}_{2} \mathrm{e} / \mathrm{mile}$. The fourth data point, provided in SENTECH/ORNL VP study, is slightly higher as a direct result of that region's carbon-intensive generation mix (the NERC region formerly referred to as the East Central Reliability Coordination Agreement, or ECAR).

\section{GHG Emissions Projections for Future PHEVs under Average Conditions}

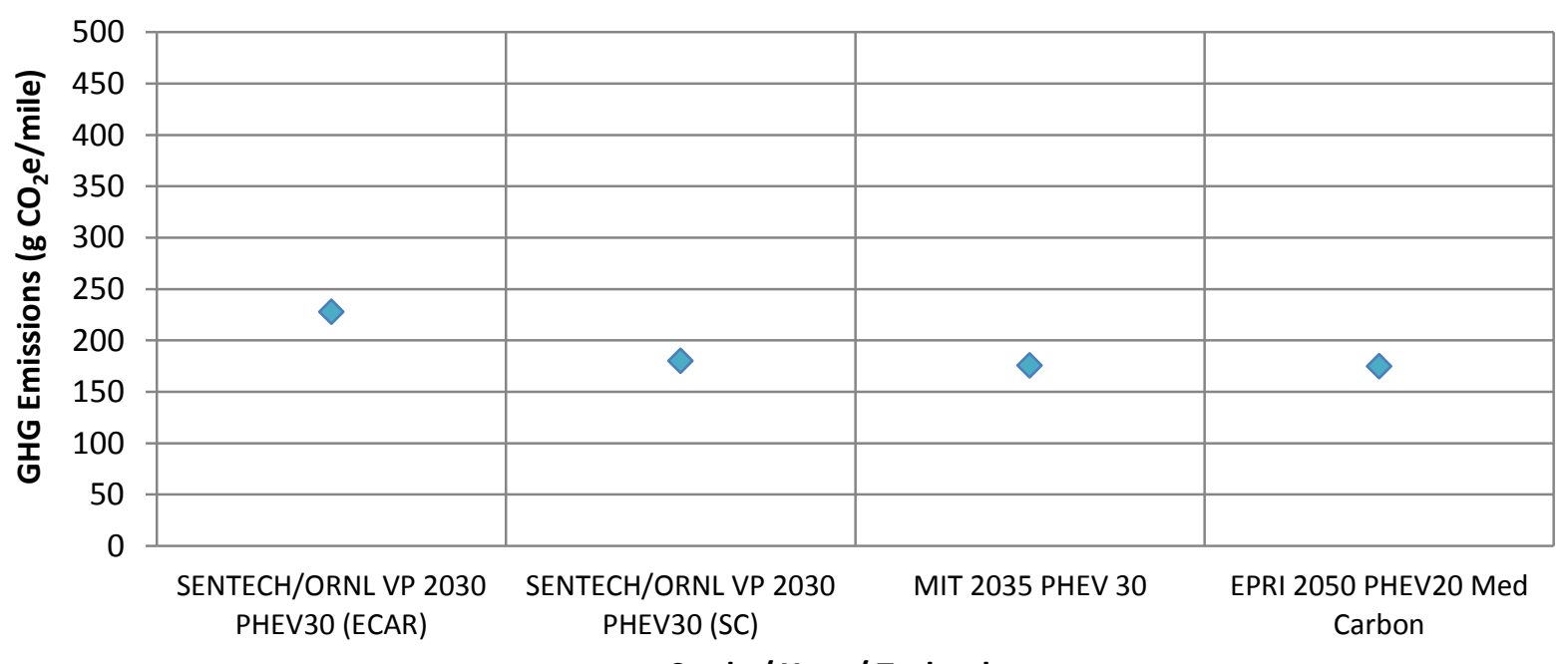

Study / Year / Technology

Many of the reports investigated for this comparative study present multiple scenarios with various future electricity generation mixes to infer how GHG emissions from PHEVs may differ among geographic regions. This emissions data for future PHEVs with varying generation mixes are shown on the upper half of the following page. (The AER and fuel blend are held constant to allow for a meaningful comparison.) According to the figure, the highest emissions values typically originate from PHEVs charging in highercarbon generation mixes, while the lowest originate from renewable or other low-carbon electricity mixes. It is interesting to note that EPRI/NRDC's "high carbon" scenario is lower than SENTECH/ORNL's "average" mix for southern California (SC). This is most likely due to a lower assumed carbon intensity for EPRI/NRDC's "high carbon" electricity mix than that of the southern California electricity mix used in SENTECH/ORNL VP.

While many organizations consider multiple fuel blends in their reports, SENTECH/ORNL VP and MIT 2035 are the only reports that consider various fuel blends for future PHEV scenarios. SENTECH/ORNL VP considers three different fuel blends: 1) gasoline, referred to as E10; 2) an average blend of $30 \% \mathrm{E} 10$ and $70 \%$ cellulosic E85, referred to as E30; and 3) cellulosic E85. MIT 2035 also considers cellulosic ethanol. GHG emissions data for PHEV30s, operating on "average" electricity generation mix using the aforementioned fuel blends, are shown on the lower half of the following page. According to this figure, a higher percentage of ethanol generally leads to lower GHG emissions. 


\section{EXECUTIVE SUMMARY}

\section{GHG Emissions Projections for Future PHEVs under Varying Electricity Generation Mixes}

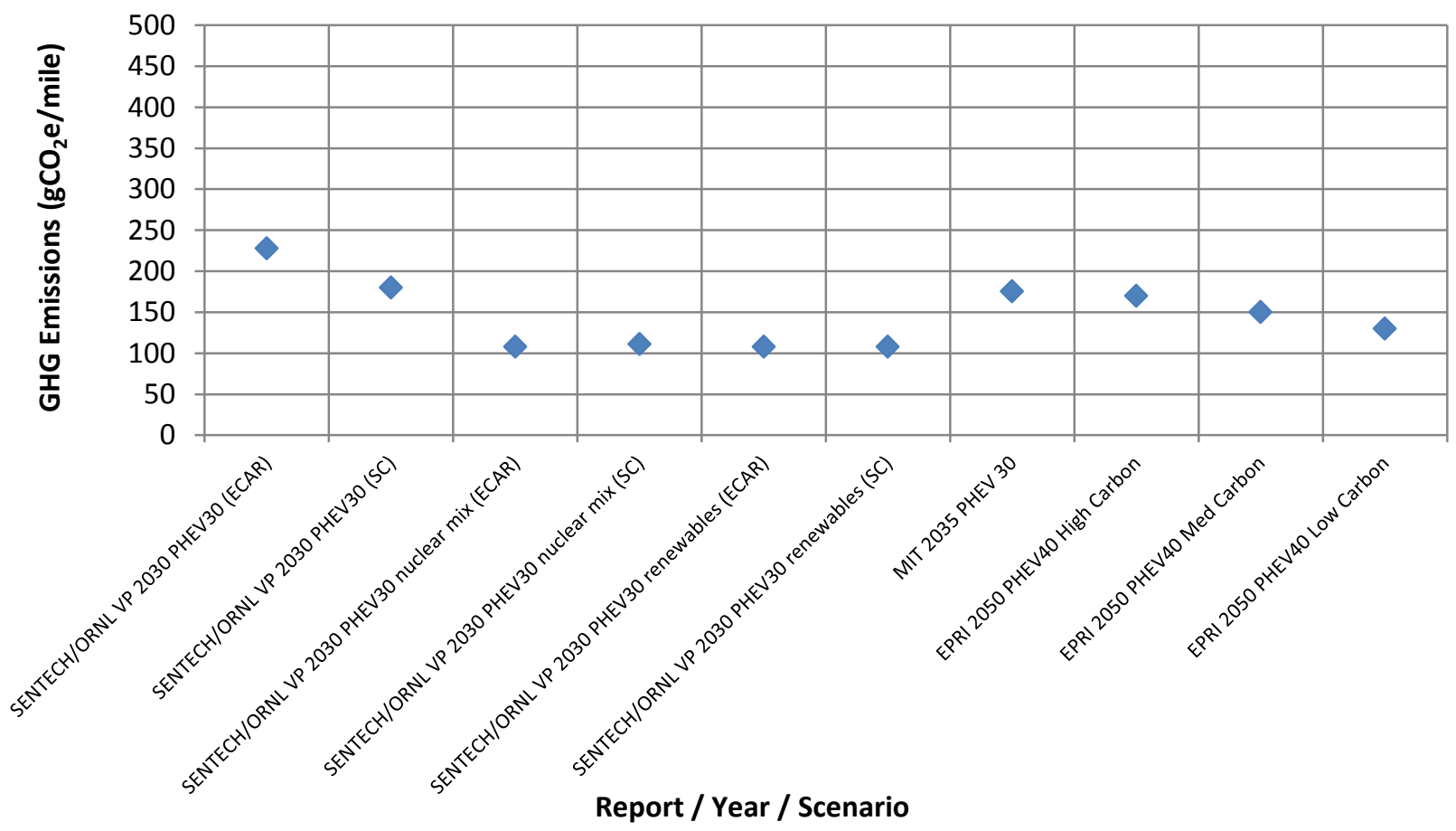

\section{GHG Emissions Projections for Future PHEVs with Varying Fuel Blends}

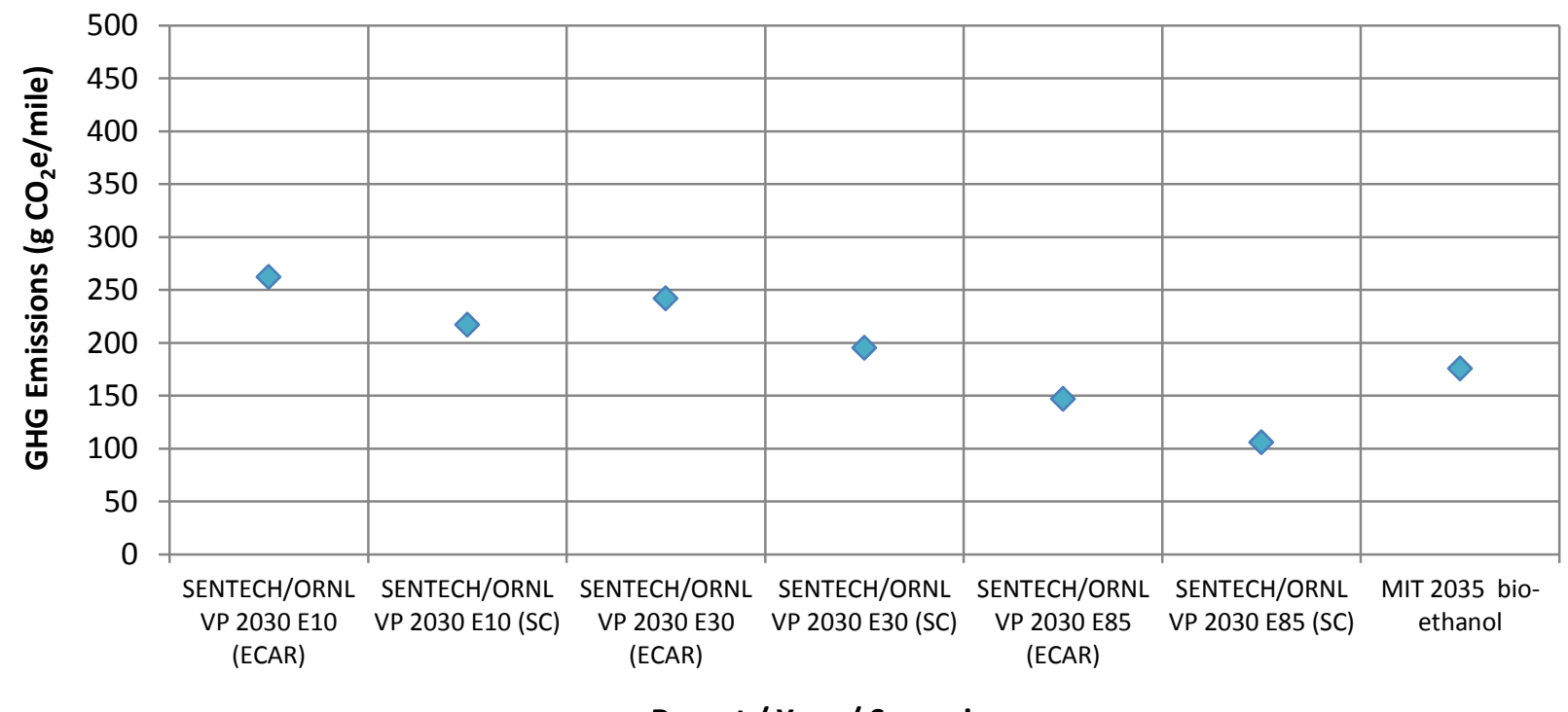

Report / Year / Scenario 


\section{EXECUTIVE SUMMARY}

Combining the assumptions of fuel blends and electricity generation mixes for all future PHEVs projections presents the reports' findings in a broader spectrum. However, direct comparisons made between data will yield weaker outcomes. The general trend is that the higher carbon intensive electricity and higher percentage of ethanol lead to higher GHG emissions. Secondary factors also introduce the use of different computational models along with varying assumptions for glider technology improvement, government intervention, and driving cycles, which introduce more possible scenarios. Therefore, an "apples-to-apples" comparison at this point becomes much weaker. All of the future PHEV emissions data from all scenarios included in this comparative study can be seen below.

GHG Emission Projections for All Future PHEVs

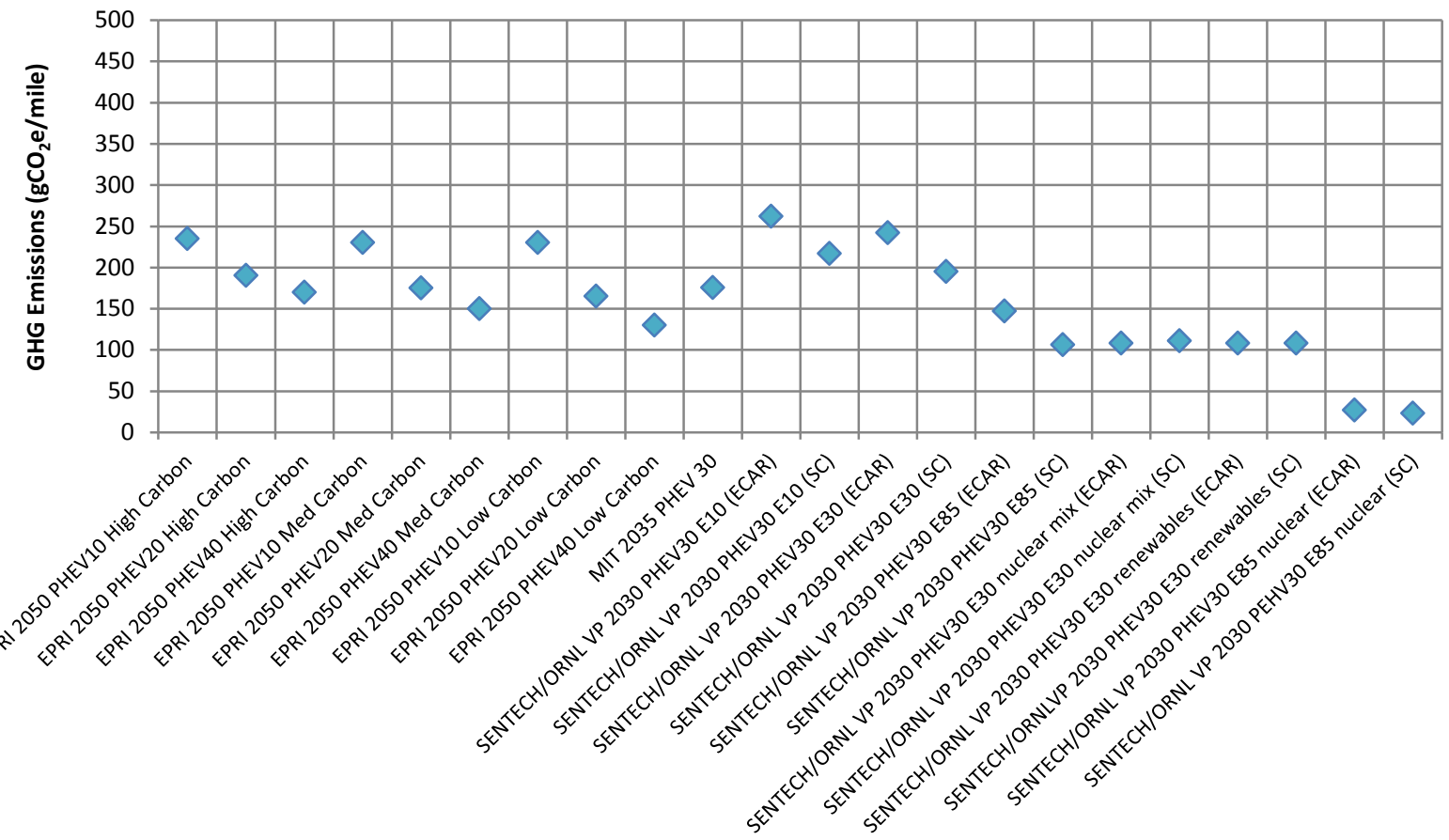

Study / Year / Scenario 


\section{MARKET PENETRATION}

Annual market penetration rates for PHEVs have been identified and extracted from all applicable studies for review in this comparative study. PHEV annual market penetration refers to the ratio of the U.S. PHEV annual sales to the total U.S. light-duty vehicle (LDV) annual sales. Analysis of 15 studies is included in this portion of the comparative study, although some reports provide more scenarios than simply the most probable PHEV annual market penetration rate. Rather, many present sensitivity analyses with multiple scenarios in an attempt to identify the impact of changing assumptions, or "What if' situations, on PHEV annual market penetration. In fact, MIT's study entitled "Prospects for Plug-in Hybrid Electric Vehicles in the United States and Japan: A General Equilibrium Analysis" includes 24 different scenarios. For reports with numerous scenarios, both conservative and aggressive scenarios are often included, sometimes resulting in a wide range of possible penetration rates. The ambiguous future for PHEVs is mostly due to uncertainty with technological advances, government interventions, and potential PHEV buyer behavior.

Of the studies reviewed for the annual market penetration portion of the comparative study, ten provided sufficient information on the major assumptions categories relevant to PHEV market penetration. The table below summarizes this information as it related to each of the assumption categories. It is interesting to note that across the ten studies, no two organizations selected the same set of assumption categories for consideration in their study. Hence, this creates a challenge when attempting to compare the studies' market penetration projections on an "apples-to-apples" basis.

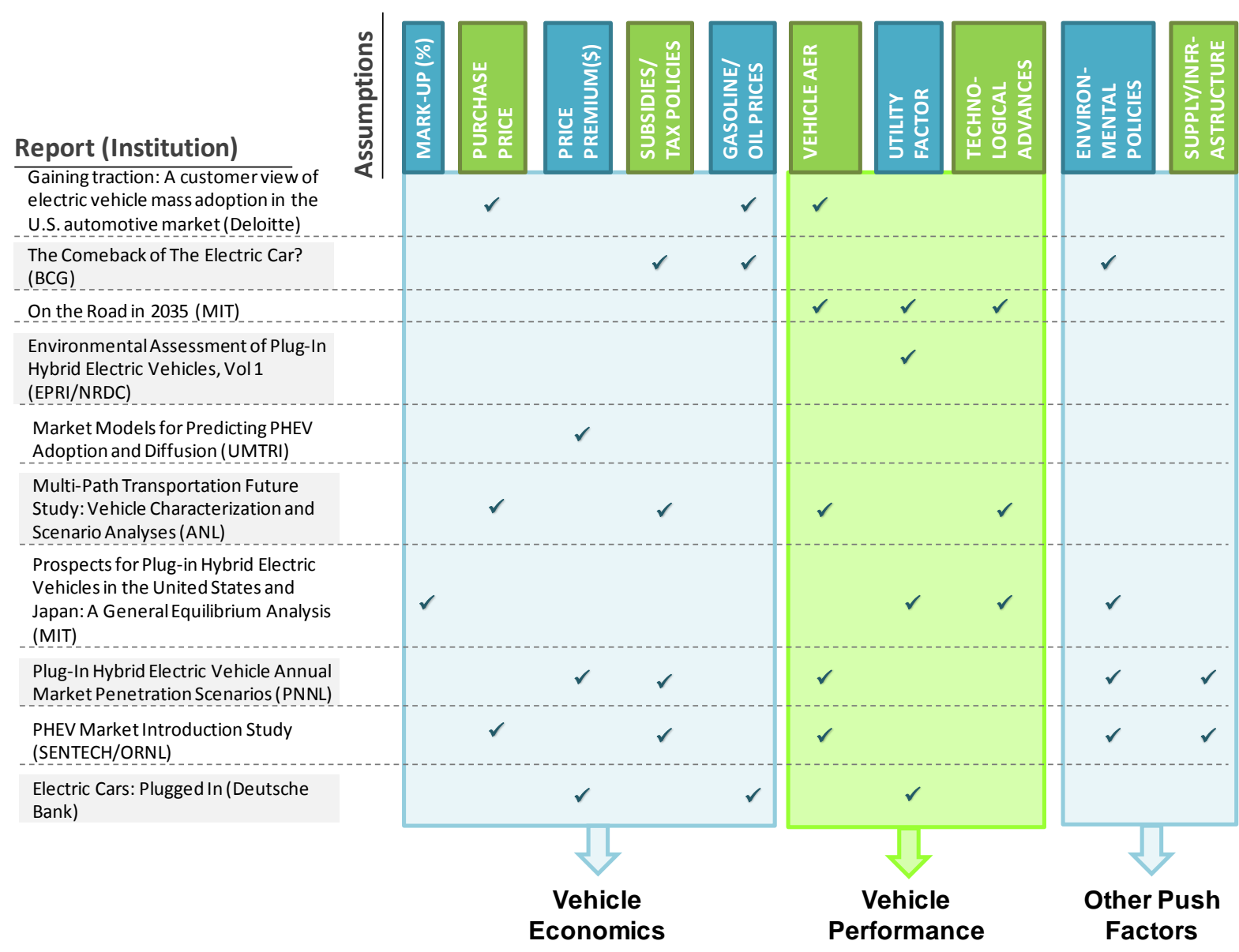




\section{EXECUTIVE SUMMARY}

The figure below shows a comprehensive look at all annual market penetration scenarios for PHEVs in the all studies mentioned earlier, as well as from other expert opinions. Often, organizations present three scenarios in their studies to represent different levels of market penetration of PHEVs. Although these three scenarios are not necessarily named "high," "medium," and "low," in the respective publication, they are referred to as such in this study to allow the reader to easily differentiate basic scenarios across studies. During the timeframe of 2010 to 2050, data from the studies present a wide range of annual market penetration values. Most notable, in 2050, the annual market penetration for PHEVs ranges from $0 \%$ to $90 \%$.

PHEV Annual Market Penetration Scenarios Spanning 2012 - 2050

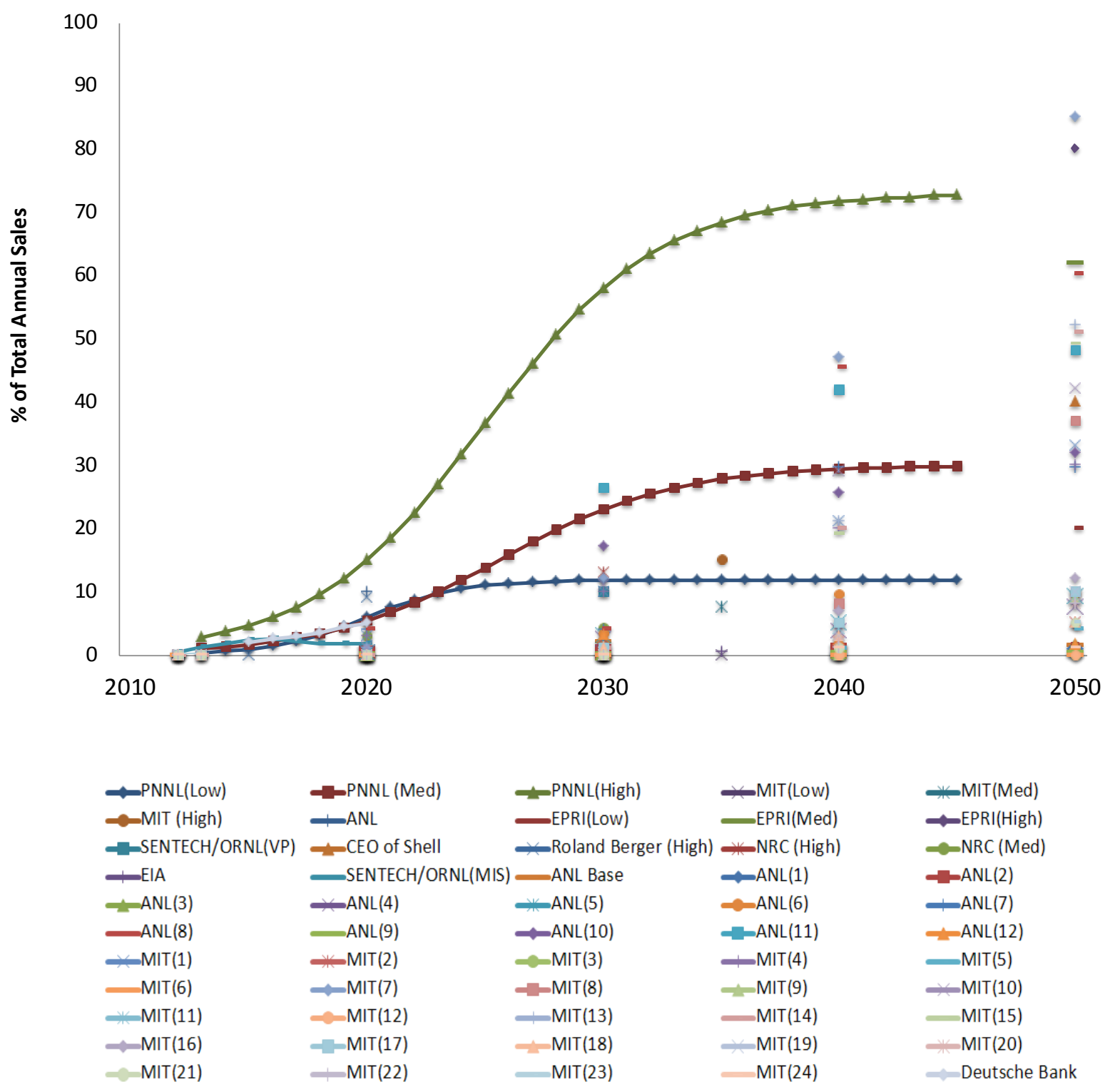


According to the figure below, in $2050,65 \%$ of the data points collected in this comparative study suggest that PHEV annual market penetration will fall between $0 \%$ and $20 \%$. Twenty percent of the data points for 2050 suggest that PHEV annual market penetration will fall between $21 \%$ and $50 \%$. The remaining $15 \%$ of the data points suggest that PHEV annual market penetration will exceed $50 \%$ of sales. Again, it is important to note that many of the data points are the result of sensitivity analyses rather than actual forecasts, leading to high variability in projections. However, the level of concentration within each bubble may be considered representative of what most organizations expect the PHEV industry to look like in 2050.

\section{PHEV Annual Market Penetration Scenarios for 2050 and the Corresponding Concentration of Scenarios}

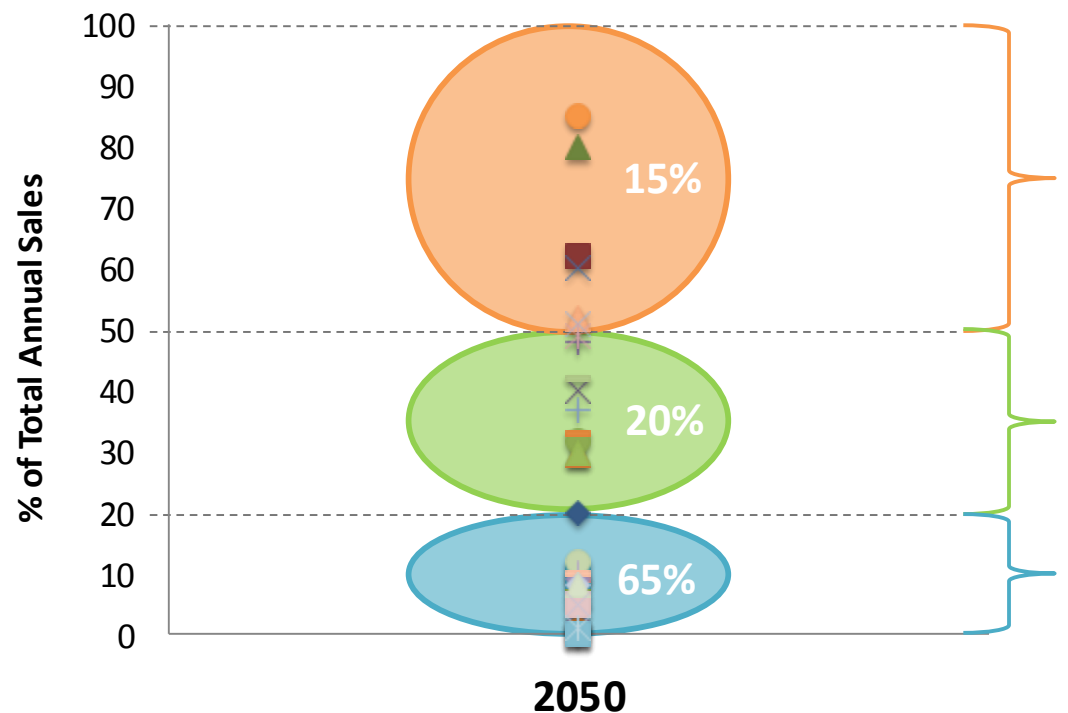

$15 \%$ of scenarios suggest PHEVs will comprise more than $50 \%$ of the total annual sales

$20 \%$ of scenarios suggest PHEVs will comprise 21\% $50 \%$ of the total annual sales

$65 \%$ of scenarios suggest PHEVs will comprise less than or equal to $20 \%$ of the total annual sales

\begin{tabular}{|c|c|c|c|c|c|}
\hline EPRI(Low) & EPRI(Med) & EPRI(High) & $\sim$ CEO of Shell & ANL Base & $-A N L(1)$ \\
\hline$\rightarrow A N L(2)$ & $\longrightarrow \mathrm{ANL}(3)$ & $=\mathrm{ANL}(4)$ & $\rightarrow$ ANL(5) & $\Rightarrow \mathrm{ANL}(6)$ & $\therefore \mathrm{ANL}(7)$ \\
\hline$\because A N L(8)$ & ANL(9) & ANL(10) & ANL(11) & $\Rightarrow \mathrm{ANL}(12)$ & $\longrightarrow \mathrm{MIT}(1)$ \\
\hline هIT(2) & $=\mathrm{MIT}(3)$ & $\therefore \mathrm{MIT}(4)$ & $\oiiint \mathrm{MIT}(5)$ & MIT(6) & MIT(7) \\
\hline MIT(8) & $=\mathrm{MIT}(9)$ & $M I T(10)$ & MIT(11) & $=\mathrm{MIT}(12)$ & $\rightarrow \mathrm{MIT}(13)$ \\
\hline$\asymp \mathrm{MIT}(14)$ & MIT(15) & MIT(16) & MIT(17) & MIT(18) & MIT(19) \\
\hline$-\mathrm{MIT}(20)$ & $-\mathrm{MIT}(21)$ & $M I T(22)$ & MIT(23) & MIT(24) & \\
\hline
\end{tabular}

Market penetration rates for battery electric vehicles (BEV) and HEVs are also briefly investigated in this study. BEVs are found to have the most conservative annual market penetration forecast in that beyond 2020, BEVs maintain 0\% annual market penetration for all scenarios in the reports that only investigate $\mathrm{BEVs}$. HEV annual market penetration is relatively consistent across most studies forecasting a range between $10 \%$ and $50 \%$ throughout the timeframe 2020 to 2050 . 


\section{OIL DISPLACEMENT}

Electric vehicle technologies are capable of displacing significant volumes of oil and gasoline relative to conventional vehicles since much, if not all, of the miles driven are powered by electricity. Oil displacement projections attributable to various vehicle technology scenarios are reviewed in this portion of the comparative study. Ideally, to compare these different scenarios, each report would use the same methodology and/or use the same assumption categories. By viewing the key assumptions in the table below, it becomes obvious that every organization has chosen a unique approach for deriving oil displacement projections. Overall, their timelines span anywhere from 2010 to 2100.

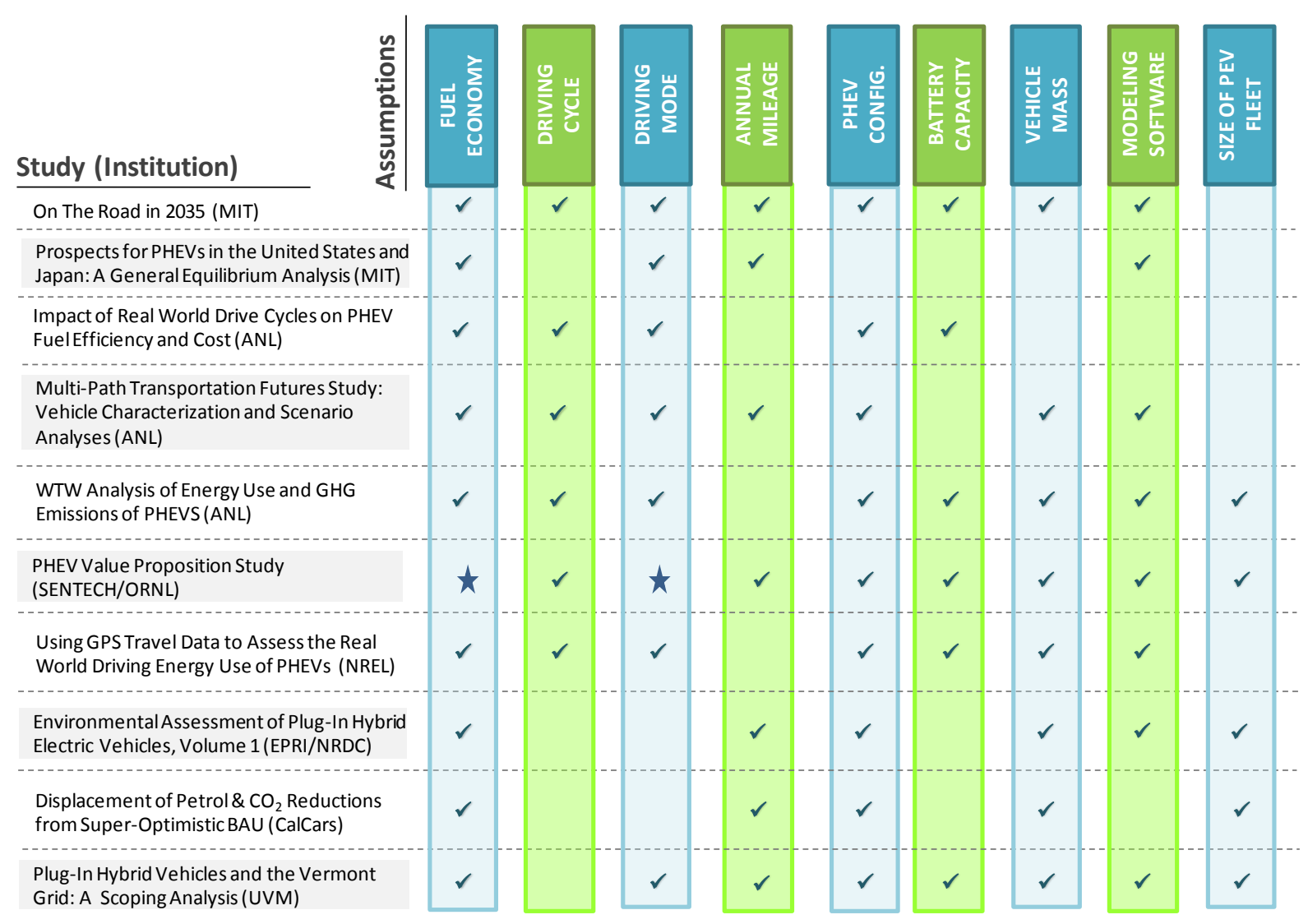

$\uparrow$ Indicates a value that was calculated directly from other data given

One of the more straightforward variables for comparing oil displacement achievable by PHEVs is the fuel economy rating for the relative conventional vehicle. Present day fuel economy values for this category range anywhere from 18 to $33 \mathrm{mpg}$, according to the reports investigated in this comparative study. Forecasted values for conventional vehicles are displayed in the following figure, which also encompasses values for which a reference year was not given. Erring on the conservative side, these values are assigned to the present day. Within each data set, fuel economy generally improves as time progresses. However, these rises do not correspond to a definitive trend in the data overall. For instance, the lowest value for year 2045 equals the mid-level estimates for 2010. Every study examined in depth provided a value for conventional vehicle fuel economy, either directly, or by providing other data (e.g. annual mileage, annual gasoline consumption) from which it can be derived. 


\section{EXECUTIVE SUMMARY}

\section{Estimates of All Conventional Vehicl Fuel Economies by Year}

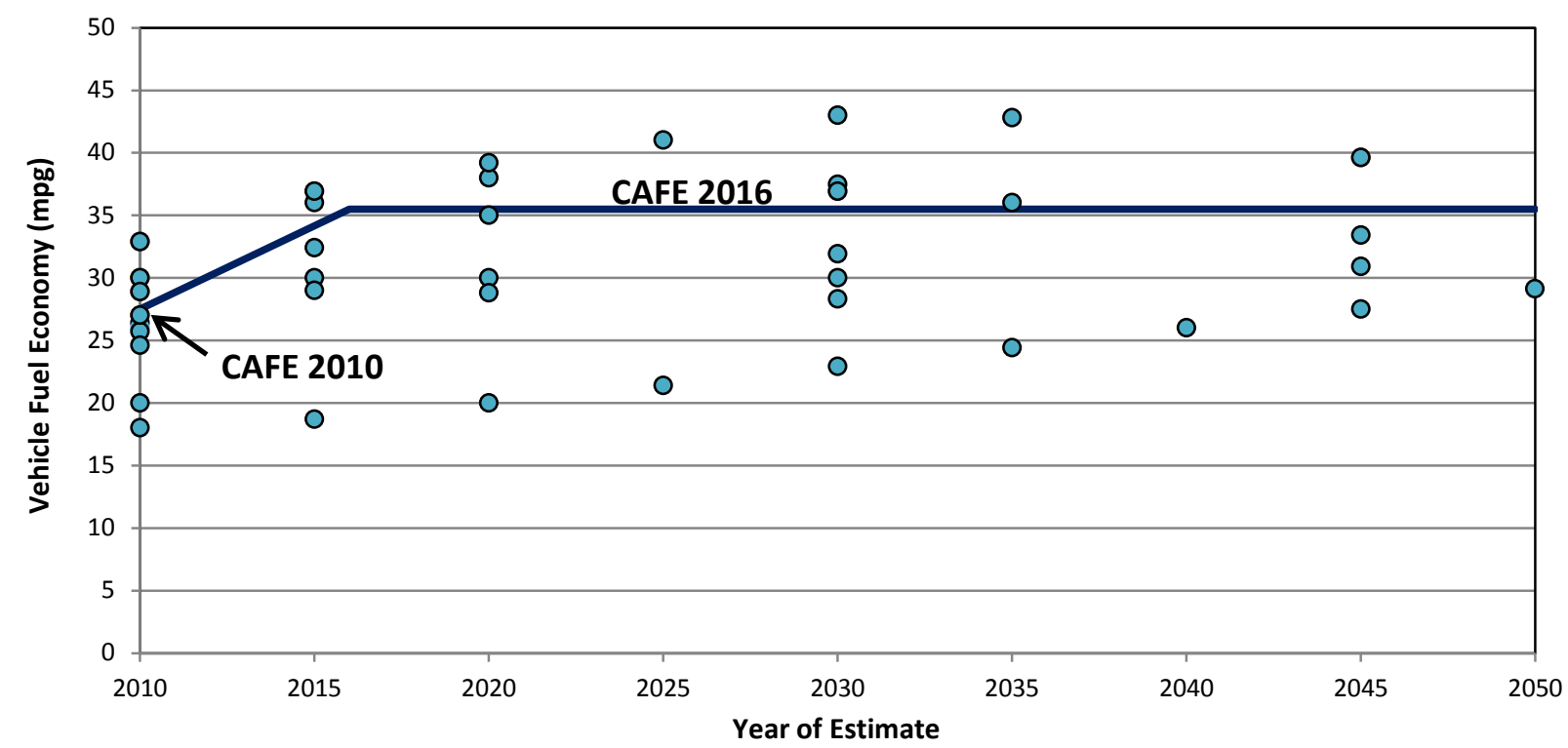

In addition to fuel economy data for the baseline conventional vehicle, fuel economy values for PHEVs are compiled (below) to allow for comparisons. The PHEV fuel economy values identified in this comparative study range from $51 \mathrm{mpg}$ to $205 \mathrm{mpg}$. The two reports with fuel economy values for an AER of 10, 20, 30 and 40 (the ANL EVS and the SENTECH/ORNL VP studies) show strong linear results. The two studies conducted by MIT result in similar fuel economy values, as well as the two studies conducted by NREL.

\section{Comparison of PHEV Fuel Economies as a Function of AER}

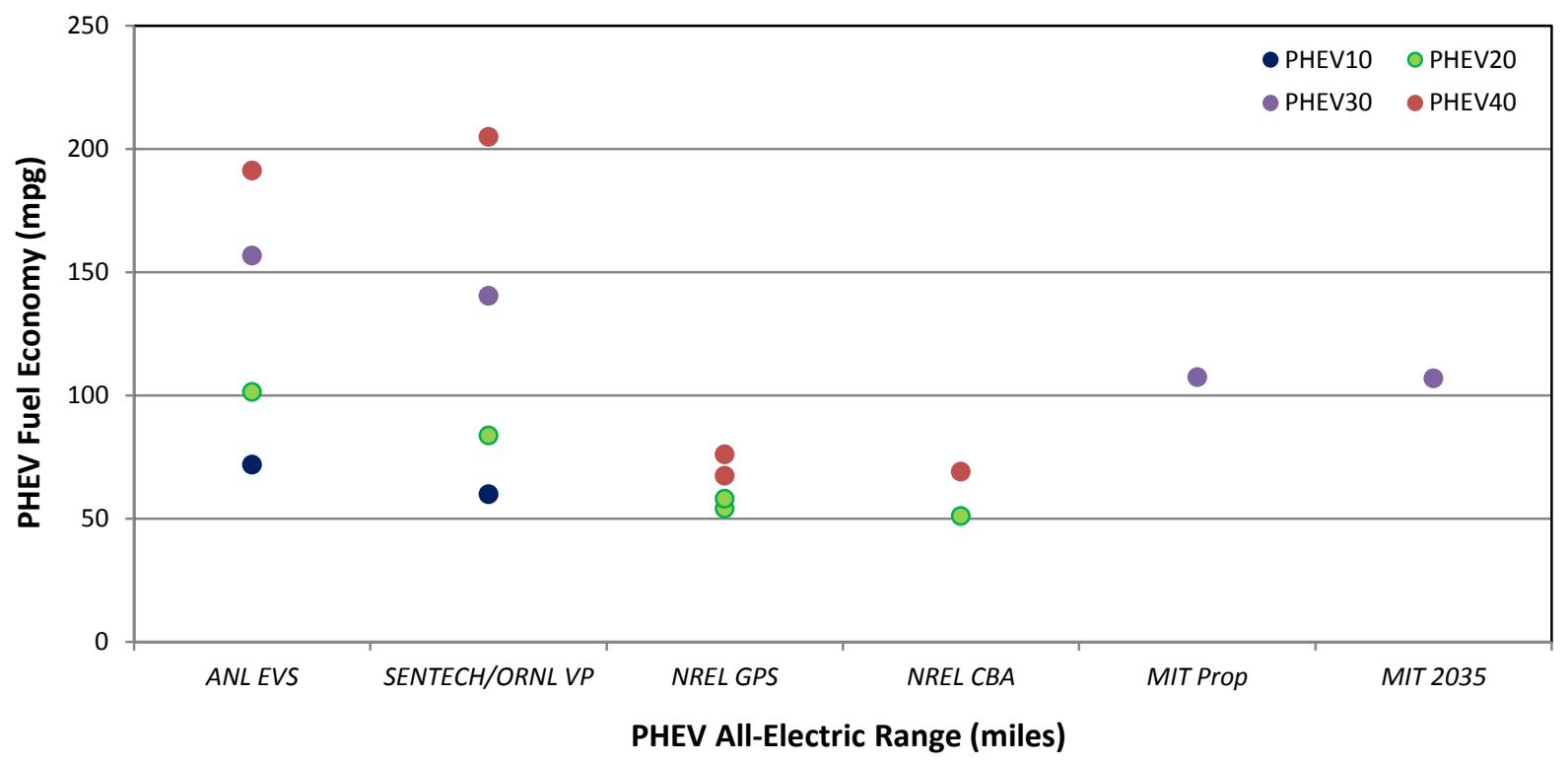




\section{EXECUTIVE SUMMARY}

Below, the resultant gallons of gasoline displaced by each type of PHEV (relative to a baseline conventional vehicle) are plotted per thousand vehicle miles traveled. This shows the PHEV20 to have the closest agreement in displacement results among studies and the PHEV30 to have the least agreement. The large variation in gasoline displacement for the PHEV30 appears to correspond with a variation in timeframe. MIT Prop sets up scenarios for the year 2100, at which time technology will have progressed from its present status, which is represented by the ANL EVS and UVM studies, and from its status in 2030 and 2035, the values portrayed by the SENTECH/ORNL VP study and the MIT 2035 study. The two PHEV30 values depicted for the MIT 2035 report correspond to its predictions for the present day and in 2035, with displacement increasing over time.

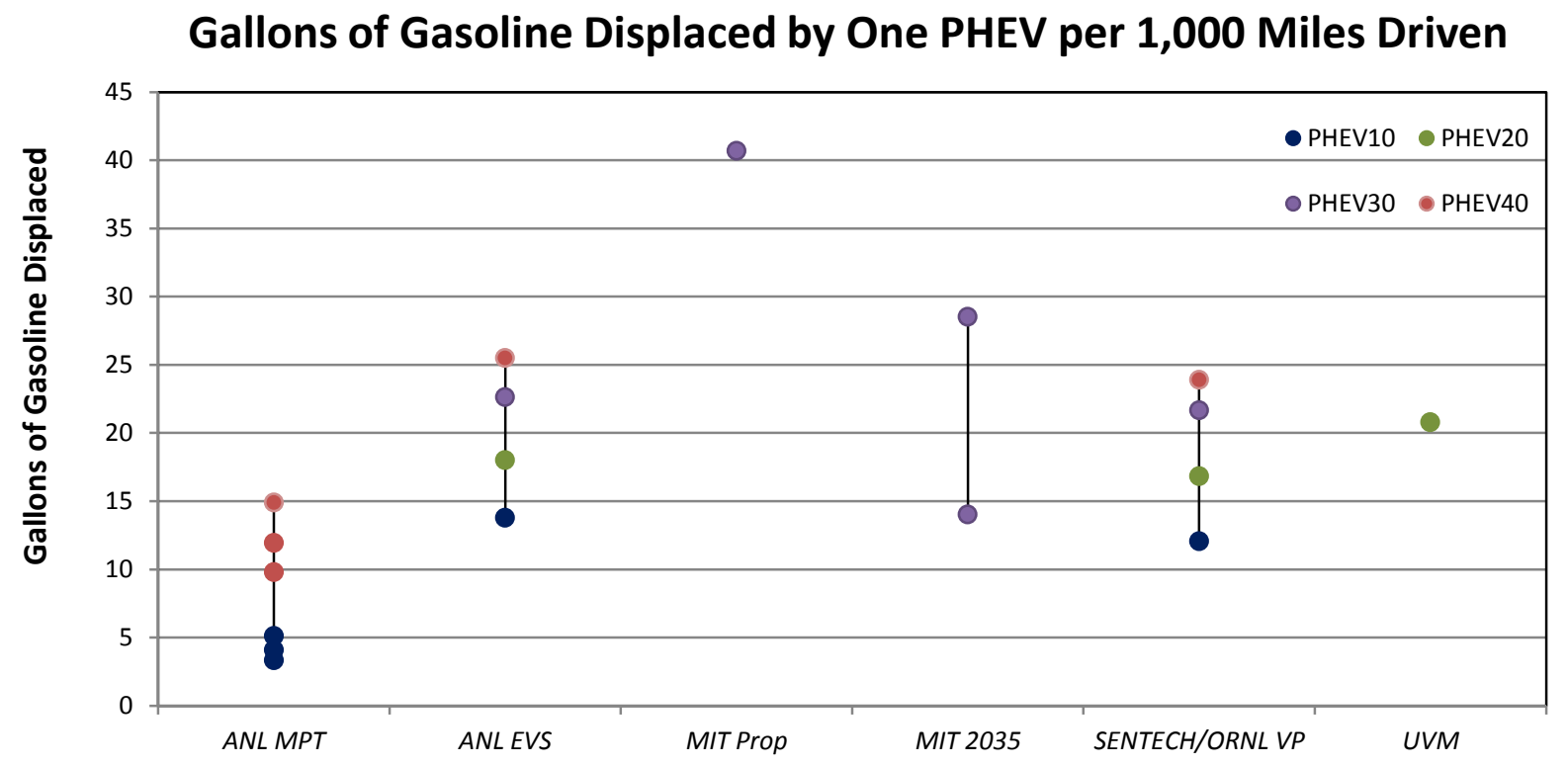

Comparing the fuel economy data of conventional vehicles to PHEVs, it is concluded that PHEVs are forecast to displace anywhere from $24 \%$ to $90 \%$ of the gasoline used by a conventional vehicle, but most estimates put their displacement potential between $30 \%$ and $60 \%$.

Gasoline displacement calculations begin with a single vehicle's gasoline reduction over a comparable conventional vehicle, but the overall amount of gasoline displaced by a certain vehicle type (e.g., PHEV fleet) ultimately depends on the number of that vehicle model on the road. With PHEV penetration rate projections in 2030 ranging from 1 million to almost 207 million units, the range of potential oil displacement is very broad and difficult to pinpoint. 


\section{CONCLUSIONS}

The overall future of electric vehicle technologies is still uncertain and subject to great debate by the scientific community. National laboratories, universities, market analysis firms, and others have published reports discussing the future of electric vehicle technologies especially regarding their associated GHG emissions, annual market penetration rate, and oil displacement potential. This comparative study attempts to present an unbiased review of different reports that discusses electric vehicle technologies with respect to these three major categories.

As explained throughout the report, the vast differences in approaches among the 31 reports investigated create a challenge when attempting to compare "apples-to-apples." The inconsistencies in assumption categories across the different studies further weaken the ability to compare one report to another. Therefore, the accuracy of the comparative analysis is constrained by five variables: 1) variation in the assumptions addressed, 2) variation in the year of the assumptions, 3) variation in the type of vehicle, 4) hidden assumptions, and 5) ambiguous assumptions. Therefore, as displayed below, a full comparative analysis across the 31 studies would likely be distorted since requiring an "apples-to-apples" comparative study would require compounded assumptions in order to bring the studies on the same ground. Hence, a breakdown of the assumptions supporting the scenarios and the data points is presented in this comparative study, and comparisons are only performed when a strong comparison could be made.

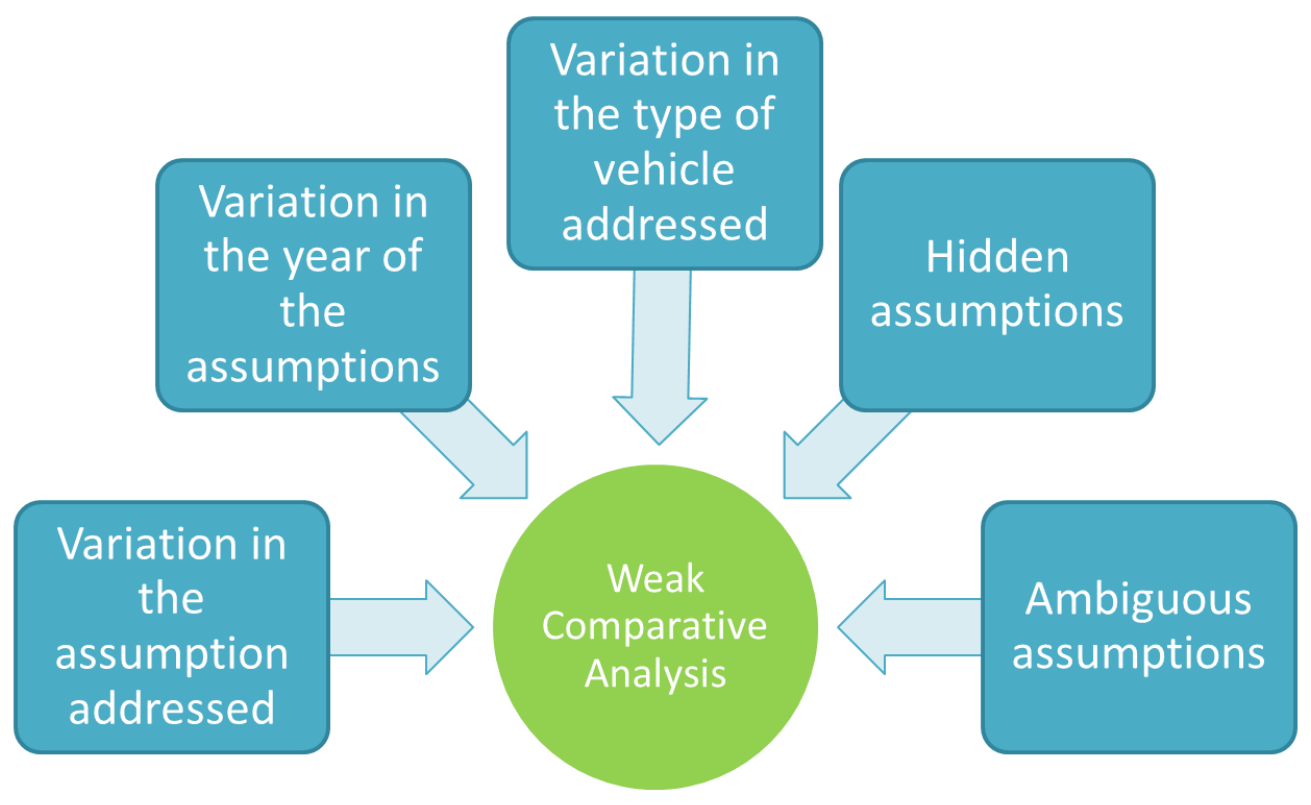

GHG Emissions. With regards to the baseline conventional and alternative vehicle technologies, the data points suggest overall agreement among the major studies. Of course, small discrepancies in the data exist, which can likely be attributed to the different models used to calculate emissions and the assumptions made on "average" electricity generation mixes, fuel blends, etc. Even though no two reports use the exact same assumptions or present identical results, none can be deemed "right" or "wrong." Each 


\section{EXECUTIVE SUMMARY}

group clearly defines their assumptions and methods for arriving at their results. Ultimately, it appears that each report is generally reaching similar conclusions, just building different scenarios to demonstrate them.

When the various electricity generation mixes for each report are investigated, the results are initially scattered. However, an overall trend can be seen that relates the emissions value to the carbon intensity of the electricity generation mix being used, assuming fuel blend and AER are held constant. Generally speaking, the carbon intensity levels of the key inputs (electricity generation and fuel blend) have the greatest impacts on the resultant GHG emissions. Similarly, when investigating the various fuel blends used across studies, the carbon intensity of the fuel blend appears to be directly related to the vehicle emissions.

Annual Market Penetration. The electric vehicle annual market penetration outlook is highly diverse across the reports reviewed in this comparative study. This is especially true for PHEVs in 2050 where the annual market penetration ranges from $0 \%$ to almost $90 \%$. The variation in the PHEV annual market penetration forecasts could be partly justified by studies using different assumptions, which the project team breaks down for each scenario provided in the reports reviewed. BEVs have the most conservative annual market penetration forecast in that, beyond 2020, BEVs maintain 0\% annual market penetration for scenarios set in reports that only investigate BEVs. HEV annual market penetration is relatively consistent across most studies forecasting a range between $10 \%$ and 50\% throughout the timeframe 2020 to 2050 .

Oil Displacement. Although single PHEVs are capable of displacing a large percentage of oil relative to a conventional vehicle, they are unlikely to make a significant contribution to fleet-wide petroleum displacement until production ramps up into the millions. As such, many critical factors that will affect their ability to displace petroleum, such as future conventional fuel economy, PHEV AER, and the ease of recharging are still unknowns. However, most studies agree that with PHEVs as a significant portion of the light vehicle fleet, imported petroleum consumption can be drastically reduced. RAND Corporation asserts that 10 million PHEV40s on the road could displace $1.8-2.9$ billion gallons of gasoline per year. Using the U.S. Energy Information Administration's conversion factor of 20 gallons of gasoline per barrel of petroleum, this translates to 90 to 145 million barrels of oil per year that 10 million PHEV40s could displace. 


\section{Introduction}

\subsection{Background}

Numerous organizations have published reports in recent years that investigate the ever changing world of electric vehicle (EV) technologies and their potential effects on society. Specifically, projections have been made on greenhouse gas (GHG) emissions associated with these vehicles and how they compare to conventional vehicles or hybrid electric vehicles (HEVs). Similar projections have been made on the volumes of oil that these vehicles can displace by mostly consuming grid electricity instead of petroleumbased fuels. Finally, the rate that these new vehicle fleets will enter the market will greatly affect the impact on the environment and national economy.

New ideas, technologies, and possibilities are introduced often, and projected values are likely to be refined as announcements continue to be made. As a result, over time, a multitude of projections has resulted in a wide range of possible future outcomes for GHG emissions, oil displacement, and market penetration associated with various EV technologies. This leaves the reader with two key questions:

1) Why does such a collective range in projected values exist in these reports?

2) What assumptions have the greatest impact on the outcomes presented in these reports?

\subsection{Objective}

Since it is impractical for an average reader to review and interpret all the various vehicle technology reports published to date, Sentech Inc. and the Oak Ridge National Laboratory have conducted a comparative study to make these interpretations. The primary objective of this comparative study is to present a snapshot of all major projections made on GHG emissions, oil displacement, or market penetration rates of EV technologies. From the extensive data found in relevant publications, the key assumptions that drive each report's analysis are identified and "apples-to-apples" comparisons between all major report conclusions are attempted.

\subsection{Approach}

Initiated in July 2010, Sentech, Inc. and the Oak Ridge National Laboratory (ORNL) conducted this comparative study as an addendum to the PHEV Value Proposition Study with the goal of identifying recent publications that address GHG emissions, market penetration, and oil displacement associated with plug-in hybrid electric vehicles (PHEV). The general approach that was applied to the analysis is:

- Search Relevant Literature. An extensive search of recent analyses that address the environmental impacts, market penetration rates, and oil displacement potential of various EV technologies was conducted

- Consolidate Studies. Upon completion of the literature search, a list of analyses that have sufficient data for comparison and that should be included in the study was compiled.

- Identify Key Assumptions. Disparity in conclusions very likely originates from disparity in simple assumptions. In order to compare "apples-to-apples," key assumptions were identified in each study to provide the basis for comparing analyses.

- Extract Information. Each selected report was reviewed, and information on key assumptions and data points was extracted.

- $\quad$ Overlay Data Points. Visual representations of the comprehensive conclusions were prepared to identify general trends and outliers.

- Draw Final Conclusions. Once all comparisons are made to the greatest possible extent, the final conclusions were draw on what major factors led to the variation in results among studies. 


\section{Literature Review}

Thirty-one reports were identified as being relevant to this comparative study. In this chapter, a brief summary of the project scope, approach, and conclusions for each study is provided.

\subsection{Massachusetts Institute of Technology (MIT) - "On the Road in 2035" \\ Publication Date: 2008 \\ Referred to as "MIT 2035"}

The scope of "On the Road in 2035" is to assess the future of light duty vehicles (LDV) and their impact on energy use, petroleum consumption, and the environment. The market penetration portion of this study is comprised of three scenarios exploring different directions in which the U.S. LDV can evolve. The three scenarios are: 1) "Turbocharged Internal Combustion Engine (ICE)," 2) "Market Mix - No Clear Winner," and 3) "Hybrid Strong."

The study forecasts the annual market penetration for PHEVs to range from 0 to $15 \%$ by 2035 . It also forecasts the market penetration for the gasoline hybrid to range between 15 and $40 \%$ by 2035 . The range in market penetration is primarily dependent on the level of technological advances between now and 2035 (see Table 1).

Table 1: Vehicle market penetration rates included in MIT's "On the Road in 2035"

\begin{tabular}{|c|c|c|c|}
\hline Scenarios & Turbocharged ICE & Market Mix & Hybrid Strong \\
\hline \multicolumn{4}{|c|}{ Annual Market Penetration for 2035} \\
\hline PHEV & $0 \%$ & $7.5 \%$ & $15 \%$ \\
\hline Gasoline Hybrid & $15 \%$ & $15 \%$ & $40 \%$ \\
\hline \multicolumn{4}{|l|}{ Assumptions } \\
\hline Technological Advances & $\begin{array}{l}\text { Intensive for the diesel } \\
\text { and the turbocharged }\end{array}$ & $\mathrm{N} / \mathrm{A}$ & Intensive for the hybrid \\
\hline
\end{tabular}

To analyze the fuel consumption and GHG emissions of future LDVs, MIT researchers use two simulation tools: 1) ADVISOR (ADvanced Vehlcle SimulatOR) developed by the National Renewable Energy Laboratory (NREL) and 2) GREET (The Greenhouse Gases, Regulated Emissions, and Energy Use in Transportation Model) developed by Argonne National Laboratory (ANL). MIT researchers include the lifecycle GHG emissions associated with the manufacturing and disposal aspects of vehicle manufacturing for its analysis. MIT researchers assume several advancements in glider technology for all vehicle technologies for 2035 , including a $25 \%$ reduction in aerodynamics, $33 \%$ reduction in tire rolling resistance, $20 \%$ reduction in curb weight, and $5 \%$ increase in transmission efficiency. These assumptions help conventional vehicles to remain competitive with HEVs and PHEVs through 2035. For its PHEV emissions data, the team uses an average U.S. electricity generation mix that produces $640 \mathrm{~g} \mathrm{CO}_{2} \mathrm{e} / \mathrm{kWh}$. A summary of MIT's emissions data for this study can be seen in Figure 1. 
MIT 2035 GHG Emissions

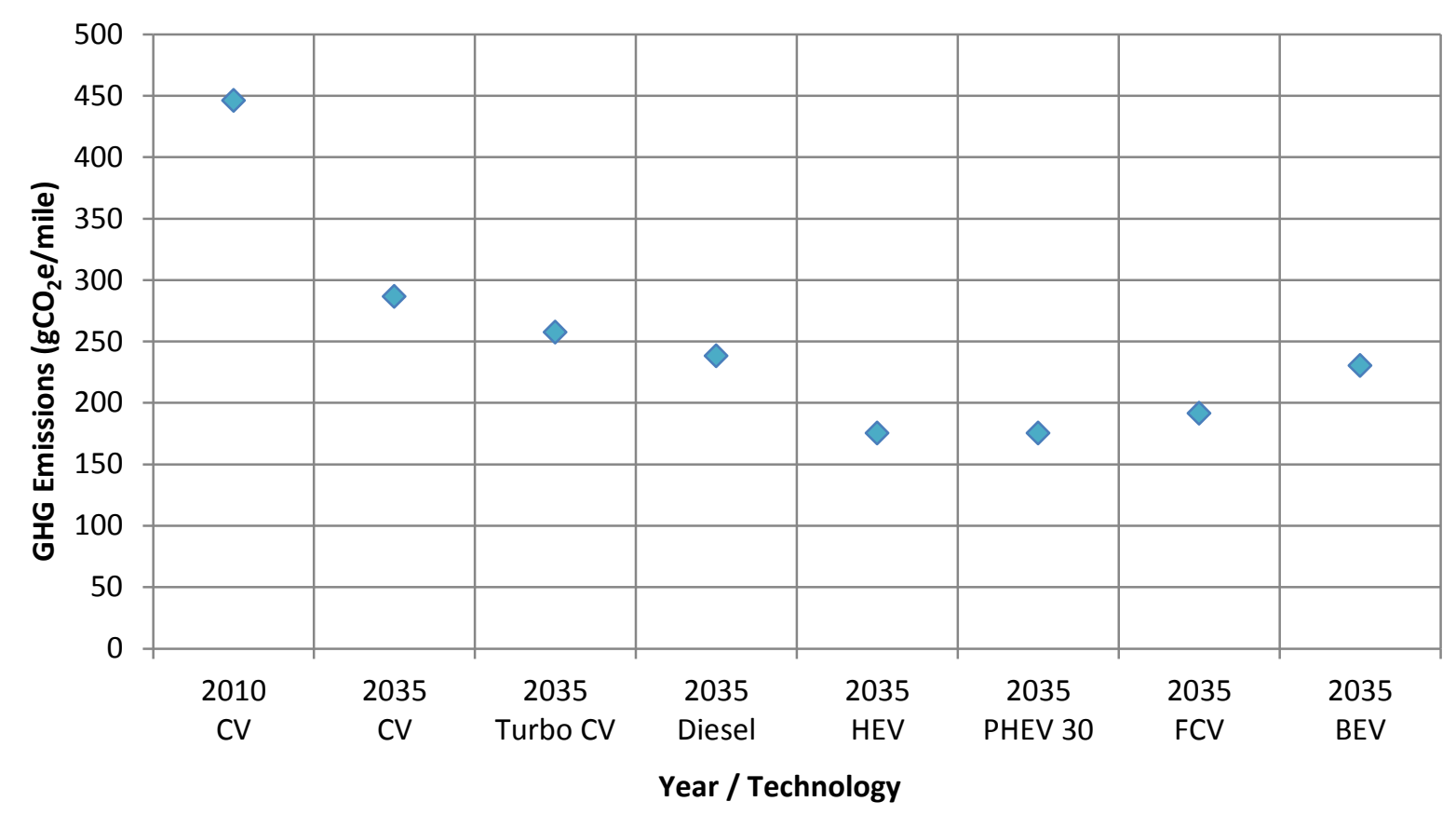

Figure 1: GHG Emission Projections from MIT 2035

\subsection{MIT - "Prospects for Plug-In Hybrid Electric Vehicles in the United States and Japan: \\ A General Equilibrium Analysis" \\ Publication Date: 2009 \\ Referred to as "MIT Prop"}

This report investigates the impact of vehicle markup and vehicle utility factor (UF) on the timing of PHEV annual market penetration in order to identify the conditions under which the PHEV could most greatly contribute to reductions in $\mathrm{GHG}$ emissions.

The vehicle UF refers to the fraction of driving that the vehicle could operate in an all-electric mode. This is usually directly related to the driver's daily commute distance and their driving patterns. In other words, a driver whose commutes involve shorter trips and more charging pauses will yield a higher UF.

The report also analyzes the impact of the absence and presence of advanced cellulosic biofuel technology and an environmental policy that provides an economy-wide carbon constraint. The policy scenario is drawn from the 2007 U.S. Climate Change Science Program. The environmental policy is referred to as "450 ppm" ", since such a policy in the United States would be consistent with the world achieving the 450

\footnotetext{
${ }^{1}$ According to the world Energy Outlook for $2008450 \mathrm{ppm}$ refers to ensuring that the atmospheric concentration of emissions is stabilized at 450 parts per million (ppm) in $\mathrm{CO}_{2}$ equivalent terms

http://www.worldenergyoutlook.org/docs/weo2008/WEO2008 es english.pdf
} 
ppm environmental target. The report uses a computable general equilibrium model to forecast the rate of the PHEV annual market penetration.

In all, MIT Prop presents 24 scenarios with a wide range of assumptions made for vehicle markup, utility factor, biofuels technology, and the $450 \mathrm{ppm}$ policy:

- Role of PHEV Markup:

○ PHEV Markup - $15 \%, 30 \%, 80 \%(\mathrm{UF}=0.6)$

- Role of PHEV Utility Factor:

○ PHEV Utility Factor $-0.3,0.6,0.8$ (Markup $=30 \%$ )

- Sensitivity to Policy and Biofuels Availability:

○ PHEV Markup - $15 \%, 30 \%, 80 \%, 450$ ppm policy $(\mathrm{UF}=0.6)$

- PHEV Markup, Biofuels - $15 \%, 30 \%, 80 \%$, No Policy (UF $=0.6$ )

○ PHEV Markup, Biofuels - $15 \%, 30 \%, 80 \%, 450 \mathrm{ppm}$ policy (UF $=0.6$ )

- PHEV Markup - 15\%, 30\%, 80\%, 450 ppm policy (Markup=30\%)

- PHEV Markup, Biofuels - 15\%, 30\%, 80\%, No Policy (Markup $=30 \%$ )

○ PHEV Markup, Biofuels - 15\%, 30\%, 80\%, 450 ppm policy (Markup=30\%)

The report concludes that vehicle markup has a more significant impact on PHEV annual market penetration than the utility factor. Also, the presence of biofuels has a negative impact on PHEV penetration because it represents a cost-competitive alternative technology that is assumed to be $\mathrm{CO}_{2}$ neutral. Finally, if PHEVs are priced at a $15 \%$ markup, then they could penetrate the market even without an environmental policy and could cause a 30\% reduction in oil consumption over the next century. Table 2 shows market penetrations of some of the scenarios discussed.

Table 2: PHEV annual market penetration rates projected in MIT Prop

\begin{tabular}{|l|c|c|c|c|}
\hline Scenarios & 2020 & 2030 & 2040 & 2050 \\
\hline Annual Market Penetration for PHEVs \\
\hline Markup 15\%, no policy, no biofuel & $3 \%$ & $10 \%$ & $21 \%$ & $33 \%$ \\
\hline Markup 15\%, no policy, biofuel & $3 \%$ & $10 \%$ & $20 \%$ & $30 \%$ \\
\hline Markup 80\%, no policy, biofuel & $0 \%$ & $0 \%$ & $0 \%$ & $0 \%$ \\
\hline Markup 15\%, policy, no biofuel & $1 \%$ & $12 \%$ & $47 \%$ & $85 \%$ \\
\hline
\end{tabular}

\subsection{Argonne National Laboratory (ANL) - "Impact of Component Size on Plug-In Hybrid Energy Consumption Using Global Optimization" \\ Publication Date: 2008 \\ Referred to as "ANL CS"}

The scope of ANL CS is to investigate the impact of PHEV component size on their electric system energy, power on control, and energy consumption. PHEVs with several different AERs are modeled in this study, each based on a parallel pre-transmission architecture. Three different Environmental Protection Agency 
(EPA) driving cycles are used for each vehicle: Urban Dynamometer Driving Schedule (UDDS), Highway Federal Emissions Test (HWFET), and Unified Dynamometer Driving Schedule (LA92). ANL uses the global optimization algorithm to ensure a fair comparison between different vehicles. The results are used to highlight control patterns and to present potential minimal fuel consumption and GHG emissions. The GHG emissions, calculated using the GREET model, for a PHEV20 using the three different driving cycles can be seen in Figure 2.

\section{ANL CS 2010 PHEV20 GHG Emissions}

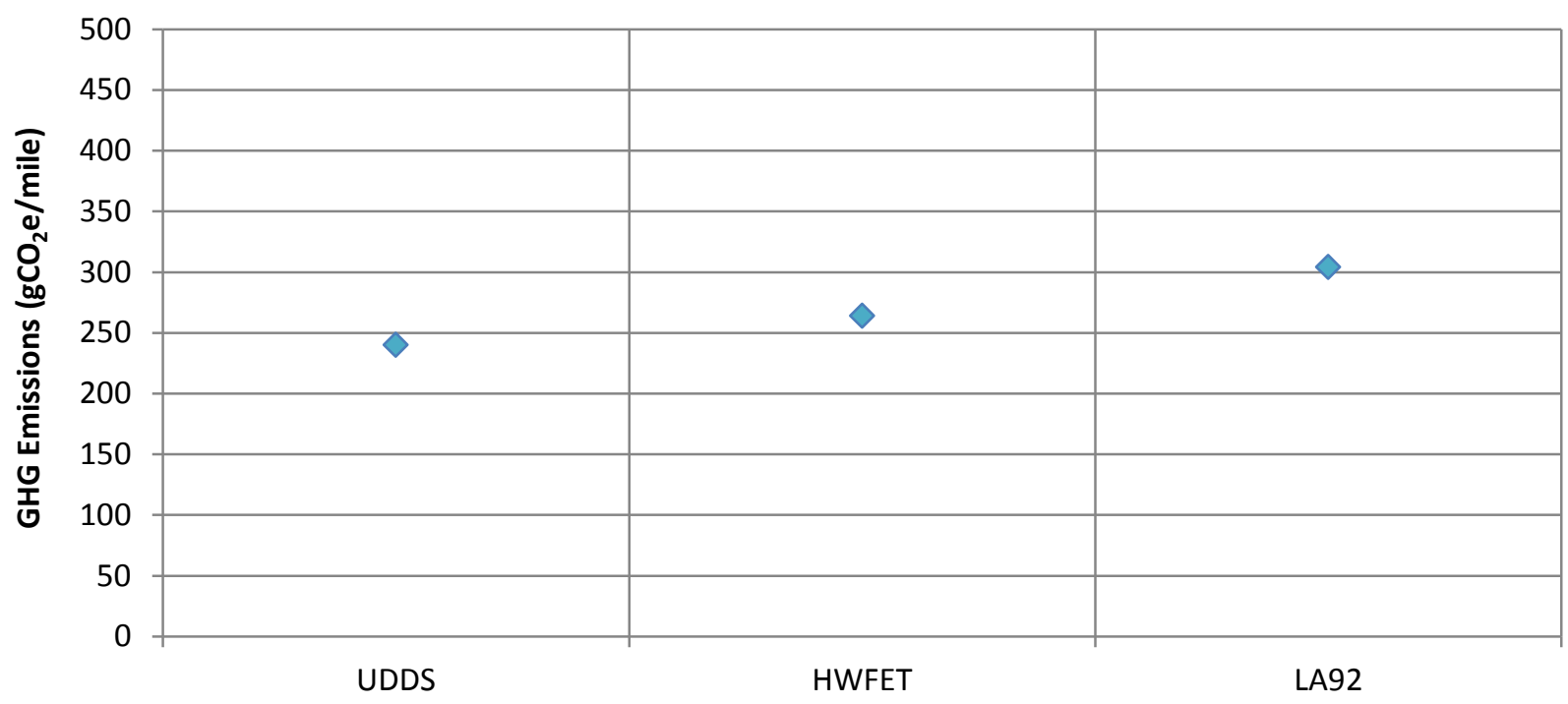

EPA Driving Cycle

Figure 2: WTW GHG emissions data for the year 2010 included in ANL CS

\subsection{ANL- "Impact of Real World Drive Cycles on PHEV Fuel Efficiency and Cost for Different Powertrain and Battery Characteristics" \\ Publication Date: 2009 \\ Referred to as "ANL EVS"}

In this report, ANL attempts to quantify the effects of different drive cycles on PHEV fuel efficiency. The real-world data used in this assessment is obtained from over 100 vehicles documented in a 2005 study based in Kansas City.

Second-by-second speed data are collected through on-board diagnostic ports and GPS devices. These driving cycles are simulated for conventional vehicles, HEVs, and PHEVs with three different driving strategies. The first uses an electric vehicle / charge sustaining (EV/CS) strategy (also referred to as "Thermostat") where the vehicle runs in all-electric mode until the battery's state of charge (SOC) reaches $30 \%$, then switches to CS mode. The next is a load-engine-power strategy that defines a power threshold and turns on the engine to provide additional wheel power if required. The third uses the optimum engine 
power strategy that also sets a power threshold and attempts to keep the engine running at close to peak efficiency, while using the engine to recharge the battery during charge depleting $(C D)$ mode if necessary.

The average trip length was 11.4 miles, and with 363 trips taken, approximately 4,140 miles are covered. The results for all driving strategies could be calculated using the total amount of liquid fuel consumed by each vehicle to drive the total miles in the 100+ drive cycles. The real-world drive cycle data can be seen in Table 3.

Table 3: ANL EVS fuel use data for PHEVs in real-world drive cycles

\begin{tabular}{|l|c|c|c|}
\hline Vehicle & $\begin{array}{c}\text { Total Fuel } \\
\text { Consumed (L) }\end{array}$ & $\begin{array}{c}\text { Corresponding Fuel } \\
\text { Economy (mpg) }\end{array}$ & $\begin{array}{c}\text { \% Fuel Displaced Relative } \\
\text { to Conventional }\end{array}$ \\
\hline Conventional & 454 & 34.5 & - \\
\hline HEV & 328 & 47.8 & 27.6 \\
\hline PHEV - 4 kWh & 238 & 65.9 & 47.5 \\
\hline PHEV - 8 kWh & 172 & 91.1 & 62 \\
\hline PHEV - 12 kWh & 99 & 158.3 & 78 \\
\hline PHEV - 16 kWh & 54 & 290.2 & 88 \\
\hline
\end{tabular}

Instead of labeling PHEVs according to their AER, the report labels them according to their total battery capacity. The $4 \mathrm{kWh}$ PHEV is listed with a CD distance of 10 miles. Therefore, the battery sizes correspond with the AERs shown in Table 4.

Table 4: ANL EVS PHEV categories and corresponding AER values

\begin{tabular}{|l|c|}
\hline PHEV Configuration & Correlating AER (miles) \\
\hline Split 4 kWh & 10 \\
\hline Split 8 kWh & 20 \\
\hline Thermo 12 kWh & 30 \\
\hline Thermo 16 kWh & 40 \\
\hline
\end{tabular}

Results in Table 5 are given for the load engine power strategy only for the $4 \mathrm{kWh}$ battery and the optimum engine power strategy for the $8 \mathrm{kWh}$ battery. Comparing these figures to the results shown above highlights the major impact on fuel economy that a driving strategy may have. 
Table 5: ANL EVS fuel consumption by vehicle configuration

\begin{tabular}{|l|c|c|}
\hline Vehicle Type & $\begin{array}{c}\text { Fuel Consumption } \\
\text { (L/100 km) }\end{array}$ & $\begin{array}{c}\text { Fuel Economy } \\
\text { (mpg) }\end{array}$ \\
\hline Conventional & 6.61 & 35.6 \\
\hline HEV & 4.69 & 50.2 \\
\hline PHEV - Split 4 kWh & 3.27 & 71.9 \\
\hline PHEV - Split 8 kWh & 2.32 & 101.4 \\
\hline PHEV - Thermo 12 kWh & 1.5 & 156.8 \\
\hline PHEV - Thermo 16 kWh & 1.23 & 191.2 \\
\hline
\end{tabular}

Fuel displacement in ANL EVS is found to increase linearly with the available electrical energy independent of driving strategy. This data is seen in Figure 3.

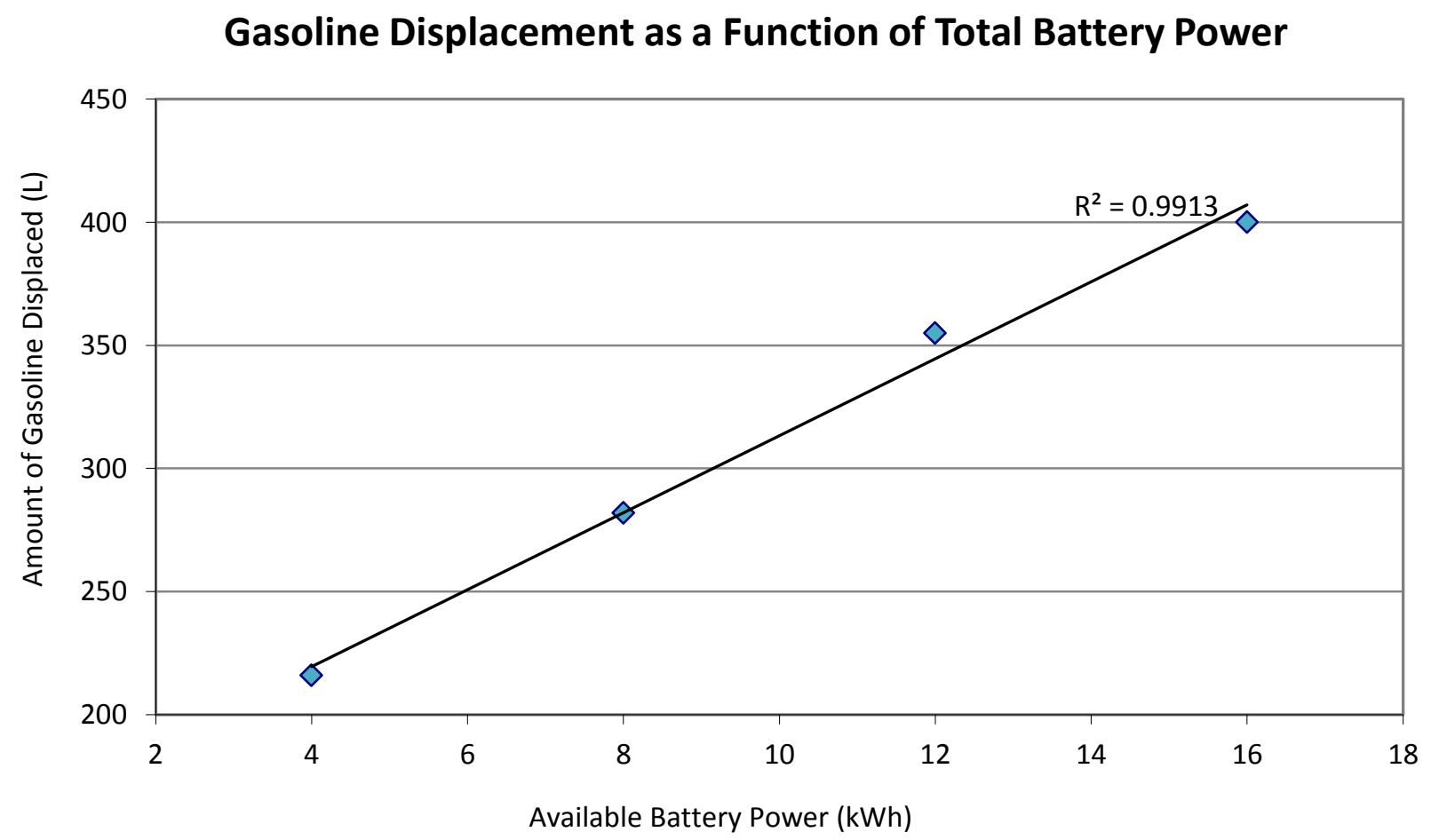

Figure 3: Trend of gasoline displacement with available battery power 


\subsection{ANL - "Multi-Path Transportation Future Study: Vehicle Characterization and Scenario Analyses" Publication Date: 2009 \\ Referred to as "ANL MPT"}

The scope of ANL MPT compares alternative ways to make significant reductions in oil use and carbon emissions from LDVs in the United States. ANL uses the National Energy Modeling System (NEMS) model in this study, which includes a vehicle choice model that uses vehicle and fuel prices to estimate vehicle market penetration. The study suggests three potential scenarios: 1) A mixed scenario where the government avoids picking a winner, 2) a hydrogen success scenario, and 3) a PHEV and ethanol scenario where the cost of cellulosic ethanol is reduced and rapid improvement in the lithium-ion battery is achieved.

The report also presents four sets of results for each scenario that assume:

1) Vehicle prices developed by "literature review."

2) Vehicle prices developed to attain U.S. Department of Energy (DOE) FreedomCAR program cost targets, or "program goals."

3) Literature review vehicle prices plus subsidies.

4) "Program goals" vehicle prices plus subsidies.

In addition to PHEVs, this report also discusses battery electric vehicles (BEV) and HEVs. It suggests that BEVs will have a zero annual market penetration from 2020 to 2050, and HEVs will have a high annual market penetration that reaches $40 \%$ by 2020 in some scenarios and declines to $15 \%$ by 2050 in other scenarios.

Table 6 presents four distinctive sets of results for each of the three major scenarios, yielding a total of 12 different sets of results that forecast PHEV annual market penetration rates. For example, the first PHEV annual market penetration forecast of $0.2 \%$ by 2030 is based on the hydrogen success scenario under the literature review prices assumption. The study provides a comprehensive list of the vehicle prices in various years and according to different configurations. Table 6 shows the annual market penetration rates assumed by the four sets of results.

Table 6: PHEV market penetration rates included in ANL MPT

\begin{tabular}{|l|c|c|c|}
\hline Scenarios & Hydrogen Success & Mixed & PHEVs \& Ethanol \\
\hline Annual Market Penetration for PHEVs for 2030 (\%) & \multicolumn{2}{|l}{} \\
\hline Literature Review Prices without Subsidies & $0.2 \%$ & $0.2 \%$ & $0.3 \%$ \\
\hline Program Goals Prices without Subsidies & $3.3 \%$ & $2.3 \%$ & $3 \%$ \\
\hline Literature Review Prices with Subsidies & $0.1 \%$ & $25.5 \%$ & $33.2 \%$ \\
\hline Program Goal Prices with Subsidies & $3.2 \%$ & $17.2 \%$ & $26.4 \%$ \\
\hline
\end{tabular}

Table 7 is a snapshot of the assumptions for 2030 for an SI PHEV 40 vehicle. The majority of the variation is due to changes in the incremental prices of the vehicle, the presence or absence of subsidies, and the 
supply curve. The supply curve is mainly defined by government initiatives to push for a specific kind of vehicle technology over another.

Table 7: PHEV (spark-ignited) assumptions made in ANL MPT

\section{PHEV Assumptions}

\begin{tabular}{|l|l|}
\hline Vehicle Subsidies & $\$ 7,500$ \\
\hline Vehicle Retail Price SI PHEV 40 for $\mathbf{2 0 3 0}$ & \multicolumn{2}{|l|}{} \\
\hline Literature Review & $\$ 30,791$ \\
\hline Program Goals & $\$ 26,991$ \\
\hline Incremental Price for SI PHEV40 relative to 2007 Reference SI for $\mathbf{2 0 3 0}$ \\
\hline Literature Review & $\$ 8,934$ \\
\hline Program Goals & $\$ 5,134$ \\
\hline
\end{tabular}

\subsection{ANL - "Well-to-Wheels Analysis of Energy Use and Greenhouse Gas Emissions of Plug-in Hybrid Electric Vehicles" \\ Publication Date: 2010 \\ Referred to as "ANL WTW"}

For this report, ANL focuses on energy use and GHG emissions associated with PHEVs. For their calculations, ANL assumes that $10 \%$ of all vehicles in 2020 will be PHEVS. ANL's Powertrain System Analysis Toolkit (PSAT) is used to carry out fuel efficiency calculations, and GREET is used for GHG emissions calculations. PHEVs with AERs of $10,20,30$, and 40 miles are examined using two different powertrain architectures: the power split configuration and the series configuration. ANL researchers calculate an equivalent "on road" driving cycle based on established EPA formulas. ANL considers multiple electricity generation mixes ranging from "coal intensive" to "renewable." They also consider multiple fuel blends in their analysis, including gasoline, diesel, corn-based E85, biomass-based E85, and hydrogen. ANL concludes that the two main factors that impact the energy use and GHG emissions of PHEVs compared with baseline gasoline technologies are 1) the regional electricity generation mix used for battery recharging and 2) the adjustment of fuel economy and electricity consumption to reflect "real-world" driving conditions. Figure 4 presents the resultant emissions data for several different vehicle and fuel technologies. 


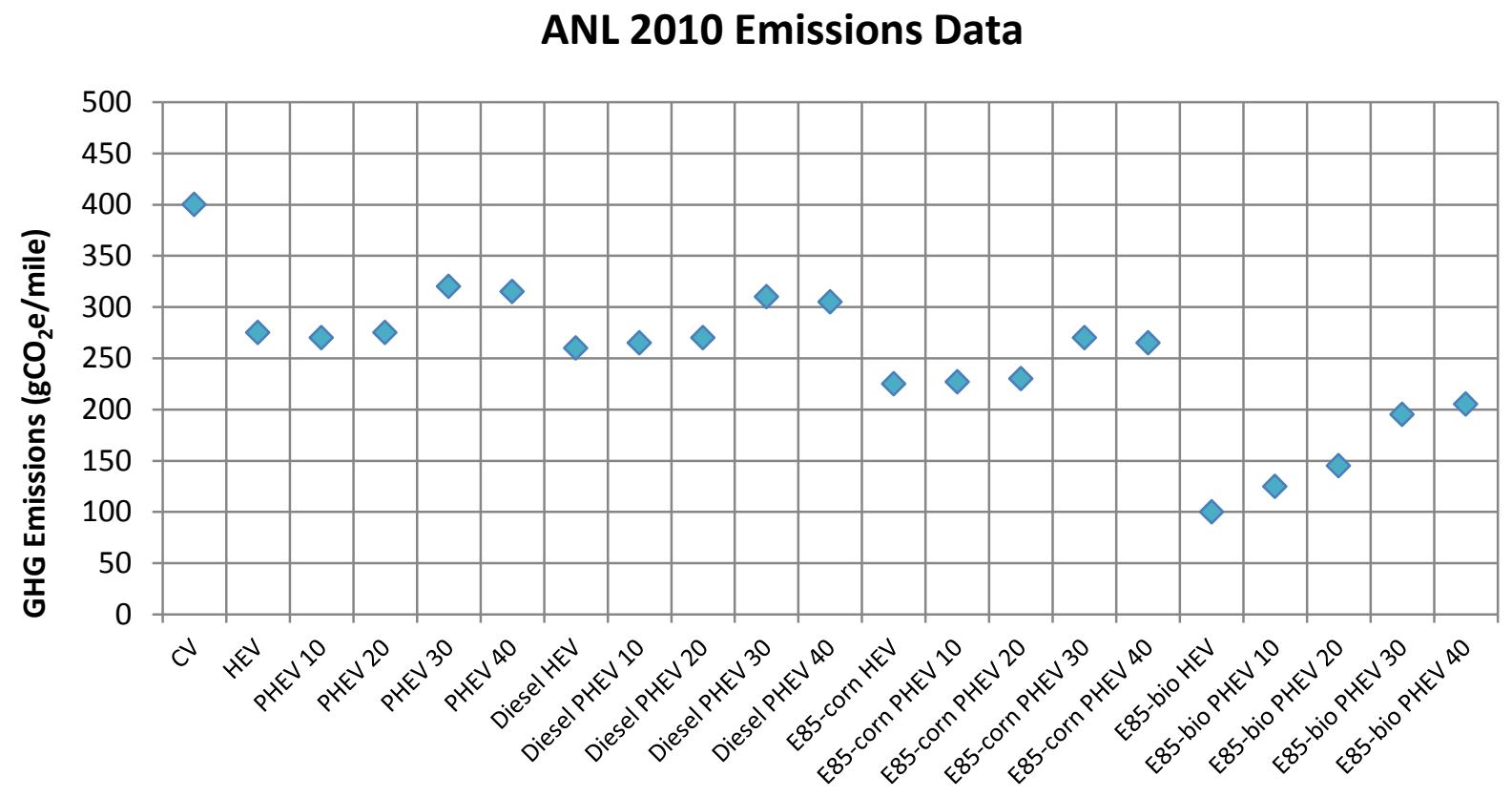

Technology

Figure 4: GHG emissions data included in ANL WTW

The power-split configuration is used for PHEV10s and PHEV20s, and the series configuration is used for PHEV30s and PHEV40s. PHEV10s are assumed to travel $25 \%$ in CD mode, while PHEV40s reach $51 \%$ in CD mode. PHEV10s and PHEV20s are found to potentially reduce gasoline consumption by over $60 \%$ in $\mathrm{CD}$ mode, while the series powertrain models could reach over $90 \%$. Power-split PHEVs have the ability to extend their electric range if they run in blended CD mode.

Simulations are run using the standard EPA UDDS and HWFET drive cycles, and the standard EPA drive cycles are used to determine each vehicle's fuel economy. Three sets of assumptions are applied to each vehicle corresponding to reductions in glider mass, drag coefficient, and fuel cell system cost. The scenarios are determined to be either $90 \%$ likely to occur by $2020,50 \%$ likely, or $10 \%$ likely. The middle scenario of $50 \%$ likely is used for further analysis.

A utility factor is quantified and assumes that the probability of PHEV purchase is invariant to the distance driven each day. Further analysis employs travel data from a National Highway Traffic Safety Administration (NHTSA) 2001 survey. Overall, PHEVs are found to reduce petroleum consumption by $40 \%$ to $60 \%$ compared to ICEs. PHEVs running on E85 fuel reduce gasoline use by $80 \%$ to $90 \%$. Also, ANL finds that as the degree of electrification increases, so does the sensitivity of the battery power to the vehicle mass. Finally, using a $43 \%$ city and $57 \%$ highway fuel economy mix, ANL concludes, overall, that a higher AER corresponds to higher gasoline displacement and higher GHG emissions.

\subsection{SENTECH, Inc. / ORNL - "Plug-in Hybrid Electric Vehicle Market Introduction Study" Publication Date: 2010 Referred to as "SENTECH/ORNL MIS"}

In this report, the project team analyzes the impact of nine potential policies relative to a current policy 
case. The objective of the report is to determine which policies could have the highest impact on PHEV sales with minimum cost of implementation. The project team used the ORNL Market Acceptance of Advanced Automotive Technologies (MA ${ }^{3} \mathrm{~T}$ ) model in addition to the University of Michigan Transportation Research Institute's (UMTRI) Virtual AutoMotive Market Place (VAMMP) model to forecast PHEV annual market penetration. In this comparative study, analysis of only the current policy case scenario will be completed. The current policy case scenario uses three major assumptions:

1) The Plug-In Vehicle Tax Credit, introduced in EISA 2007, offers between $\$ 2,500$ and $\$ 7,500$ in tax credits to consumers.

2) Advanced battery manufacturing grants worth $\$ 2$ billion are available to domestic automotive, battery, and component manufacturers.

3) $\$ 400$ million is available for electric drive vehicles and electrification infrastructure demonstration and evaluation projects.

SENTECH's current policy case is one of the few scenarios suggesting that the current U.S. administration goal of introducing 1 million plug-in hybrid vehicles onto the road by 2015 can be achieved (Obama 2009). The study forecasts a PHEV penetration rate from 2012 to 2020, including an annual market penetration rate of $2.5 \%$ in 2015 , as shown in Table 8.

Table 8: PHEV market penetration from SENTECH/ORNL MIS

\begin{tabular}{|l|c|c|}
\hline Scenarios & 2015 & 2020 \\
\hline Annual Market Penetration For PHEVs (\%) \\
\hline Current Policy Case & $424,000(2.5)$ & $333,000(1.8)$
\end{tabular}

\subsection{SENTECH, Inc. / ORNL - "Plug-In Hybrid Electric Vehicle Value Proposition Study" Publication Date: 2010 Referred to as "SENTECH/ORNL VP"}

The scope of this report is to identify and evaluate value-added propositions for PHEVs that will help overcome the initial price premium relative to comparable ICEs and HEVs, and to assess other nonmonetary benefits and barriers associated with an emerging PHEV fleet, including environmental, societal, and grid impacts. The authors compile a list of value propositions from a PHEV Value Proposition Study workshop that more than 120 PHEV industry stakeholders attended. They then brainstorm with the intent to arrive at a general consensus of what the marketplace will be like in 2030. Using the list of propositions, SENTECH/ORNL conduct two regional case studies - one in southern California (SC) and the other in the North American Electric Reliability Corporation, or NERC, region formerly known as the East Central Area Reliability Coordination Agreement (ECAR). Beyond these two regions, SENTECH/ORNL also considered electricity mixes generated by nuclear power and renewable energy sources.

The report assumes a pre-transmission parallel hybrid architecture with a 30-mile AER that uses lithium-ion batteries. It also assumes that Corporate Average Fuel Economy (CAFE) standards for LDVs will exceed 
$35 \mathrm{mpg}$, and the fuel economy of all vehicles will benefit from a $30 \%$ glider weight reduction by 2030 relative to today's vehicles (NHTSA 2009). Three different fuel blends are explored in the study, with the first being current-day gasoline, referred to as E10. The second fuel blend assumed $30 \%$ of the vehicles used $\mathrm{E} 10$ and $70 \%$ of the vehicles used cellulosic E85, for an equivalent of E30. The last fuel blend considered is cellulosic E85. Assumptions are also made in the report for driving habits, home charging habits, and PHEV market penetration in 2030. PSAT and GREET were used to calculate the GHG emissions associated with the PHEVs specified within this report. The emissions data published in SENTECH/ORNL VP can be seen in Figure 5. The first data point is their value for a 2010 conventional vehicle, while the rest of the data points are projections for model year 2030.

\section{SENTECH/ORNL VP GHG Emissions}

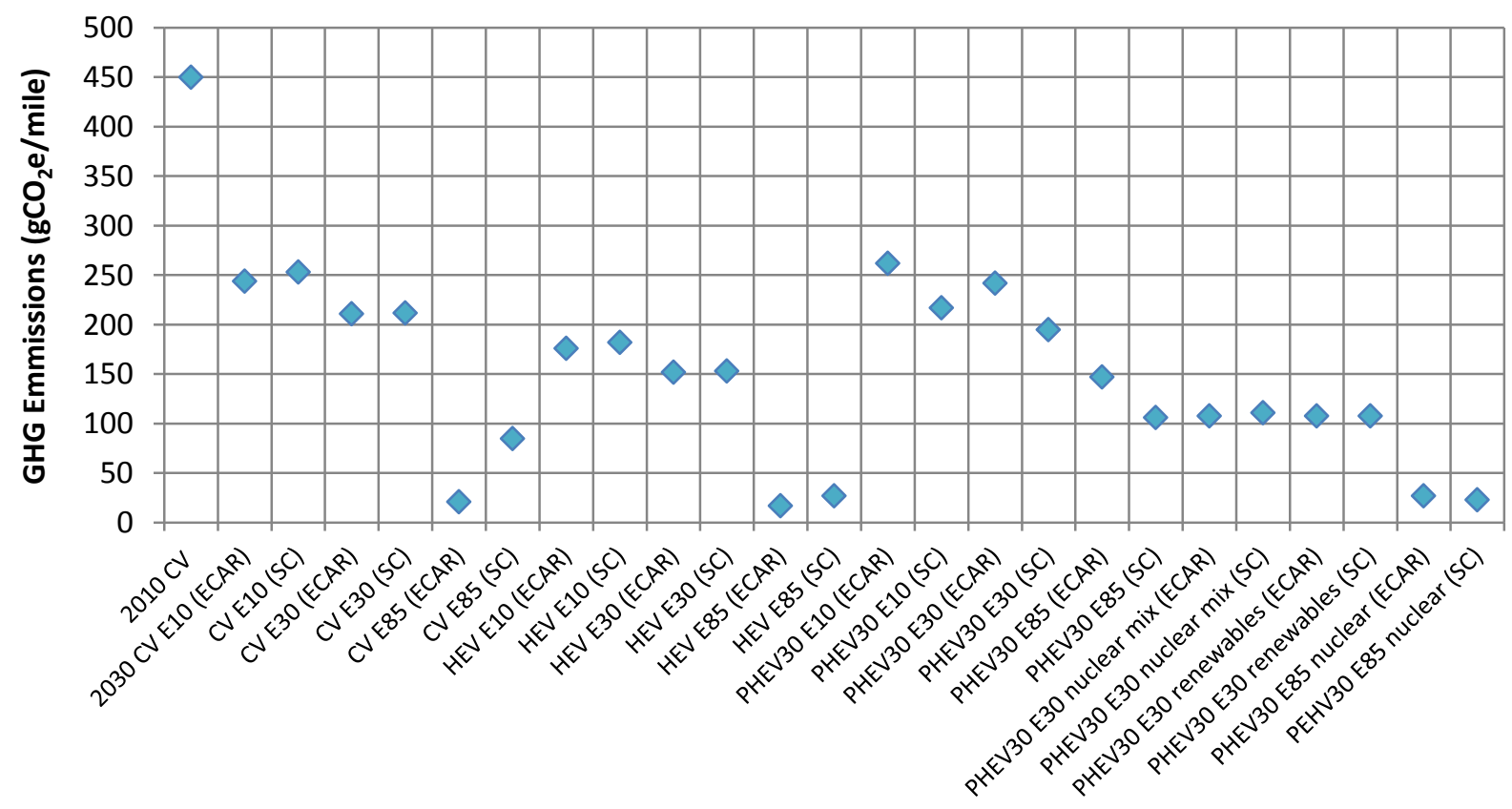

Year / Technology / Scenario

Figure 5: GHG emissions data from SENTECH/ORNL VP 


\subsection{ORNL - "Impact of Plug-in Hybrid Vehicles on the Electric Grid" \\ Publication Date: 2006 \\ Referred to as "ORNL Impact"}

As the title suggests, ORNL seeks to understand the ramification s of introducing 1 million PHEVs into the VACAR sub-region of the Southeast Electric Reliability Council, which coverings much or all of South Carolina, North Carolina, and Virginia. ORNL's Oak Ridge Competitive Electricity Dispatch, or ORCED, model is used to simulate the hourly dispatch of power generators to meet for the region over one year. The resulting impact of this PHEV fleet on regional electricity demand ranged from 1,400 to 6,000 MW, depending on vehicle characteristics, battery characteristics, charger voltage level, amperage and duration. Changes in these factors also play a role in the emissions generated. For example, while nighttime charging is found to have less of an impact on peak loads, and generation adequacy, the relative amounts of emissions changes significantly because coal-fired generation increases during this time.

\subsection{Pacific Northwest National Laboratory (PNNL) - "Impacts Assessment of Plug-In Hybrid Vehicles on Electric Utilities and Regional U.S. Power Grids" \\ Publication Date: 2007 \\ Referred to as "PNNL Impact"}

PNNL analyzes the potential ability of the current U.S. power grid to support a fleet of plug-in electric vehicles (PEV). The overall average for the LDV fleet is assumed to be $73 \%$, which could displace 6.5 million barrels of oil equivalent per day, or approximately $52 \%$ of the nation's oil imports, compared to current usage. A PHEV with an AER of 33 miles is used, with an $8.6 \mathrm{kWh}$ battery for a compact sedan and a $9.9 \mathrm{kWh}$ battery for a midsize sedan. Results are divided into 14 regions with two different charging scenarios. For 24 -hour charging, grid potential ranges from $18 \%$ to $127 \%$, while 12 -hour charging ranges from $10 \%$ to $73 \%$.

\subsection{PNNL - "Plug-in Hybrid Electric Vehicle Annual Market Penetration Scenarios" Publication Date: 2008 Referred to as "PNNL MPS"}

In this report, PNNL analyzes the economic drivers, technology constraints, and market potential for PHEVs in the United States. Three different scenarios are provided: 1) The Hybrid Technology-Based Assessment, 2) The R\&D Goals Achieved, and 3) Supply-Constrained. The "Hybrid Technology-Based Assessment" scenario is built off of hybrid forecasts and the ultimate PHEV market share is based on prior Electric Power Research Institute (EPRI) and National Resources Defense Council (NRDC) projects. This report also assumes that PHEV technology advancement will be accelerated. The "R\&D Goals Achieved" scenario assumes that DOE goals for PHEVs are achieved. Accordingly, PNNL performs a Delphi analysis asking industry experts to forecast PHEV market penetration. Specific assumptions are given, such as that the price premium for PHEVs is $\$ 4,000$ relative to existing hybrid technology. The "Supply Constrained' scenario assumes that PHEV sales are constrained only by the supply of vehicles and batteries. Under this scenario, the off-peak capacity of the electric grid infrastructure can meet the demand of $73 \%$ of LDVs in the United States in 2045. A summary of these scenarios can be seen in Table 9. 
Table 9: PHEV market penetration in PNNL MPS

\begin{tabular}{|l|c|c|c|c|}
\hline Scenarios & 2020 & 2030 & 2040 & 2045 \\
\hline \begin{tabular}{l} 
Annual Market Penetration for PHEVs \\
\hline Hybrid Technology-Based Assessment
\end{tabular} & $6 \%$ & $12 \%$ & $12 \%$ & $12 \%$ \\
\hline $\begin{array}{l}\text { R\&D Goals Achieved } \\
\text { Supply-Constrained }\end{array}$ & $5 \%$ & $23 \%$ & $29 \%$ & $30 \%$ \\
\hline
\end{tabular}

\subsection{NREL - "Battery Requirements and Cost-Benefit Analysis for Plug-In Hybrid Vehicles" Presentation Date: 2007 Referred to as "NREL CBA"}

NREL's presentation does not predict future characteristics of the PHEV fleet, but rather gives an overview of the alternatives to ICE vehicles, and of PHEV technology components, benefits, and barriers. An annual mileage of 15,000 is assumed, with PHEVs operating in a blended strategy to optimize benefits. Lower battery costs and higher gas prices are stated requirements to make PHEVs economically attractive.

Traditionally, petroleum consumption increases while domestic oil production decreases. With most LDVs being driven less than 40 miles per day, PHEVs could be a way to reduce imported petroleum dependence. When comparing these factors and vehicles to a conventional ICE, petroleum dependence is decreased by over one-third at minimum and by over $80 \%$ at maximum for PHEVs. The percentage oil reduction for both HEVs and PHEVs can be seen in Table 10. The fuel economy and fuel consumption for the various vehicle technologies used by NREL can be seen in Table 11.

Table 10: NREL defines the effectiveness of electric vehicle technology to displace petroleum depending on driving strategy

\begin{tabular}{|l|c|c|}
\hline & \% Oil reduction in CD mode & $\%$ Oil reduction in CS mode \\
\hline HEV & \multicolumn{2}{|c|}{$10 \%-35 \%$} \\
\hline PHEV & $50 \%-80 \%$ & $35 \%-50 \%$ \\
\hline
\end{tabular}


Table 11: Fuel economy and consumption for NREL's vehicle simulations

\begin{tabular}{|l|c|c|}
\hline & Gasoline Fuel Economy (mpg) & Annual Gasoline Consumption (gal) \\
\hline ICE & 27 & 564 \\
\hline HEV & 36 & 416 \\
\hline PHEV20 & 51 & 297 \\
\hline PHEV40 & 69 & 218 \\
\hline
\end{tabular}

In NREL CBA, PHEVs are recognized as potentially contributing to national energy security, but the barriers associated with battery life, packaging, safety, and cost must first be addressed.

\subsection{NREL - "Using GPS Travel Data to Assess the Real World Driving Energy Use of Plug- in Hybrid Electric Vehicles" \\ Publication Date: 2007 \\ Referred to as "NREL GPS"}

In this report the authors tackle the uncertainty in predicted PHEV performance due to variance in standard test cycles and real-world driving cycles. To do this, second-by-second driving profiles over a period of 24 hours are obtained from GPS data in 227 vehicles. Simulating these profiles in the software ADVISOR allow for a real-world analysis of advanced vehicle systems. For this study, HEVs and PHEVs are assumed to use a parallel powertrain configuration. The performance predicted by the ADVISOR model is shown Table 12.

HEVs are seen to reduce fuel consumption by $29 \%$, PHEV20s by almost $55 \%$, and PHEV40s by about $66 \%$, compared to a conventional ICE. PHEVs are assumed to begin the day fully charged and not charge again until they were done being used for the day. While this study provides a more realistic idea of hybrid performance, the results are limited by the number of vehicles tracked, the limited geographic scope (St. Louis, Missouri), and the analysis of travel patterns for a single weekday. Even with aggressive driving profiles, the use of a blended CD mode strategy allows PHEVs to run on less than $50 \%$ of the fuel an ICE consumes. 
Table 12: Vehicle specifications for NREL's simulations using real-world driving data in NREL GPS

\begin{tabular}{|l|c|c|c|c|}
\hline & Conventional & HEV & PHEV20 & PHEV40 \\
\hline Curb Mass (kg) & 1,429 & 1,399 & 1,488 & 1,567 \\
\hline Fuel Economy (mpg) & 26 & 39.2 & 54 & 67.4 \\
\hline AER - Urban (mi) & N/A & N/A & 22.3 & 35.8 \\
\hline
\end{tabular}

PHEVs run in CD mode and then switched to CS mode when the battery's charge became too low. For an unknown driving distance, this strategy allows for the maximum petroleum displacement. The fuel economy values are calculated based on GPS data and can be seen in Table 13.

Table 13: Comparison of fuel economy results from GPS driving data compared to fuel economies calculated using EPA's standard test cycles

\begin{tabular}{|l|c|c|}
\hline Vehicle Type & Real-World Fuel Economy (mpg) & Standard Cycle Fuel Economy (mpg) \\
\hline Conventional & 26 & 26 \\
\hline HEV & 37 & 39.2 \\
\hline PHEV20 & 58 & 54 \\
\hline PHEV40 & 76 & 67.4 \\
\hline
\end{tabular}

Comparing these values to mileage calculated through standard driving cycles, both plug-in hybrid models performed better than expected, while the conventional and hybrid vehicles failed to meet their predicted mileages. Using real-world driving cycles derived from GPS data, the actual AER achieved for the plug-in hybrids was considerably less than their rating value. This data can be seen in Table 14.

Table 14: NREL comparison of the results calculated from the drive cycle GPS data for the AER of the PHEV20 and PHEV40

\begin{tabular}{|l|c|c|}
\hline AER $(\mathrm{mi})$ & PHEV20 (\% of fleet) & PHEV40 (\% of fleet) \\
\hline $\mathbf{0}-\mathbf{5}$ & 49.5 & 56.5 \\
\hline $\mathbf{5}-\mathbf{1 0}$ & 15 & 13 \\
\hline $\mathbf{1 0}-\mathbf{1 5}$ & 18 & 10 \\
\hline $\mathbf{1 5}-\mathbf{2 5}$ & 23 & 9.5 \\
\hline $\mathbf{2 5}-\mathbf{4 0}$ & 0 & 8 \\
\hline
\end{tabular}

Therefore, NREL concluded that replacing a fleet of midsize ICE vehicles with PHEVs would cut daily gasoline use by about $50 \%$. 


\subsection{Electrification Coalition - "Electrification Roadmap: Revolutionizing Transportation and Achieving Energy Security"}

Publication Date: 2009

Referred to as "EC"

The Electrification Roadmap serves as a guide for transforming the U.S. light-duty transportation industry into one that is almost completely powered by electricity. Unlike the other reports highlighted in this comparative study, the Electrification Coalition does not provide forecasts on total PEV market penetration. Instead, it provides annual market penetration goals for BEVs and PHEVs separately. This report sets a national goal for electrification; it suggests that by $2040,75 \%$ of the vehicle miles traveled (VMT) in the United States should be electric miles. The electric miles could be performed by any form of grid-enabled vehicle, not restricted to PHEVs. Table 15 highlights two PEV annual market penetration milestones for years 2020 and 2050 set by the Coalition. This report discusses strategies to support the achievement of the national electrification goal. The milestones are relative to PEVs in general, including both PHEVs and $B E V s$, and do not specify the unique contribution by each vehicle type. The study also suggests that BEV annual sales will overcome PHEV annual sales by 2040. Various initiatives to support the achievement of the goal relative to the battery technology, charging infrastructure, and gasoline taxes are provided in this report.

Table 15: Annual PEV annual market penetration milestones from the Electrification Coalition's report

Annual Market Penetration Milestones

Annual PEV (PHEV \& BEV)
2020

5 million units $(25 \%)$
2030

15 million units $(90 \%)$

The Roadmap references EPRI/NRDC's report entitled, "Environmental Assessment of Plug-In Hybrid Electric Vehicles, Volume 1," for their emissions data. The Coalition discusses the wheel-to-wheel (WTW) analysis of a current day conventional vehicle and compares it to a current day PHEV powered with electricity that is generated from power plants using a five different fuel source scenarios: 1) "2010 Old Coal", 2) "2010 Old Coal w/ Gas Turbine (GT)," 3) "2010 Old Coal with Carbon Capture (CC)," and 4) "Renewables." The report does not state any further assumptions in relation to their GHG emissions data. Its $\mathrm{GHG}$ emissions data can be seen in Figure 6. 


\section{Electrification Coalition GHG Emissions}

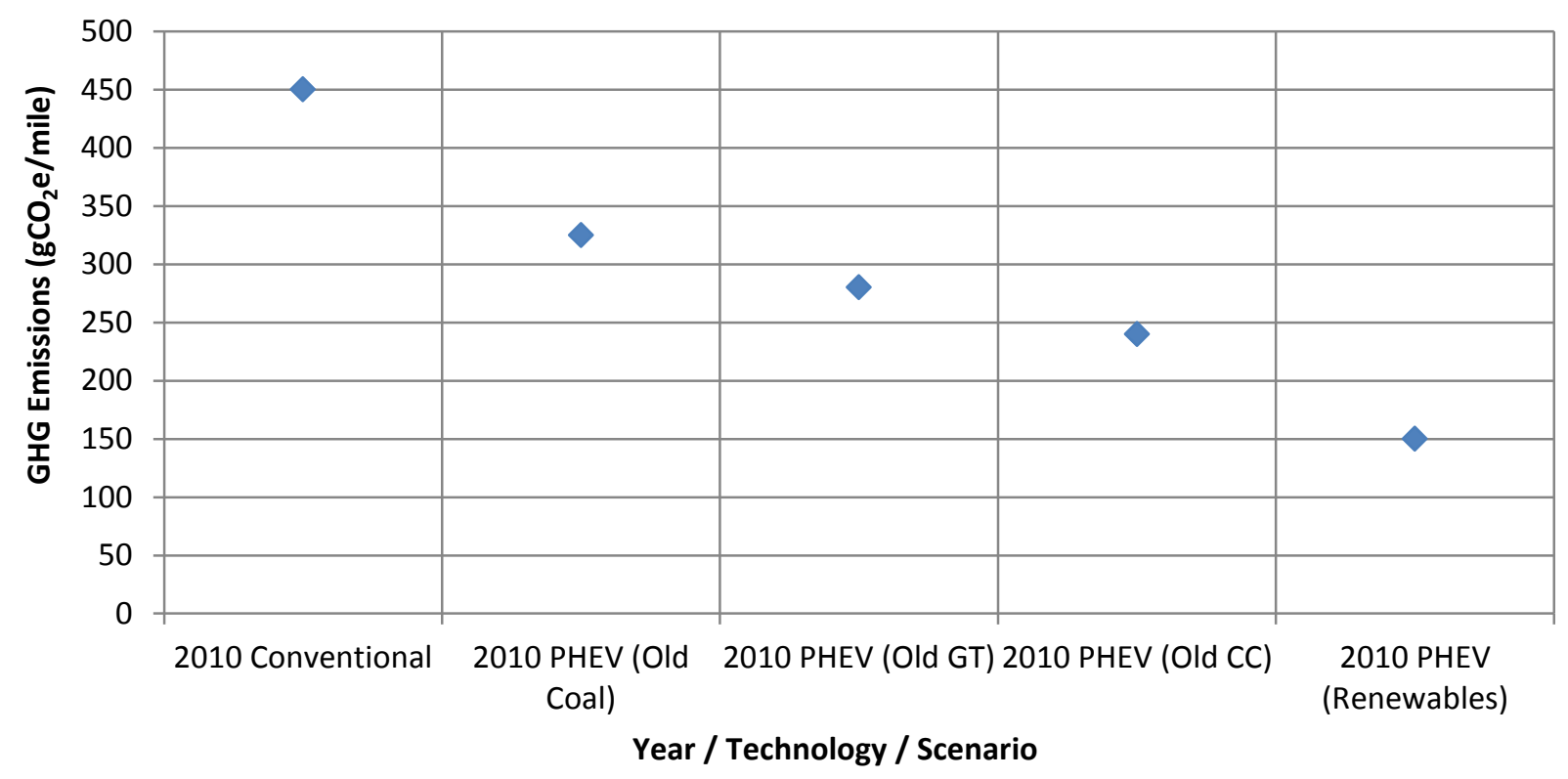

Figure 6: Selected GHG emissions data from the Electrification Coalition

\subsection{U.S. Energy Information Administration (EIA) - "Annual Energy Outlook" Publication Date: 2010 Referred to as $A E O$}

The Annual Energy Outlook 2010 briefly discusses unconventional vehicle technologies with respect to both annual market penetration and GHG emissions. Information published in Annual Energy Outlook 2010 is created using the EIA's NEMS model to estimate the future sales of these vehicles, which include HEVs, PHEV10s and PHEV40s. Table 16 presents these annual sales penetration rates.

Table 16: Vehicle penetration rates projected in the Annual Energy Outlook 2010

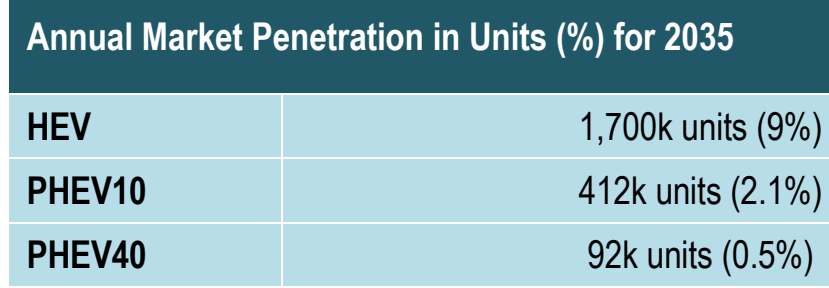

According to the $A E O$, the total annual HEV sales will account for 1.12 million vehicles in 2020 and will grow to 2.2 million vehicles in 2035. AEO also estimates that total LDV sales will reach 19 million by 2035. The report does not include any scenario analyses, but rather presents the potential evolution of 
unconventional vehicle technologies. The published report does not discuss the assumptions supporting the PEV forecast.

Related to GHG emissions, AEO assumes the adoption of CAFE standards put forth by the EPA and NHTSA for LDVs in model years 2012 through 2016, followed by a modest increase through the 2020 model year to meet the requirements of EISA 2007 (NHTSA 2009, EISA 2007). The study shows an increase in demand for energy and electricity in the transportation sector; however, the report does not give GHG emissions data for individual vehicle technologies or for the various mixes of generated electricity.

\subsection{EPRI/NRDC - "Environmental Assessment of Plug-In Hybrid Electric Vehicles, Volume} 1: Nationwide Greenhouse Gas Emissions"

Publication Date: 2007

Referred to as "EPRl"

The primary objective of this report, prepared jointly by EPRI and the NRDC, is to analyze two scenarios from an environmental standpoint: one without PHEVs and one where PHEVs comprise $40 \%$ of the vehicle fleet (and also $50 \%$ of new vehicle sales) in 2030. The report proceeds to assess the impact of widespread PHEV adoption on GHG emissions and on nationwide air quality. The project team studies three fleet penetration scenarios (Low, Medium, and High) developed from choice-based market modeling of the consumer preference among PHEV, HEV, and conventional vehicle options. The annual market penetration rates pulled from these three scenarios are seen in Table 17.

Table 17: Vehicle market penetration by EPRI/NRDC

\begin{tabular}{|l|c|c|c|}
\hline $\begin{array}{l}\text { Annual Market Penetration } \\
\text { Scenarios for PHEVs in 2050 }\end{array}$ & Low & Medium & High \\
\hline PHEV & $20 \%$ & $62 \%$ & $80 \%$ \\
\hline HEV & $24 \%$ & $24 \%$ & $15 \%$ \\
\hline
\end{tabular}

The report suggests that HEVs will enter the market gradually in 2010 and reach maximum penetration in 2050. According to the study findings, market penetration for PHEVs in 2050 will range between $20 \%$ and $80 \%$; HEV market penetration will range from $15 \%$ to $24 \%$. Although the study mentions some of the factors defining market adoption, such as vehicle cost and vehicle supply, it does not discuss how those factors would change across different scenarios. The utility factor assumptions, seen in Table 18, vary across the different PHEV AERs (e.g., 10, 20, 40 miles) and are also highly dependent on the annual VMT. These values are estimates extracted from a graph. The utility factors given portray the maximum and minimum values achieved over the period of a year. Looking at the range of vehicle classes examined utility factors range from $15 \%$ for vehicles between 14,000 and $19,500 \mathrm{lbs}$ to $22 \%$ for an LDV. The study assumes that PHEVs will be available in vehicles up to $19,500 \mathrm{lbs}$ and with three different AERs of 10, 20, and 40 miles. 
Table 18: Range of utility factors analyzed by EPRI/NRDC for each PHEV AER

\begin{tabular}{|l|c|}
\hline AER (mi) & Utility Factor Range \\
\hline 10 & $0.13-0.55$ \\
\hline 20 & $0.24-0.89$ \\
\hline 40 & $0.5-0.94$ \\
\hline
\end{tabular}

To investigate the effect of the various scenarios on GHG emissions, EPRI/NRDC assumes three different electricity generation mixes of low, medium, and high carbon intensities. Using EPRI's National Electric System Simulation Integrated Evaluator (NESSIE) and EIA's NEMS model, this leads to nine different outcomes spanning the potential long-term GHG emissions impacts of PHEVs. EPRI/NRDC uses this to predict the emissions of PHEV10s, 20s, and 40s in model year 2050. This data can be seen in Figure 7. EPRI/NRDC also investigates the emissions from a 2010 PHEV20 using 14 different electricity generation methods, ranging from coal to nuclear and renewable sources, and compares them to current conventional vehicle and HEV technologies. This emissions data can be seen in Figure 8.

\section{EPRI 2050 GHG Emissions}

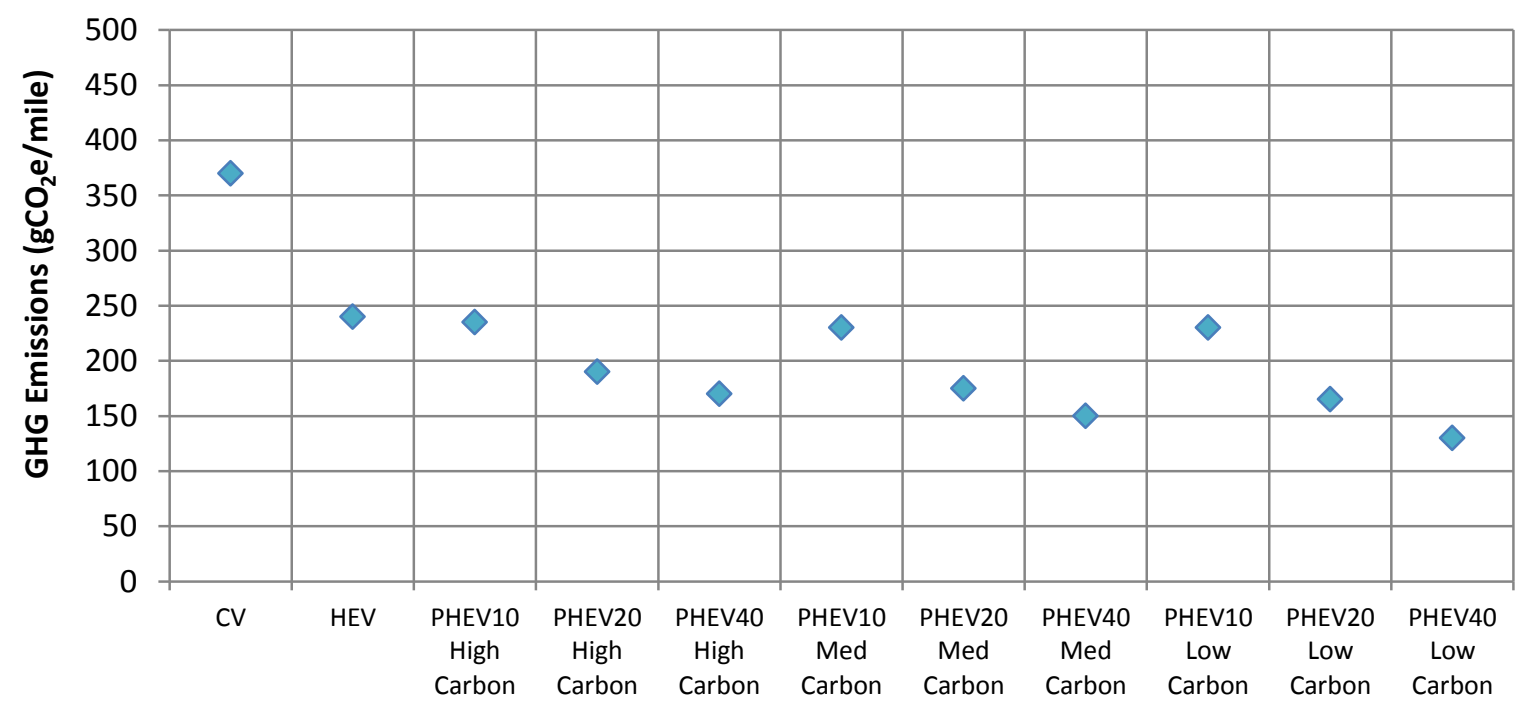

Technology / Scenario

Figure 7: GHG emissions data from EPRI for 2050 


\section{EPRI 2010 GHG Emissions}

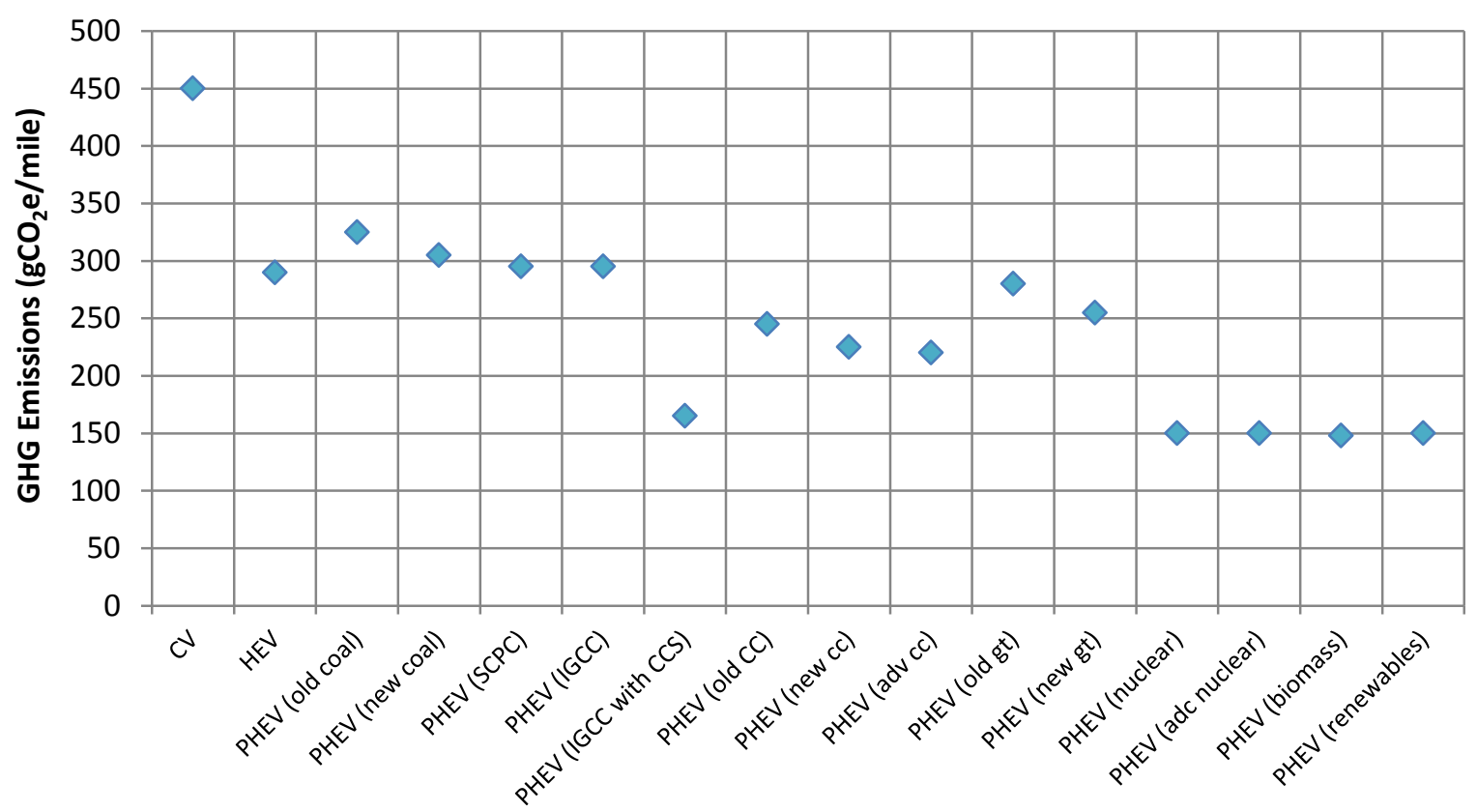

Technology / Scenario

Figure 8: GHG emissions data for various electricity mixes from EPRI for 2010

\subsection{EPA - "Analysis of the Transportation Sector: Greenhouse Gas and Oil Reduction}

Scenarios"

Publication Date: 2010

Referred to as "EPA"

In this report, EPA investigates various scenarios within the transportation sector that could reduce GHG emissions and oil usage. EPA uses the EIA Annual Energy Outlook 2009 as a baseline for fuel economy assumptions. EPA then assumes two scenarios for alternative vehicle penetration, technology improvements, and the electrification of the transportation sector, referred to as "Scenario A" (aggressive) and "Scenario B" (very aggressive). Modeling was conducted primarily using the EPA's Advanced Transportation Limited Analysis Spreadsheet (ATLAS). However, only the pump-to-wheels (PTW) emissions of the transportation sectors are analyzed; the well-to-pump emissions for fuels and electricity generation are not included. The results are reported as tons of $\mathrm{CO}_{2}$ for the different transportation sectors, but data is not given for individual vehicle technologies. For this reason their results cannot be directly compared to the other studies included in this report, even though the assumptions and scenarios from this study merit discussion. 


\subsection{National Research Council (NRC) - "Transitions to Alternative Transportation Technologies" \\ Publication Date: 2010 \\ Referred to as "NRC"}

This report covers an in-depth analysis to determine the potential impact of PHEVs on the consumption of oil and the reduction of $\mathrm{CO}_{2}$ emissions. The report also compares the impact of increased prevalence of biofuels, hydrogen, and fuel cell vehicles, as well as efficiency enhancements in conventional vehicles. The study explores two PHEV scenarios: a Probable and a Maximum. NRC uses a modified version of their model developed in house for the 2008 Hydrogen Report to forecast PHEV annual market penetration. These annual penetration rates are seen in Table 19.

Table 19: PHEV annual market penetration by NRC

\begin{tabular}{|l|c|c|}
\hline Scenarios & Probable & Maximum \\
\hline PHEVs by $\mathbf{2 0 3 0}$ & 4.3 & 11 \\
\hline Annual Market Penetration (\%) & 13,000 & 40,000 \\
\hline Annual Sales (1,000 units)
\end{tabular}

The report suggests that the maximum practical scenario would lead to 240 million cumulative PHEVs on the road by 2050. This scenario would require strong policy intervention that could be achieved in different ways: subsidies to purchasers, taxes on fuels, etc. The current policy incentives defined in this report will be sufficient to achieve the probable scenario that could lead to 110 million PHEVs cumulative on the road by 2050 . The study did not go further into the policies because it exceeded the scope of their study.

For assessing emissions, the report considers two vehicles: 1) a parallel configuration PHEV10 and 2) a series configuration PHEV40. These were examined, along with conventional vehicles and HEVs, in several unique scenarios, including a reference case, two different PHEV penetration rates, hydrogen success, advanced efficiency of conventional HEVs and non-hybrids, and a biofuels scenario. The report presents emissions data for each scenario in the form of a percentage reduction of fuel use and GHG emissions for the transportation sector. However, no individual vehicle technology data are given in NRC's report.

\subsection{Roland Berger - "Powertrain 2020 Li-ion Batteries - The Next Bubble Ahead?" Publication Date: 2010 Referred to as "Roland Berger"}

Roland Berger's report forecasts the market share of electrified powertrains in major global markets. Since only a brief version of the report was accessible for this comparative study, it is unclear which models Roland Berger used to make these forecasts. Only the high scenario forecast from 2015 to 2020 in China, Japan, the United States, and Western Europe was available for use in this comparative study. Table 20 shows that, under the high scenario, the annual market penetration for PHEVs can grow from $0 \%$ in 2015 to $9 \%$ in 2020 . 
Table 20: Vehicle market penetration rate projections in Roland Berger's high scenario

\begin{tabular}{|l|c|c|c|}
\hline Vehicle Type & $\begin{array}{c}\text { HEV } \\
\text { (mild \& full) }\end{array}$ & $\begin{array}{r}\text { PHEV } \\
\text { (series \& parallel) }\end{array}$ & BEV \\
\hline Annual Market Penetration For 2015 & \multicolumn{2}{|c|}{} \\
\hline High Scenario & $10 \%$ & $0 \%$ & $0 \%$ \\
\hline Annual Market Penetration For 2020 & $13 \%$ & $9 \%$ & $4 \%$ \\
\hline High Scenario
\end{tabular}

\subsection{Deloitte - "Gaining Traction: A customer view of electric vehicle mass adoption in the U.S. automotive market" \\ Publication Date: 2010 \\ Referred to as "Deloitte"}

The scope of Deloitte's study is to forecast the annual market penetration of BEVs and PHEVs. Deloitte uses its demand-driven analytics methodology model to assess annual market penetration rates. Input for modeling was gathered through a market research survey of potential EV users. Deloitte performed a sensitivity analysis across three scenarios: aggressive, probable, and conservative. As shown in Table 21, the study forecasts the annual market penetration rates for $\mathrm{BEV}$ s and $\mathrm{PHEV}$ s to range between $0.3 \%$ and $0.5 \%$ in 2015 . Market penetration is predicted to grow to between $1.9 \%$ and $5.6 \%$ in 2020 . Changes in the gasoline price, vehicle price, and total range are identified as primary drivers for growth in this market.

Table 21: Market penetration forecasts for electric vehicle technologies in Deloitte

\begin{tabular}{|l|c|c|c|}
\hline Scenarios & \multicolumn{1}{c|}{ Conservative } & Probable & Aggressive \\
\hline Annual Market Penetration for BEVs and PHEVs in units (\%) & \\
\hline For 2015 & 45,000 units $(0.3 \%)$ & 60,000 units $(0.4 \%)$ & 75,000 units $(0.5 \%)$ \\
\hline For $\mathbf{2 0 2 0}$ & 285,000 units $(1.9 \%)$ & 465,000 units $(3.1 \%)$ & 840,000 units $(5.6 \%)$ \\
\hline Key Assumptions & & & \\
\hline Vehicle Price & $\$ 45,000$ & $\$ 35,000$ & $\$ 25,000$ \\
\hline Vehicle Range & 100 miles & 200 miles & 350 miles \\
\hline Gasoline Price & $\$ 3.00 /$ gal & $\$ 3.50 /$ gal & $\$ 4.50 /$ gal \\
\hline
\end{tabular}




\subsection{Deutsche Bank - "Electric Cars: Plugged In" Publication Date: 2008 Referred to as "Deutsche Bank"}

Deutsche Bank's report suggests that PEVs are capable of more aggressive growth than most reports included in this comparative study. The report analyzes the potential of electric vehicle technologies, including HEVs, BEVs, and PHEVs, and performs a cost-benefit analysis across the types of vehicles examined relative to a conventional vehicle. Accordingly, it suggests that HEVs will have the greatest potential because they provide the highest economic benefit for consumers. Key assumptions include a PHEV price premium of $\$ 8,000$, with $75 \%$ of the price premium caused by the cost of battery pack, and a future cost of gasoline of $\$ 4$ per gallon. Deutsche Bank, in discussion with Global Insights, Roland Berger, and other industry experts, forecasts one scenario for the penetration of BEVs from 2015 to 2020, which increases from $1 \%$ of annual sales to $2 \%$ during this time period. Deutsche Bank also concludes that PHEVs will reach a $2 \%$ annual market penetration by 2015 and would grow to $5 \%$ of new vehicle sales by 2020. The study's annual market penetration forecasts for each vehicle type are show in Table 22.

Table 22: Projected annual market penetration for electric vehicle technologies in Deutsche Bank

\begin{tabular}{l|c|c|c|}
\hline Vehicle Type & Hybrid (micro, mild \& full) & PHEV & BEV \\
\hline Annual Market Penetration For 2015 in Units (\%) \\
\hline Expert Opinion & $3.566 \mathrm{M}(19 \%)$ & $375,000(2 \%)$ & $188,000(1 \%)$ \\
\hline Annual Market Penetration For 2020 & $1.036 \mathrm{M}(5 \%)$ & $414,000(2 \%)$ \\
\hline Expert Opinion & $8.703 \mathrm{M}(42 \%)$ &
\end{tabular}

With regards to fuel displacement, the report combines the effects of all HEVs, PHEVs, and BEVs collectively. Fuel savings are determined by the extent to which HEVs, PHEVs and BEVs could run on electric power, which in turn is mostly limited by the vehicle battery capacity. PHEV designs are assumed to operate on electric power $50 \%$ of the time. Global Insights projected that $47 \%$ of the passenger vehicle fleet will be comprised of these vehicles in 2020 , of which $5 \%$ will be PHEVs. The team also concludes that a $10 \%$ reduction in oil imports, with a corresponding increase in domestic energy use, would add at least $\$ 60$ billion to the U.S. economy.

\subsection{The Boston Consulting Group (BCG) - "The Comeback of the Electric Car" Publication Date: 2010 Referred to as "BCG"}

In this report, BCG evaluates the viability of leading vehicle technological options and then presents its views of the most likely market scenario for 2020 along with its implications. The vehicle types considered in this report include the advanced ICE, mild hybrid, full hybrid, range extended electric vehicle (RE-EV), and the BEV. This report does not provide data on PHEVs alone, but rather on hybrid cars in general (HEVs and PHEVs combined), and includes both the full and mild versions of HEVs. BCG uses its 
propulsion-market model to develop three scenarios for the year 2020 - Slowdown, Steady Pace, and Acceleration. The development of three scenarios is mainly driven by the public response to the arising environmental concerns.

BCG forecasts the annual market penetration for HEVs and PHEVs combined to range between $18 \%$ and 32\% in 2020 (see Table 23), and for BEV market penetration to range between $0 \%$ and $5 \%$. The range mostly results from variation in environmental regulations, government policies, and oil prices. BCG forecasts total U.S. LDV sales for 2020 to be 20.7 million units.

Table 23: Projected annual market penetration rates for electric vehicle technologies in BCG

\begin{tabular}{|l|c|c|c|}
\hline Scenarios & \multicolumn{1}{|c|}{ Slowdown } & Steady Pace & Acceleration \\
\hline Annual Market Penetration in units (\%) for 2020 & & \\
\hline Hybrid (mild, full, PHEV) & $3.7 \mathrm{M}$ units $(18 \%)$ & $5.4 \mathrm{M}$ units $(26 \%)$ & $6.6 \mathrm{M}$ units $(32 \%)$ \\
\hline RE-EV & $(<1 \%)$ & 600,000 units $(3 \%)$ & $1 \mathrm{M}$ units $(5 \%)$ \\
\hline BEV & $(<1 \%)$ & 400,000 units $(2 \%)$ & $1 \mathrm{M}$ units $(5 \%)$ \\
\hline Assumptions & & & \\
\hline Environmental Policies $/$ & Low & Enforcing Current & Intensive \\
\hline Government Subsides & $\$ 60$ & $\$ 150$ & $\$ 300$ \\
\hline Oil Price (per bbl) & & & \\
\hline
\end{tabular}

\subsection{UMTRI - "Market Models for Predicting PHEV Adoption and Diffusion" \\ Publication Date: 2009 \\ Referred to as "UMTRI"}

The scope of UMTRI's report is to predict PHEV market adoption using six different models. Four of the six models assume a fixed saturation level: Bass, Generalized Bass (GBass), Logistic, and Gompertz.

According to those four models, the market is expected to reach its peak between 2017 and 2020, with annual sales ranging between 345 and 371,000 units. The difference in the range is justified by model design itself, such as with the GBass model, which takes the price premium into consideration while the Bass model does not. All four models follow a similar cumulative path until 2019, when they reach 1.5 million cumulative PHEV adoptions. This data, which can be seen in Table 24, suggests that the PHEV market will not meet the current administration's goal of having 1 million PHEVs on the road by 2015 (Obama 2009). UMTRI's predictions have some important caveats. First, they assume that HEVs and PHEVs are similar products but not simply generations of the same product. If the assumption was made that they are generations of the same product, then the market adoption ratio would have been even smaller. 
Table 24: Annual market penetration projections for PHEVs in UMTRI based on specific models

\begin{tabular}{|l|c|c|c|c|}
\hline Model & Bass & GBass & Logistic & Gompertz \\
\hline Peak Year & 2018 & 2017 & 2018 & 2020 \\
\hline Sales at Peak & 343,000 & 350,000 & 345,000 & 370,000 \\
\hline Market Potential & $1.9 \mathrm{M}$ & $1.8 \mathrm{M}$ & $1.9 \mathrm{M}$ & $4.4 \mathrm{M}$ \\
\hline
\end{tabular}

The two final models, entitled Centrone and the Consideration Purchase Model, do not use a fixed saturation level. The Centrone model output is sensitive because the standard errors of the parameters are very large. In the Consideration Purchase Model, PHEV sales are extremely sensitive to the price of the vehicle. Accordingly, the model derives three scenarios where sales range between 5,000 and 19,000 units in 2015. The medium scenario has the tilde ( ) symbol next to the scenarios' names. The tilde symbol refers to the fact that the PHEV annual market penetration figures were derived from the graphs presented in the study and they were not numerically listed in the study's text. Resulting ranges in market penetration are mainly justified by the variation in price premium. This market penetration data resulting from the Consideration Purchase Model are seen in Table 25.

Table 25: PHEV annual market penetration rates provided by the Consideration Purchase Model

\begin{tabular}{|c|c|c|c|}
\hline \multicolumn{4}{|c|}{ Consideration Purchase Model } \\
\hline Scenarios & Low & Medium & High \\
\hline \multicolumn{4}{|c|}{ Annual Market Penetration for PHEVs (units) } \\
\hline For 2015 & 5,000 & $\mathrm{~N} / \mathrm{A}$ & 119,000 \\
\hline For 2025 & 84,000 & $1.2 \mathrm{M}$ & $1.891 \mathrm{M}$ \\
\hline For 2035 & 380,000 & $4.2 \mathrm{M}$ & $6.021 \mathrm{M}$ \\
\hline \multicolumn{4}{|l|}{ Key Assumptions } \\
\hline PHEV Price Premium & $\$ 10,000$ & $\$ 5,000$ & $\$ 2,500$ \\
\hline
\end{tabular}

\subsection{Carnegie Mellon University (CMU) - "Life Cycle Assessment of Greenhouse Gas Emissions from Plug-in Hybrid Vehicles: Implications for Policy" \\ Publication Date: 2008 \\ Referred to as "CMU"}

The scope of CMU's report is to assess the lifecycle GHG emissions from PHEVs and compare these emissions to those associated with conventional vehicles and HEVs. CMU uses the Economic Input-Output Life Cycle Assessment model to calculate GHG emissions data. Various fuel blends and carbon intensities of electricity are used to investigate the possibility for reduced GHG emissions achievable with PHEVs. 
Figure 9 presents CMU's emissions data for all scenarios, assuming gasoline is used to fuel the ICE vehicle. Figure 10 presents the same scenarios, but cellulosic ethanol is used as the fuel instead of gasoline.

\section{CMU 2008 GHG Emissions (gasoline)}

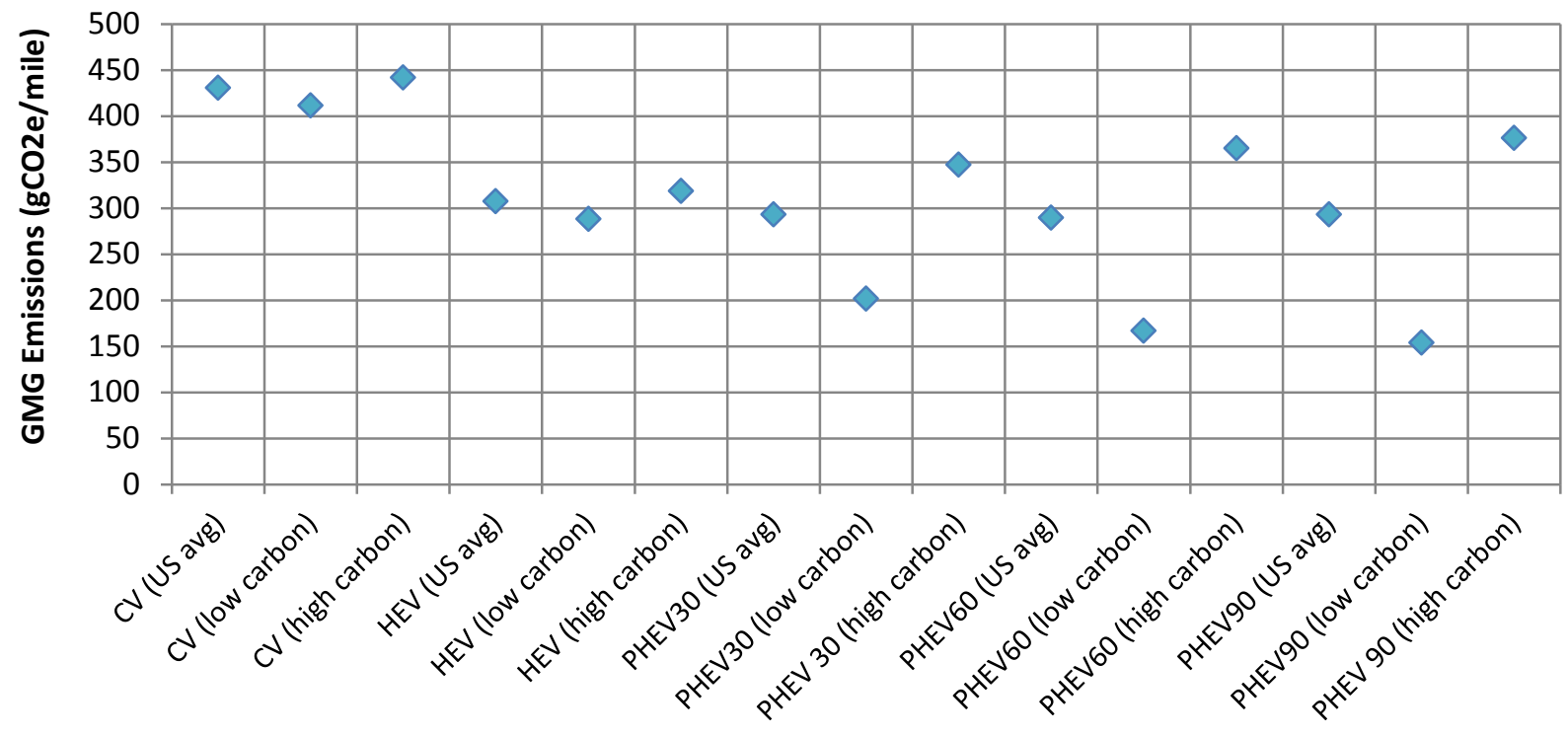

Technology / Scenario

Figure 9: GHG emissions data for all scenarios in CMU using gasoline

\section{CMU 2008 GHG Emissions (cellulosic E85)}

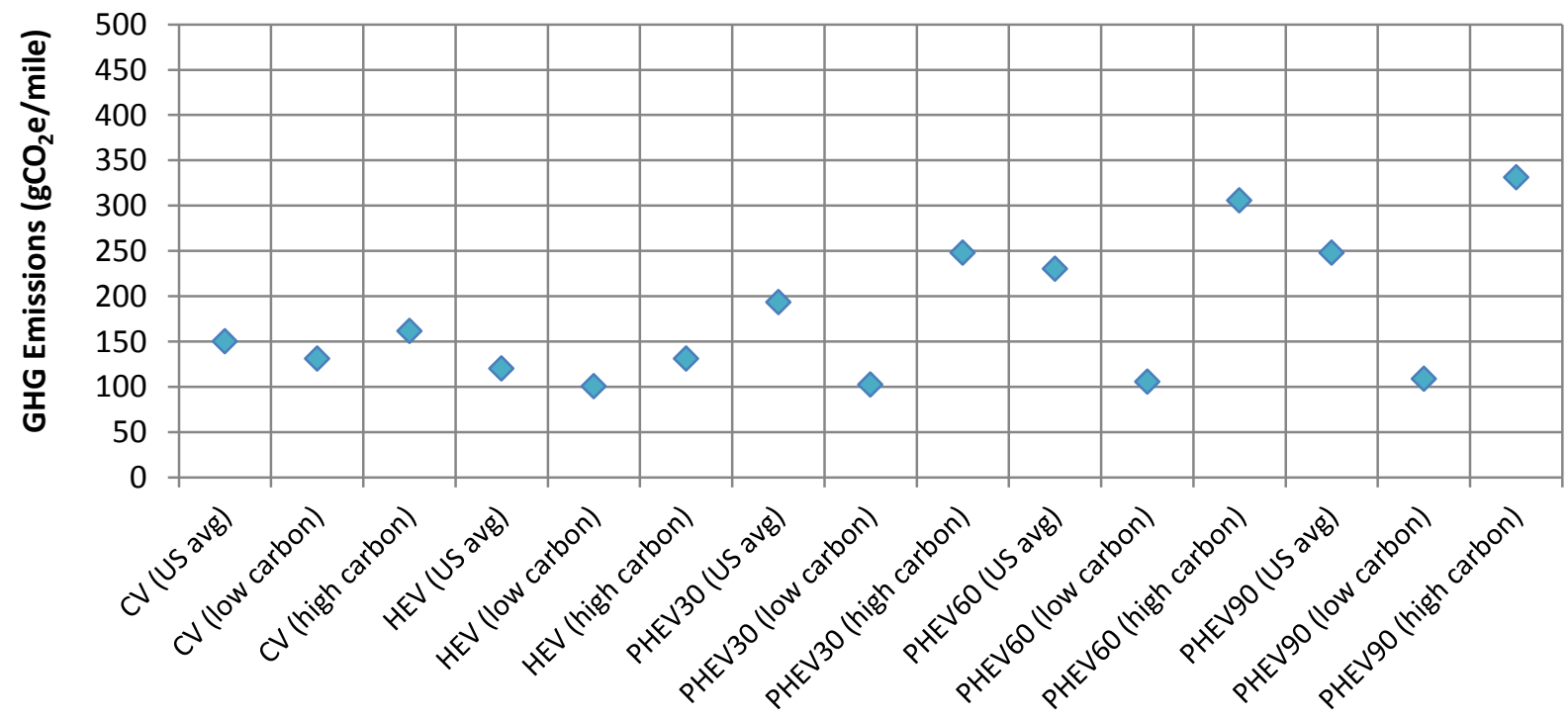

Technology / Scenario

Figure 10: GHG emissions data for all scenarios in CMU using cellulosic E85 


\subsection{California Cars Initiative (CalCars) - "Displacement of Petroleum \& $\mathrm{CO}_{2}$ Reductions from Super-Optimistic Business-as-Usual Mass Production of Light Vehicle PHEVs" \\ Publication Date: 2009 \\ Referred to as "CalCars"}

CalCars is a charitable, non-profit organization founded in 2002 to promote PHEVs as a key to addressing oil dependence and global warming both nationally and internationally. The purpose of its report is to analyze the environmental impacts from an aggressive penetration of PHEVs into the LDV fleet. Under the report's "super-optimistic" scenario, PHEV sales reach 40,000 in 2011 and rise by $50 \%$ each year until they comprise $9 \%$ of the LDV market in 2020, and $42 \%$ in 2024. By 2030, PHEVs dominate the auto industry with $100 \%$ of total sales and $81 \%$ of all vehicles on the road. The average AER for new PHEVs is projected to rise from 20 miles in 2010 to 50 miles in 2050. Passenger vehicles in the United States are estimated to number 250 million in January 2010 and reach 375.7 million in 2050. Vehicles are assumed to travel 12,000 miles each year, requiring 660 gallons of gasoline per vehicle per year, and 165 billion gallons total in 2010. The scenario is repeated with the inclusion of ICEs converted to PHEVs, leading to faster integration into the fleet. The effects of biofuels are also examined for each scenario, but only PHEV data was extracted from this report for use in this comparative study. Despite the rapid deployments in both scenarios, only CalCar's converted ICE model scenario meets President Obama's goal of 1 million PHEVs on the road in 2015 (Obama 2009). PHEV sales for the CalCar scenarios are seen in Figure 11.

\section{Fleet Fuel Savings as a Function of PHEV Sales}

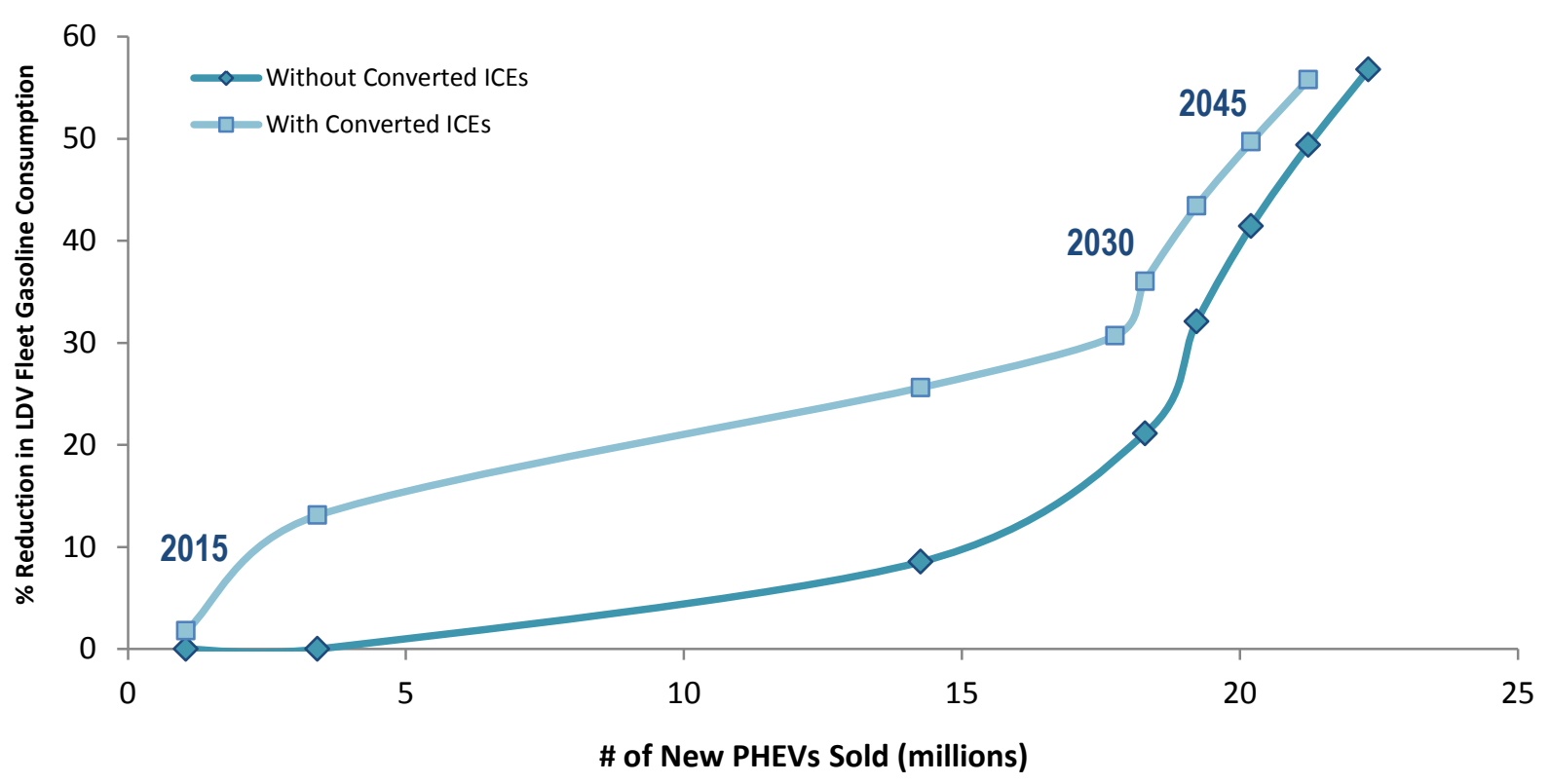

Figure 11: Fleet fuel consumption savings as a function of PHEV sales, provided in CalCars 


\subsection{University of Vermont (UVM) Transportation Center - "Plug-In Hybrid Vehicles and the Vermont Grid: A Scoping Analysis" \\ Publication Date: 2008 \\ Referred to as "UVM"}

This study assesses the ability of the Vermont electric grid to support PHEVs on a large scale. The environmental impacts of plug-in hybrids are also examined. Given the state's low-carbon electricity generation mix, the use of PHEVs is forecast to decrease both the state's oil consumption and its GHG emissions. A PHEV20 is used to model PHEV integration for fleets of 50,000 (model scenario); 100,000; and 200,000 units. The size of the vehicle, the method of calculating fuel economy, and the vehicle charging strategies all strongly impact the UVM analysis results.

The group uses technical specifications from EPRI/NRDC's “Environmental Assessment of Plug-In Hybrid Electric Vehicles, Volume 1: Nationwide Greenhouse Gas Emissions" for their input values when simulating conventional and plug-in vehicles in ADVISOR. No timeframe is specified in this study, and no future increases in fleet size and electricity use are considered. With an average annual VMT of 12,379 miles per vehicle, the study predicts a gasoline displacement of 11.39 million gallons per year for a 50,000 vehicle fleet when replacing ICEs with a fuel economy of $28.9 \mathrm{mpg}$. Other fuel economy values are used in other sections. When addressing GHG emissions, an ICE gets $27.7 \mathrm{mpg}$, and when addressing the economics of PHEV use, an ICE gets $25.5 \mathrm{mpg}$. This is relevant when calculating oil displacement volumes, since this 1.2 mpg difference scales to over 933,000 gallons per year for 50,000 PHEV20s and over 3.7 million gallons for 200,000 PHEV20s.

Introducing PHEV20s into the state LDV mix as demonstrated in the scenarios listed could displace anywhere from 11.39 million gallons of gasoline annually to 51.5 million gallons for 50,000 and 200,000 PHEV20s, respectively. The study concludes that the state's electricity grid is capable of handling 100,000 PHEV20s at its current capacity if delayed nighttime charging is implemented. Given these limitations, the Vermont grid is deemed robust enough to support 200,000 PHEVs only if an optimal charging strategy is used. Assuming that $40 \%$ of VMT are electric, these fleets would displace 25.8 million and 51.5 million gallons of gasoline per year, respectively. By using the conversion factor of 20 gallons of gasoline per barrel of oil taken from the U.S. EIA website (EIA 2010), Vermont's gasoline displacement data can be calculated and is seen in Table 26.

Table 26: Predicted gasoline displacement for the state of Vermont with respect to the size of its PHEV fleet

$$
\text { \# of PHEV20s Gallons of Gasoline Displaced Annually Barrels of Oil Displaced Annually }
$$

\begin{tabular}{|l|c|c|}
\hline $\mathbf{5 0 , 0 0 0}$ & $11.39 \mathrm{M}$ & $227.8 \mathrm{M}$ \\
\hline $\mathbf{1 0 0 , 0 0 0}$ & $25.8 \mathrm{M}$ & $516 \mathrm{M}$ \\
\hline $\mathbf{2 0 0 , 0 0 0}$ & $51.5 \mathrm{M}$ & $1.03 \mathrm{M}$ \\
\hline
\end{tabular}

While social and environmental effects were also studied in UVM, only data concerning the potential for oil displacement in the different scenarios was extracted for use in the comparative study. 


\subsection{JD Power and Associates -"Drive Green 2020: More Hope Than Reality?"}

Publication Date: 2010

Referred to as "JD Power"

In this report, JD Power addresses future HEV, PHEV, and BEV integration out to 2020 along with consumer reservations on purchasing these vehicles. While the paper addresses the global HEV fleet, only the U.S. data is used in this comparative study. In 2020, JD Power forecasts U.S. combined sales of HEVs and PHEVs to reach $1.67 \mathrm{M}$ units, accounting for less than $10 \%$ of all passenger vehicles sold in this year. The United States are anticipated to account for over $43 \%$ of hybrid sales in 2020 . BEV unit sales are forecasted to reach 107,000 by 2020 , representing less than $1 \%$ of the U.S. LDV market.

This study's forecast for the global oil supply shows it to be stable within this timeframe. JD Power identifies market challenges of BEVs to be related to battery-based issues (e.g., life expectancy, driving range, production cost reductions), infrastructure development to support the fleet, and consumer acceptance of the new technology. As more models become available and people become more familiar with the technology, sales of these vehicles are expected to grow at an accelerated pace.

\subsection{University of California-Davis - "Plug-In Hybrid Vehicle GHG Impacts in California: Integrating Consumer-Informed Recharge Profiles with an Electricity-Dispatch Model" Publication Date: 2010 \\ Referred to as "UCD"}

This study constructs PHEV emissions scenarios to address inherent relationships between vehicle design, driving and recharging behaviors, seasonal and time-of-day variation in GHG-intensity of electricity, and total GHG emissions. The authors constructed electricity demand profiles scaled to 1 million PHEVs, and input them into an hourly California electricity supply model to simulate GHG emissions. The study includes multiple scenarios with varying PHEV configurations, electricity generation mixes, and vehicle technologies. However, the emissions results are reported in $\mathrm{CO}_{2}$ emission per million vehicles. While it is possible to see differences in emissions results with the different scenarios, this data cannot be directly compared to data from the other reports. Because the market size and penetration rates for the various technologies are not given in the report, a strong comparison with the other reports was not possible for this comparative study without further assumptions being made.

\subsection{RAND Corporation - "Environmental, Security, and Economic Issues of Electricity as a Transportation Fuel" \\ Publication Date: 2010 \\ Referred to as "RAND"}

RAND's report investigates the environmental, security, and economic aspects present with four technology options: PHEV20, PHEV40, range extended electric vehicle (RE-EV), and BEV. However, only analysis on the PHEV40 is provided in the report. With regards to oil displacement, RAND states that every 10 million PHEV40s in the LDV fleet will displace between 5 million and 8 million gallons of gasoline per day. A single PHEV40 will displace 2,200 to 3,700 gallons of gasoline over its lifetime while a BEV displaces 3,200 to 4,800 gallons of gasoline in a lifetime. However, the length of the vehicle lifetime, whether in miles or years, 
is unspecified. The assumed fuel economy values are also unspecified, making further analysis difficult without imposing outside assumptions.

\subsection{The Institute of Electrical and Electronics Engineers (IEEE) - "A Review of Results from Plug-in Hybrid Electric Vehicle Impact Studies" \\ Publication Date: 2009 \\ Referred to as "IEEE"}

With PHEVs not yet on the market, all performance data in this report for PHEVs is derived from computer simulations and converted HEVs. Various operating modes, drive cycles, and commute lengths greatly drove the results of this study. IEEE compares the results from several reports on PHEV performance, concluding that they do displace gasoline and that large scale PHEV deployment can only currently be supported by the existing electric grid with off-peak charging. The lack of specific oil displacement and GHG emission values limit the utility of this report for use in this comparative study, as does its lack of stated assumptions for the different reports reviewed.

\subsection{Toronto Atmospheric Fund - "Plug-In Hybrids: Prospects and Progress" Publication Date: 2007 Referred to as "TAF"}

This report outlines steps that the city of Toronto has taken towards GHG emission reductions through PHEVs, including its Climate Plan adopted in 2007. Trip distance, mean speed, and driver aggressiveness are cited as the top determinants of a PHEV's fuel economy in this study. The testing of two different PHEVs on the road shows fuel economy improvements from $30 \%$ to $55 \%$. It also displays how fuel economy varies with distance traveled: a 1 to $5 \mathrm{~km}$ trip results in a fuel economy of $4.5 \mathrm{~L} / 100 \mathrm{~km}$, and a 30 to $35 \mathrm{~km}$ trip results in $2.5 \mathrm{~L} / 100 \mathrm{~km}$. While the report presents $\mathrm{GHG}$ emissions data for the transportation sector and reductions from the presence of PHEVs, the GHG emissions data could not be derived for individual PHEVs or other vehicle technologies. Therefore, direct comparisons between this report and others included in the comparative study could not be made. 


\section{Comparison of GHG Emissions}

This chapter reviews and compares GHG emission levels attributable to various vehicle technologies as presented in all applicable studies reviewed in this comparative study. The numerous publications on this topic result in an overwhelming amount of GHG emissions data. The GHG emissions data are reported in a variety of ways, including those for the transportation sector as a whole, the lifetime GHG emissions for individual technologies, and the reductions in $\mathrm{GHG}$ emissions compared to a baseline. This study will focus on the $\mathrm{GHG}$ emissions data that are reported for individual vehicle technologies. Once the assumptions and scenarios are analyzed, the data leads to more meaningful comparisons. The following nine reports provided GHG emissions data that is utilized in this comparative study:

1. SENTECH, Inc. / ORNL - "PHEV Value Proposition Study"

2. EC - "Electrification Roadmap: Revolutionizing Transportation and Achieving Energy Security"

3. MIT - "On the Road in 2035"

4. ANL - "Well-to-Wheels Analysis of Energy Use and GHG Emissions of PHEVs"

5. ANL - "Impact of Component Size on Plug-In Hybrid Energy Consumption Using Global Optimization"

6. EPRI/NRDC - "Environmental Assessment of PHEVs, Volume 1: Nationwide GHG Emissions"

7. EPA - "Analysis of the Transportation Sector: GHG and Oil Reduction Scenarios"

8. NRC - "Transitions to Alternative Transportation Technologies"

9. CMU - "Life Cycle Assessment of GHG Emissions from PHEVs: Implications for Policy"

This study's findings cover a wide range of years, scenarios, and technologies, and the values vary from 17 to 450 grams of carbon dioxide equivalent per mile $\left(\mathrm{gCO}_{2} \mathrm{e} / \mathrm{mile}\right)$ per vehicle. A preliminary glance of this data can be seen in Figure 12. Following this preliminary glance, discussion will begin to break down the assumptions that each report uses to formulate their scenarios and calculate their results. At the end of this chapter, the data points in Figure 12 will be sorted from highest to lowest once all major trends have been identified and analyzed. 
GHG Emissions Projections for All Vehicles and Scenarios

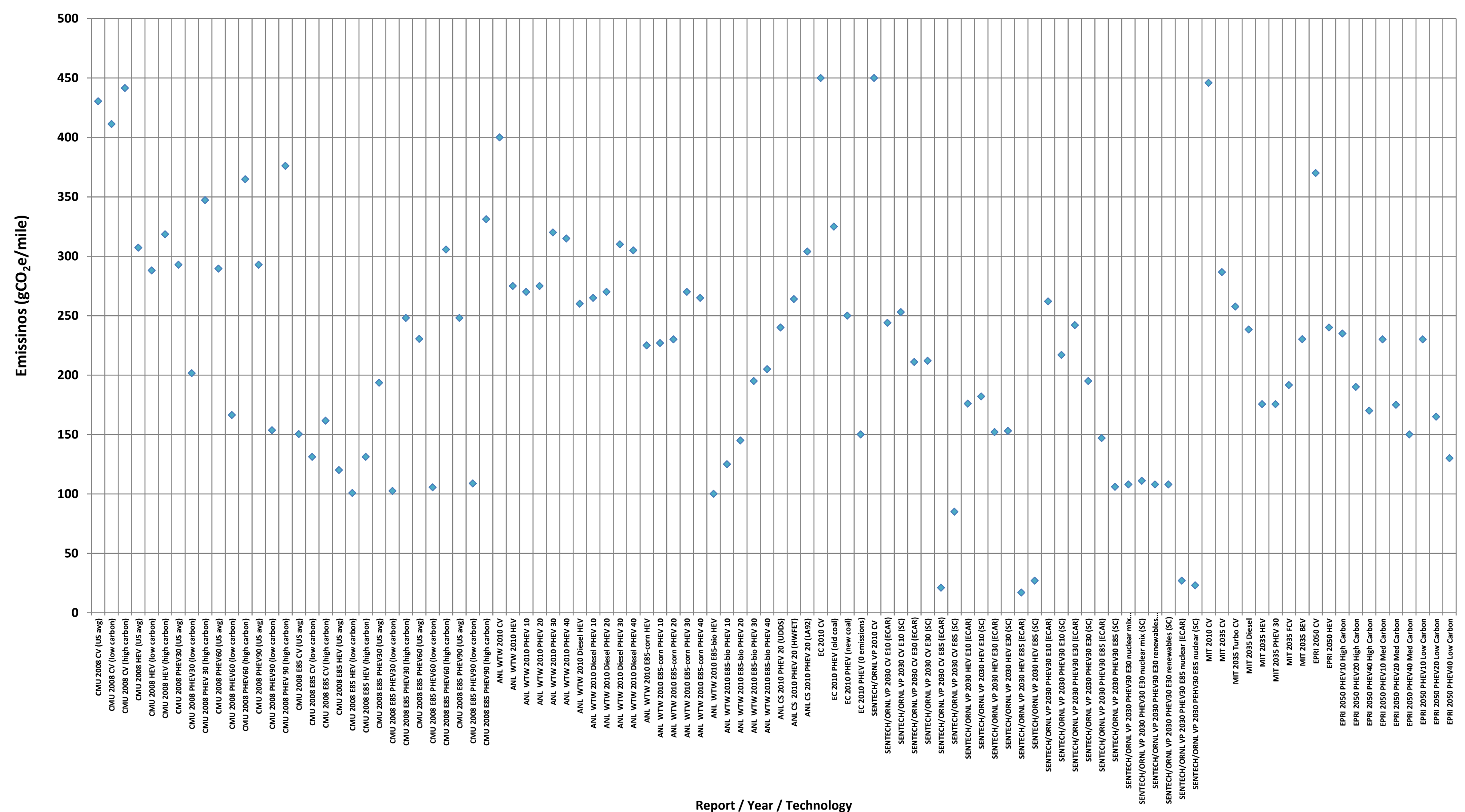




\subsection{Assumptions}

To compare the results from multiple studies, the key assumptions in each report must first be identified, broken down, and compared side by side. When dealing with GHG emissions, a few of the more prevalent assumptions include:

- Emissions Source - Multiple sources of emissions are often taken into account when assessing the manufacturing, operation, and disposal of automobiles. For example, PTW emissions only measures emissions produced from the operation of the automobile itself, while WTW emissions adds those produced from the production of the fuel and/or electricity. Some reports go beyond WTW to include the vehicle lifetime emissions associated with the manufacturing and disposal of that automobile.

- Electricity Generation Mix - Across the nation, the most utilized source of electricity generation is currently coal-burning plants that produce large amounts of GHG emissions. Renewable energy power plants produce smaller amounts of GHG emissions; however, new electricity generation methods and more advanced facilities take time to build before they can be utilized. The resources used to generate the electricity that charge a PHEV have a major impact on its WTW emissions. Many of the reports included in this comparative study present multiple scenarios and technologies for use in the generation of electricity to account for the wide range of electricity generation mixes in place across the United States.

- Advancements in Conventional Vehicle and Glider Technology - Car manufacturers are still working to improve current internal combustion technology that will enhance fuel mileage and lower GHG emissions. New turbocharger designs, advancements in diesel technology, and improvements in lightweight materials will all help conventional vehicles to compete with future alternative fuel blends and powertrain designs. Advancements in glider technology such as weight, aerodynamics, transmission efficiency, and tire rolling resistance will also help to reduce the work load and lower emission across all vehicle technologies. Several of the reports assume aggressive advancements in these areas that ultimately lead to lower emissions data in the future.

- Fuel Blend - Multiple reports investigate the use of fuels or fuel blends other than current day gasoline, or E10, in their calculations. Some of these fuel blends include corn-based ethanol, cellulosic ethanol, and biodiesel.

- Government Influence - Government mandates and CAFE standards can have a large impact on what type of vehicle platforms that automobile manufacturers will choose to produce (NHTSA 2009). In anticipation of such regulations, many of the reports predict lower emissions data based on how aggressive the government mandates may be in the future.

- Modeling Program - The model(s) used by a group to calculate fuel mileage and GHG emissions for their assessment can have a direct impact on their reported data. Well known models such as GREET, PSAT, NEMS, and NESSIE are used widely by many groups. Other groups may develop and use in-house models, equations, and/or methods to calculate this information.

- PHEV Configuration - Many different types of PHEV architectures have been developed, with the two main categories being series and parallel. Furthermore, two modes of operation can be chosen for PHEVs - charge depleting (CD) and charge sustaining (CS). Several combinations of these configurations were analyzed in reports included in this chapter.

- Driving Cycle - Many driving cycles have been certified by the EPA for fuel efficiency testing and simulating (EPA 2010). While some reports simply incorporate one or more of these driving cycles into their analysis, others apply "real world" driving conditions to these cycles to more accurately predict fuel efficiency and emissions from various vehicle technologies. 
Table 27 matches the aforementioned assumptions with the studies that were selected for review in this chapter. A check mark indicates that the assumption was critical for the emissions results for each of the reports. It is interesting to note that no two reports use the same set of assumptions to formulate their results.

Table 27: Key assumptions used to guide analysis in the most relevant reports found

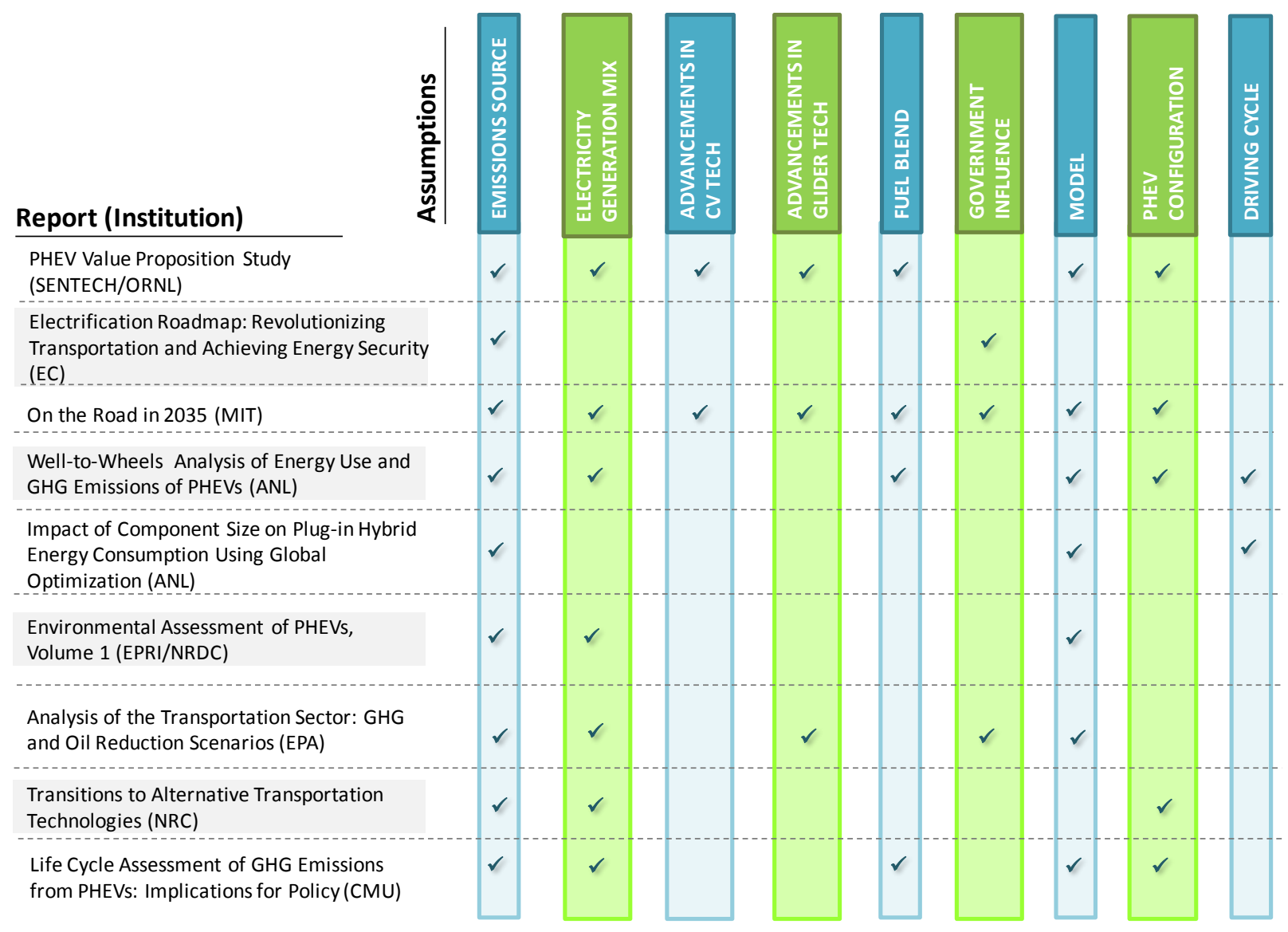

Tables 28 through 35 provide a breakdown of assumptions for each individual report and give more details about the scenarios used to arrive at their individual results. "High," "medium," and "low" refer to the aggressiveness of the assumption and its impact on GHG emissions. The more aggressive assumptions typically lead to a higher reduction in GHG emissions. 
Table 28: Detailed assumptions for the "PHEV Value Proposition Study" written by SENTECH/ORNL

\section{PHEV Value Proposition Study (SENTECH/ORNL)}

Year Published: 2010

Years of Analysis: 2010, 2030

\begin{tabular}{|l|c|c|}
\hline \multicolumn{1}{|c|}{ High } & Medium \\
\hline Emissions Source & LOW \\
\hline Electricity Gen Mix & ECAR, SC \\
\hline Adv in CV Tech & Ceduced Weight \\
\hline Adv in Glider Tech & Cellulosic E30 \\
\hline Fuel Blend & E10 \\
\hline Gov't Influence & CAFE Standards \\
\hline Model: & PSAT, GREET E85 \\
\hline PHEV Configuration: Pre-Transmission Parallel PHEV 30 \\
\hline Driving Cycle: \\
\hline
\end{tabular}

Table 29: Detailed assumptions for the "Electrification Roadmap" published by the Electrification Coalition

\section{Electrification Roadmap (Electrification Coalition)}

Year Published: 2009

Year of Analysis: 2010

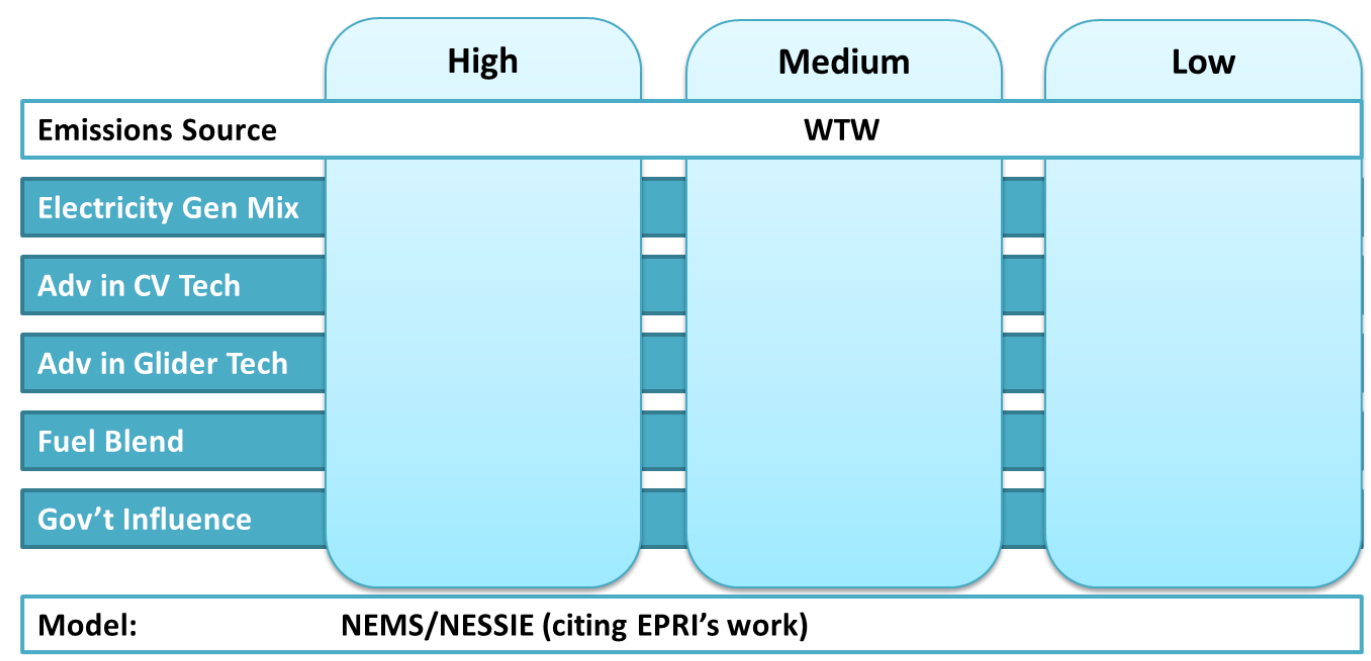

PHEV Configuration:

Driving Cycle: 
Table 30: Detailed assumptions for MIT's “On the Road in 2035"

On the Road in 2035 (MIT)

Year Published: 2008

Year of Analysis: 2035

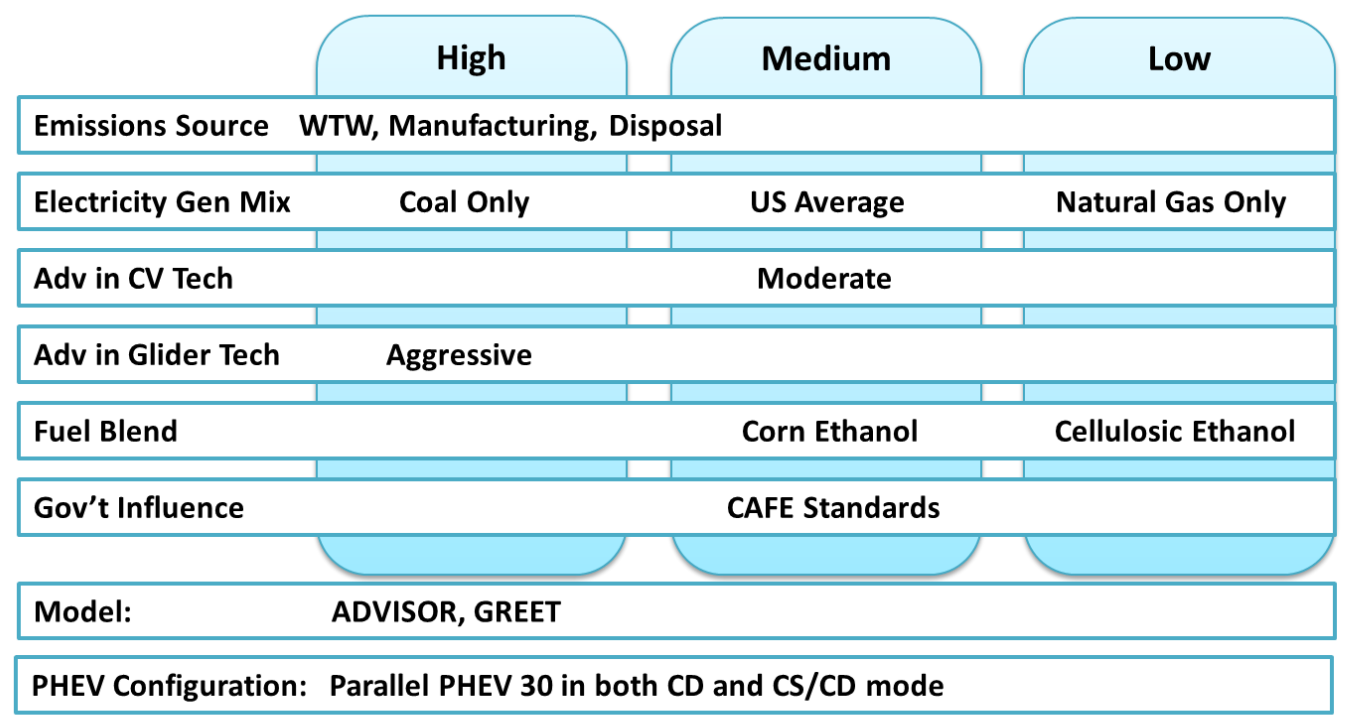

Driving Cycle:

Table 31: Detailed assumptions for ANL's "WTW Analysis of Energy Use and GHG Emissions of PHEVs

WTW Analysis of Energy Use and GHG Emissions of PHEVs (ANL)

Year Published: 2010

Year of Analysis: 2010

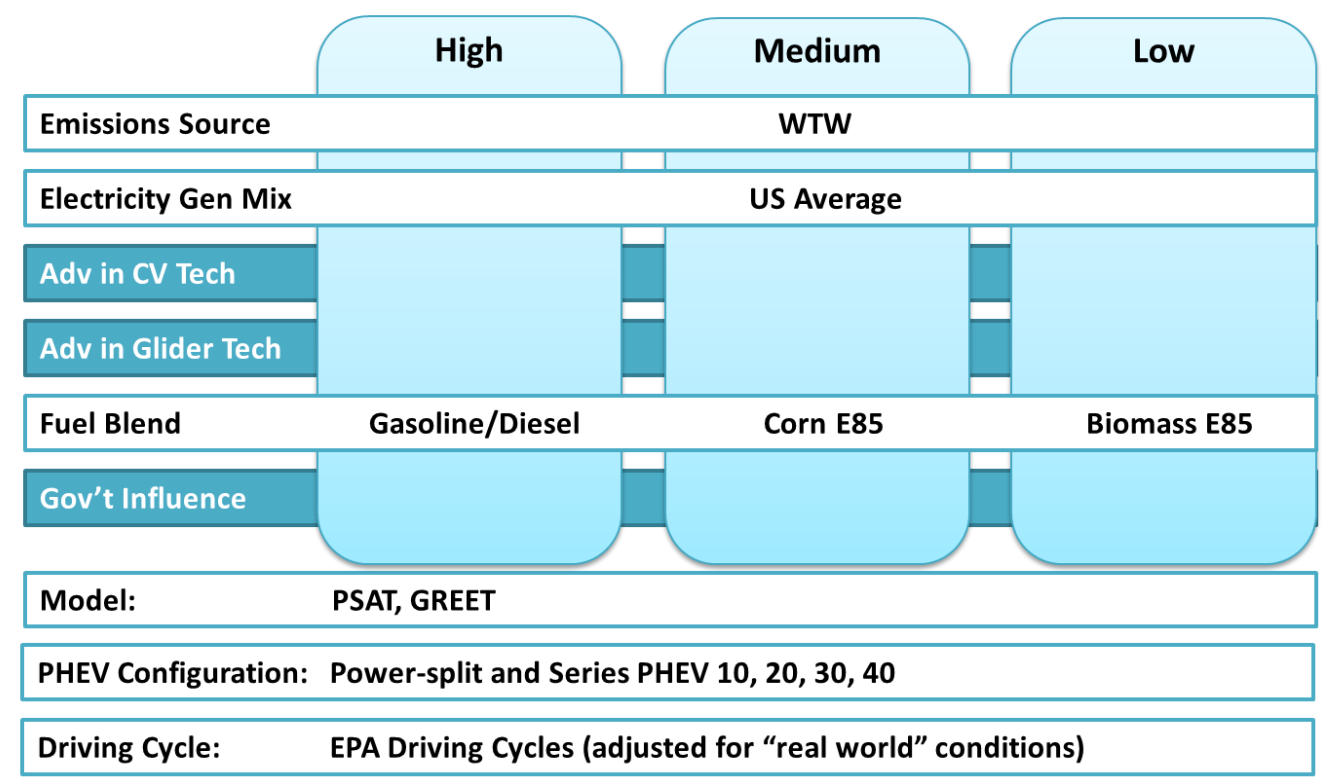


Table 32: Detailed assumptions for ANL's "Impact of Component Size on PHEV Energy Consumption"
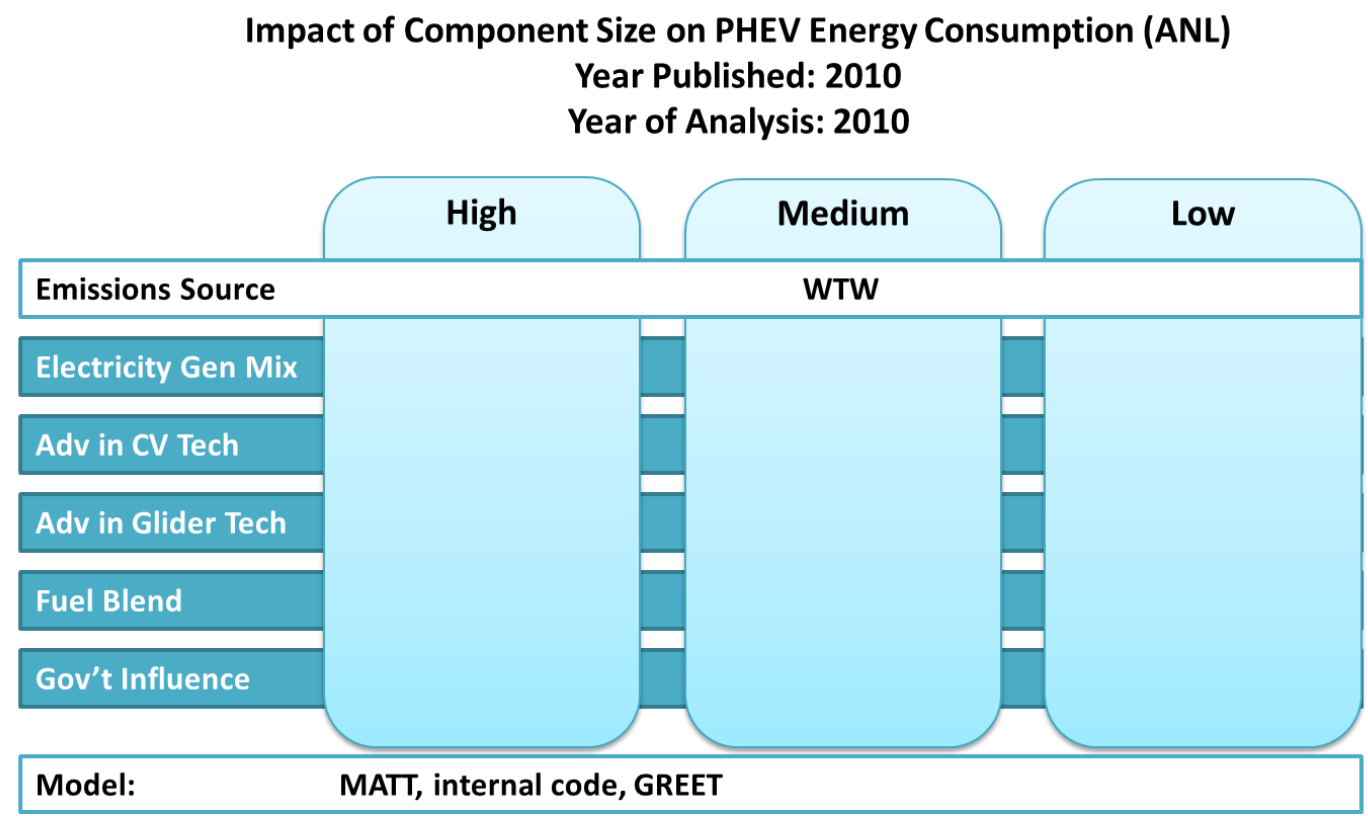

PHEV Configuration:

Driving Cycle: $\quad$ UDDS, HWFET, LA92

Table 33: Detailed assumptions for EPRI/NRDC's "Environmental Assessment of PHEVs, Volume 1"

Environmental Assessment of PHEVs, Volume 1: Nationwide GHG Emissions (EPRI/NRDC) Year Published: 2007

Years of Analysis: 2010, 2050

\begin{tabular}{|l|l|l|l|}
\hline \multicolumn{1}{|c|}{ High } & Medium & Low \\
\hline Emissions Source & WTW \\
\hline Electricity Gen Mix & High & \multicolumn{2}{|c|}{ Low } \\
\hline Adv in CV Tech & \\
\hline Adv in Glider Tech \\
\hline Fuel Blend \\
\hline Gov't Influence \\
\hline
\end{tabular}

PHEV Configuration:

Driving Cycle: 
Table 34: Detailed assumptions for EPA's “Analysis of the Transportation Sector"

\section{Analysis of the Transportation Sector: GHG and Oil Reduction Scenarios (EPA)}

Year Published: 2010

Years of Analysis: through $\mathbf{2 0 3 0}$

\begin{tabular}{|l|l|l|}
\hline \multicolumn{1}{|c|}{ High } & Medium & Low \\
\hline Emissions Source & PTW Only \\
\hline Electricity Gen Mix & Aggressive & \\
\hline Adv in CV Tech & Aggressive \\
\hline Adv in Glider Tech & \\
\hline Fuel Blend & CAFE Standards \\
\hline Gov't Influence & ATLAS \\
\hline Model:
\end{tabular}

PHEV Configuration:

Driving Cycle:

Table 35: Detailed assumptions for CMU's "Life Cycle Assessment of GHG Emissions from PHEVs: Implication of Policy"

Life Cycle Assessment of GHG Emissions from PHEVs: Implications for Policy (CMU)

Year Published: 2008

Years of Analysis: 2008

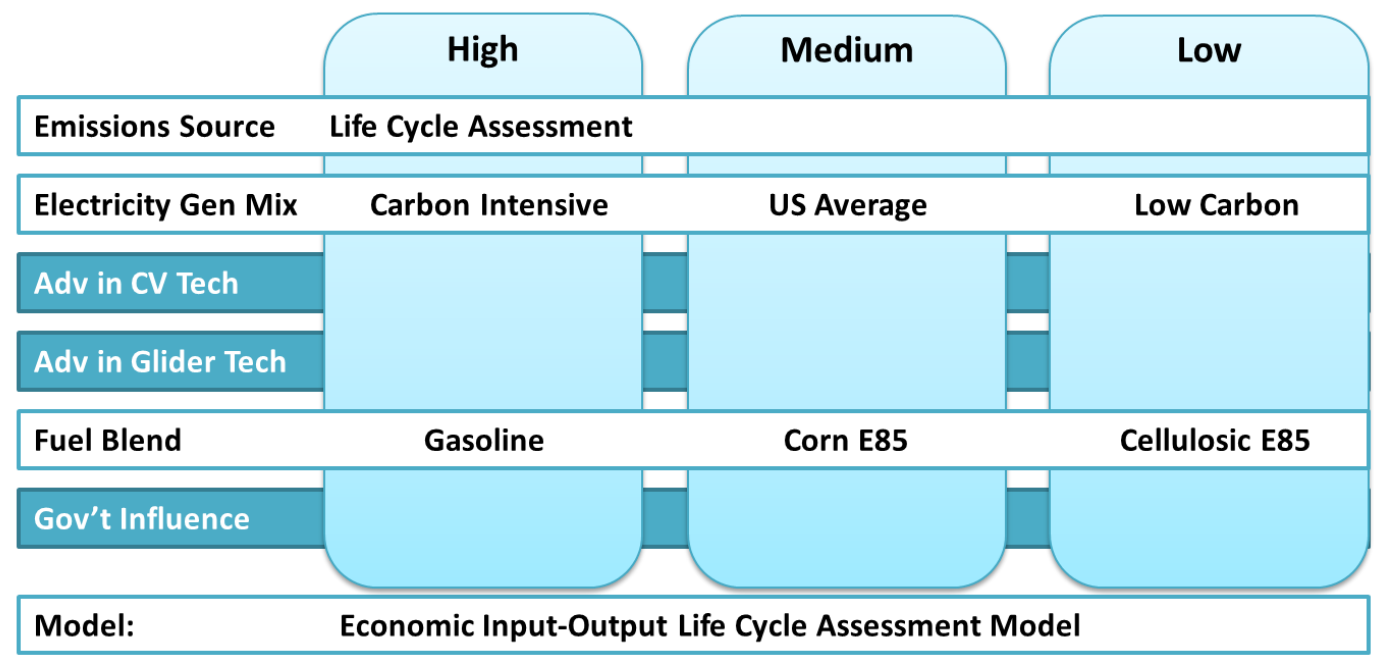

PHEV Configuration:

Driving Cycle: 


\subsection{GHG Emissions Trends among Reports}

Now that the assumptions from each report have been identified and understood, comparisons of data can begin between similar sets of assumptions. These comparisons can first be divided into two different categories according to timeline - Current and Future - which will each be investigated in this section. Although all assumptions are critical for arriving at each study's results, there are three major sets of assumptions within the Current and Future categories that lead to meaningful comparisons. These are Baseline Conditions, Electricity Generation Mix, and Fuel Blends.

\subsubsection{Current}

The comparisons in this section are all comprised of data that represents GHG emissions associated with both current technology and current-day scenarios.

\subsubsection{Baseline}

Six of the reports reviewed in this section present the emissions produced by a current conventional vehicle powered by gasoline as their basis for comparison with other various technologies. Figure 13 presents the emissions data for the current conventional vehicle documented in these six reports. The six data points are quite similar to each other, all falling in between $400-450 \mathrm{~g} \mathrm{CO}_{2} \mathrm{e} /$ mile. ANL WTW presents the most conservative value of $400 \mathrm{~g} \mathrm{CO}_{2} \mathrm{e} / \mathrm{mile}$, while the rest of the reports are closer to $450 \mathrm{~g} \mathrm{CO}_{2} \mathrm{e} / \mathrm{mile}$.

\section{GHG Emissions Projections for Current Conventional Vehicles}

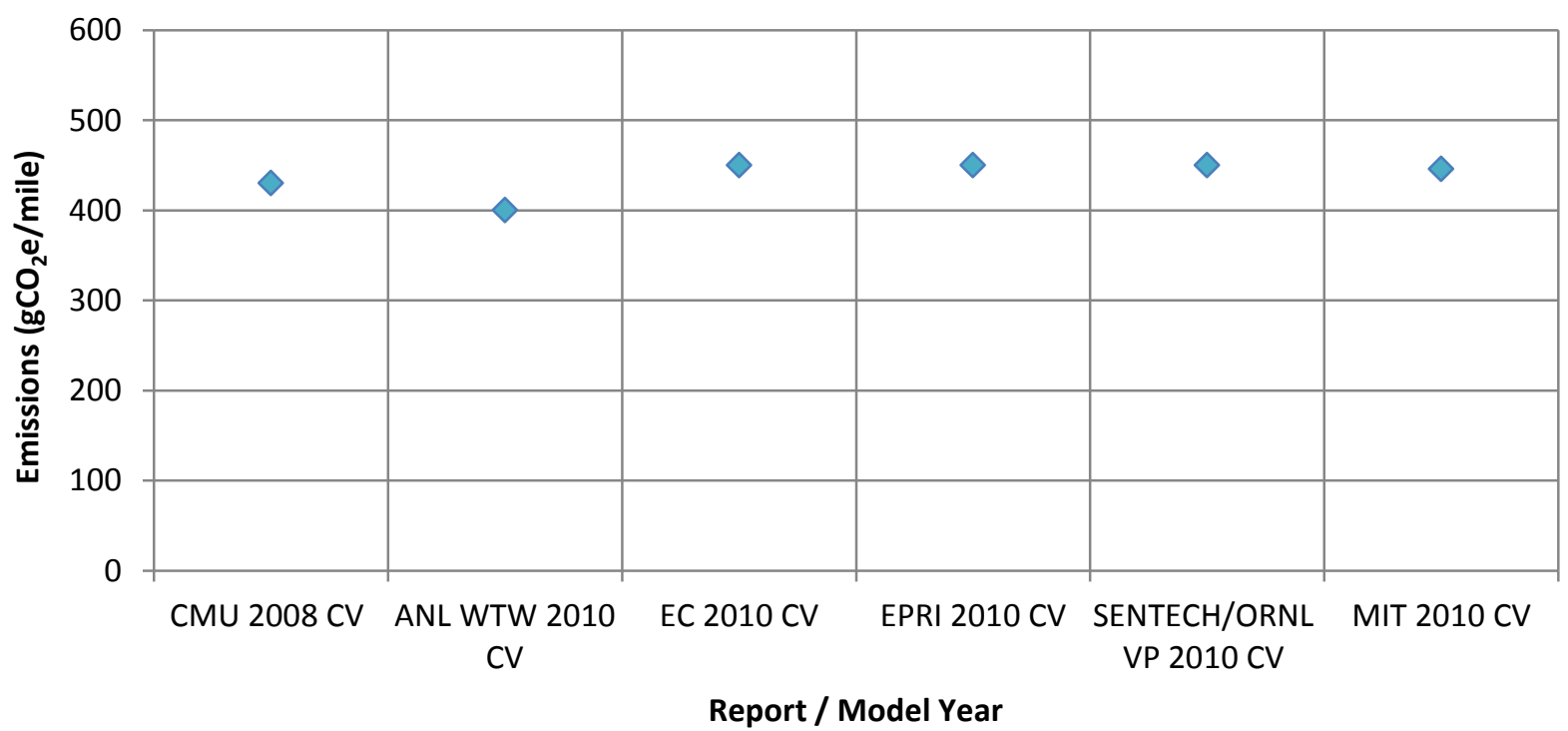

Figure 13: GHG emissions for current-day conventional vehicle

A similar comparison, made in Figure 14, shows current PHEV emissions data reported in each study, assuming a current day "average" electricity generation mix (also referred to as "old coal") and using an average fuel blend. Similar to the conventional vehicle results, these PHEV data points all consistently fall within $50 \mathrm{~g} \mathrm{CO}_{2} \mathrm{e} /$ mile of each other, suggesting general agreement on current PHEV emissions when using a current day average electricity generation mix across studies. 


\section{GHG Emissions Projections for Current PHEVs under Average Conditions}

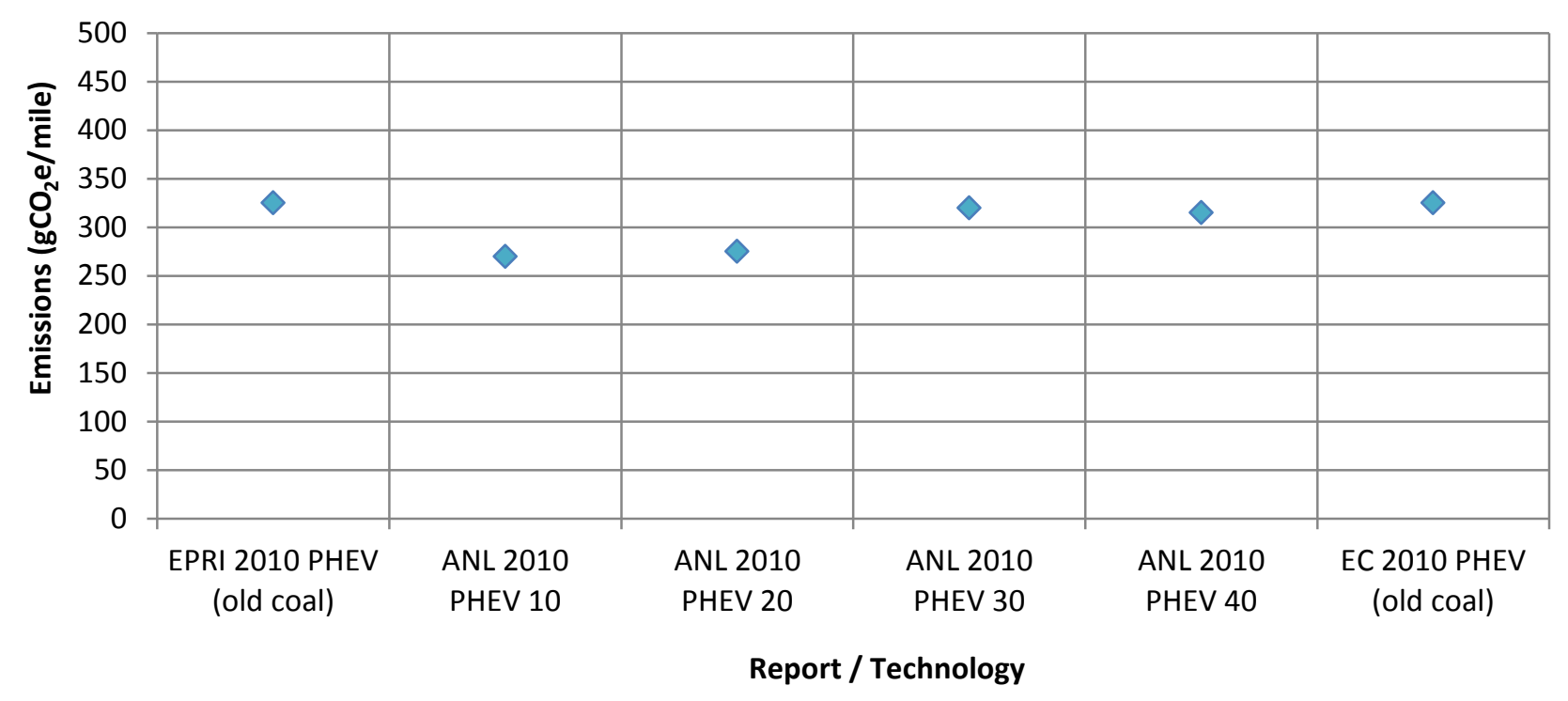

Figure 14: GHG emissions for current PHEVs using an average electricity generation mix and fuel blend

\subsubsection{Effect of Electricity Generation Mix on Current GHG Emissions}

Multiple reports considered electricity generation mixes as a major factor for calculating current PHEV emissions. However, to make a meaningful comparison, the AER and fuel blend need to be held constant. Therefore, Figure 15 presents all available emissions data for current day PHEV30s using the current gasoline blend but with varying electricity generation mixes. The values range from $148 \mathrm{~g} \mathrm{CO}_{2} \mathrm{e} / \mathrm{mile}$ (EPRI/NRDC's biomass scenario), to $347 \mathrm{gCO}_{2} \mathrm{e} / \mathrm{mile}$ (CMU's PHEV30 using electricity generated from a high carbon source). 


\section{GHG Emissions Projections for Current PHEV30s Using Varying Electricity Mixes}

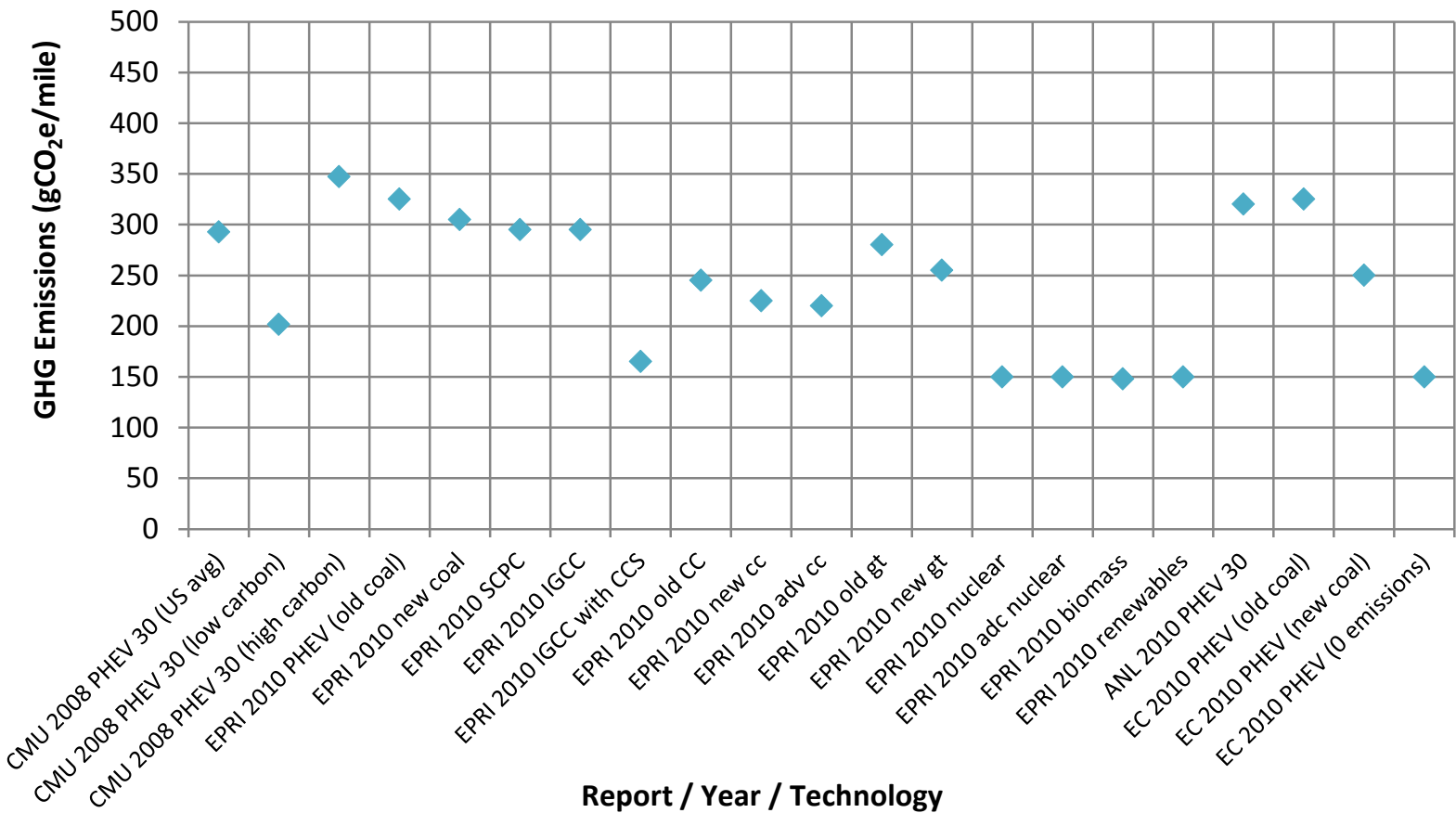

Figure 15: Emissions for current PHEV30s using various electricity mixes and average fuel blend

While the emissions data from Figure 15 appears scattered, a trend can be realized that correlates emissions to the carbon intensity of the electricity mix if it is plotted from highest to lowest with respect to emissions, as shown in Figure 16. The high carbon intensity electricity generation mixes (e.g., "high carbon" and "old coal") on the left side of the figure lead to current day PHEV emissions of 325 to $375 \mathrm{~g}$ $\mathrm{CO}_{2} \mathrm{e} / \mathrm{mile}$, whereas low carbon-intensive scenarios, such as "nuclear", and "biomass," on the right side of the figure predict current day PHEV emissions of only approximately $150 \mathrm{~g} \mathrm{CO}_{2} \mathrm{e} / \mathrm{mile}$. 


\section{GHG Emissions Projections for Current PHEV30s Using Varying Electricity Mixes, Sorted}

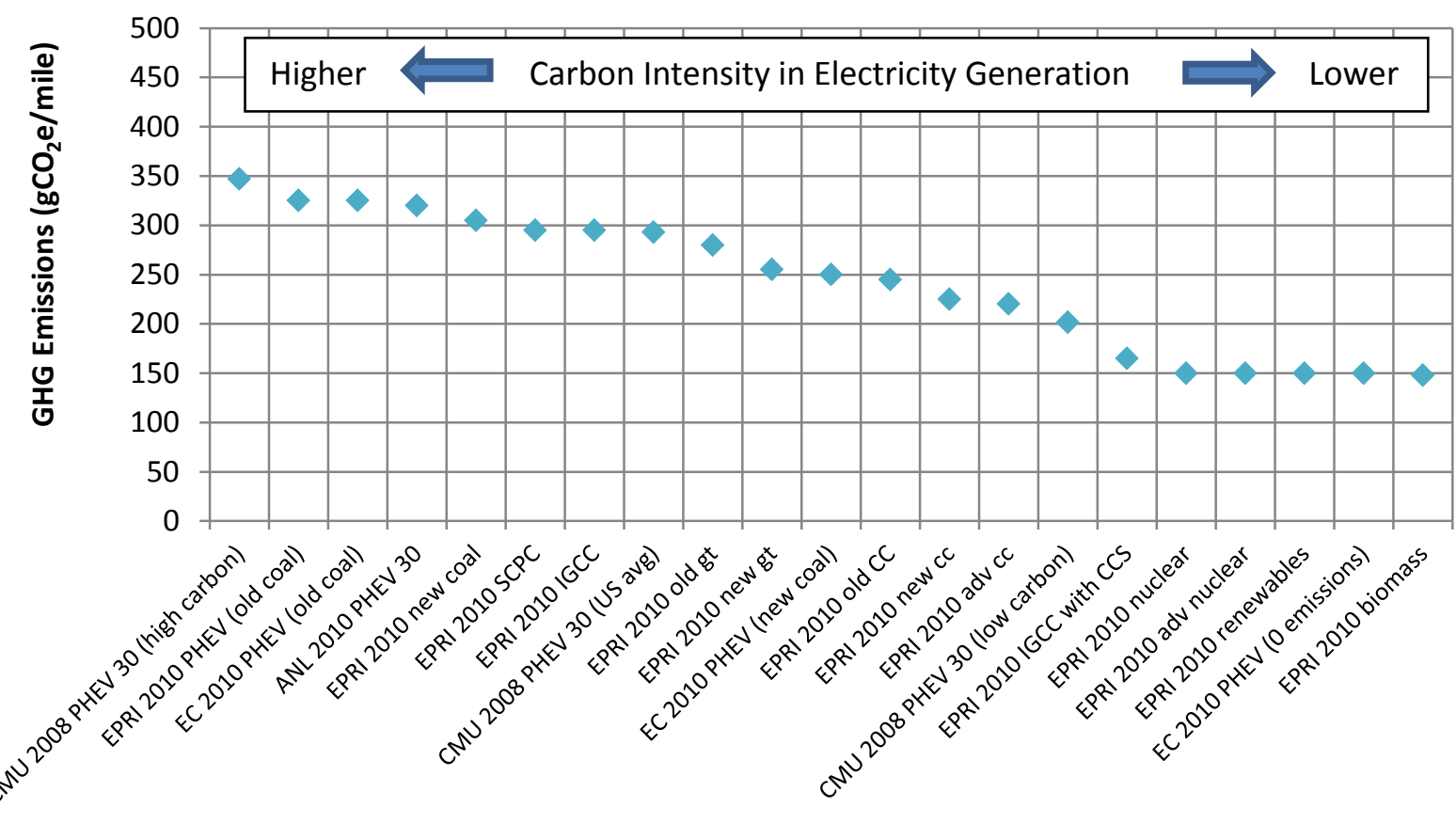

Report / Year / Technology

Figure 16: GHG emissions for current PHEV30s using various electricity mixes, assuming an average fuel blend, plotted highest to lowest with respect to GHG emissions

\subsubsection{Effect of Fuel Blend on Current GHG Emissions}

Fuel blends also proved to be a key driver for vehicle GHG emissions across reports investigated in this comparative study. SENTECH/ORNL and CMU both investigated different blends of cellulosic ethanol in their respective studies while ANL considered corn ethanol, cellulosic ethanol, and diesel fuel. Although multiple data points are given by each study, a similar electricity generation mix and PHEV AER were chosen to allow for a fair comparison. The resulting comparison is shown in Figure 17, which presents emissions data for various fuel blends used in current PHEV30s, powered by an "average" electricity generation mix. For both CMU and ANL, the highest emissions value for the PHEV30 occurs using the current gasoline fuel blend, or E10, and the lowest value is achieved using cellulosic E85. Similar to what was shown with varying the electricity generation mix, increased carbon intensity of the fuel blend generally leads to increased $\mathrm{GHG}$ emissions originating from the vehicle. 


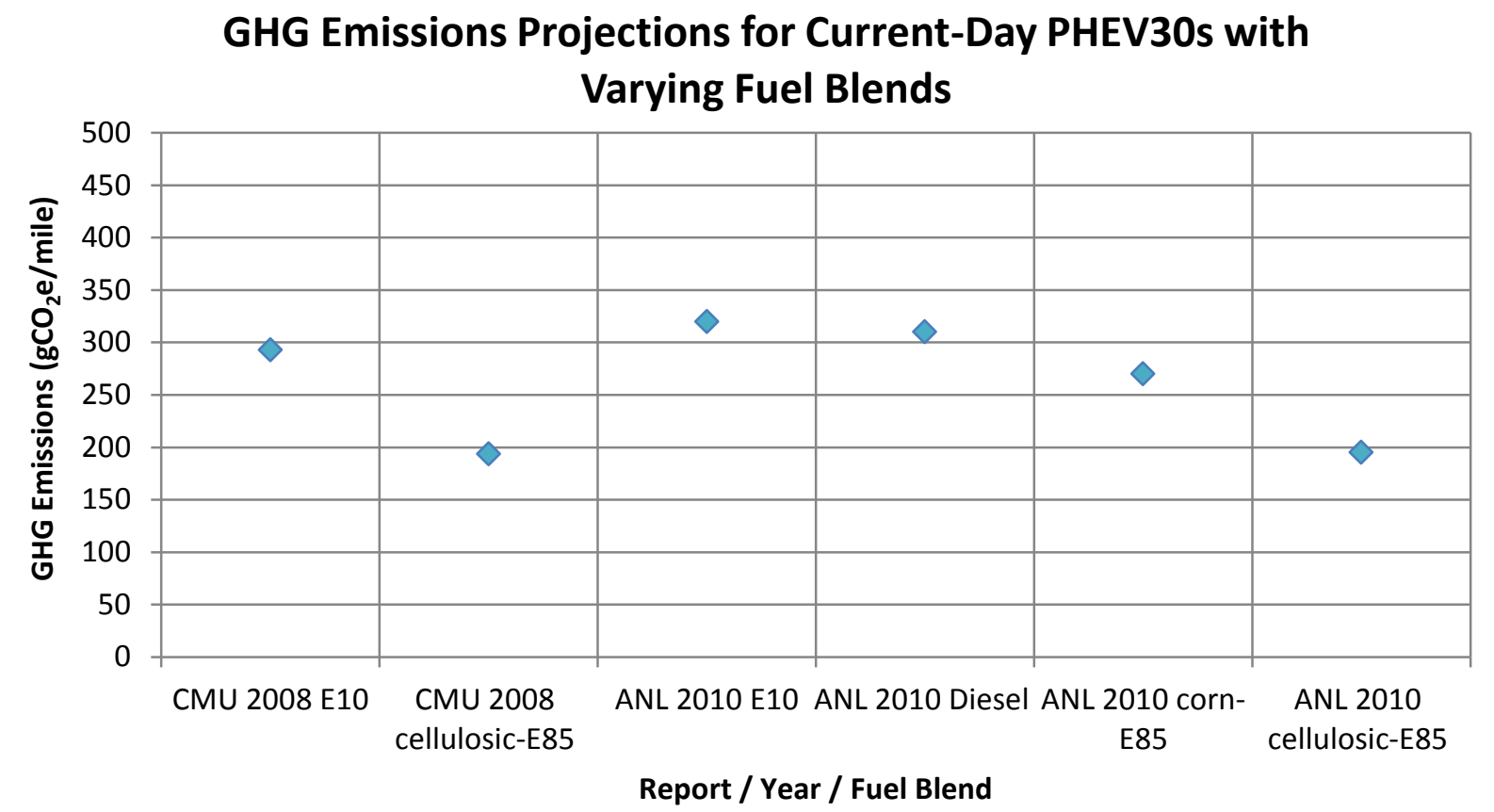

Figure 17: Emissions for current PHEV30s with various fuel blends powered by an "average" electricity generation mix

\subsubsection{Combining Assumptions}

Many of the reports included in this comparative study present multiple scenarios that combine various electricity generation mixes with multiple fuel blends and PHEV AERs. Plotting these extensive data points from all reports on one chart allows major trends to be identified and general conclusions to be drawn. For example, when plotted largest to smallest in Figure 18, the reader begins to recognize best-case and worstcase scenarios. Generally speaking, the most carbon intensive (and, therefore, highest emitting) scenarios comprise PHEVs that are charged using high-coal generation mixes and consume gasoline (in addition to electricity). In contrast, the optimal case, from a GHG emissions standpoint, uses PHEVs that charge from low-carbon electricity mix grids (e.g., nuclear, biomass) and consume high cellulosic ethanol fuel blends. 


\section{GHG Emissions Projections for All Current-Day PHEVs}

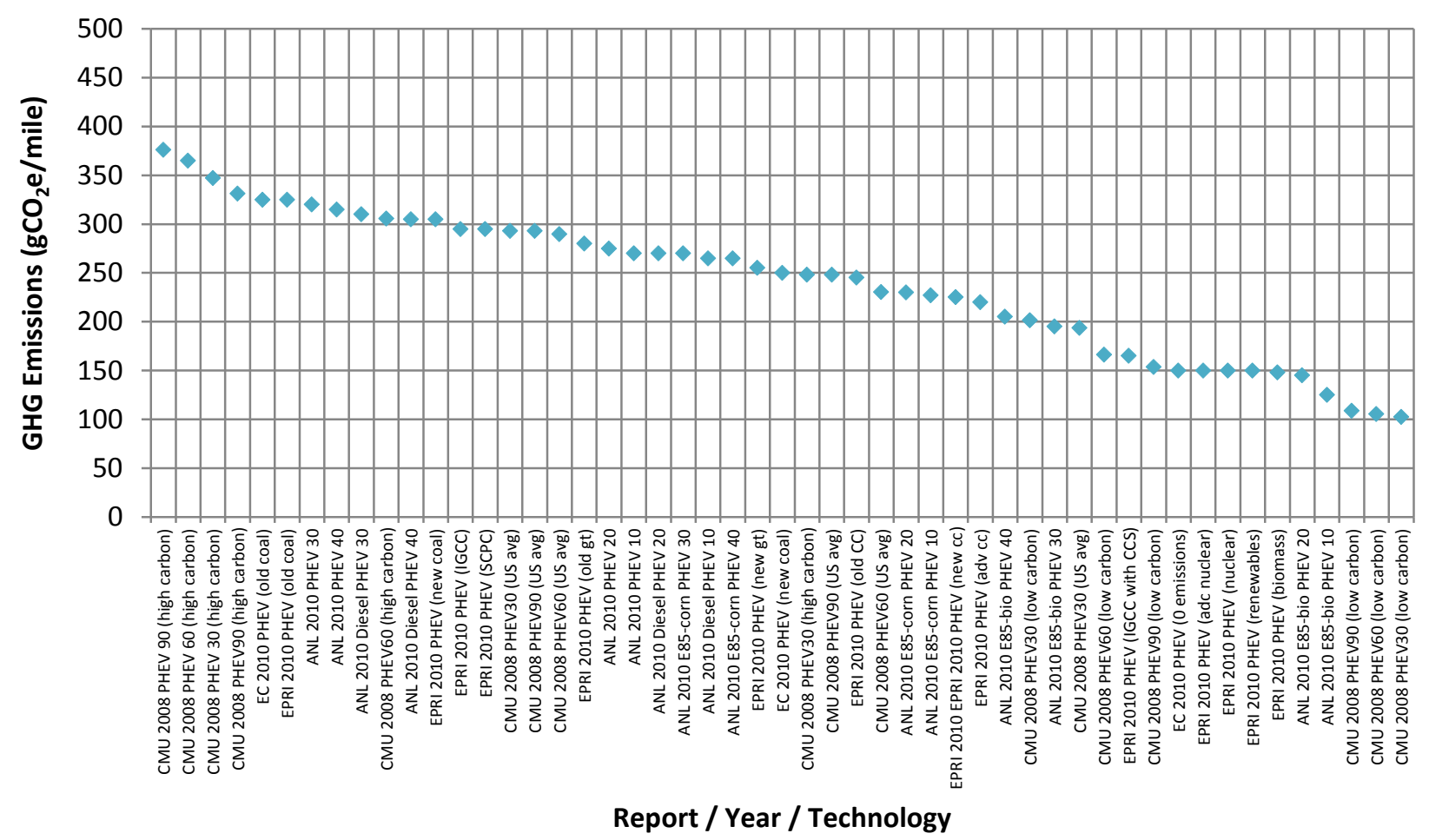

Figure 18: All data points for current PHEV emissions

Although several comparisons have been made for the "current" GHG emissions category using the three key assumption groups - Baseline Conditions, Electricity Generation Mix, and Fuel Blends, - some secondary factors also play a role in determining GHG emissions but cannot be placed into one of the aforementioned comparisons. Examples of these secondary factors include varying driving cycles, different computational models, and levels of government intervention. However, the ability to separate this data into meaningful comparisons is not practical for this report. 


\subsubsection{Future}

In addition to current projections, the second major category of comparing $\mathrm{GHG}$ emissions among major studies is by the future projections. Each of the comparisons in this section use data from reports that are predicting the emissions associated with future vehicle technologies, generation mixes, and fuel blends. Several secondary factors, such as varying driving cycles, different computational models, and levels of government intervention, help drive future GHG emissions, but the level of detail needed for their inclusion in this study is infeasible.

\subsubsection{Baseline}

In order for GHG emissions improvements to be predicted for PHEVs and other electric vehicle technologies, a baseline conventional vehicle is often defined. Both SENTECH/ORNL VP and MIT 2035 assume substantial improvements in internal combustion technology and glider technology in their respective studies that allow conventional vehicles to be more competitive with alternative vehicle technologies in the future. In contrast, EPRI/NRDC assumes less aggressive advancements in conventional vehicle technology over the upcoming decades. This range of data for future conventional vehicles, which assume standard gasoline as a fuel, can be seen in Figure 19. The SENTECH/ORNL VP and MIT 2035 values represent the lower limit, roughly between $250-300 \mathrm{gCO}_{2} \mathrm{e} /$ mile, while the $E P R I$ data point sets the upper limit at $370 \mathrm{~g} \mathrm{CO}_{2} \mathrm{e} / \mathrm{mile}$.

Future Conventional Vehicle Emissions

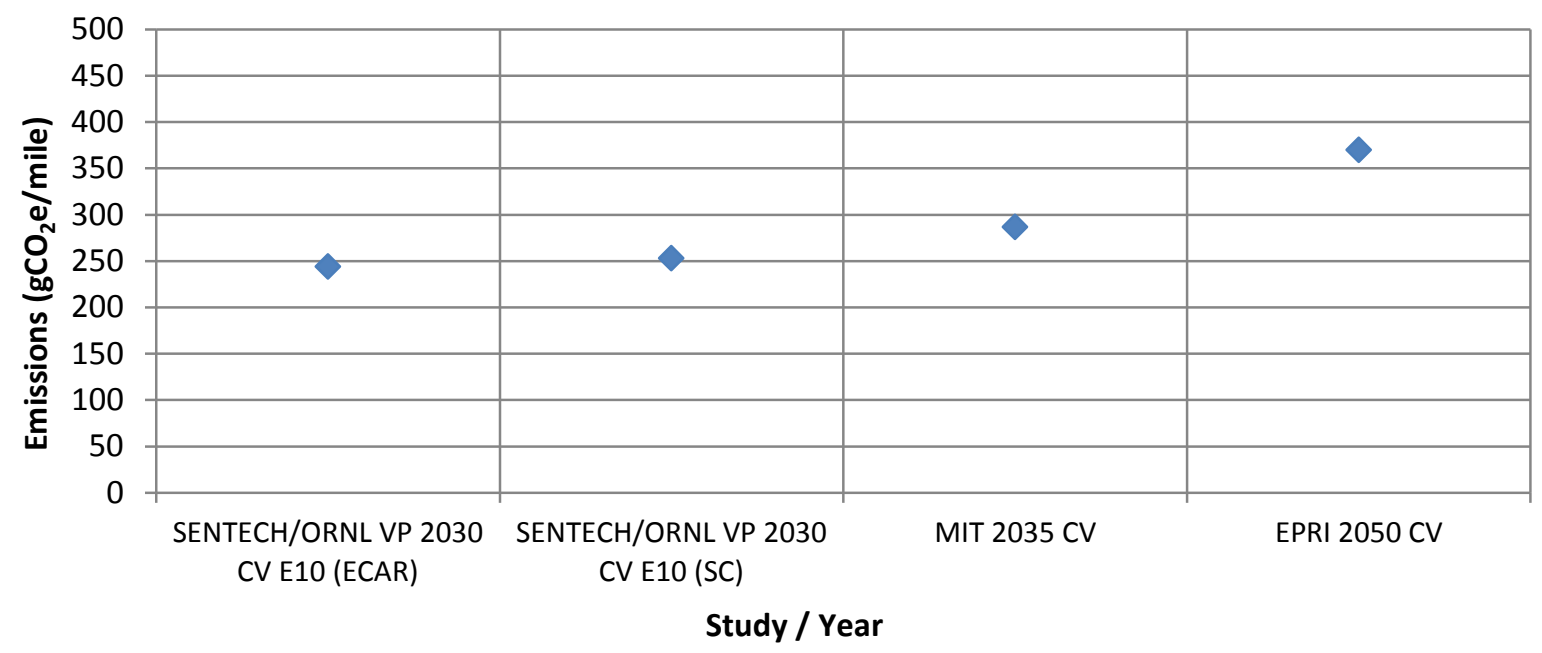

Figure 19: GHG emissions for future conventional vehicles using an average fuel blend

In addition to conventional vehicles, a similar baseline comparison can be made for future PHEV emissions using an "average" electricity generation mix, gasoline (E10) as fuel, and a similar AER. This comparison can be seen in Figure 20. Three of the four data points are very similar at approximately $180 \mathrm{~g} \mathrm{CO}{ }_{2} \mathrm{e} / \mathrm{mile}$. The fourth data point, provided in SENTECH/ORNL VP study, is slightly higher as a direct result of ECAR's carbon-intensive generation mix. 


\section{GHG Emissions Projections for Future PHEVs under Average Conditions}

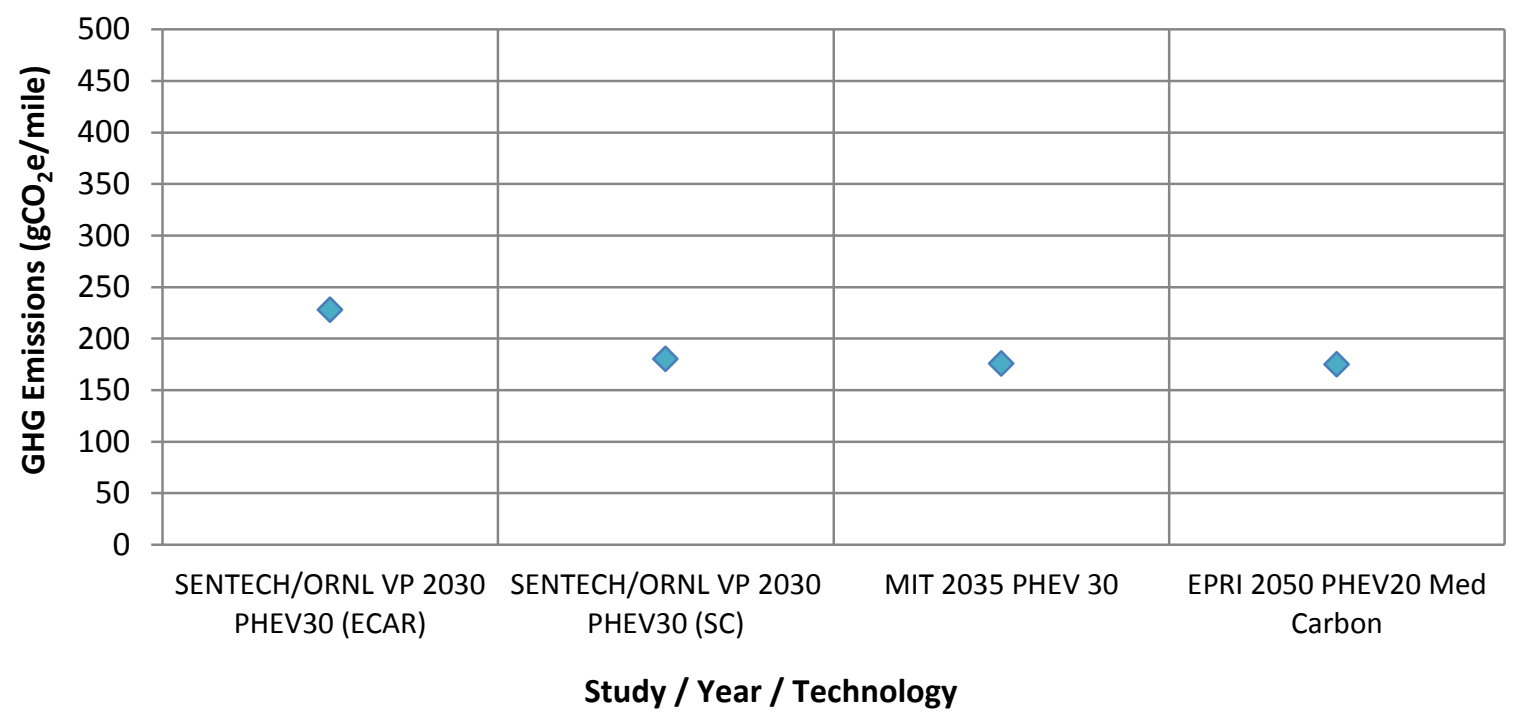

Figure 20: GHG emissions for future PHEV30s using an average electricity mix and average fuel blend

\subsubsection{Effect of Electricity Generation Mix on Future GHG Emissions}

As demonstrated in the "current" category, many of the reports investigated for this comparative study present multiple scenarios with various future electricity generation mixes to infer how GHG emissions from PHEVs may differ among geographic regions. Figure 21 displays the emissions data in these studies for future PHEVs with similar AERs using an average gasoline blend. (The AER and fuel blend are held constant to allow for a meaningful comparison.) According to the figure, the highest emissions values typically originate from PHEVs charging in higher-carbon generation mixes, while the lowest originate from renewable or other low-carbon electricity mixes. It is interesting to note that EPRI/NRDC's "high carbon" scenario is lower than SENTECH/ORNL's "average" mix for southern California. This is most likely due to a lower assumed carbon intensity for EPRI/NRDC's "high carbon" electricity mix than that of the southern California electricity mix used in SENTECH/ORNL VP. 


\section{GHG Emissions Projections for Future PHEVs under Varying Electricity Generation Mixes}

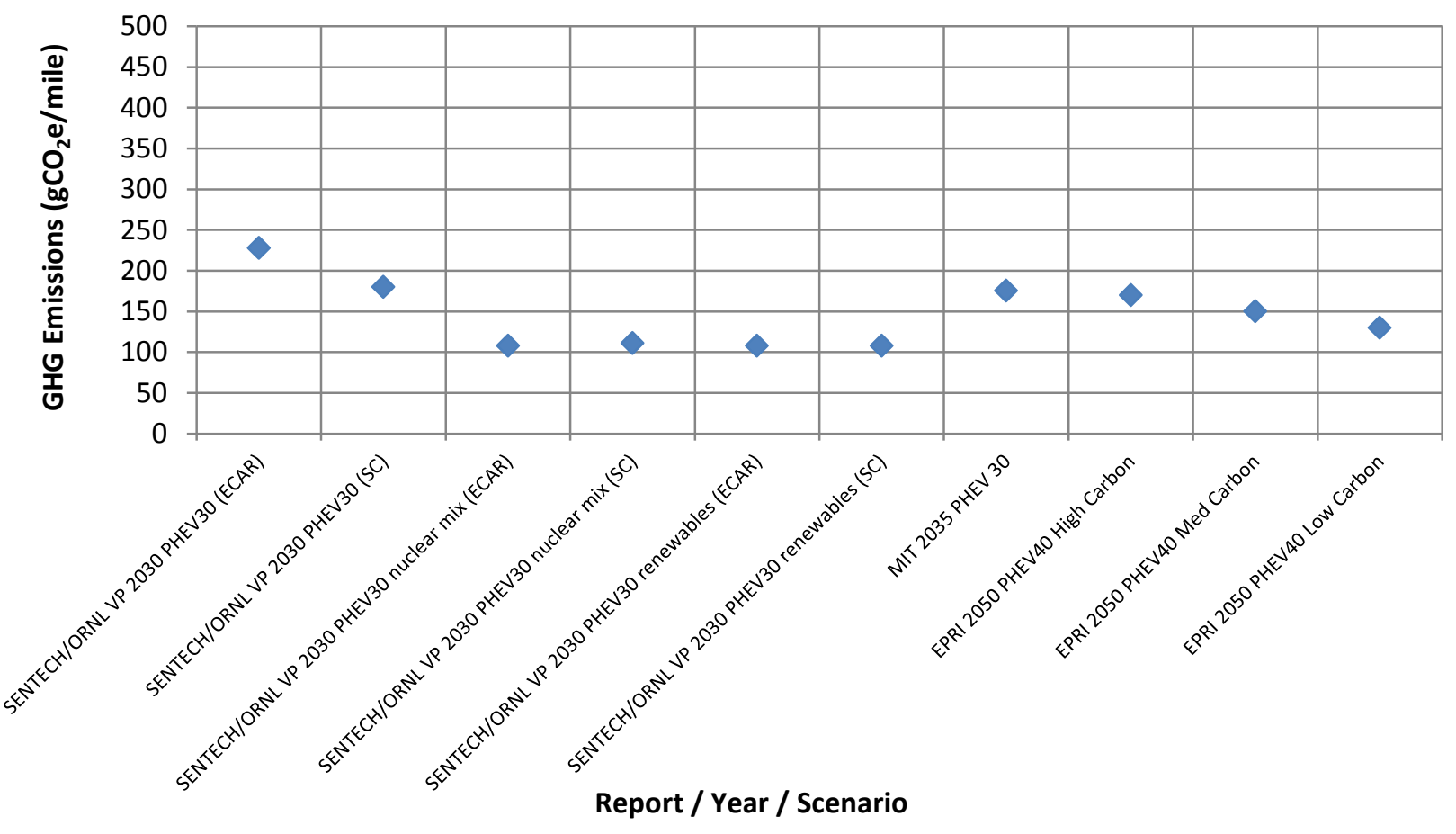

Figure 21: Future PHEV GHG emissions using various electricity generation mixes and an average fuel blend

\subsubsection{Effect of Fuel Blends on Future GHG Emissions}

While many organizations consider multiple fuel blends in their reports, SENTECH/ORNL VP and MIT 2035 are the only reports that consider various fuel blends for future scenarios. SENTECH/ORNL VP considers three different fuel blends: 1) gasoline, referred to as E10; 2) an average blend of $30 \% \mathrm{E} 10$ and $70 \%$ cellulosic E85, referred to as E30; and 3) cellulosic E85. MIT 2035 also considers cellulosic ethanol. Figure 22 presents the GHG emissions data for a PHEV30, operating on "average" electricity generation mix using the aforementioned fuel blends. As seen from the figure, a higher percentage of ethanol generally leads to lower $\mathrm{GHG}$ emissions.

\subsubsection{Combining Assumptions}

As with the "current" GHG emissions category, combining the assumptions of fuel blends and electricity generation for all PHEVs in the future category presents the reports' findings in a broader spectrum. However, direct comparisons made between data will yield weaker outcomes. The general trend is the same as the "current" GHG emissions category in that the higher carbon intensive electricity and higher percentage of ethanol lead to higher GHG emissions. Secondary factors also introduce the use of different computational models along with varying assumptions for glider technology improvement, government intervention, and driving cycles, which introduce more possible scenarios. Therefore, an "apples-to-apples" comparison at this point becomes much weaker. All of the future PHEV emissions data can be seen in Figure 23. 


\section{GHG Emissions Projections for Future PHEVs with Varying Fuel Blends}

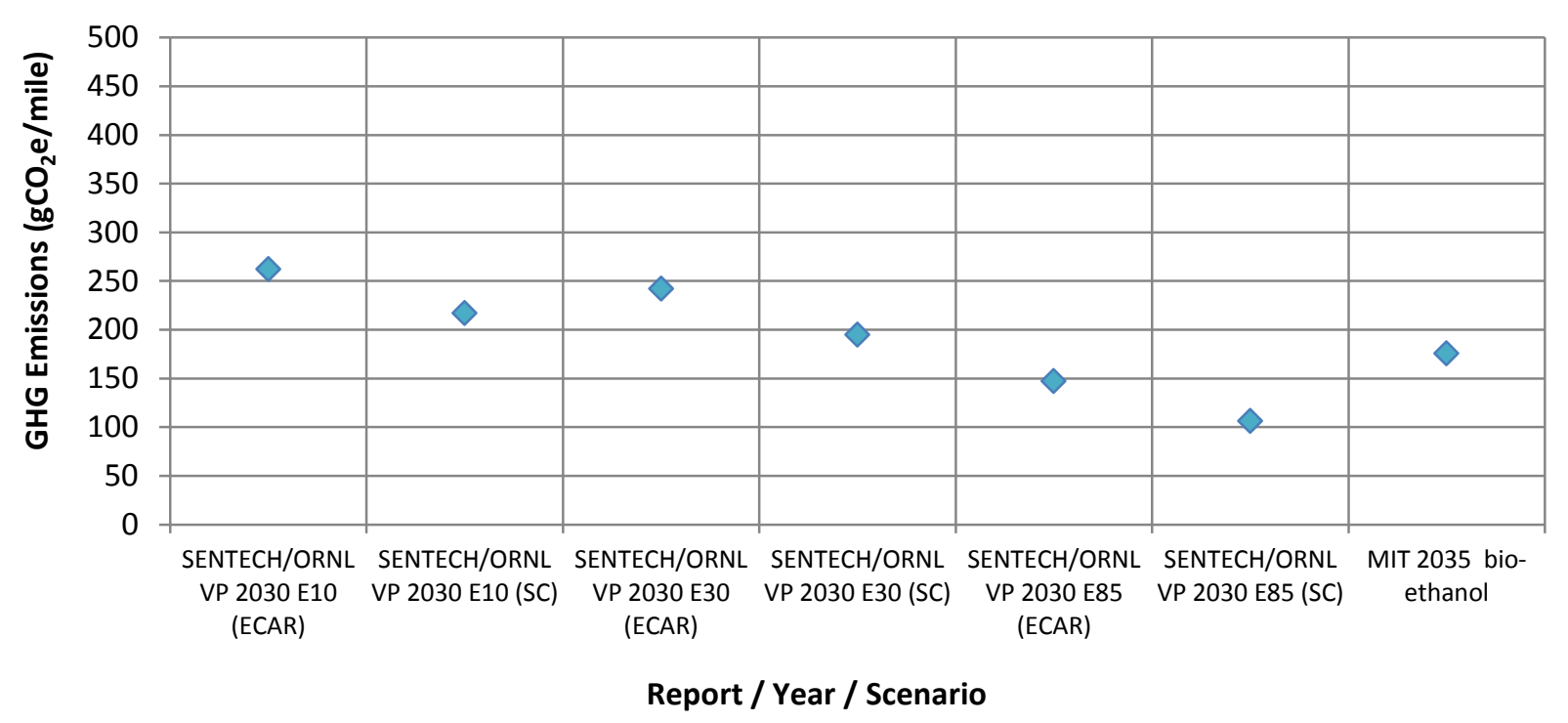

Figure 22: Future PHEV30 GHG emissions using various fuel blends and an "average" electricity generation mix

\section{GHG Emissions Projections for All Future PHEVs}

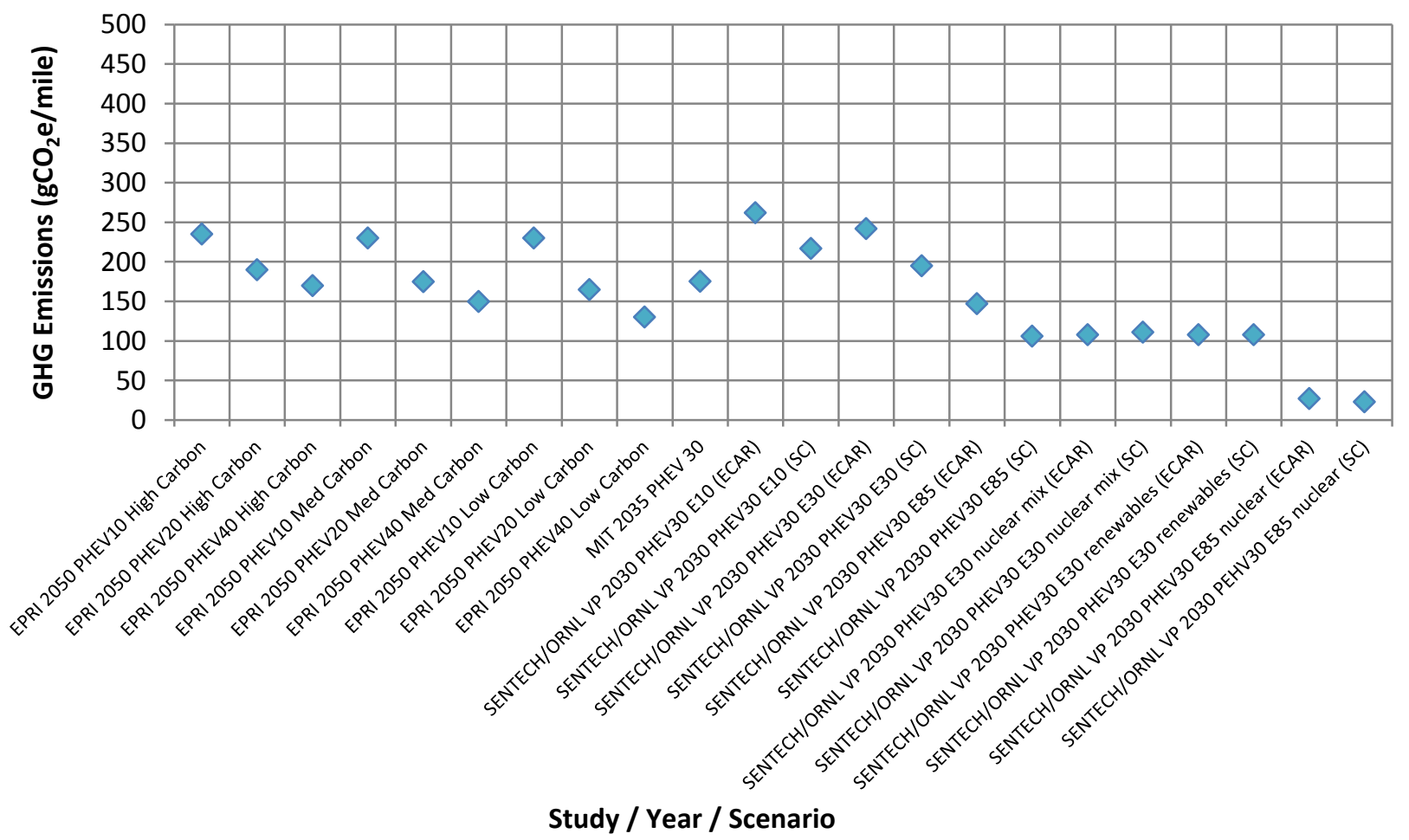

Figure 23: Future PHEV GHG emissions, including all electricity mixes and fuel blends 


\subsection{Conclusions}

Reflecting on the comparisons made in this chapter, a few general conclusions can be drawn for both the current and future $\mathrm{GHG}$ emissions data:

- With regard to the baseline for conventional and alternative vehicle technologies, the data points suggest overall agreement among the major studies. Of course, small discrepancies in the data exist, which can likely be attributed to the different models used to calculate emissions and the assumptions made on "average" electricity generation mixes, fuel blends, etc. Even though no two reports use the exact same assumptions or present identical results, none can be deemed "right" or "wrong." Each group clearly defines their assumptions and methods for arriving at their results. Ultimately, it appears that each report is generally reaching similar conclusions, just building different scenarios to demonstrate them.

- By identifying and comparing key assumptions associated with GHG emissions, the preliminary data presented in Figure 12's scatterplot becomes meaningful as trends begin to emerge. To present a clearer overall picture, Figure 24 on the following page takes all of the data points and rearranges them from highest to lowest with respect to $\mathrm{GHG}$ emissions. Generally speaking, the higher the carbon intensity of the inputs (electricity generation and fuel blend) the higher the emissions, assuming AER and other key assumptions are held constant.

- Incorporating assumptions made on all secondary factors makes for much weaker comparisons among the data points. However, it is important to note that these factors, including the modeling tools used, vehicle technology, PHEV configuration, government influence, and driving cycles, are all critical to defining the results, but trends become more challenging to identify as more factors are introduced. Therefore, the GHG emissions portion of this comparative study was limited to three key factors (generation mix, fuel blend, AER, and biofuel pathway) as identified by the project team. 


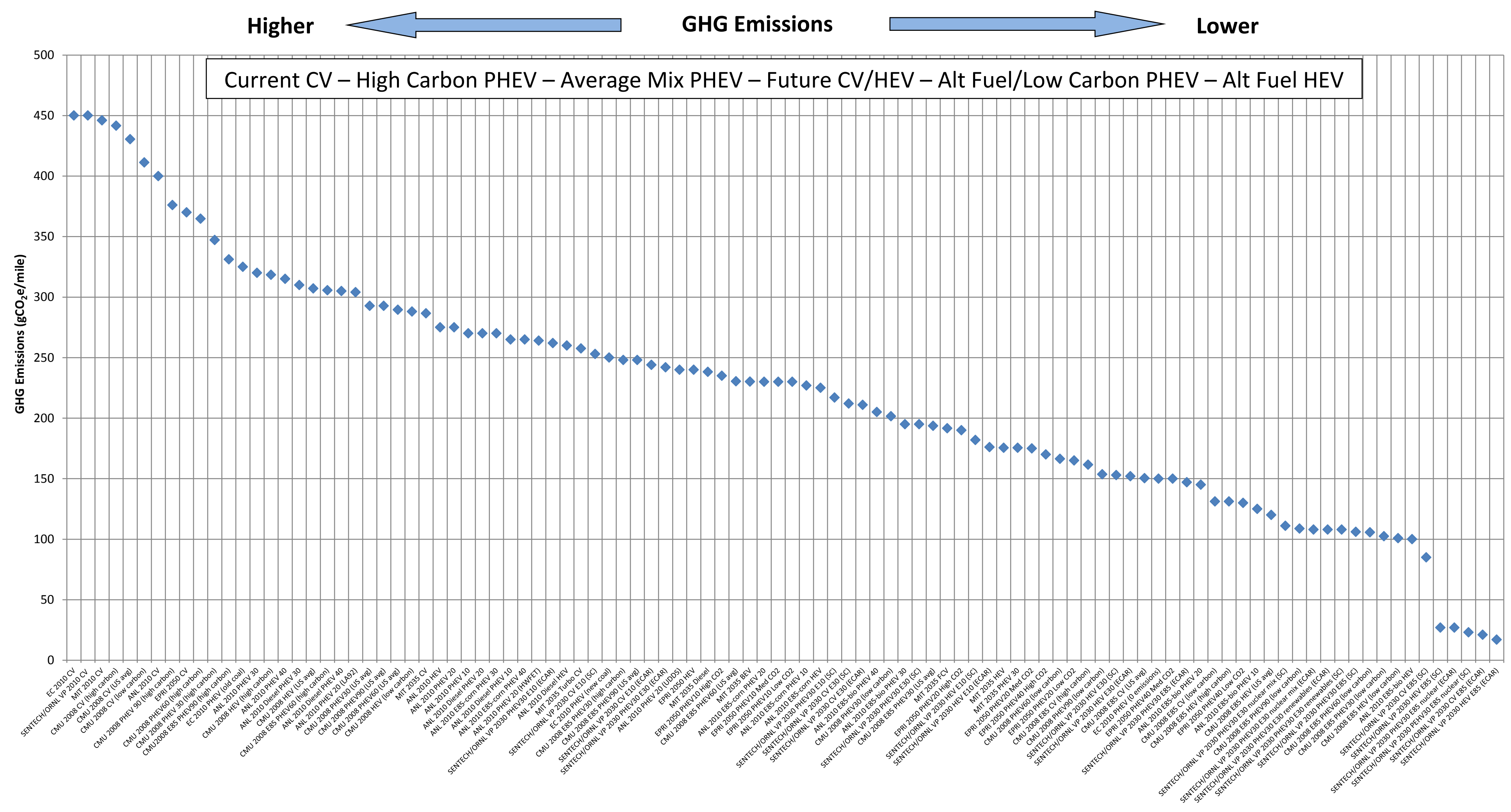

Study / Year / Technology 


\section{Comparison of Annual Market Penetration Rates}

This chapter reviews and compares PHEV annual market penetration rates extracted from all applicable studies reviewed in this comparative study. PHEV annual market penetration refers to the ratio of the U.S. PHEV annual sales to the total U.S. LDV annual sales. Analysis of fifteen studies is included in this chapter, although some studies provide more scenarios than just the most probable PHEV annual market penetration rate. Rather, many present sensitivity analyses with multiple scenarios in an attempt to identify the impact of changing assumptions, or "What if" situations, on PHEV annual market penetration. In these cases, both conservative and aggressive scenarios may be included, sometimes resulting in a wide range of possible penetration rates.

A large proportion of the variation between possible PHEV annual penetration rates can be justified by variation in the assumptions. Therefore, no annual market penetration scenarios reviewed are considered right or wrong, but rather each of the annual market penetration scenarios is deemed appropriate within the context of the specific study's assumptions and simulation model tools used. The ultimate objective is simply to attempt to provide an unbiased review of the reports published to date on the topic.

The following fifteen reports provide market penetration data that is utilized in this comparative study:

1. MIT - "On The Road in 2035"

2. MIT - "Prospects for Plug-In Electric Hybrid Vehicles in the United States and Japan: A General Equilibrium Analysis"

3. ANL - "Multi-Path Transportation Future Study: Vehicle Characterization and Scenario Analyses"

4. SENTECH/ORNL - "Plug-in Hybrid Electric Vehicle Market Introduction Study"

5. PNNL - "Plug-in Hybrid Electric Vehicle Market Penetration Scenarios"

6. Electrification Coalition - "Electrification Roadmap: Revolutionizing Transportation and Achieving Energy Security"

7. EPRI/NRDC - "Environmental Assessment of Plug-In Hybrid Electric Vehicles, Volume 1: Nationwide Greenhouse Gas Emissions"

8. EIA - "Annual Energy Outlook 2010"

9. NRC - "Transitions to Alternative Transportation Technologies"

10. Roland Berger - "Powertrain 2020 Li-ion Batteries - The next bubble ahead?"

11. Deloitte - "Gaining Traction: A customer view of electric vehicle mass adoption in the U.S. automotive market"

12. Deutsche Bank - "Electric Cars: Plugged In"

13. BCG - "The Comeback of the Electric Car"

14. UMTRI - "Market Models for Predicting PHEV Adoption and Diffusion"

15. JD Power and Associates - "Drive Green 2020: More Hope than Reality?"

The number of scenarios presented in each report ranges from 1 to 24 . When a report presents multiple scenarios, they often do not suggest that one of their scenarios is most likely to occur nor is probability allocated to their scenarios. For studies that attempt to forecast the future of PHEVs, results are still relatively vague. The ambiguous future for PHEVs is mostly due to uncertainty with technological advances, government interventions, and potential PHEV buyer behavior. In this chapter, PHEV annual market penetration scenarios will be presented in addition to assumptions that drive the results of each scenario. 


\subsection{Assumptions}

As will be discussed in the trends among studies section of this comparative study, the annual market penetration forecast for PHEVs varies strongly across the 15 studies reviewed. A large portion of this variation is due to the different assumptions made by each organization. This section of the comparative study will try to explore the various assumptions supporting the different PHEV market penetration scenarios. Generally speaking, a collection of major assumption categories are repeatedly mentioned across the 15 studies:

1. Vehicle Price Mark-Up (\%) - The vehicle price mark-up refers to the incremental PHEV price relative to an equivalent performance ICE-only vehicle. The vehicle mark-up is referred to in this paper in terms of percentage increase rather than dollar amount. Vehicle mark-up is often negatively correlated with the PHEV annual market penetration forecast. The more expensive PHEVs are expected to be, the slower their annual market penetration is likely to be.

2. Purchase Price - Vehicle purchase price refers to the actual amount for which the vehicle sells. Like other cost-related assumptions, the purchase price is often negatively correlated to the PHEV annual market penetration forecast.

3. Price Premium (\$) - A third way of referring to the additional price an auto buyer needs to pay for the PHEV relative to a conventional ICE or an HEV is the price premium in dollar amount. Once again, the price premium negatively correlates with the PHEV annual market penetration forecast.

4. Government Subsidies/Tax Policies - This assumption refers to the government offsetting a portion of a PHEV's price premium. Government subsidies are positively correlated with PHEV annual market penetration. The higher the amount of government subsidies for PHEV buyers, the faster the PHEV annual market penetration will likely occur.

5. Gasoline/Oil Prices - This assumption refers to either the "per mile" price of gasoline or the "per barrel" price of oil. The gasoline/oil prices are positively correlated with the PHEV annual market penetration. Because PHEV owners are less affected by rising gasoline prices, the PHEVs are in a favorable economic position relative to other conventional vehicles when gasoline/oil prices are at its highest.

6. Vehicle AER - The vehicle's all-electric driving range usually varies between 10 to 40 miles for PHEVs. Because the cost associated with the vehicle batteries is currently so high, increasing the driving range increases the vehicle purchase price significantly. The absolute factor of increasing vehicle ranges may but not necessarily have a positive impact on the annual market penetration for PHEVs.

7. Utility Factor - The utility factor refers to the percentage of miles that the vehicle could drive in allelectric mode. The higher frequency of shorter trips with more charging pauses results in a higher utility factor. It could be positively correlated with the PHEV annual market penetration forecast because auto buyers can realize savings from using electricity. This makes the break-even point closer and prompts a stronger annual market penetration for PHEVs.

8. Technological Advances - This assumption refers to whether vehicle technologies will realize major technological advances in the near future. Technological advancements are often facilitated by government grants made in support of a specific green technology. The more the technological advances that PHEVs realize, the more the cost of the vehicle will decline, and, therefore the greater their annual market penetration may be.

9. Environmental Policies - Environmental policies may affect automakers, auto buyers, and others as a means of protecting the environment. Environmental policies could be positively correlated with PHEV annual market penetration since they may result in lower GHG emissions. The stricter 
the environmental policies, the more motivated the automakers and buyers may be to shift toward PHEVs and other green vehicle technologies.

10. Supply Chain/Infrastructure - A robust supply chain supports higher availability of PHEVs, batteries, and the infrastructure needed to support an electric vehicle industry. Limitation in the supply chain or the infrastructure could directly limit the penetration of PHEVs.

Of the 15 studies reviewed for the annual market penetration portion of the comparative study, ten provided sufficient information on the major assumptions categories defined above. Table 36 summarizes this information as it related to each of the assumption category. It is interesting to note that across the ten studies, no two organizations selected the same set of assumption categories for consideration in their study. Hence, this creates a challenge when attempting to compare the studies' market penetration projections on an "apples-to-apples" basis.

Table 36: Assumptions overview for PHEV market penetration rates

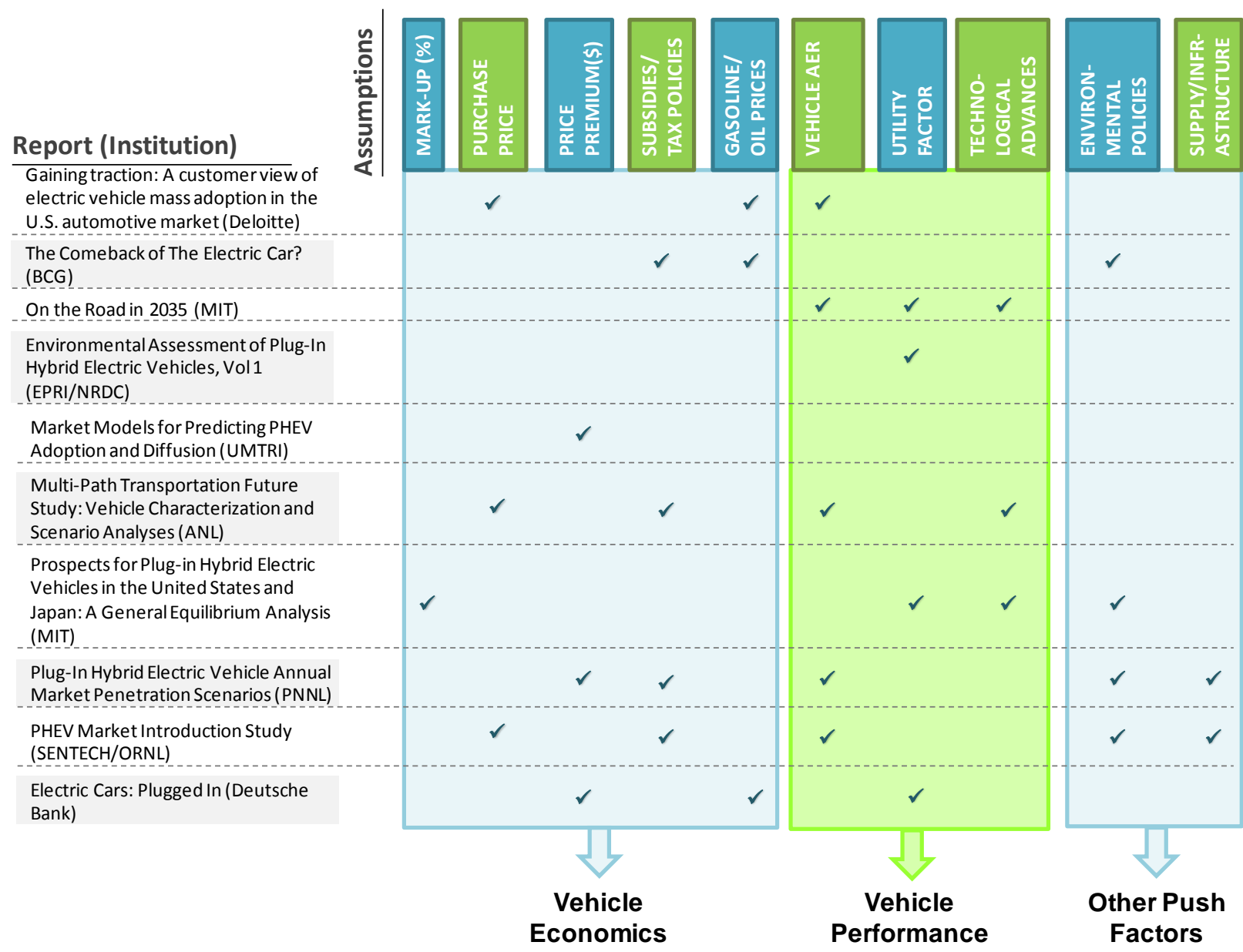

Although there are ten different assumption categories defined in this section, many of those categories reflect the same issues. Hence the ten different assumption categories could also be grouped into three large groups for simplicity: 1) vehicle economics, 2) vehicle performance, and 3) other push factors. 
The vehicle economics group, which includes 1) vehicle price mark-up, 2) purchase price, 3) price premium, 4) government subsidies, and 5) gasoline/oil price, all affect the vehicle buyer concerns on the cost of the vehicle. While different studies address this issue in different ways, they all answer the question of how much the car will cost initially and how much savings can be expected in the future. Unfortunately, these different methods of addressing the vehicle economics create a difficult stage for comparison. For instance, comparing a price markup of $30 \%$ to a purchase price of $\$ 25,000$ is not direct. Similarly, comparing a price premium relative to existing hybrids to a price premium relative to conventional vehicles is also very challenging. To do so would require making various assumptions that might distort the accuracy of the analysis. It is interesting to note that eight of the ten studies mentioned at least one assumption in regards to vehicle economics. Table 37 shows the specific details for the eight studies that made assumptions relative to the vehicle economics.

Table 37: Detailed assumptions regarding vehicle economics

\begin{tabular}{|c|c|c|c|c|c|}
\hline \multirow[b]{2}{*}{ Report (Institution) } & \multicolumn{5}{|c|}{ Assumptions } \\
\hline & $\begin{array}{c}\text { PRICE } \\
\text { MARK-UP }\end{array}$ & $\begin{array}{l}\text { PURCHASE } \\
\text { PRICE }\end{array}$ & $\begin{array}{c}\text { PRICE } \\
\text { PREMIUM }\end{array}$ & $\begin{array}{l}\text { SUBSIDIES/ } \\
\text { TAX POLICIES }\end{array}$ & $\begin{array}{l}\text { GAS/OIL } \\
\text { PRICES }\end{array}$ \\
\hline $\begin{array}{l}\text { Gaining traction: A customer view of } \\
\text { electric vehicle mass adoption in the } \\
\text { U.S. automotive market (Deloitte) }\end{array}$ & & $\begin{array}{l}\$ 25,000 \\
\$ 35,000 \\
\$ 45,000\end{array}$ & & & $\begin{array}{c}\$ 3, \$ 3.50 \\
\$ 4 / \mathrm{gal}\end{array}$ \\
\hline $\begin{array}{l}\text { The Comeback of The Electric Car? } \\
\text { (BCG) }\end{array}$ & & & & $\begin{array}{l}\text { Current, } \\
\text { higher tax } \\
\text { incentives }\end{array}$ & $\begin{array}{c}\$ 60, \$ 150, \\
\$ 300 / \mathrm{bbl}\end{array}$ \\
\hline $\begin{array}{l}\text { Market Models for Predicting PHEV } \\
\text { Adoption and Diffusion (UMTRI) }\end{array}$ & & & $\begin{array}{l}\$ 2,500, \$ 5,000 \\
\$ 10,000 \text { rel. to } \\
\text { conventional }\end{array}$ & & \\
\hline $\begin{array}{l}\text { Multi-Path Transportation Futures } \\
\text { Study: Vehicle Characterization and } \\
\text { Scenario Analyses (ANL) }\end{array}$ & & & & $\$ 7,500$ & $\begin{array}{c}\$ 93 / \mathrm{bbl} \text { or } \\
\$ 3.20 / \mathrm{gal}\end{array}$ \\
\hline $\begin{array}{l}\text { Prospects for Plug-in Hybrid Electric } \\
\text { Vehicles in the United States and } \\
\text { Japan: A General Equilibrium Analysis } \\
\text { (MIT) }\end{array}$ & $\begin{array}{l}0.3 \%, 0.6 \%, \\
0.8 \%\end{array}$ & & & & \\
\hline $\begin{array}{l}\text { Plug-In Hybrid Electric Vehicle Annual } \\
\text { Market Penetration Scenarios (PNNL) }\end{array}$ & & & $\begin{array}{l}\$ 4,000 \text { rel. to } \\
\text { existing hybrid }\end{array}$ & & \\
\hline $\begin{array}{l}\text { PHEV Market Introduction Study } \\
\text { (SENTECH/ORNL) }\end{array}$ & & $\$ \$ \$$ & & $\$ 2,500$ to & \\
\hline $\begin{array}{l}\text { Electric Cars: Plugged In (Deutsche } \\
\text { Bank) }\end{array}$ & & & $\begin{array}{l}\$ 8,000 \text { rel. to } \\
\text { conventional }\end{array}$ & & \$4/gal \\
\hline
\end{tabular}

Similarly, the three assumption categories - vehicle range, utility factor, and technological advances measure vehicle performance in some manner. Seven out of the ten studies mention at least one assumption regarding the vehicle performance. Finally, supply chain / infrastructure and environmental policies are both considered as other push factors that could increase the annual market penetration rate of PHEVs. Half of studies mention at least one of these push factors in their analyses. 
Each of the ten studies used to support the annual market penetration portion of this comparative study has been visually broken down by the specific assumptions that support its respective scenarios. Some studies only present one scenario while others have as many as 24 . Often, organizations present three scenarios in their studies to represent different levels of market penetration of PHEVs. Although these three scenarios are not necessarily named "high," "medium," and "low," in this section they will be referred to as such to allow the reader to easily differentiate basic scenarios across studies. The high, medium, and low scenarios always refer to PHEV annual market penetration scenarios, and may not also apply to other electric vehicle technologies. For example, a "high" scenario that refers to a high annual market penetration for PHEVs might also refer to a low annual market penetration for HEVs or BEVs. The year of the analysis provided in each assumptions breakdown (e.g., 2030) refers to the year when the assumptions will be valid, which may differ from the report's publication date. The scope of the vehicles addressed (e.g., HEV, BEV, PHEV) in each study is also defined in the tables.

Tables 38-47 display the select assumptions used in each of this section's ten studies. In a few of these diagrams, an " $X$ " symbol represents the absence of the specific assumption category whereas a check mark $(\checkmark)$ refers to the presence of the specific assumption category. It should be noted that, in Figure 46, "LR" refers to the literature review prices, while "PG" refers to program goal prices. The "LR" prices were developed through literature review and do not necessarily achieve the associated DOE vehicle program goals. The "PG" prices do assume the DOE vehicle program goals are met. The report itself presents actual prices for various types of vehicles in year 2015, 2030, and 2045. As for the technological advances categories, "M" refers to the mixed scenario / no technology winner where fuel prices are lower than in the base case. "PHEV" refers to a scenario where PHEVs and ethanol are the winning technologies, and this scenario also assumes the most optimistic cellulosic ethanol prices and the most optimistic share of household that are able to plug in their vehicles. Finally, "H2" refers to the third scenario characterized by hydrogen technology success. This scenario also assumes the most optimistic hydrogen prices. 
Table 38: Detail assumptions for "Gaining Traction: A customer view of electric vehicle mass adoption in the U.S. automotive market" by Deloitte

Gaining Traction: A Customer View of Electric Vehicle Mass Adoption in the U.S. Automotive Market (Deloitte)

\begin{tabular}{|c|c|c|c|}
\hline & $\begin{array}{l}\text { High PHEV } \\
\text { Penetration }\end{array}$ & $\begin{array}{l}\text { Medium PHEV } \\
\text { Penetration }\end{array}$ & $\begin{array}{l}\text { Low PHEV } \\
\text { Penetration }\end{array}$ \\
\hline Purchase Price & Low (\$25K) & Medium (\$35K) & High (\$45K) \\
\hline \multicolumn{4}{|l|}{ Price Premium (\$) } \\
\hline \multicolumn{4}{|l|}{ Subsidies/Tax Policies } \\
\hline Gasoline/Oil Prices & High (\$4.50/gal & High (\$3.50/gal) & High (\$3/gal) \\
\hline & & & \\
\hline Vehicle AER & High (350 mi) & Medium (200 mi) & Low $(100 \mathrm{mi})$ \\
\hline \multicolumn{4}{|l|}{ Utility Factor } \\
\hline \multicolumn{4}{|l|}{ Technological Advances } \\
\hline \multicolumn{4}{|l|}{ Environmental Policies } \\
\hline \multicolumn{4}{|l|}{ Supply/Infrastructure } \\
\hline \multicolumn{4}{|c|}{$\begin{array}{l}\text { Year of the analysis: } \mathbf{2 0 2 0} \\
\text { Type of vehicle(s) considered: BEV and PHEV }\end{array}$} \\
\hline
\end{tabular}

Table 39: Detailed assumptions for "The Comeback of the Electric Car?" by BCG

The Comeback of The Electric Car? (BCG)

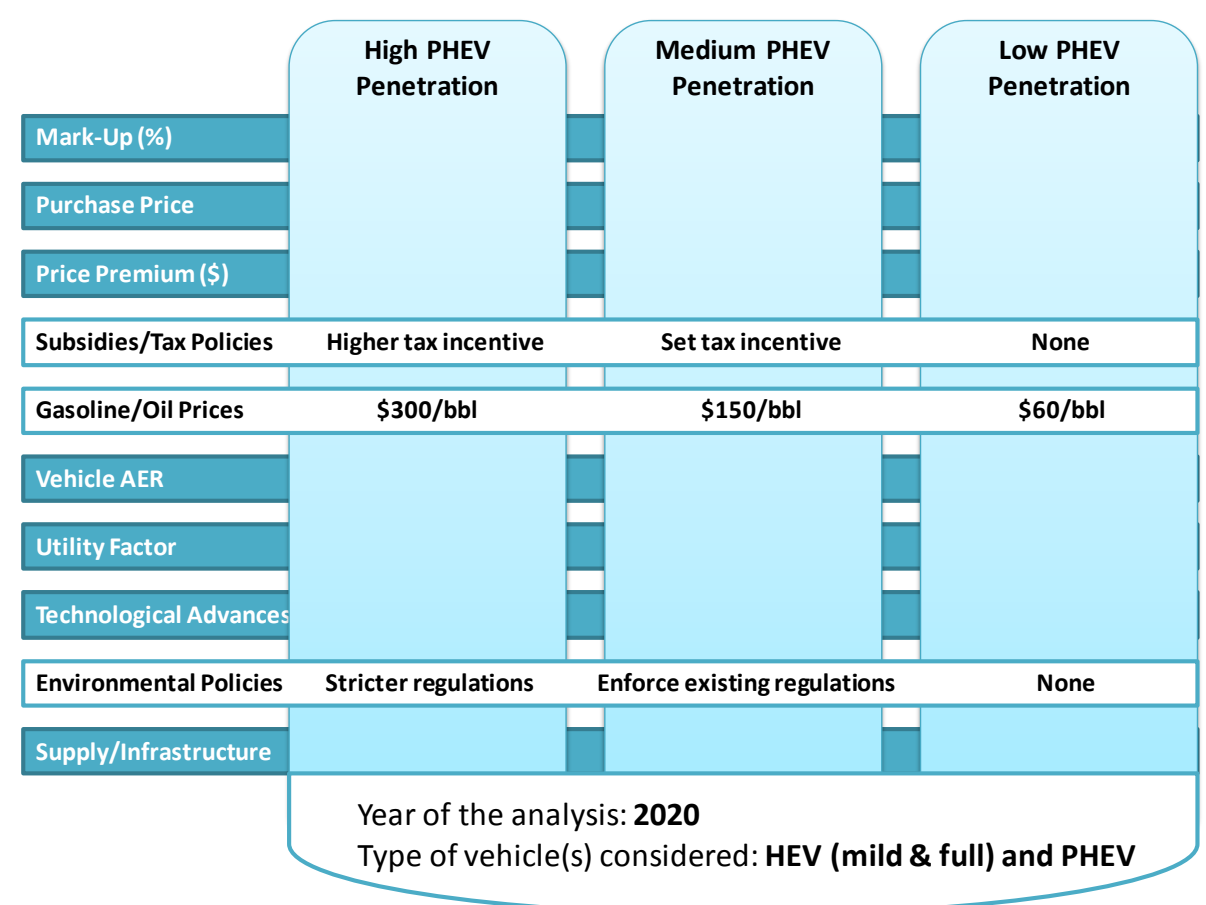


Table 40: Detailed Assumptions for "On the Road in 2035" by MIT

On the Road in 2035 (MIT)

\begin{tabular}{|c|c|c|c|}
\hline & $\begin{array}{l}\text { High PHEV } \\
\text { Penetration }\end{array}$ & $\begin{array}{l}\text { Medium PHEV } \\
\text { Penetration }\end{array}$ & $\begin{array}{l}\text { Low PHEV } \\
\text { Penetration }\end{array}$ \\
\hline \multicolumn{4}{|l|}{ Mark-Up (\%) } \\
\hline \multicolumn{4}{|l|}{ Purchase Price } \\
\hline \multicolumn{4}{|l|}{ Price Premium (\$) } \\
\hline \multicolumn{4}{|l|}{ Subsidies/Tax Policies } \\
\hline \multicolumn{4}{|l|}{ Gasoline/Oil Prices } \\
\hline \multirow[t]{2}{*}{ Vehicle AER } & $30 \mathrm{mi}$ & $30 \mathrm{mi}$ & $30 \mathrm{mi}$ \\
\hline & & & \\
\hline \multicolumn{4}{|l|}{ Utility Factor } \\
\hline Technological Advances & Intensive for hybrid & No clear winner & $\begin{array}{l}\text { Intensive for the diesel } \\
\text { and turbocharged }\end{array}$ \\
\hline \multicolumn{4}{|l|}{ Environmental Policies } \\
\hline \multicolumn{4}{|l|}{ Supply/Infrastructure } \\
\hline & $\begin{array}{l}\text { Year of the a } \\
\text { Type of vehi }\end{array}$ & 2035 & HEV \\
\hline
\end{tabular}

Table 41: Detailed assumptions for "Market Models for Predicting PHEV Adoption and Diffusion" by UMTRI

Market Models for Predicting PHEV Adoption and Diffusion (UMTRI)

\begin{tabular}{|c|c|c|c|}
\hline & $\begin{array}{l}\text { High PHEV } \\
\text { Penetration }\end{array}$ & $\begin{array}{c}\text { Medium PHEV } \\
\text { Penetration }\end{array}$ & $\begin{array}{l}\text { Low PHEV } \\
\text { Penetration }\end{array}$ \\
\hline \multicolumn{4}{|l|}{ Mark-Up (\%) } \\
\hline \multicolumn{4}{|l|}{ Purchase Price } \\
\hline Price Premium (\$) & $\$ 2,500$ & $\$ 5,000$ & $\$ 10,000$ \\
\hline \multicolumn{4}{|l|}{ Government Subsidies } \\
\hline \multicolumn{4}{|l|}{ Gasoline/Oil Prices } \\
\hline \multicolumn{4}{|l|}{ Vehicle AER } \\
\hline \multicolumn{4}{|l|}{ Utility Factor } \\
\hline \multicolumn{4}{|l|}{ Technological Advances } \\
\hline \multicolumn{4}{|l|}{ Environmental Policies } \\
\hline \multicolumn{4}{|l|}{ Supply/Infrastructure } \\
\hline & $\begin{array}{l}\text { Year of th } \\
\text { Type of ve }\end{array}$ & : 2010 - 2050 & \\
\hline
\end{tabular}


Table 42: Detailed assumptions for "Plug-In Hybrid Electric Vehicle Annual Market Penetration Scenarios" by PNNL

Plug-In Hybrid Electric Vehicle Annual Market Penetration Scenarios (PNNL)

\begin{tabular}{|c|c|c|c|}
\hline & \multirow[t]{3}{*}{$\begin{array}{l}\text { High PHEV } \\
\text { Penetration }\end{array}$} & \multirow[t]{3}{*}{$\begin{array}{l}\text { Medium PHEV } \\
\text { Penetration }\end{array}$} & \multirow[t]{3}{*}{$\begin{array}{l}\text { Low PHEV } \\
\text { Penetration }\end{array}$} \\
\hline Mark-Up (\%) & & & \\
\hline \multirow{2}{*}{\multicolumn{4}{|c|}{$\$ 4,000$ relative to existing hybrid }} \\
\hline & & & \\
\hline Subsidies/Tax Policies & \multicolumn{3}{|c|}{ Current incentives for existing hybrid are extended to PHEV } \\
\hline \multicolumn{4}{|l|}{ Gasoline/Oil Prices } \\
\hline Vehicle AER & \multicolumn{3}{|c|}{$40 \mathrm{mi}$} \\
\hline \multicolumn{4}{|l|}{ Utility Factor } \\
\hline Technological Advances & & & $\begin{array}{l}\text { Advancements in } \\
\text { hybrid technology }\end{array}$ \\
\hline Environmental Policies & \multicolumn{3}{|c|}{$\begin{array}{l}\text { Current policies for existing } \\
\text { hybrid are extended to PHEV }\end{array}$} \\
\hline \multicolumn{4}{|c|}{$\begin{array}{r}\text { Supply/Infrastructure Off-peak infrastructure meet } \\
\qquad 73 \% \text { of demand by U.S. LDV }\end{array}$} \\
\hline & $\begin{array}{l}\text { Year of th } \\
\text { Type of ve }\end{array}$ & $\begin{array}{l}\text { s: } 2008 \\
\text { onsidered: PHE }\end{array}$ & \\
\hline
\end{tabular}

Table 43: Detailed assumptions for "Electric Cars: Plugged In" by Deutsche Bank

Electric Cars: Plugged In (Deutsche Bank)

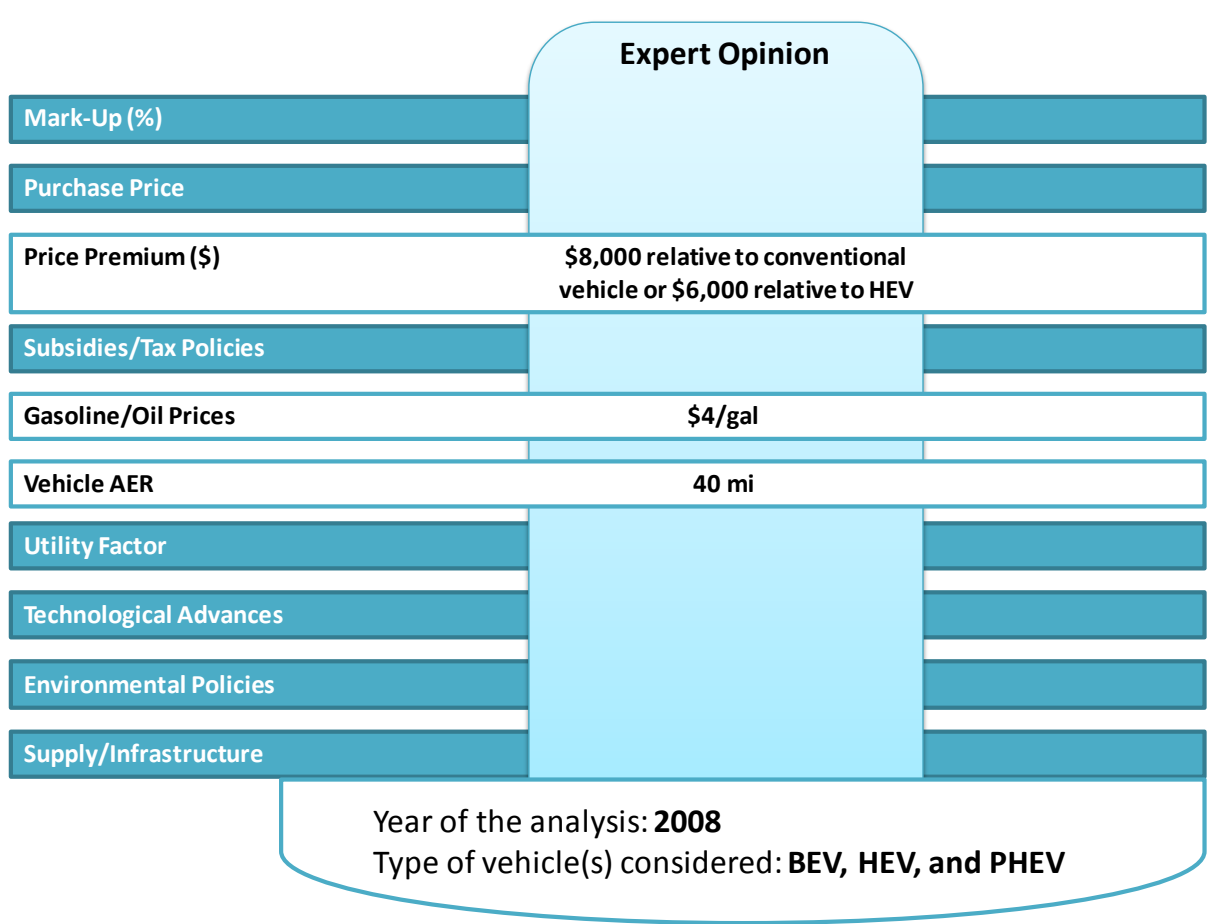


Table 44 : Detailed assumptions for "PHEV Market Introduction Study" by SENTECH/ORNL

PHEV Market Introduction Study (SENTECH/ORNL)

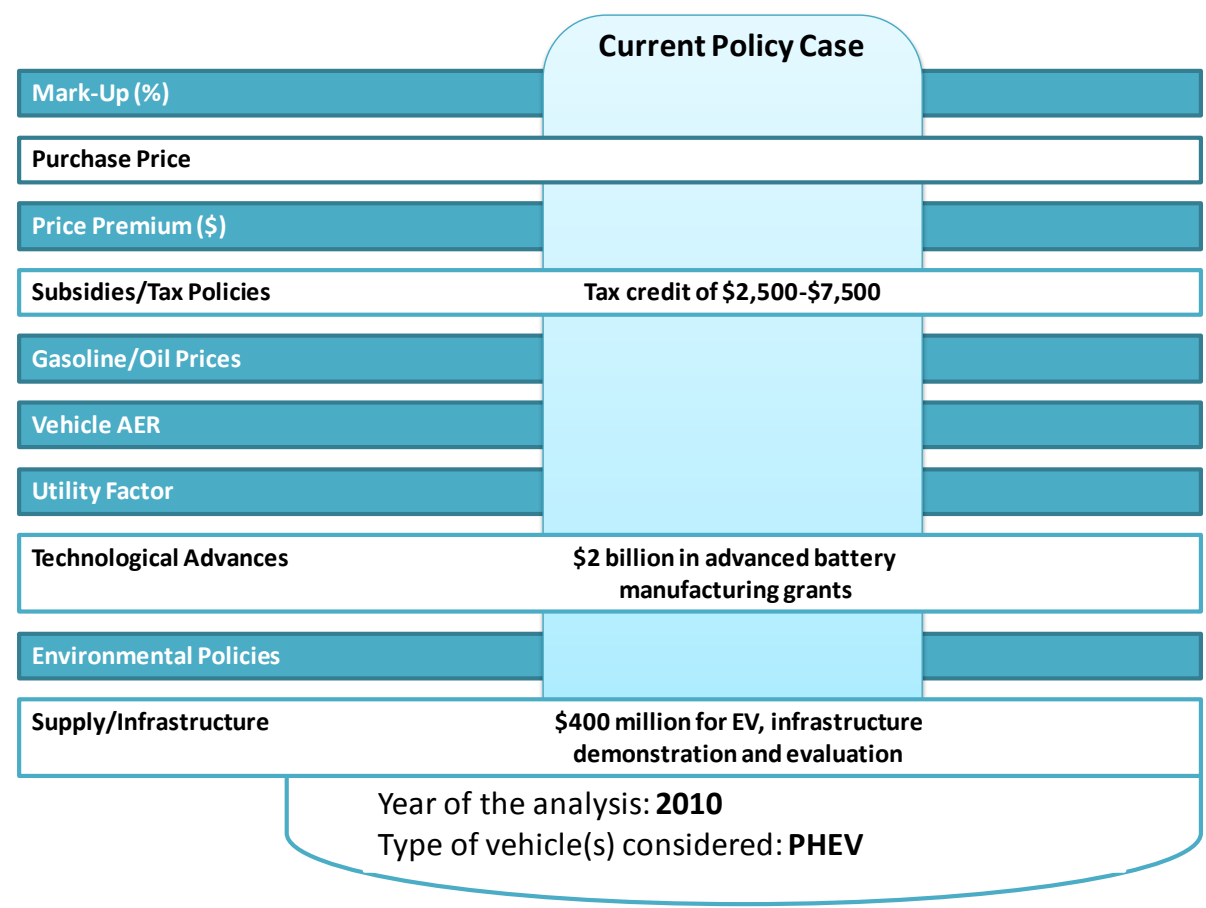

Table 45 : Detailed assumptions for "Prospects for Plug-in Hybrid Electric Vehicles in the United States and Japan: A General Equilibrium Analysis" by MIT (1 of 2 sets)

Prospects for Plug-in Hybrid Electric Vehicles in the United States and Japan: A General Equilibrium Analysis 1 of 2 (MIT)

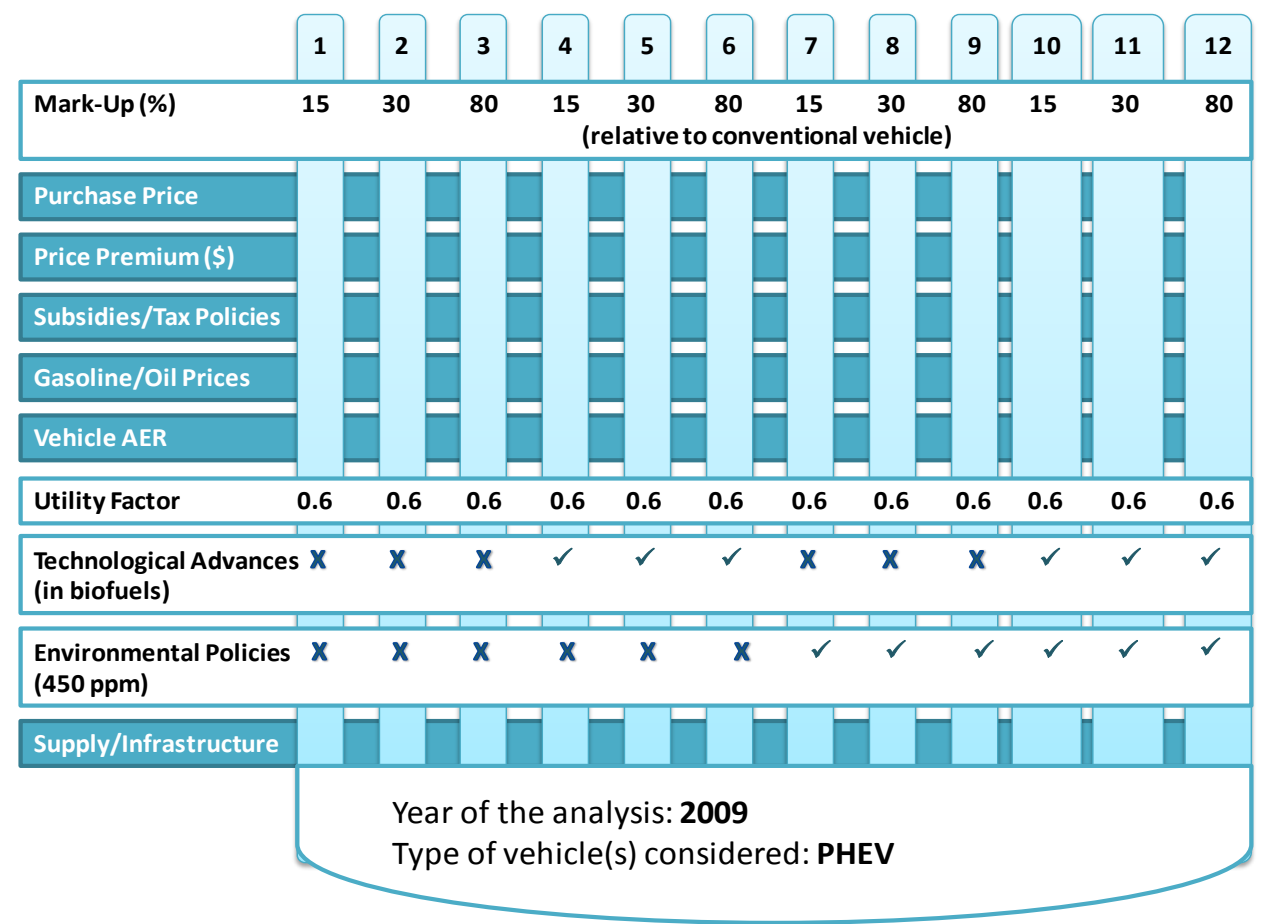


Table 46: Detailed assumptions for "Prospects for Plug-in Hybrid Electric Vehicles in the United States and Japan: A General Equilibrium Analysis" by MIT (2 of 2 sets)

Prospects for Plug-in Hybrid Electric Vehicles in the United States and Japan: A General Equilibrium Analysis 2 of 2 (MIT)

\begin{tabular}{|c|c|c|c|c|c|c|c|c|c|c|c|c|}
\hline & 13 & 14 & 15 & 16 & 17 & 18 & 19 & 20 & 21 & 22 & 23 & 24 \\
\hline \multirow[t]{2}{*}{ Mark-Up (\%) } & 30 & 30 & 30 & 30 & 30 & 30 & 30 & 30 & 30 & 30 & 30 & 30 \\
\hline & \multicolumn{12}{|c|}{ (relative to conventional vehicle) } \\
\hline \multicolumn{13}{|l|}{ Purchase Price } \\
\hline \multicolumn{13}{|l|}{ Price Premium (\$) } \\
\hline \multicolumn{13}{|l|}{ Subsidies/Tax Policies } \\
\hline \multicolumn{13}{|l|}{ Gasoline/Oil Prices } \\
\hline \multicolumn{13}{|l|}{ Vehicle AER } \\
\hline \multirow[t]{2}{*}{ Utility Factor } & 0.8 & 0.6 & 0.3 & 0.8 & 0.6 & 0.3 & 0.8 & 0.6 & 0.3 & 0.8 & 0.6 & 0.3 \\
\hline & & & & & & & & & & & & \\
\hline \multicolumn{2}{|c|}{$\begin{array}{l}\text { Technological Advances } \mathrm{X} \\
\text { (in biofuels) }\end{array}$} & $x$ & $x$ & $\checkmark$ & $\checkmark$ & $\checkmark$ & $x$ & $x$ & $x$ & $\checkmark$ & $\checkmark$ & $\checkmark$ \\
\hline $\begin{array}{l}\text { Environmental Policies } \\
\text { (450 ppm) }\end{array}$ & $x$ & $x$ & $\mathbf{x}$ & $x$ & $\mathbf{x}$ & $\mathbf{x}$ & $\checkmark$ & $\checkmark$ & $\checkmark$ & $\checkmark$ & $\checkmark$ & $\checkmark$ \\
\hline \multicolumn{13}{|l|}{ Supply/Infrastructure } \\
\hline \multicolumn{13}{|c|}{ Year of the analysis: 2009} \\
\hline & & & & & & & & & & & & \\
\hline
\end{tabular}

Table 47: Detailed assumptions for "Multi-Path Transportation Futures Study: Vehicle Characterization and Scenario Analyses" by ANL

Multi-Path Transportation Futures Study: Vehicle Characterization and Scenario Analyses (ANL)

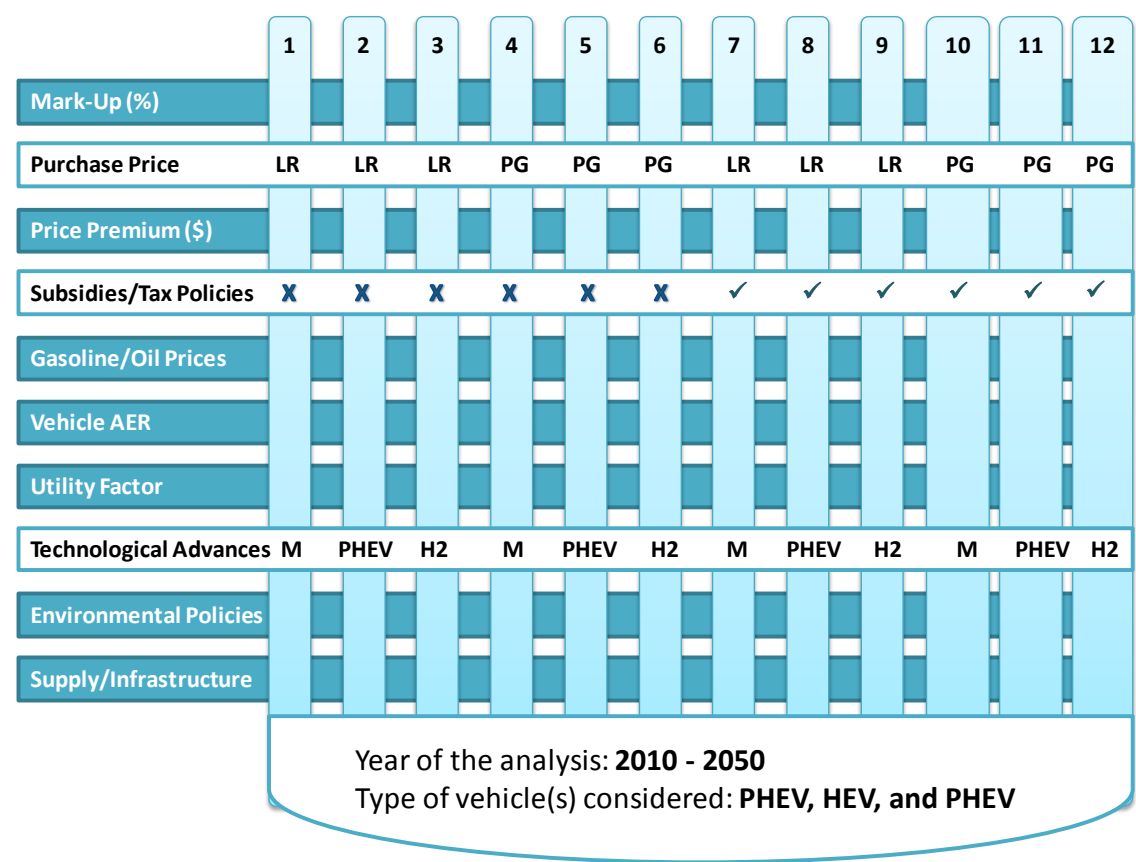




\subsection{Annual Market Penetration Rates - Trends among Studies}

In this section, annual market penetration data extracted from the fifteen studies on electric vehicle technologies. The project team is attempting to investigate potential trends across the data points. PHEV annual market penetration will be the focus of this section but annual market penetration of HEVs and BEVs will also be discussed where relevant.

\subsubsection{PHEV Annual Market Penetration Scenarios}

Figure 25 shows a comprehensive look at all annual market penetration scenarios for PHEVs in the 15 studies mentioned earlier, as well as from other expert opinions. The figure covers the timeframe starting in 2010 and ending in 2050, and data from the studies present a wide range of annual market penetration values for most of these years. Most notable, in 2050, the annual market penetration for PHEVs ranges from $0 \%$ to $90 \%$. This variation could mostly be explained by the different assumptions used in the broad range of scenarios and the simulation models used. As previously mentioned, it is important to note that many of those scenarios do not necessarily reflect the opinions of researchers about what will actually happen in the future. Rather, they include a set of sensitivity analyses in an attempt to test various possibilities that could occur in the future.

As previously mentioned, studies with three scenarios for possible PHEV annual market penetration are referred to as high, medium, and low scenarios in this figure to simplify the comparison for the reader. Studies with more than three scenarios are classified by numbering the scenarios in the order presented in that study. More detailed information on the references for the specific assumptions supporting each scenario can be found in the assumptions section 4.1 .

In an attempt to investigate possible trends across scenarios presented in Figure 25, the project team connected the data points for each scenario when possible. Figure 26 is the result of connecting free standing data points in Figure 25 throughout the timeline analyzed. The purpose of connecting the data points in this comparative study is to more easily identify shapes/directions of scenarios by creating trend lines rather than relying on limited data points. In most cases, organizations clearly state the penetration rates in their respective studies; however, in other cases, the exact data points are not provided so data is oftentimes retrieved from available figures, and connecting the data points allows holes to be filled. The overall shapes of the trend lines after connecting the data points are relatively similar to the respective report's published charts. It is interesting to note that most of the scenarios reflect an upward moving trend but with very different coefficients. 
PHEV Annual Market Penetration Scenarios Spanning 2012 - 2050

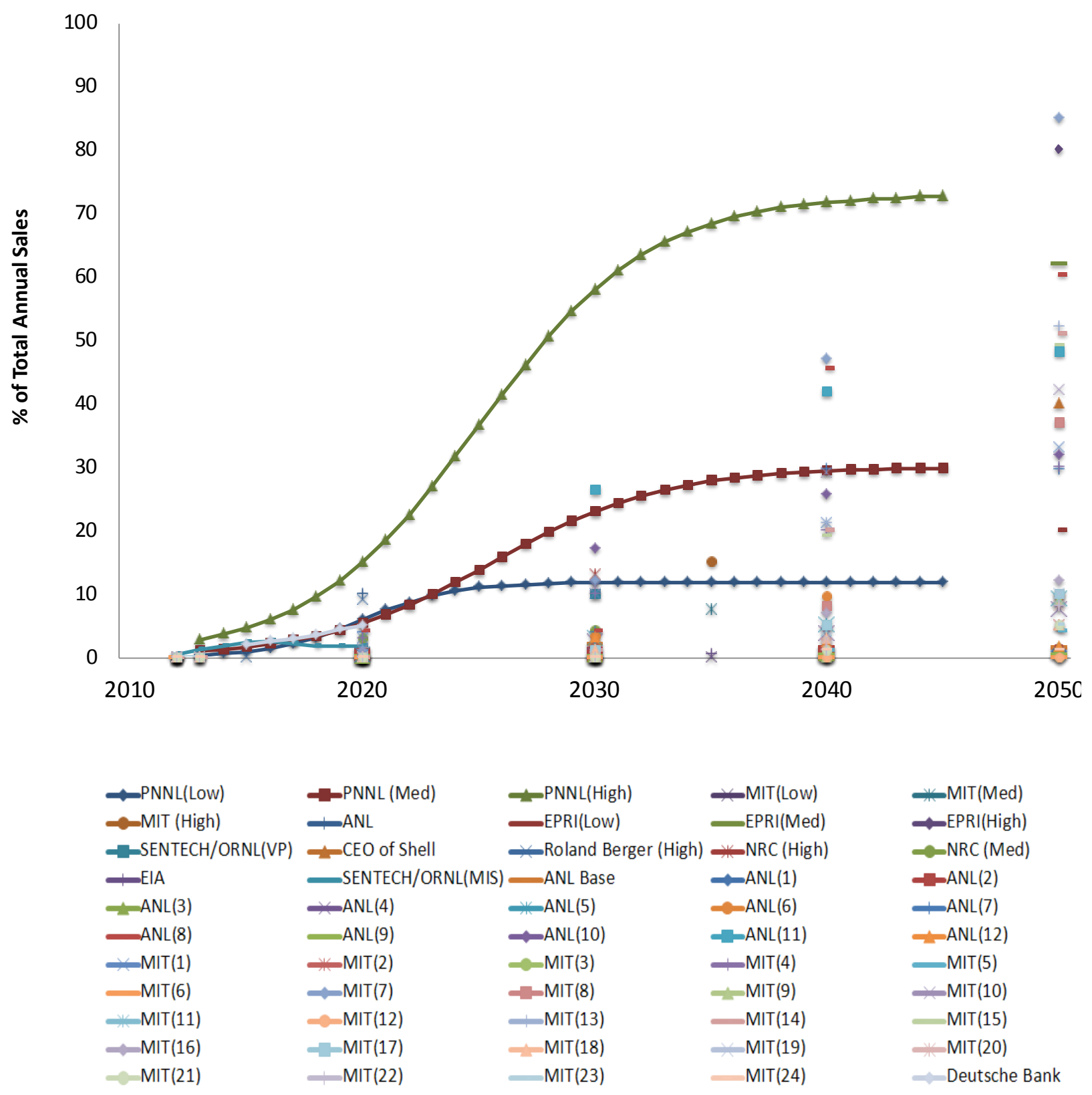

Figure 25: PHEV annual market penetration scenarios $2012-2050$ by percentage of total annual sales 
PHEV Annual Market Penetration Scenarios Spanning 2012 - 2050

(After Connecting the Datapoints)

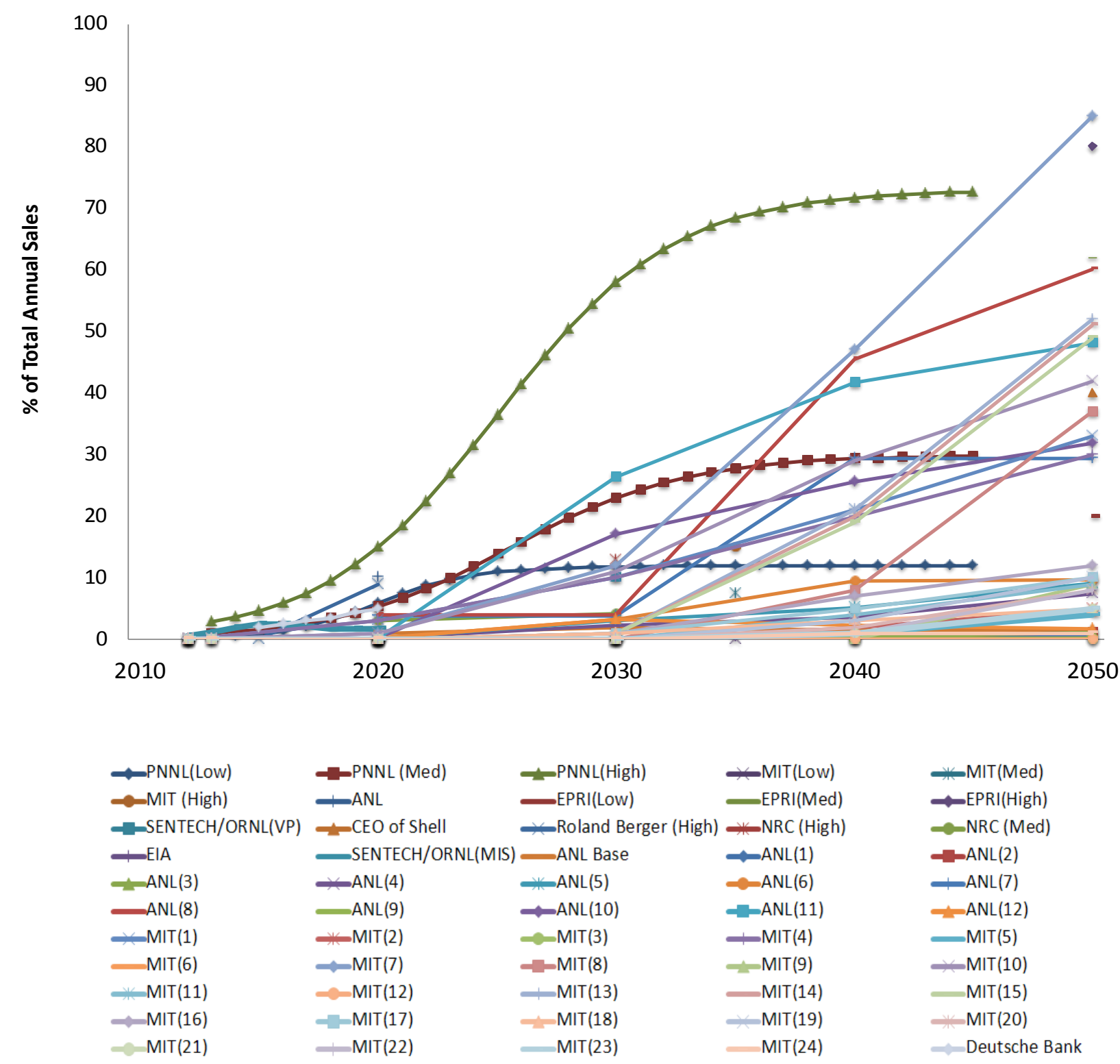

Figure 26: PHEV annual market penetration scenarios spanning 2012 - 2050 (after connecting the single data points within the same study)

Figure 27 shows PHEV sales in terms of thousands of units, rather than percentage of annual sales presented in Figures 25 and 26 . The project team generated the values for PHEV unit sales based on the annual sales forecasts for LDVs in the U.S. market from 2012 to 2050 presented in Appendix A. This data is generated by ORNL's MA ${ }^{3} T$ model. Data from additional studies and expert opinions that only show penetration values in terms of unit sales (not percentages) are documented here. 
PHEV Annual Market Penetration Scenarios Spanning 2012 - 2050

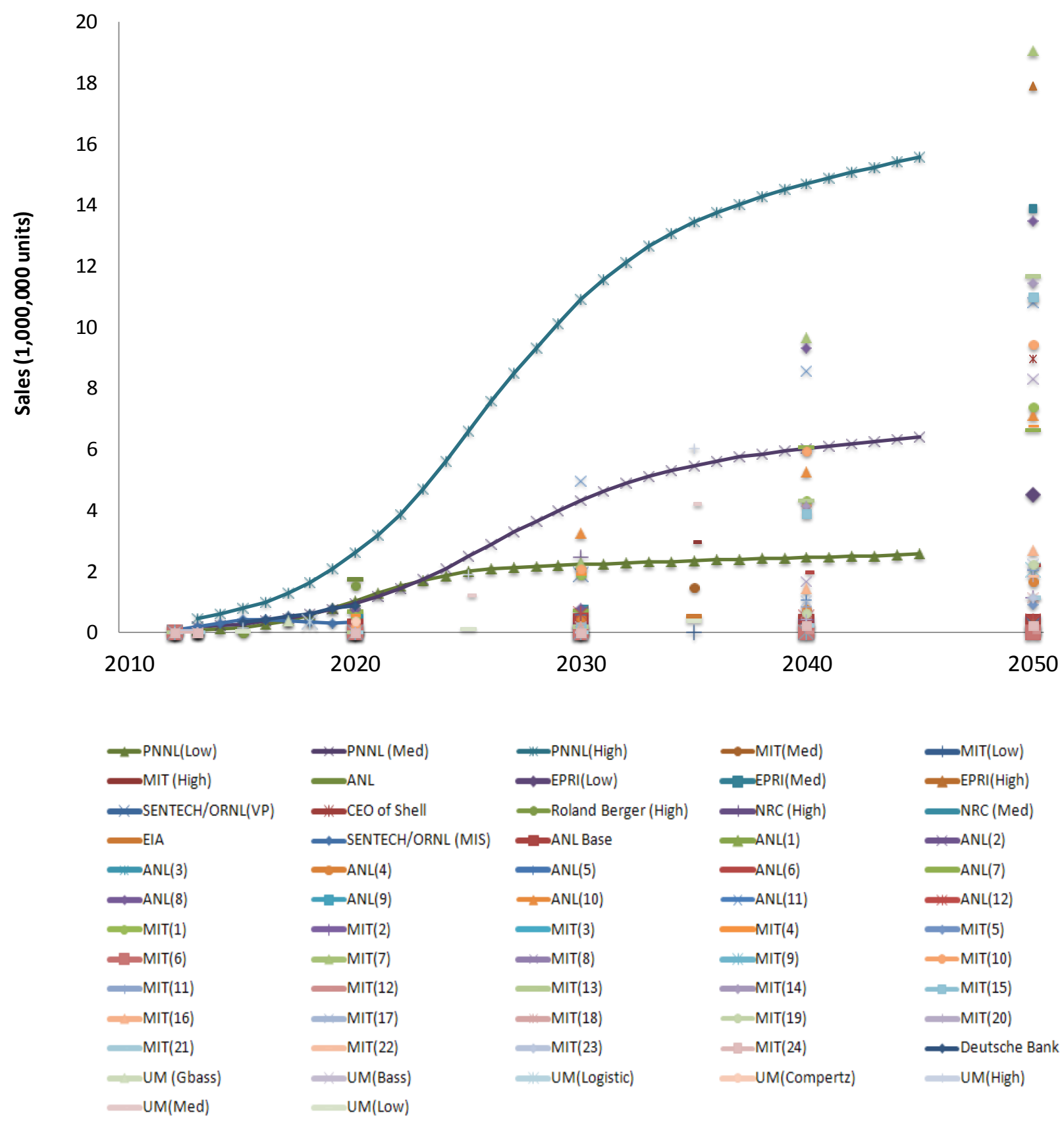

Figure 27: PHEV annual market penetration rates from 2012 - 2050 in terms of unit sales 


\subsubsection{Concentration of PHEV Annual Market Penetration Projections in 2050}

Figure 28 shows that, in $2050,65 \%$ of the data points collected in this comparative study suggest that PHEV annual market penetration will fall between $0 \%$ and $20 \%$. Twenty percent of the data points for 2050 suggest that PHEV annual market penetration will fall between $21 \%$ and $50 \%$. The remaining $15 \%$ of the data points suggest that PHEV annual market penetration will exceed $50 \%$ of sales. Again, it is important to note that many of the data points are the result of sensitivity analyses rather than actual forecasts, leading to high variability in projections. However, the level of concentration within each bubble may be considered representative of what most organizations expect the PHEV industry to look like in 2050.

\section{PHEV Annual Market Penetration Scenarios for 2050 and the Corresponding Concentration of Scenarios}

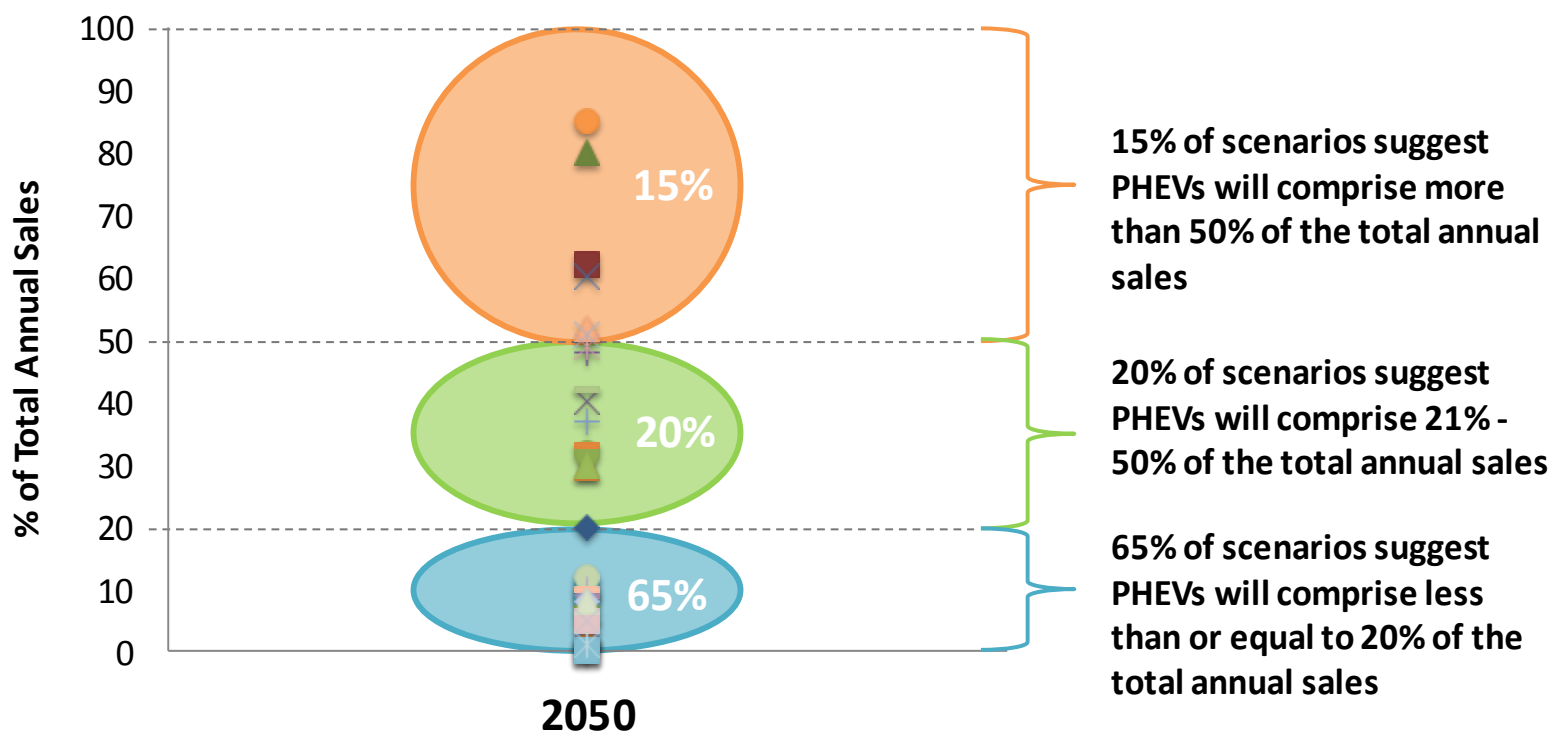

\begin{tabular}{|c|c|c|c|c|c|}
\hline -EPRI(Low) & EPRI(Med) & $\Rightarrow$ EPRI(High) & $\leadsto$ CEO of Shell & ANL Base & $-A N L(1)$ \\
\hline$\Longrightarrow$ ANL(2) & $=\mathrm{ANL}(3)$ & $\Longrightarrow \mathrm{ANL}(4)$ & $\rightarrow$ ANL(5) & $\Rightarrow A N L(6)$ & $\because A N L(7)$ \\
\hline$\because A N L(8)$ & ANL(9) & $\rightarrow$ ANL(10) & ANL(11) & $=\mathrm{ANL}(12)$ & $\longrightarrow \mathrm{MIT}(1)$ \\
\hline$\sim \mathrm{MIT}(2)$ & $\Rightarrow \mathrm{MIT}(3)$ & $\simeq \mathrm{MIT}(4)$ & 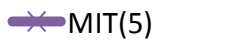 & 舟MIT(6) & MIT(7) \\
\hline $\mathrm{MIT}(8)$ & $=\mathrm{MIT}(9)$ & $=\mathrm{MIT}(10)$ & $\sim \mathrm{MIT}(11)$ & $=\operatorname{MIT}(12)$ & $=\mathrm{MIT}(13)$ \\
\hline$\because M I T(14)$ & MIT(15) & $-M I T(16)$ & $\mathrm{MIT}(17)$ & $M I T(18)$ & $\mathrm{MIT}(19)$ \\
\hline$\Rightarrow \mathrm{MIT}(20)$ & $\Rightarrow \mathrm{MIT}(21)$ & MIT(22) & $\because \mathrm{MIT}(23)$ & MIT(24) & \\
\hline
\end{tabular}

Figure 28: PHEV annual market penetration scenarios for 2050 and the concentration of scenarios 


\subsubsection{Drivers for Most Aggressive and Most Conservative Scenarios in 2050}

Most Aggressive Scenarios: As previously suggested, the range for PHEV annual market penetration as of 2050 is very diverse, ranging from $0 \%$ to nearly $90 \%$ of annual sales. To better understand the cause of the most aggressive rates, the seven scenarios that result in PHEV annual market penetration higher than $45 \%$ in 2050 are specifically examined. The ANL report "Multi-Path Transportation Future Study: Vehicle Characterization and Scenario Analyses" has two scenarios that are perceived as aggressive, and the MIT report "Prospects for Plug-In Electric Hybrid Vehicles in the United States and Japan: A General Equilibrium Analysis" has five scenarios that are considered aggressive. Others reports include "very aggressive" scenarios but did not provide enough depth for the assumptions to be analyzed in this section.

Table 48 shows the assumptions supporting the most aggressive scenarios as of 2050. It suggests that for PHEV annual market penetration to exceed $45 \%$ in 2050, PHEV prices will need to drop considerably. In addition, improved vehicle performance and enhanced vehicle AER will greatly support the PHEV annual market penetration leading up to this year. Finally, presence of a carbon constraint policy and absence of an alternative green technology could enhance the PHEV annual market penetration, but it is not essential for the PHEVs to flourish. It is important to note that the list of assumptions in Table 48 is interdependent. In other words, one assumption may substitute for another assumption and still ensure high PHEV annual market penetration. For example, if the PHEV price is still considerably more expensive than a conventional vehicle but the PHEV's performance is tremendously improved, then PHEVs could still realize an aggressive forecasted penetration rate through 2050.

Table 48: Assumptions supporting the highest PHEV penetration scenarios as of 2050

Assumptions Supporting the Highest Penetration Scenarios as of $\mathbf{2 0 5 0}$

\begin{tabular}{|c|c|c|c|}
\hline anort (Scenarin) & VEHICLE ECONOMICS & VEHICLE PERFORMANCE & OTHER PUSH FACTORS \\
\hline $\begin{array}{l}\text { Multi-Path Transportation Futures } \\
\text { Study: Vehicle Characterization and } \\
\text { Scenario Analyses (ANL8) }\end{array}$ & $\begin{array}{l}\text { - } \quad \text { LR prices } \\
\text { - } \quad \text { Subsidies }\end{array}$ & $\begin{array}{l}\text { Mixed technological } \\
\text { advances }\end{array}$ & - $\mathbf{N} / \mathbf{A}$ \\
\hline $\begin{array}{l}\text { Multi-Path Transportation Futures } \\
\text { Study: Vehicle Characterization and } \\
\text { Scenario Analyses (ANL 11) }\end{array}$ & $\begin{array}{l}\text { - } \text { PG prices } \\
\text { - Subsidies }\end{array}$ & $\begin{array}{l}\text { PHEV technological } \\
\text { advances }\end{array}$ & - N/A \\
\hline $\begin{array}{l}\text { Prospects for Plug-in Hybrid Electric } \\
\text { Vehicles in the United States and Japan: } \\
\text { A General Equilibrium Analysis (MIT 7) }\end{array}$ & $\begin{array}{l}15 \% \text { markup relative } \\
\text { to conventional } \\
\text { vehicles }\end{array}$ & - Utility Factor of 0.6 & $\begin{array}{l}\text { - No biofuels } \\
\text { - Carbon constraints } \\
\text { Policy }\end{array}$ \\
\hline $\begin{array}{l}\text { Prospects for Plug-in Hybrid Electric } \\
\text { Vehicles in the United States and Japan: } \\
\text { A General Equilibrium Analysis (MIT 10) }\end{array}$ & $\begin{array}{l}15 \% \text { markup relative } \\
\text { to conventional } \\
\text { vehicles }\end{array}$ & - Utility Factor of 0.6 & $\begin{array}{l}\text { - Biofuels } \\
\text { - Carbon constraints } \\
\text { policy }\end{array}$ \\
\hline $\begin{array}{l}\text { Prospects for Plug-in Hybrid Electric } \\
\text { Vehicles in the United States and Japan: } \\
\text { A General Equilibrium Analysis (MIT 13) }\end{array}$ & $\begin{array}{l}\text { - } 30 \% \text { markup relative } \\
\text { to conventional } \\
\text { vehicles }\end{array}$ & - Utility Factor of 0.8 & $\begin{array}{l}\text { - No biofuels } \\
\text { - No carbon } \\
\text { constraints policy }\end{array}$ \\
\hline $\begin{array}{l}\text { Prospects for Plug-in Hybrid Electric } \\
\text { Vehicles in the United States and Japan: } \\
\text { A General Equilibrium Analysis (MIT 14) }\end{array}$ & $\begin{array}{l}30 \% \text { markup relative } \\
\text { to conventional } \\
\text { vehicles }\end{array}$ & - Utility Factor of 0.6 & $\begin{array}{l}\text { - No biofuels } \\
\text { constraints policy }\end{array}$ \\
\hline $\begin{array}{l}\text { Prospects for Plug-in Hybrid Electric } \\
\text { Vehicles in the United States and Japan: } \\
\text { A General Equilibrium Analysis (MIT 15) }\end{array}$ & $\begin{array}{l}\text { - } 30 \% \text { markup relative } \\
\text { to conventional } \\
\text { vehicles }\end{array}$ & Utility Factor of 0.3 & $\begin{array}{l}\text { - No biofuels } \\
\text { - No carbon } \\
\text { constraints policy }\end{array}$ \\
\hline
\end{tabular}


Least Aggressive Scenarios: To provide a better understanding the most conservative scenarios and the assumptions supporting those scenarios, nine conservative scenarios that result in PHEV annual market penetration lower than 5\% in 2050 are reviewed below. ANL's report entitled "Multi-Path Transportation Future Study: Vehicle Characterization and Scenario Analyses" has five scenarios that are perceived as conservative, and the MIT report "Prospects for Plug-In Electric Hybrid Vehicles in the United States and Japan: A General Equilibrium Analysis" has four scenarios that are considered aggressive.

Figure 34 shows the assumptions supporting these more conservative scenarios as of 2050 . It suggests that for the PHEV annual market penetration to maintain a market penetration of $5 \%$ or less in 2050 , PHEV prices will need to be considerably higher than other competing vehicles. It is interesting to note that the various ANL scenarios that are considered conservative have different assumptions relative to their technological advances and their fuel prices, but most of the ANL conservative scenarios share common "LR" price, which do not meet the vehicle prices suggested by the DOE program goals. This may support the theory that consumers opt for immediate savings in the vehicle prices rather than deferred future savings in the fuel prices. Relatively moderate vehicle prices can also push the PHEV market penetration as low as $5 \%$, which is demonstrated in two conservative scenarios: MIT24 and ANL 12. Although both scenarios suggest moderate vehicle prices, there are other market conditions such as the availability of a competing green technology or a low performing vehicle that contribute to a low PHEV market penetration ratio.

Table 49: Assumptions supporting the lowest PHEV penetration scenarios of 2050

Assumptions for the Lowest Penetration Scenarios as of 2050

\begin{tabular}{|c|c|c|c|}
\hline \multirow[b]{2}{*}{ Report (Scenario) } & \\
\hline & VEHICLE ECONOMICS & VEHICLE PERFORMANCE & OTHER PUSH FACTORS \\
\hline $\begin{array}{l}\text { Multi-Path Transportation Futures Study: Vehicle } \\
\text { Characterization and Scenario Analyses (ANL1) }\end{array}$ & $\begin{array}{l}\text { - LR prices } \\
\text { - No subsidies }\end{array}$ & $\begin{array}{l}\text { - } \mathrm{H}_{2} \text { Technological } \\
\text { Advances }\end{array}$ & - N/A \\
\hline $\begin{array}{l}\text { Multi-Path Transportation Futures Study: Vehicle } \\
\text { Characterization and Scenario Analyses (ANL 2) }\end{array}$ & $\begin{array}{l}\text { - LR prices } \\
\text { - No subsidies }\end{array}$ & $\begin{array}{l}\text { - PHEV Technological } \\
\text { Advances }\end{array}$ & - N/A \\
\hline $\begin{array}{l}\text { Multi-Path Transportation Futures Study: Vehicle } \\
\text { Characterization and Scenario Analyses (ANL3) }\end{array}$ & $\begin{array}{l}\text { - LR prices } \\
\text { - No subsidies }\end{array}$ & $\begin{array}{l}\mathrm{H}_{2} \text { Technological } \\
\text { Advances }\end{array}$ & - N/A \\
\hline $\begin{array}{l}\text { Multi-Path Transportation Futures Study: Vehicle } \\
\text { Characterization and Scenario Analyses (ANL 9) }\end{array}$ & $\begin{array}{l}\text { - LR prices } \\
\text { - No subsidies }\end{array}$ & $\begin{array}{l}\text { - } \mathrm{H}_{2} \text { Technological } \\
\text { Advances }\end{array}$ & N/A \\
\hline $\begin{array}{l}\text { Multi-Path Transportation Futures Study: Vehicle } \\
\text { Characterization and Scenario Analyses (ANL11) }\end{array}$ & $\begin{array}{l}\text { - PG prices } \\
\text { - Subsidies }\end{array}$ & $\begin{array}{l}\text { - } \mathrm{H}_{2} \text { Technological } \\
\text { Advances }\end{array}$ & N/A \\
\hline $\begin{array}{l}\text { Prospects for Plug-in Hybrid Electric Vehicles in } \\
\text { the United States and Japan: A General } \\
\text { Equilibrium Analysis (MIT 10) }\end{array}$ & $\begin{array}{l}\text { - } 80 \% \text { markup relative } \\
\text { to conventional } \\
\text { vehicle }\end{array}$ & - Utility Factor of 0.6 & $\begin{array}{l}\text { - No biofuels } \\
\text { - No carbon } \\
\text { constraints policy }\end{array}$ \\
\hline $\begin{array}{l}\text { Prospects for Plug-in Hybrid Electric Vehicles in } \\
\text { the United States and Japan: A General } \\
\text { Equilibrium Analysis (MIT 13) }\end{array}$ & $\begin{array}{l}\text { - } 80 \% \text { markup relative } \\
\text { to conventional } \\
\text { vehicle }\end{array}$ & Utility Factor of 0.6 & $\begin{array}{l}\text { - Biofuels } \\
\text { - No carbon } \\
\text { constraints policy }\end{array}$ \\
\hline $\begin{array}{l}\text { Prospects for Plug-in Hybrid Electric Vehicles in } \\
\text { the United States and Japan: A General } \\
\text { Equilibrium Analysis (MIT 14) }\end{array}$ & $\begin{array}{l}80 \% \text { markup relative } \\
\text { to conventional } \\
\text { vehicle }\end{array}$ & Utility Factor of 0.6 & $\begin{array}{l}\text { - Biofuels } \\
\text { Carbon constraints } \\
\text { policy }\end{array}$ \\
\hline $\begin{array}{l}\text { Prospects for Plug-in Hybrid Electric Vehicles in } \\
\text { the United States and Japan: A General } \\
\text { Equilibrium Analysis (MIT 15) }\end{array}$ & $\begin{array}{l}\text { - } 30 \% \text { markup relative } \\
\text { to conventional } \\
\text { vehicle }\end{array}$ & - Utility Factor of 0.3 & $\begin{array}{l}\text { Biofuels } \\
\text { - Carbon constraints } \\
\text { policy }\end{array}$ \\
\hline
\end{tabular}




\subsubsection{Timeline Analysis for PHEV Annual Market Penetration Studies}

General Timeline Analysis: The 15 studies reviewed in the PHEV annual market penetration chapter were published between 2007 and 2010. The timing of the papers' publication could have had an impact on the PHEV annual market penetration scenarios due to economic conditions, OEM production plan announcements, etc. This section will analyze if in fact the timing of publication appeared to have an impact on the PHEV annual market penetration scenarios. Figure 29 shows PHEV annual market penetration forecasts for papers written in 2007, 2008, 2009, and 2010. In 2007, only the EPRI/NRDC report was issued so only one data source is provided. Starting in 2008, multiple reports on PHEV annual market penetration forecast were published annually. To date, the most studies related to PHEV annual market penetration rates were published in 2009. Finally, 2010 represents a few report publications as well, but the data captured is limited and only extended through 2030.
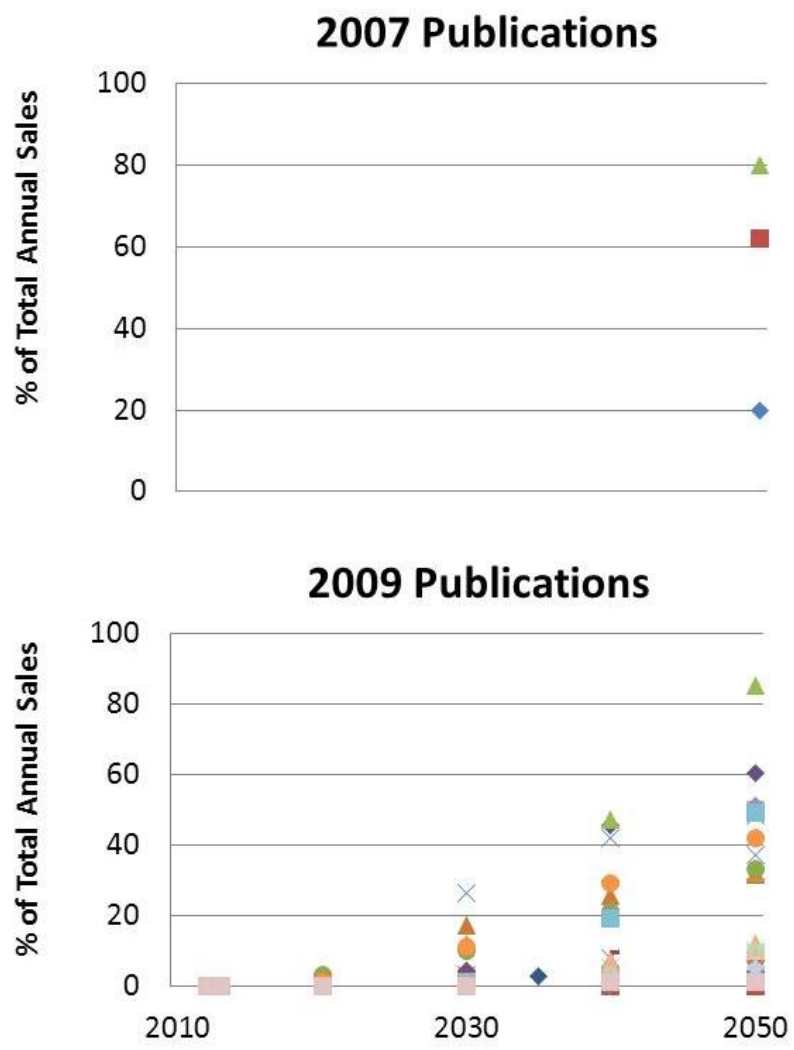

2008 Publications

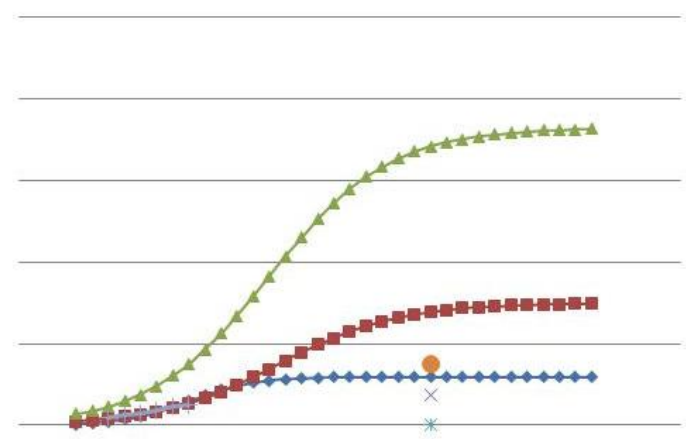

2010 Publications

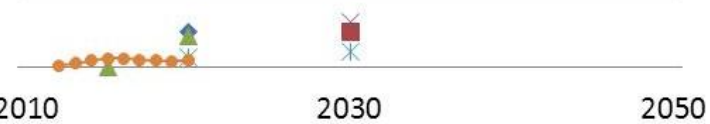

Figure 29: Timeline of publications of PHEV annual market penetration studies

When comparing the four charts chronologically from 2007 to 2010 , it is noticeable that the most aggressive single PHEV annual market penetration scenario was introduced in 2009. However, the possibility of low penetration through 2050 was mentioned frequently in the same year 2009. This is most likely due to the large number of data points relative to the other three years and the high frequency of sensitivity analyses that were published in 2009 , resulting in large variability between PHEV annual market penetration forecasts. 
Deriving Trends by Analyzing Publication Years: In an attempt to compare potential trends that emerge in different publication years, the project team averaged the annual market penetration data points for every publication year and derived yearly trends for 2008, 2009, and 2010 data points. For 2007, no other data points are provided besides $2050 \mathrm{so}$ a trend line could not be drawn. For the other years, the project team chose to derive a polynomial trend line since it had the highest $R$-square value. Accordingly, the polynomial trend fit the behavior of the curves best. Figure 30 shows these polynomial trend lines for these years. Although the time series examined is not long enough for the project team to be conclusive, Figure 30 suggests that 2007 had the most aggressive average annual market penetration scenario, followed by 2008 and 2010. The most conservative trend line is seen in 2009, which again might be due to the large number of conservative data points, forcing the trend line downward.

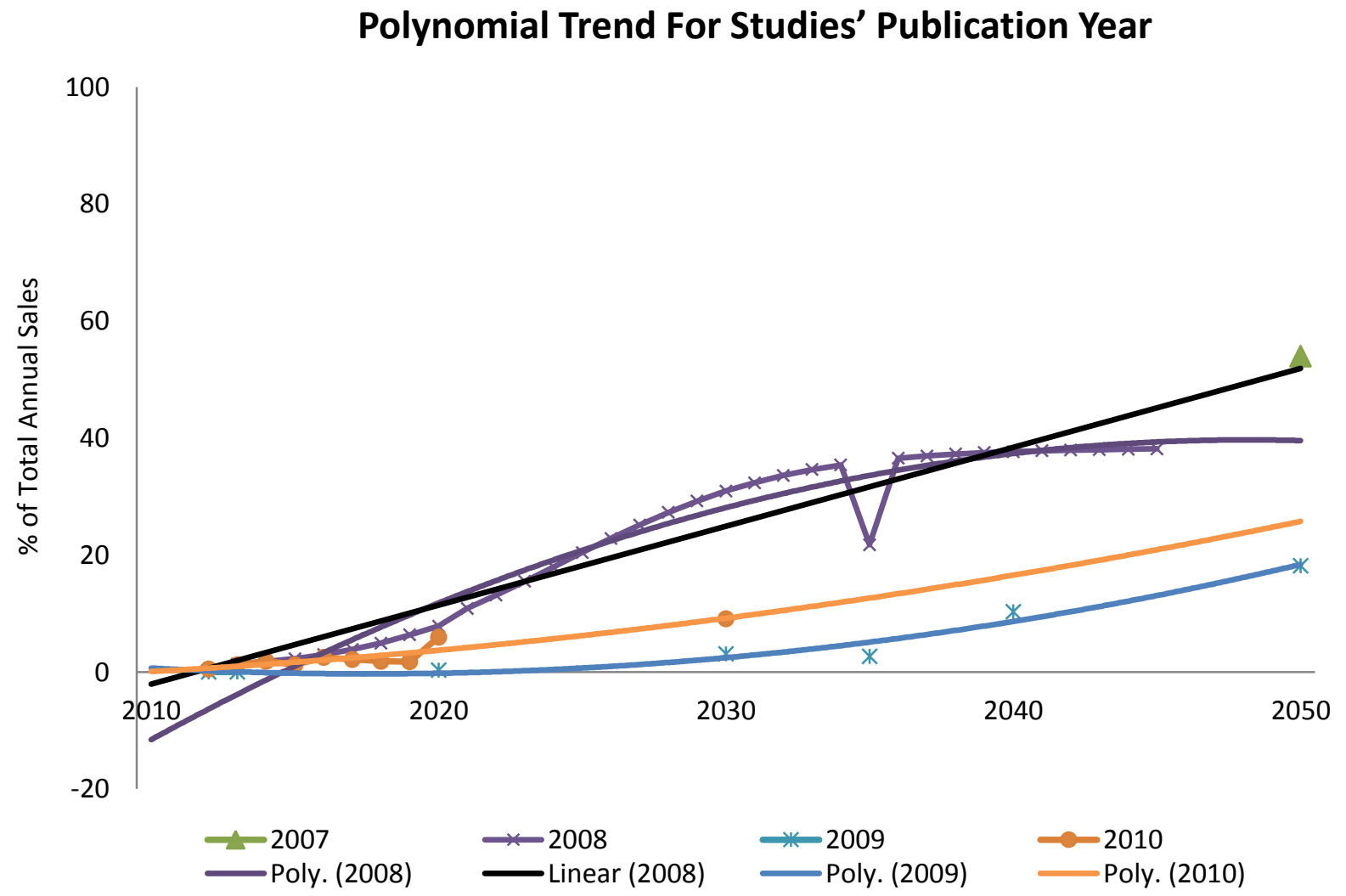

Figure 30: Polynomial trend for studies' publication year

From Figure 30, it appears that a general downward trend exists across the timeline of the publication of the studies, which may suggest that average PHEV annual market penetration scenarios are becoming more conservative with time. An exception to this pattern is seen in 2010 since the annual market penetration calculated using the average of all reports published in 2010 is higher than the average of all reports published in 2009. However, when analyzing Figure 30, it is important to note that averaging the data points might have hidden some of the PHEV annual market penetration traits such as range, frequency, etc. Overall, the project team agrees that not enough data is available to judge conclusively on this issue. 


\subsubsection{Methods Used to Derive Annual Market Penetration Rates}

The methods used by organizations to derive annual PHEV market penetration rates may have a significant effect on their studies' outcomes. The 15 studies reviewed in this chapter of the comparative study are listed in Table 50 together with the methods that each organization used to derive their annual market penetration data points. Most of the studies use simulation models to generate their PHEV annual market penetration data. Only a few studies either assumed a specific annual market penetration value or relied on expert opinion (e.g., Delphi method) to generate their PHEV annual market penetration estimates.

\section{Table 50: PHEV annual market penetration studies and simulation models}

\section{Name of Study}

1. On The Road in 2035

2. Prospects for Plug-in Hybrid Electric

Vehicles in the United States and Japan: A MIT General Equilibrium Analysis

3. Multi-Path Transportation Futures Study: Vehicle Characterization and Scenario Analyses

4. PHEV Market Introduction Study

5. Plug-In Hybrid Electric Vehicle Market Penetration Scenarios

6. Electrification Roadmap "Revolutionizing Transportation and Achieving Energy Security"

7. Environmental Assessment of Plug-In Hybrid Electric Vehicles: Volume 1

8. Annual Energy Outlook 2010

9. Transitions to Alternative Transportation Technologies-Plug-In Hybrid Electric Vehicles

10. Powertrain 2020 Li-lon Batteries - The next bubble ahead?

11. Gaining traction: A customer view of electric vehicle mass adoption in the U.S automotive market

12. Electric Cars: Plugged In

13. The Comeback of the Electric Car?

14. Market Models for Predicting PHEV Adoption and Diffusion

15. Drive Green 2020: More Hope than Reality?

MIT

ANL

EIA

BCG

\section{Author}

NEMS

SENTECH/ORNL MA3T/ VAMMP

PNNL

- Consumer Choice Model

$>$ Delphi Analysis/Expert Opinion

Electrification

Coalition

Roadmap/Objective

\begin{tabular}{l|l} 
EPRI/NRDC Unidentified &
\end{tabular}

NEMS

National

Research Council

Model used for the 2008 Hydrogen Report

Roland Berger

Unidentified

Deloitte

Deloitte's Demand Driven Analytics Methodology

Deutsche Bank

Expert Opinion

BCG Propulsion-Market Model

UMTRI

Consideration Purchase Model

JD Power and

Associates
Unidentified 


\subsubsection{BEV and HEV Annual Market Penetration}

Although the focus of this chapter is to review PHEV annual market penetration projections, the project team often came across valuable data points for HEV and BEV annual market penetration projections and determined that examining HEV and BEV annual market penetration would add value to the overall comparative study. The highlights for HEV and BEV annual market penetration projections are presented here.

HEV Annual Market Penetration. The annual market penetration rates for HEVs are often mentioned in studies reviewed by the project team. Figure 31 compiles this annual market penetration data for HEVs collected for 2012 to 2050 . The majority of HEV forecasts range between $10 \%$ and $50 \%$ starting in 2020 , and remain consistent through 2050. The data suggest that the studies are in relative agreement that HEV technology will at least maintain a 10\% market penetration between 2020 and 2050.

HEV Annual Market Penetration Scenarios Spanning 2012 - 2050

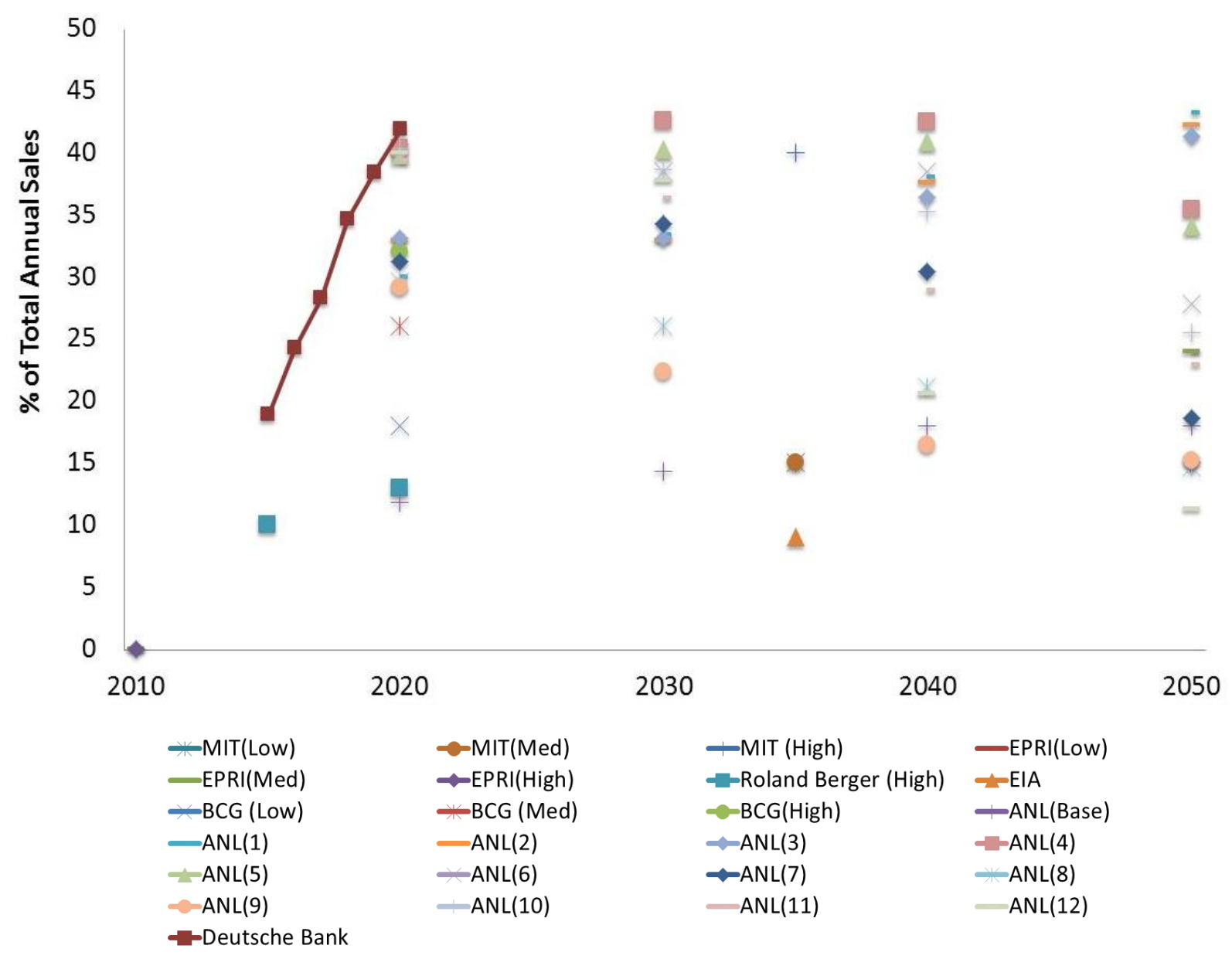

Figure 31: HEV annual market penetration projections from 2012 to 2050 
Nonetheless, the studies are not in an agreement in terms of the future prospects of HEVs' annual market penetration across the timeline analyzed. Figure 32 shows the same HEV annual market penetration scenarios as in Figure 31 after connecting the multiple data points within each scenario. Now it becomes clear that some scenarios suggest an upward trend in future HEV annual sales while other suggests a downward trend across the timeline of analysis.

HEV Annual Market Penetration Scenarios Spanning 2012 - 2050

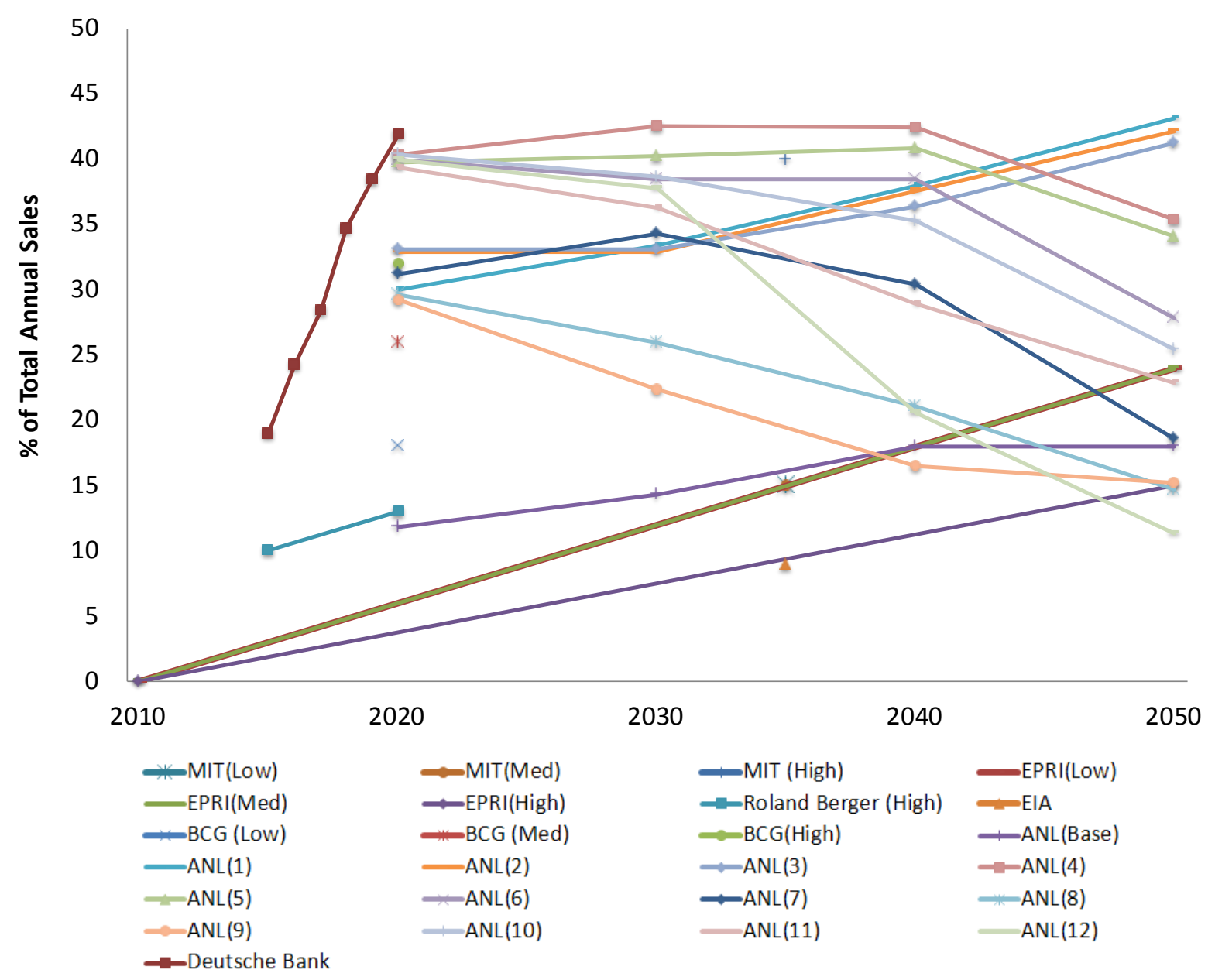

Figure 32: HEV annual market penetration spanning 2012- 2050 (After Connecting the Data Points for Each Scenario)

Although inconsistencies exist among HEV annual market penetration scenarios, they still tend to be considered less diversified than the PHEV annual market penetration scenarios. It is reasonable to assume that the relative consistency for HEV penetration is justified by the fact that the HEV technology has already progressed further in its life cycle relative to PHEVs. Also, historical HEV sales data have accumulated for almost ten years, which shows that HEVs have successfully demonstrated sufficient benefits to the consumer. PHEVs are still in the infancy of their lifecycle, which likely explains the greater uncertainty in relation to its annual market penetration outlook. 
BEV Annual Market Penetration. The annual market penetration rate for BEVs is discussed in some of the fifteen reports reviewed in this section of the paper. Figure 33 compiles these BEV annual market penetration scenarios, which range from 2012 to 2050 . It is interesting to note that most of studies only forecast BEV sales through 2020, and, in the most aggressive scenarios, projections for BEV annual market penetration only reaches $6 \%$ by 2020 . ANL is the only organization with a publication investigated in this comparative study that has projections out to 2050. Although ANL presents twelve different scenarios, all BEVs annual market penetration scenarios maintain a $0 \%$ market share through 2050. The BEV annual market penetration outlook appears to be very pessimistic in comparison to PHEV and HEV annual market penetration rates discussed earlier in this chapter.

\section{BEV Annual Market Penetration Scenarios Spanning 2012 - 2050}

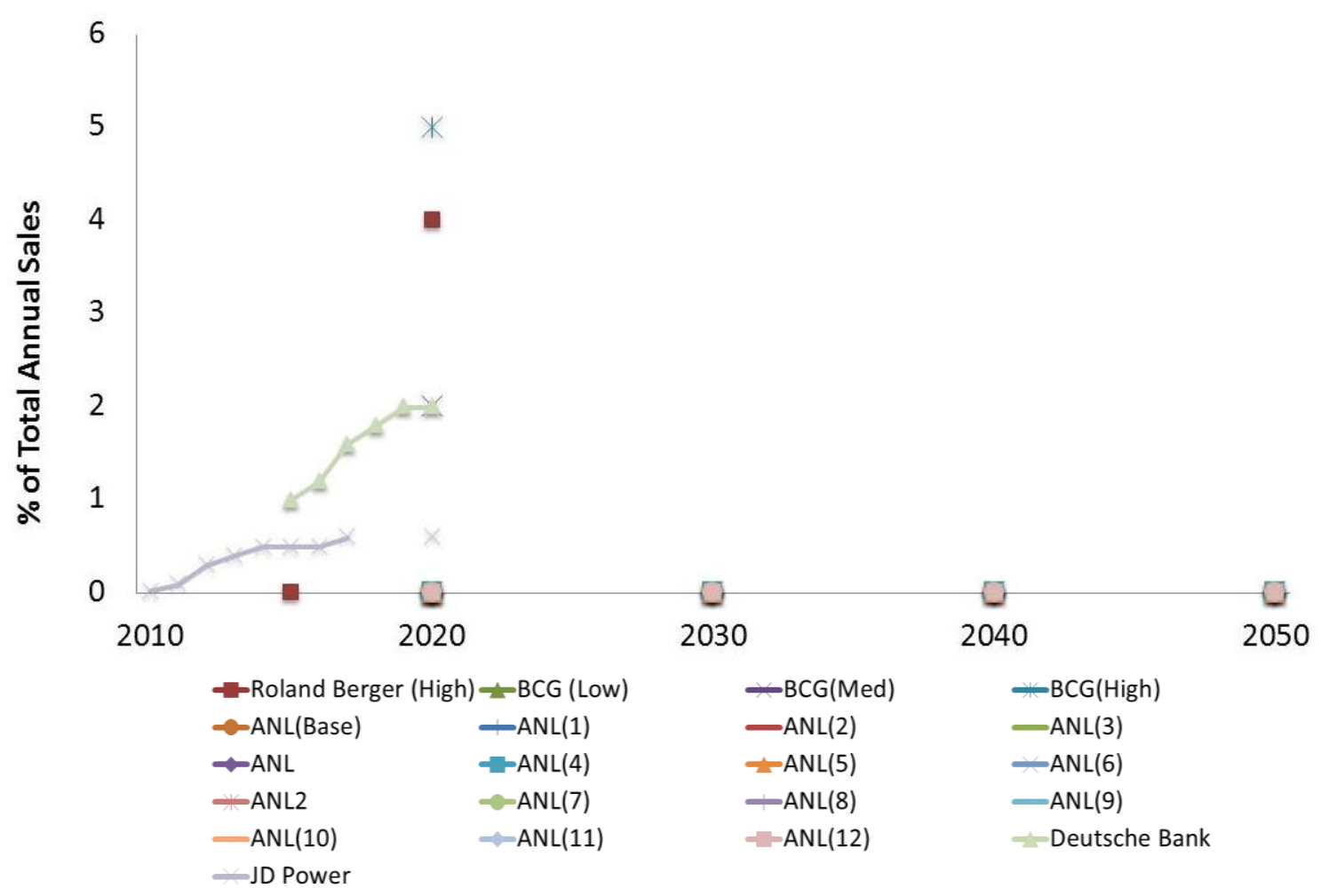

Figure 33: BEV annual I market penetration scenarios 2012-2050

The future penetration prospect of BEVs is doubted by various studies. MIT's report "On the Road in 2035" suggests that BEVs are not cost competitive in comparison to other PHEV technologies. The report also suggests that for BEVs to break even after 15 years of operations, fuel prices of $\$ 6$ per gallon are necessary.

BEV/PHEV Annual Market Penetration. Two of the studies analyze future PHEV and BEV annual market penetration rates collectively. 
Figure 34 shows these annual market penetration forecasts. It is interesting to note that a factor of five exists between the two studies for BEV/PHEV sales in 2020.

\section{BEV/PHEV Annual Market Penetration Scenarios Spanning 2012 - 2050}

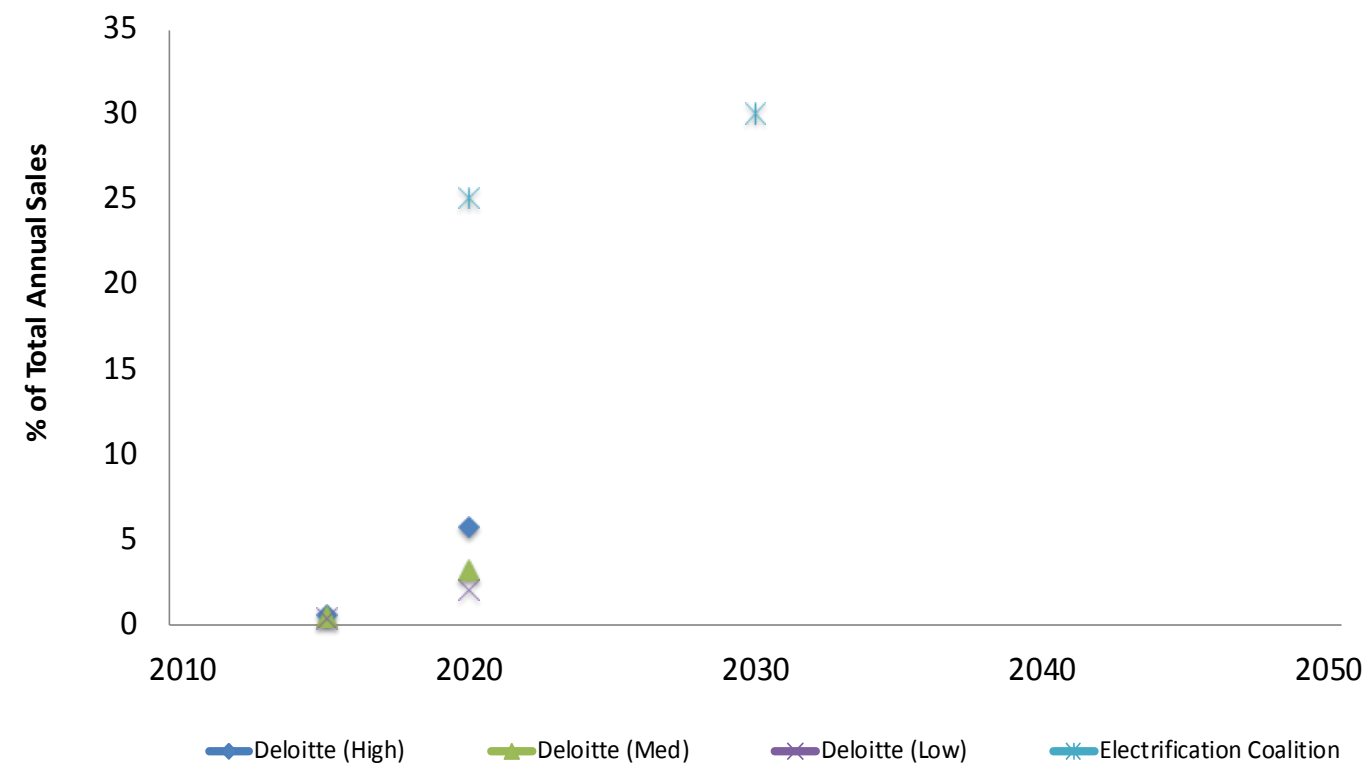

Figure 34: BEV / PHEV annual market penetration scenarios for 2012 to 2050

HEV/PHEV Annual Market Penetration. JD Power and Associates' report entitled "Drive Green 2020: More Hope than Reality?" presents their annual penetration scenarios for both HEVs and PHEVs collectively. Figure 35 displays this data graphically. 
HEV/PHEV Annual Market Penetration Scenarios Spanning 2012 - 2050

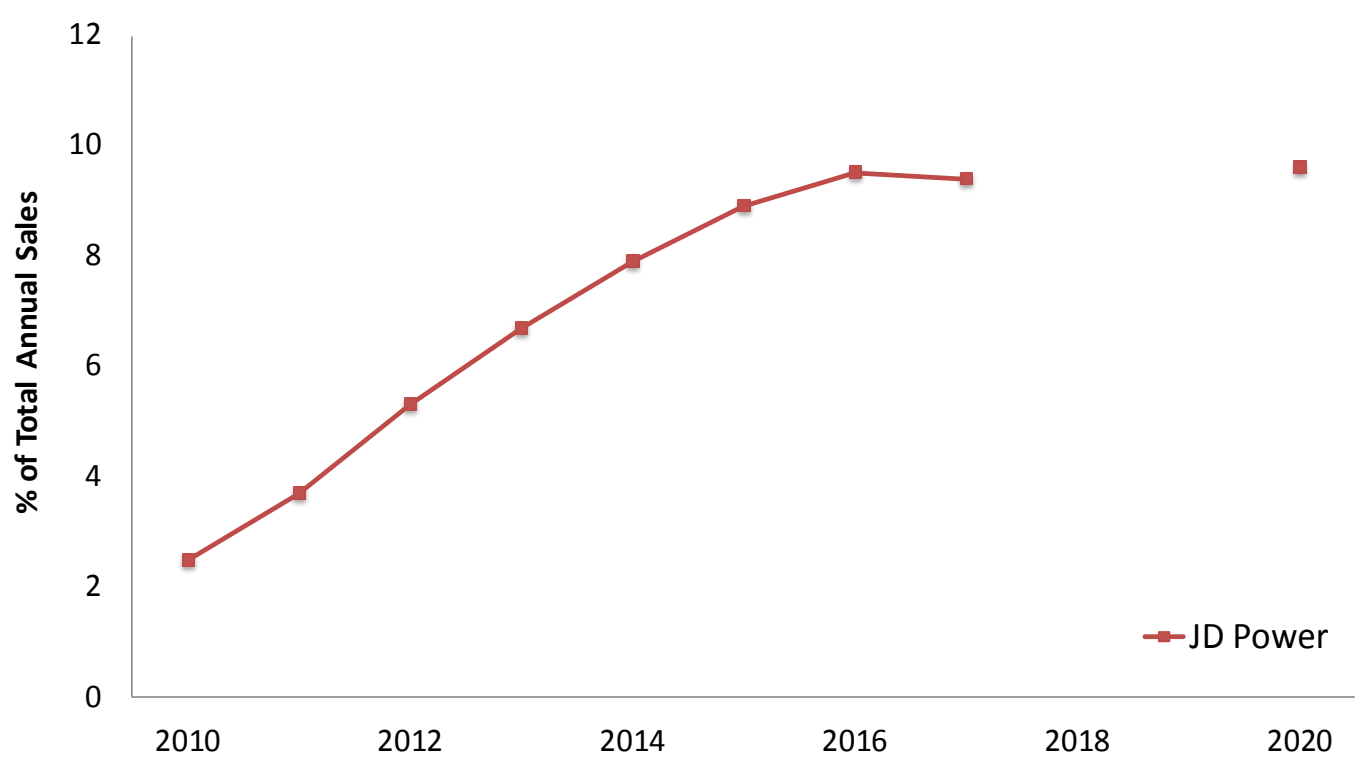

Figure 35: HEV/PHEV annual market penetration from 2012 to 2050

\subsection{Conclusions}

Based on the information extracted from the 15 studies reviewed in this section, the annual market penetration outlook for PHEVs is inconsistent across studies, resulting in single years where annual penetration rate can range from $0 \%$ to almost $90 \%$ (as demonstrated in 2050). None of those annual market penetration rates is deemed incorrect, but rather each study's results appear appropriate within the context of their own report, assumptions, and simulation model used. Only future events will determine what assumptions are accurate and if any of those annual market penetration scenarios investigated in this comparative study will become reality.

Ultimately, the possibilities for PHEV annual market penetration forecasting are endless given the numerous amounts of factors that play a role in sales projections. The project team attempted to eliminate much of this variation for a normalized "apples-to-apples" comparison across the 15 studies to be possible. However, the different sets of assumptions categories, different types of vehicles, and different year for the assumptions created challenges for doing so. In addition the studies reviewed often presented hidden and/or ambiguous assumptions. Hence, the project team opted from forcing a weak and an inaccurate comparative analysis and instead limited their analyses to the data that is published in the reports.

Finally, a brief comparison between HEV, BEV, and PHEV penetration projections reveals that the PHEV annual market penetration outlook is the most uncertain of the powertrains and presents the most diverse possibilities. The BEV annual market penetration forecast is found to have the most conservative projections overall beyond 2020. According to the available data, the annual market penetration projections for HEVs are relatively consistent across studies, forecasting a range between $10 \%$ and $50 \%$ throughout the timeframe of 2020 to 2050 . It is the opinion of the project team that the established market that HEVs have built over the last decade contributes to this relative stability in future market penetration projections. 


\section{Oil Displacement}

Electric vehicle technologies are capable of displacing significant volumes of oil and gasoline relative to conventional vehicles since much, if not all, of the miles driven are powered by electricity. This chapter reviews and compares oil displacement projections attributable to various vehicle technologies as presented in all applicable reports reviewed in this comparative study. In all, the 12 reports listed below were identified as having projections on oil displacement from these technologies.

1. MIT - "On the Road in 2035"

2. MIT - "Prospects for Plug-In Hybrid Electric Vehicles in the United States and Japan: A General Equilibrium Analysis"

3. ANL - "Impact of Real World Drive Cycles on PHEV Fuel Efficiency and Cost for Different Powertrain and Battery Characteristics"

4. ANL - "Multi-Path Transportation Future Study: Vehicle Characterization and Scenario Analyses"

5. ANL - "Well-to-Wheels Analysis of Energy Use and GHG Emissions of PHEVs"

6. SENTECH, Inc. / ORNL - "PHEV Value Proposition Study"

7. NREL - "Battery Requirements and Cost-Benefit Analysis for Plug-In Hybrid Vehicles"

8. NREL - "Using GPS Travel Data to Assess the Real World Driving Energy Use of Plug-In Hybrid Electric Vehicles"

9. EC - "Electrification Roadmap: Revolutionizing Transportation and Achieving Energy Security"

10. EPRI/NRDC - "Environmental Assessment of PHEV Volume 1: Nationwide GHG Emissions"

11. CalCars - "Displacement of Petroleum \& $\mathrm{CO}_{2}$ Reductions from Super-Optimistic-Business-asUsual Mass Production of Light Vehicle PHEVs"

12. UVM Transportation Center - "Plug-In Hybrid Vehicles and the Vermont Grid: A Scoping Analysis"

These twelve reports offer a wide variety of projections for PHEV oil displacement and the pace of PHEV commercialization. Table 51 provides a snapshot of annual oil displacement values published in these reports. Only the reports that list a specific value are included in this table.

As evidenced from the data in Table 51, the variation in results appears to be quite significant, but that is primarily due to the varying assumptions made in each scenario. Certain adjustments can be made up front, however, to reach meaningful comparisons between some of the scenarios. For example, to compare the SENTECH/ORNL VP results with the UVM results, the VP oil displacement must be adjusted to account for the total oil displaced, not just imported oil, since the study assumes $60 \%$ of oil is imported. The UVM displacement must be increased by a factor of five to reach the same fleet size. With these adjustments, SENTECH/ORNL's study estimates 12.08 million barrels of oil displaced each year and the UVM report estimates 12.9 million barrels displaced per year, which is very comparable. Studies giving fleet percentages cannot be compared directly, especially if different timeframes are listed, since this means a different total count for the LDV fleet. The rest of this chapter looks more in-depth at the reasoning behind each of these outcomes. 
Table 51: Oil displacement estimates from different reports

\begin{tabular}{|c|c|c|c|}
\hline \multicolumn{4}{|c|}{ Oil Displacement Projections } \\
\hline Study & Timeframe & Premise & $\begin{array}{l}\text { Annual Oil Displacement } \\
\text { (million bbl / yr) }\end{array}$ \\
\hline$E C$ & 2040 & $\begin{array}{l}75 \% \text { of LDV VMT are electric, } \\
\text { from some type of grid-enabled } \\
\text { vehicle }\end{array}$ & $\begin{array}{l}2,409 \text { (in comparison to } \\
\text { present day oil consumption) }\end{array}$ \\
\hline \multirow{2}{*}{ CalCars } & 2020 & PHEVs are $50 \%$ of LDV fleet & 127.2 \\
\hline & 2050 & PHEVs are $81 \%$ of LDV fleet & 4,406 \\
\hline \multirow{2}{*}{ EPRI } & 2030 & PHEVs are $40 \%$ of LDV fleet & 730 \\
\hline & 2050 & not given & 1,350 \\
\hline \multirow{3}{*}{ SENTECH/ORNL VP } & \multirow{3}{*}{2030} & 1 million PHEVs & 7.25 (imported oil) \\
\hline & & 1.1 million PHEVs & 7.98 (imported oil) \\
\hline & & 1.7 million PHEVs & 12.33 (imported oil) \\
\hline \multirow{3}{*}{ UVM } & \multirow{3}{*}{--} & 50,000 PHEVs & 0.5695 \\
\hline & & 100,000 PHEVs & 1.29 \\
\hline & & 200,000 PHEVs & 2.58 \\
\hline
\end{tabular}

\subsection{Assumptions}

As with GHG emissions and market penetration rates, assumptions necessarily have to be made in order to fully characterize the scenario and describe its limitations. The categories which are most utilized in constructing oil displacement strategies are listed below. Two studies may give values for the same category, but they cannot automatically be directly compared. For fuel savings, for example, some studies provide numbers for gallons of gasoline displaced, while others are for barrels of oil. Furthermore, some give a percentage of future gasoline or oil use displaced without providing the amount of fuel assumed as the baseline. The application of each of these categories will be discussed along with their constraints and any direct comparisons which can be made.

\section{- Fuel Economy}

- Conventional Vehicles - Given by every study analyzed in this section, the amount of fuel a PHEV displaces cannot be calculated without knowing the rate at which a conventional vehicle consumes fuel. Fuel economy standards are given by EPA, as are estimates of vehicle fuel economy. However, these are often considered unrealistic as drivers tend to be more aggressive than assumed by EPA test cycles. Vehicle modeling programs, as well as recorded driving cycles are used as a means to more accurately mimic consumer behavior.

- HEVs - The fuel economy of an HEV is not directly required to calculate the fuel economy or fuel displacement of a PEV. It is a useful value to have however, because it offers a baseline reference. A PHEV running in CS mode operates with roughly the same fuel 
economy as an HEV does, so the HEV fuel economy provides a reference point of current hybrid technology with which to compare PHEV fuel displacement.

- PHEVs - The rate at which a plug-in hybrid consumes fuel relative to a conventional vehicle will determine the effectiveness of a PHEV to displace gasoline consumption. This value depends on the drivetrain configuration used, the size of the electric battery, the driving mode, and the driving style employed.

- Driving Cycle (Real World vs. Standardized) - Driving cycle refers to the pattern of driving used to estimate or calculate the fuel economy of a vehicle. The EPA sets the official standard which, until 2008, consisted of a weighted combination of the UDDS and HWFET drive cycles. The city cycle fuel economy was decreased by $10 \%$ and the highway cycle value by $22 \%$ in an attempt to better reflect real world driving habits. This weighted average still proved to be too low, so in 2008 the EPA added three additional driving cycles into its fuel economy calculation. The new driving cycles are intended to make fuel economy values more accurate to consumer-based performance by including cold and warm engine starts, a range of outside temperatures, aggressive acceleration and climate control use. Having only been in use for a few years, very little data is available on oil displacement which uses the new five cycle standard. As a result, most vehicles in this comparative study employing EPA fuel economy values use data from the old two-cycle standard.

- Driving Mode - The driving mode of a PHEV refers to its mode of fuel consumption. A PHEV can run in CD mode, meaning it is running completely on electricity, or CS mode, meaning the engine is being used while the battery is maintained at a minimum charge level. The third option is a blended mode of operation, in which both the motor and battery are used simultaneously to achieve the highest efficiency for each. Many studies give an overall fuel economy value, which means an assumption has been made as to the driving mode used. Often, a vehicle is described as running in CD mode until the battery gets low, and then switching to CS mode. The ANL WTW report is the only one investigated in this comparative study to offer fuel economy values for CD mode and CS mode separately, but no suggestion as to the distance driven in each. Therefore, these values cannot then be compared to the fuel economy values from the other reports reviewed in this chapter.

- Temporal/Geographic Scope - While climate and terrain affect the fuel consumption of a vehicle, the effect is difficult to quantify. Colder temperatures and rougher terrain increase a vehicle's fuel consumption, but the exact relation between these properties is not well-defined.

- PHEV Configuration - The configuration of a PHEV's drivetrain also affects its performance. Power-split designs are usually used for vehicles with higher AER, and parallel designs for low AER vehicles. Depending on driving mode, a parallel configuration may extend a vehicle's electric range while series PHEVs have AERs lower than their rated value due to real world driving conditions.

- Battery Capacity - The power rating of a battery determines how much energy is available for electric travel. Higher capacities equate to longer AERs. Of the four studies giving available energy values, SENTECH/ORNL VP and ANL WTW are the only ones with values for PHEVs with AER's of 10, 20, 30 and 40 miles. NREL GPS lists battery energies for an HEV, PHEV20 and PHEV40; and $E C$ lists a PHEV40 value.

- Vehicle Mass/Weight - Vehicle mass/weight is a factor in oil displacement, but it is linked into other categories as well. Larger battery capacities can provide higher AERs, but also increase battery mass. While lighter vehicles achieve better fuel efficiencies, the reports examined here provide weight values for a number of different vehicle models and two different timeframes, so a clear correlation could not be discerned. 
- Modeling Software - Computer software programs are a useful tool to gauge the effects of different parameters on vehicle performance. Several different programs are identified in this comparative study as being used by organizations to estimate oil displacement values. These models will be described in detail later in this chapter.

- Size of PEV Fleet - Each PEV on the road is cutting down on fuel consumption to its own capacity, but the effect will not impact gasoline and oil consumption on a noticeable level unless PEVs are out on the road in force. ElA estimates that there will be 4.3 million grid-enabled vehicles on the road in 2030, with 294 million LDVs overall. PEVs then would comprise just over $1 \%$ of the fleet.

Ideally, to compare these different scenarios, each report would use the same methodology and/or use the same assumption categories. By viewing the assumptions list in Table 52 , it becomes obvious that every organization has chosen a unique approach for deriving oil displacement. The studies also cover a large range of temporal values. Overall, their timelines span anywhere from 2010 to 2100.

Table 52: Chart of main studies and their corresponding assumptions ( $九$ indicates a value that was calculated directly from other data given)

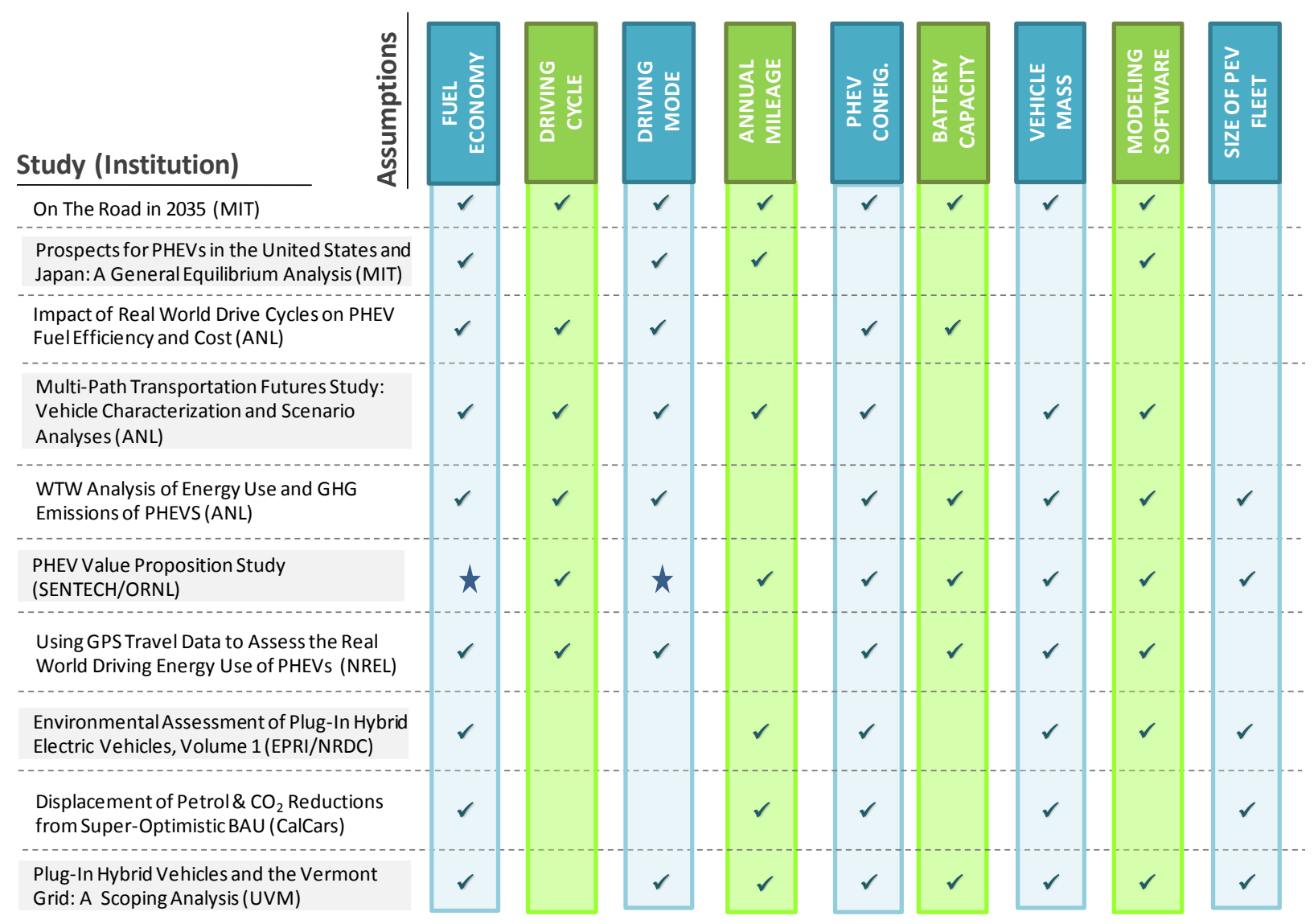

Tables 53 through 64 provide a breakdown of assumptions for each individual report and give more details about the scenarios used to arrive at their individual results. "High," "medium," and "low" refer to the aggressiveness of the assumption and its impact on oil displacement. The more aggressive assumptions typically lead to a higher displacement of oil. 
Table 53: Detailed assumptions for "On the Road in 2035" written by MIT

\begin{tabular}{l} 
On the Road in 2035 (MIT) \\
All Scenarios \\
\begin{tabular}{|l|c|}
\hline Fuel Economy (mpg) & Conventional: 26.4 (2010), 42.8 (2035); HEV: 75.9 (2035); PHEV30: 106.9 (2035) \\
\hline Driving Cycle & Combination of HWFET, US06, FTP \\
\hline Driving Mode & CD and CS/CD \\
\hline Annual Mileage & Parallel (AER of 30 mi) \\
\hline PHEV Configuration & $\mathbf{8 . 2}$ \\
\hline Battery Capacity (kWh) & 1,338 \\
\hline Vehicle Mass (kg) & ADVISOR \\
\hline Modeling Software & \\
\hline Size of PEV Fleet & \\
\hline
\end{tabular} \\
\hline
\end{tabular}

Table 54: Detailed assumptions for "Prospects for PHEVs in the United States and Japan: A General Equilibrium Analysis" by MIT

Prospects for PHEVs in the United States and Japan: A General Equilibrium Analysis (MIT)

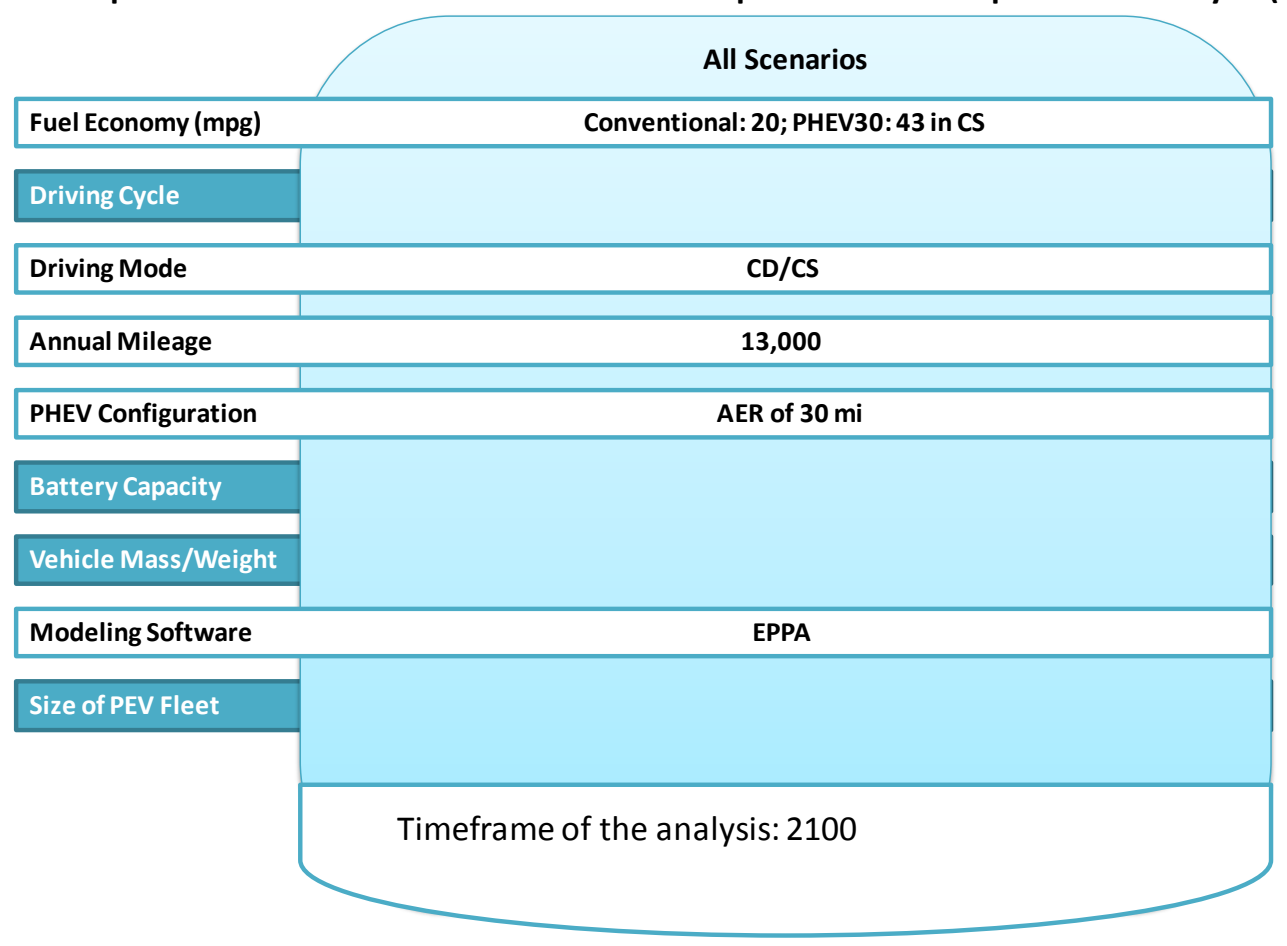


Table 55: Detailed assumptions for the "WTW Analysis of Energy Use and GHG Emissions of PHEVs" written by ANL

WTW Analysis of Energy Use and GHG Emissions of PHEVs (ANL)

\begin{tabular}{|c|c|}
\hline Fuel Economy (mpg) & CV:28.8/39.2; HEV: 41.8/58.7; PHEVs: 34 - 696 \\
\hline & \\
\hline Driving Cycle & EPA Driving Cycles (adjusted to real world conditions) \\
\hline Driving Mode & $\mathrm{CD} / \mathrm{CS}$ \\
\hline Annual Mileage & \\
\hline PHEV Configuration & Power-split / Series (AERs of 10, 20, 30, and $40 \mathrm{mi}$ ) \\
\hline Battery Capacity (kWh) & $2.1,4.1,7.0,9.3$ \\
\hline Vehicle Mass (kg) & CV: 1500 HEV/PHEV10: 1570 PHEV20: 1590 PHEV30: 1760 PHEV40: 1790 \\
\hline Modeling Software & PSAT \\
\hline Size of PEV Fleet & CA: $2.8 M \quad$ WECC: $1.9 \mathrm{M} \quad$ IL: $0.75 \mathrm{M}$ NE: $\mathbf{0 . 9 9 M}$ NY: $0.92 \mathrm{M}$ \\
\hline & Timeframe of the analysis: 2020 \\
\hline
\end{tabular}

Table 56: Detailed assumptions for "Multi-Path Transportation Futures Study: Vehicle Characterization and Scenario Analyses" written by ANL

Multi-Path Transportation Futures Study: Vehicle Characterization and Scenario Analyses (ANL)

\begin{tabular}{|l|c|}
\hline \multicolumn{1}{|c|}{ All Scenarios } \\
\hline Fuel Economy (mpg) & Conventional: 28.9-47; HEV: 46-88.6; PHEV10: 52.3 - 96; PHEV40: 67.2 - 123.4 \\
\hline Driving Cycle & UDDS \& HWFET \\
\hline Driving Mode & Blended CD \\
\hline Annual Mileage & 11,428 - 14,466 \\
\hline PHEV Configuration & AERs of 10 and 40 mi \\
\hline Battery Capacity & \\
\hline Vehicle Mass (kg) & Conventional: 1474 \\
\hline Modeling Software & PSAT \\
\hline Size of PEV Fleet & \\
\hline
\end{tabular}


Table 57: Detailed assumptions for "Impact of Real World Drive Cycles on PHEV Fuel Efficiency and Cost" written by ANL

\section{Impact of Real World Drive Cycles on PHEV Fuel Efficiency and Cost (ANL)}

\begin{tabular}{|l|c|}
\hline Fuel Economy (mpg) & Single Scenario \\
\hline Driving Cycle & Conventional: 36.8 \\
\hline Driving Mode & GPS Data, UDDS, US06 \\
\hline Annual Mileage & CD/CS, Blended CD, Blended \\
\hline PHEV Configuration & Power-split/Series (AERs of 10, 20, 30, and 40 mi) \\
\hline Battery Capacity (kWh) & \multicolumn{1}{|c|}{$\mathbf{4 , 8 , 1 2 , 1 6}$} \\
\hline Vehicle Mass/Weight & \\
\hline Modeling Software & \\
\hline Size of PEV Fleet & \\
\hline
\end{tabular}

Table 58: Detailed assumptions for the "PHEV Value Proposition Study" written by SENTECH/ORNL

\section{PHEV Value Proposition Study (SENTECH/ORNL)}

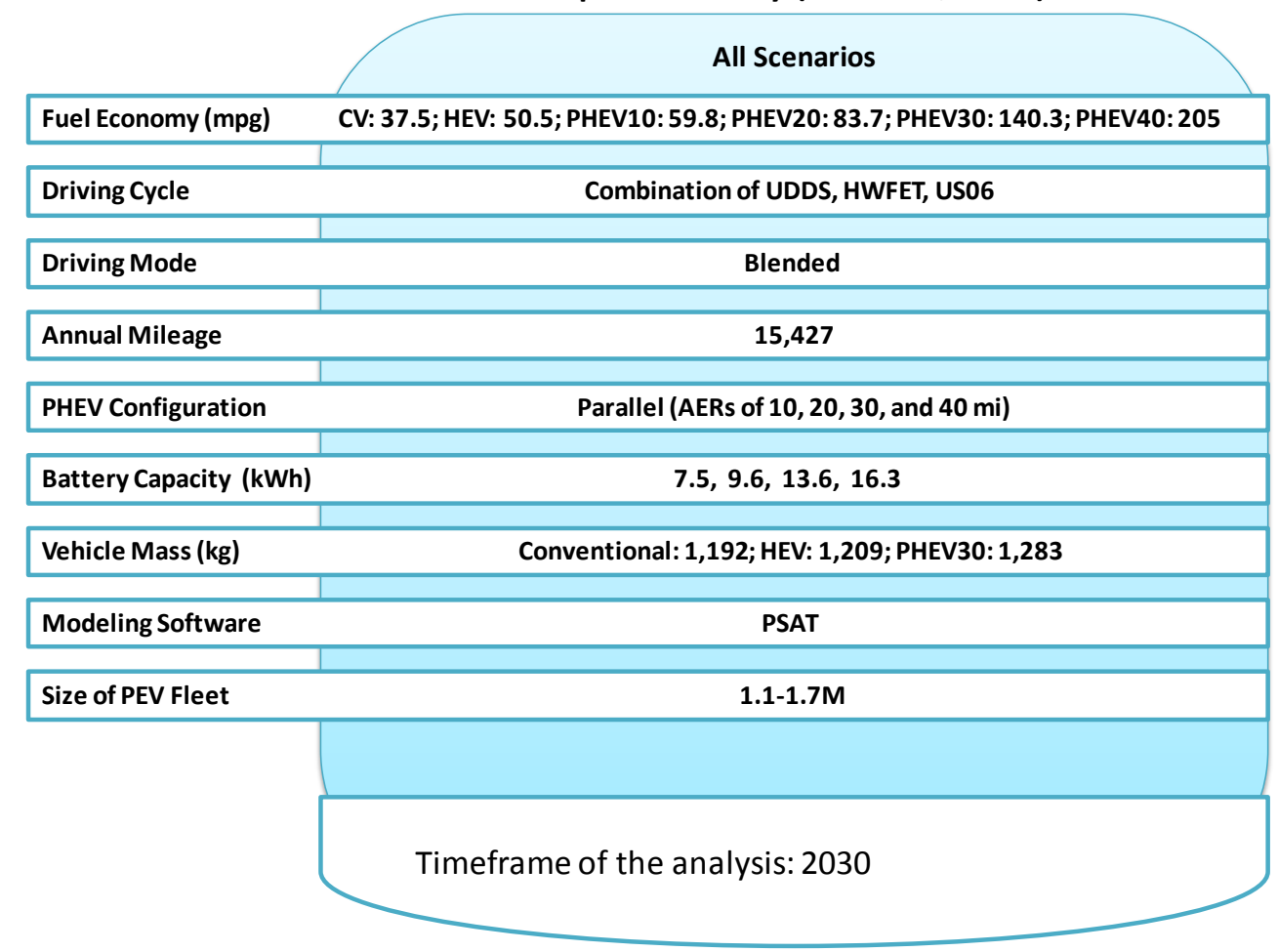


Table 59: Detailed assumptions for "Using GPS Travel Data to Assess the Real World Driving Energy Use of PHEVs" written by NREL

Using GPS Travel Data to Assess the Real World Driving Energy Use of PHEVs (NREL)

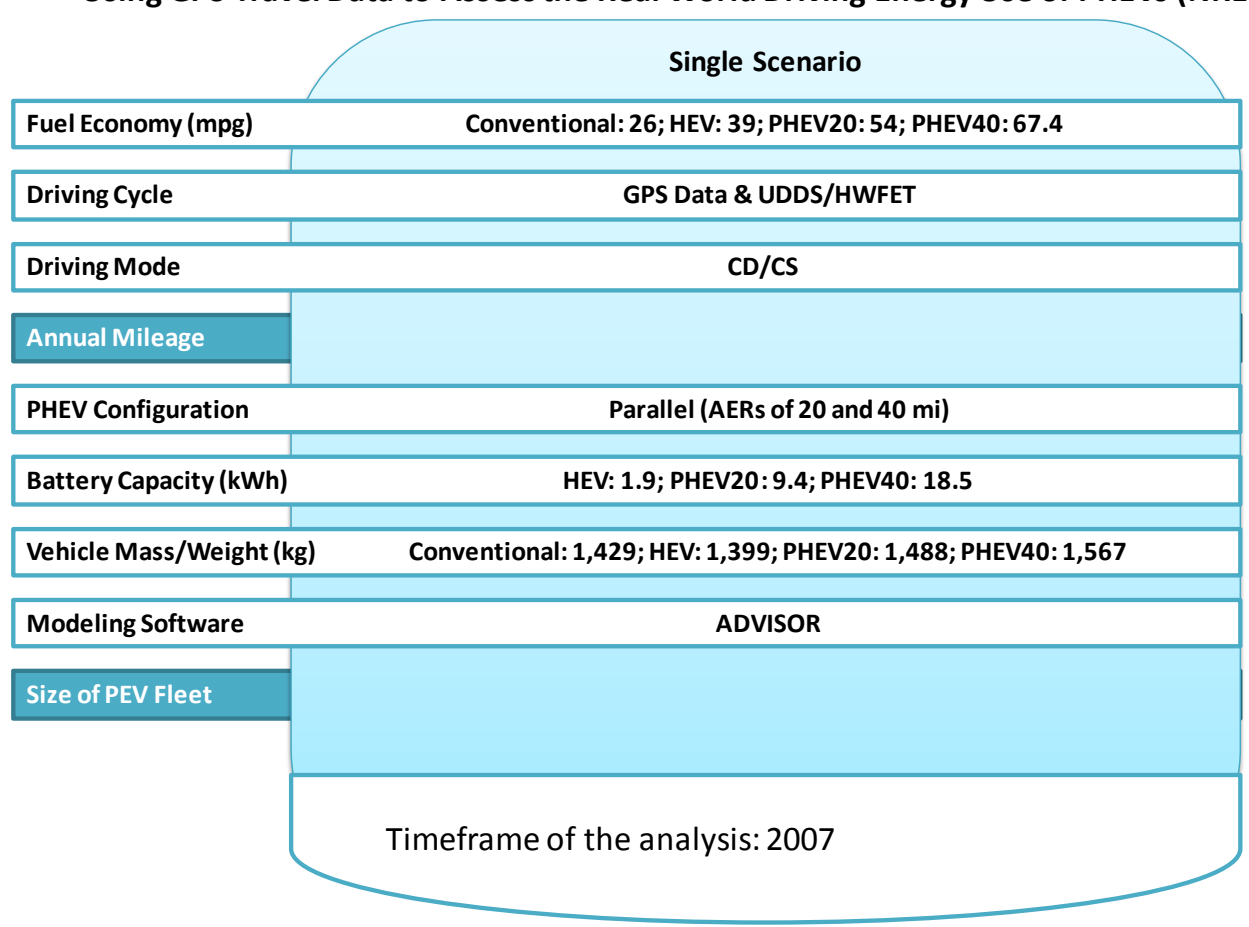

Table 60: Detailed assumptions for "Battery Requirements and Cost-Benefit Analysis of Plug-in Hybrid Vehicles" prepared by NREL

Battery Requirements and Cost-Benefit Analysis of Plug-in Hybrid Vehicles (NREL)

\begin{tabular}{|l|c|}
\hline \multicolumn{1}{|c|}{ All Scenarios } \\
\hline Fuel Economy (mpg) \\
\hline Driving Cycle \\
\hline Driving Mode \\
\hline Annual Mileage \\
\hline PHEV Configuration \\
\hline Battery Capacity (kWh) \\
\hline Vehicle Mass/Weight \\
\hline Modeling Software \\
\cline { 1 - 1 } \\
\hline Size of PEV Fleet \\
\hline
\end{tabular}


Table 61: Detailed assumptions for the "Electrification Roadmap" written by the Electrification Coalition

\section{Electrification Roadmap: Revolutionizing Transportation and Achieving Energy Security (EC)}

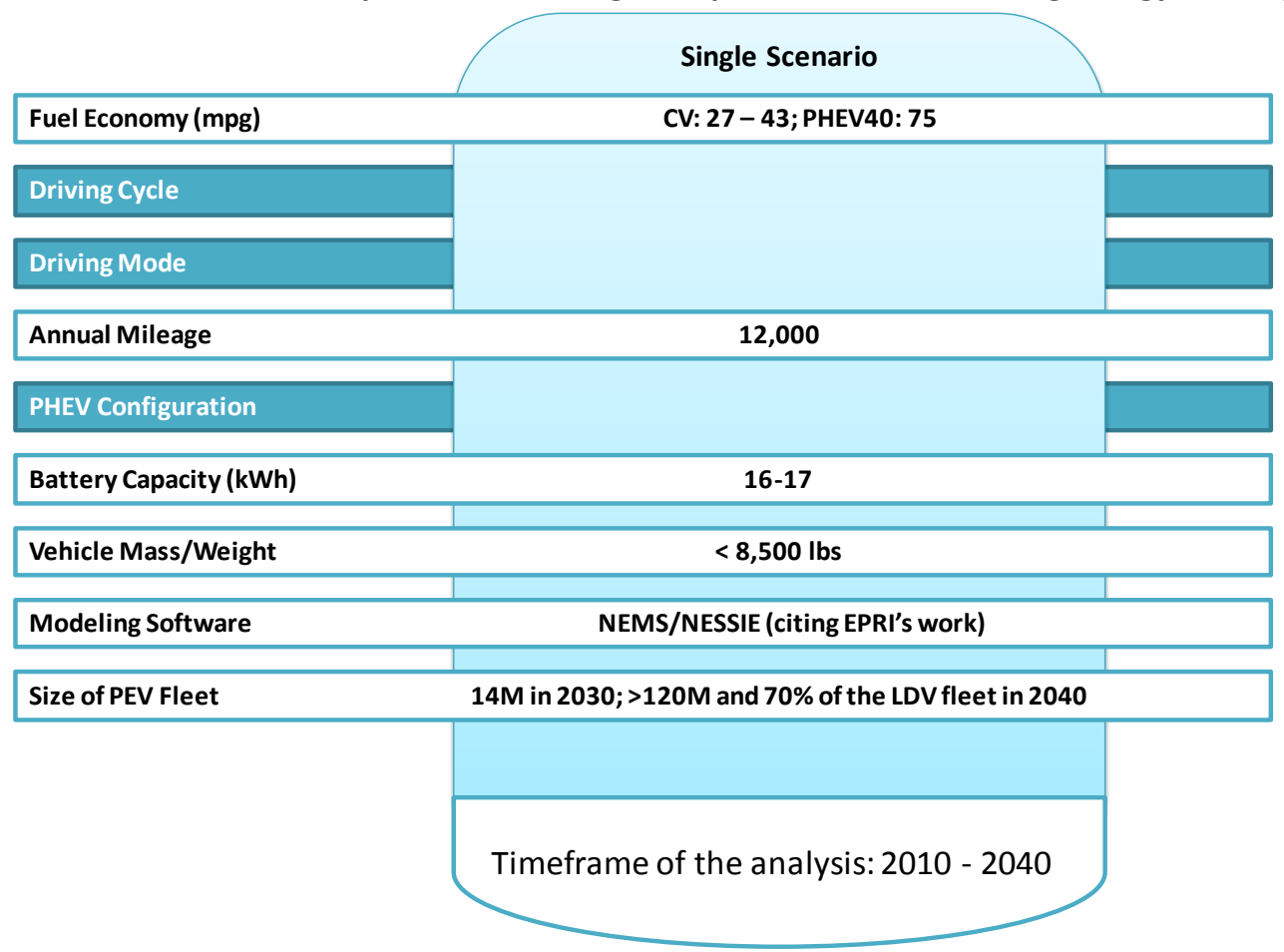

Table 62: Detailed assumptions for "Environmental Assessment of Plug-in Hybrid Electric Vehicles, Volume 1" by EPRI/NRDC

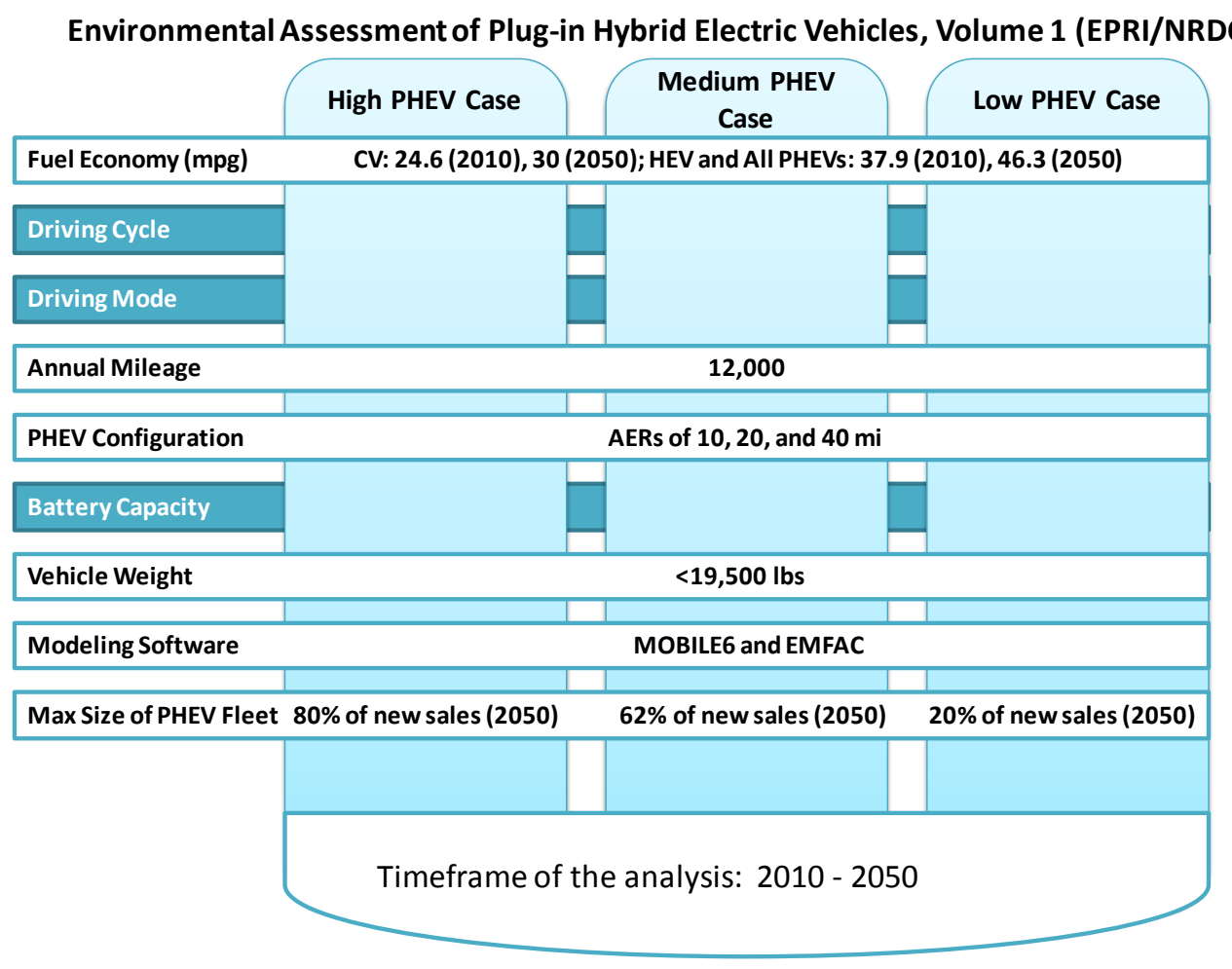


Table 63: Detailed assumptions for the "Displacement of Petroleum and $\mathrm{CO}_{2}$ Reductions from Super-Optimistic Business-as-Usual Mass Production of Light Vehicle PHEVs" written by the CalCars

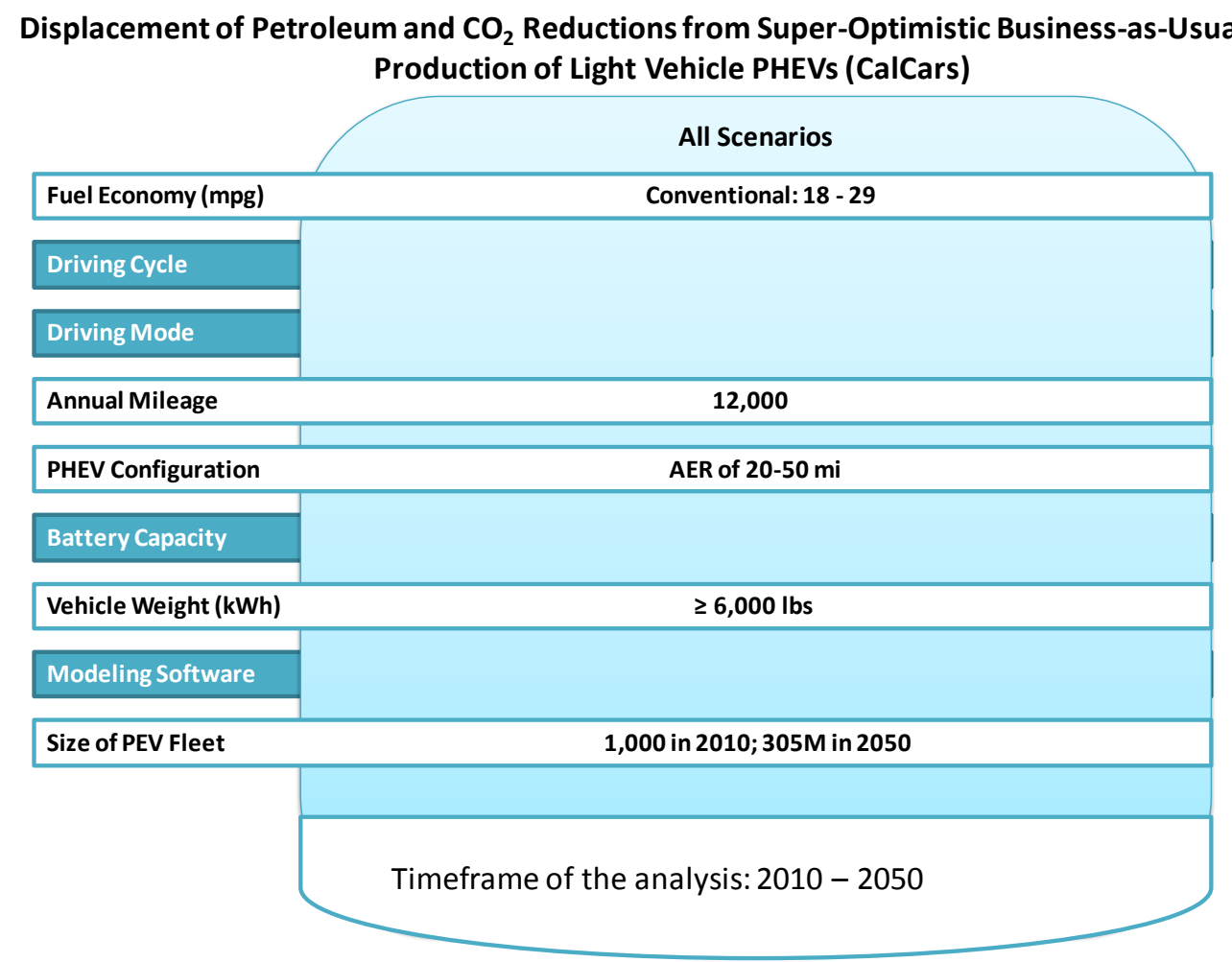

Table 64: Detailed assumptions for "Plug-in Hybrid Vehicles and the Vermont Grid: A Scoping Analysis" written by the UVM

Plug-in Hybrid Vehicles and the Vermont Grid: A Scoping Analysis (UVM)

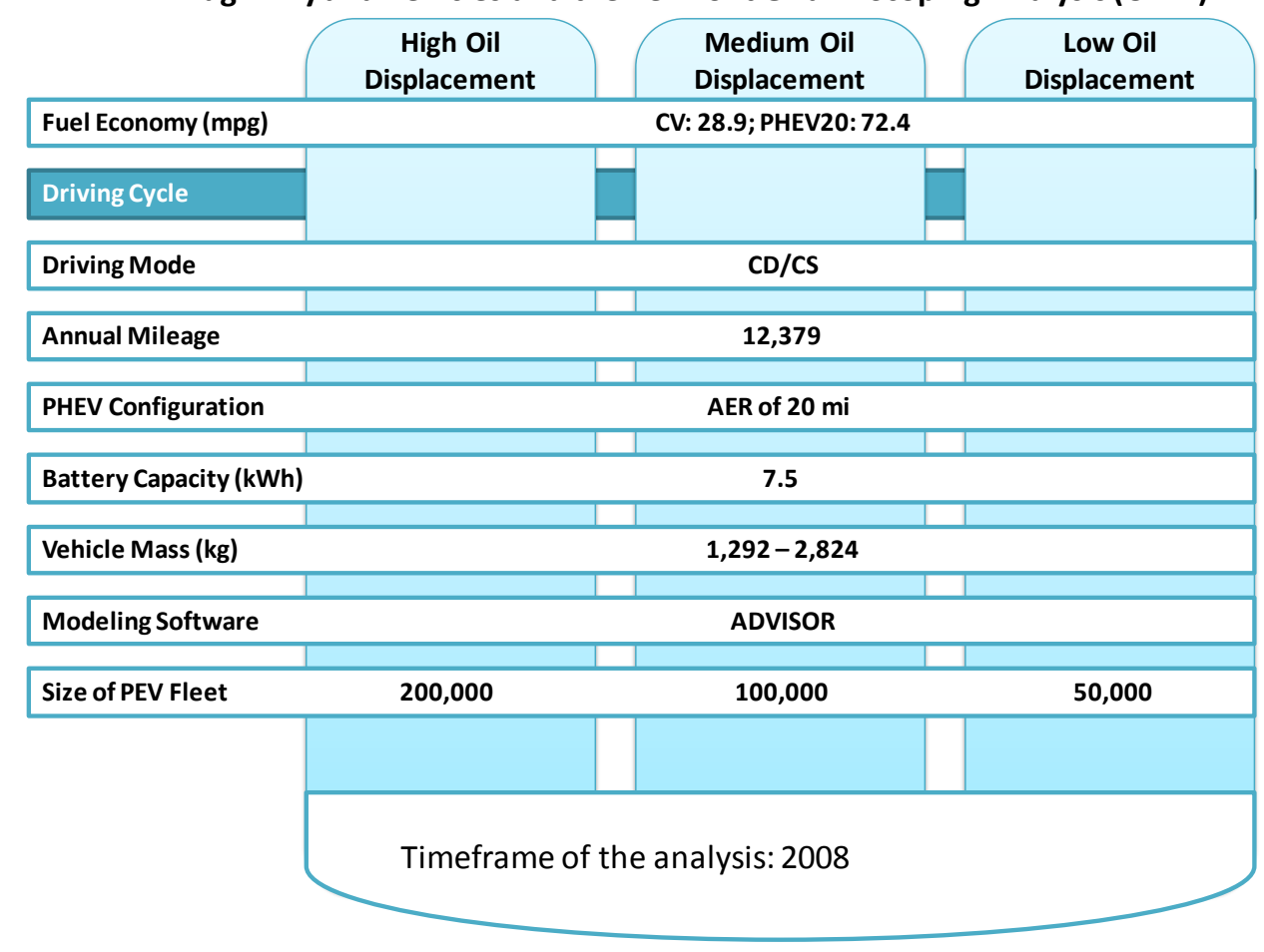




\subsection{Conventional Vehicle Fleet}

\subsubsection{Fuel Economy}

One of the more straightforward variables for comparing oil displacement achievable by PHEVs is the fuel economy rating for the relative conventional vehicle. In some cases, however, hidden variables and assumptions exist behind this value. Present day fuel economy values for this category range anywhere from 18 to $33 \mathrm{mpg}$. Forecasted values are displayed in Figure 36. This figure also encompasses values for which a reference year was not given. Erring on the conservative side, these values are assigned to the present day. Within each data set, fuel economy improves as time progresses. However, these rises do not correspond to a definitive trend in the data overall. For instance, the lowest value for year 2045 equals the mid-level estimates for 2010. Every study examined in depth provided a value for conventional vehicle fuel economy, either directly, or by providing other data (e.g. annual mileage and annual gasoline consumption) from which it can be derived.

\section{Estimates of All Conventional Vehicl Fuel Economies by Year}

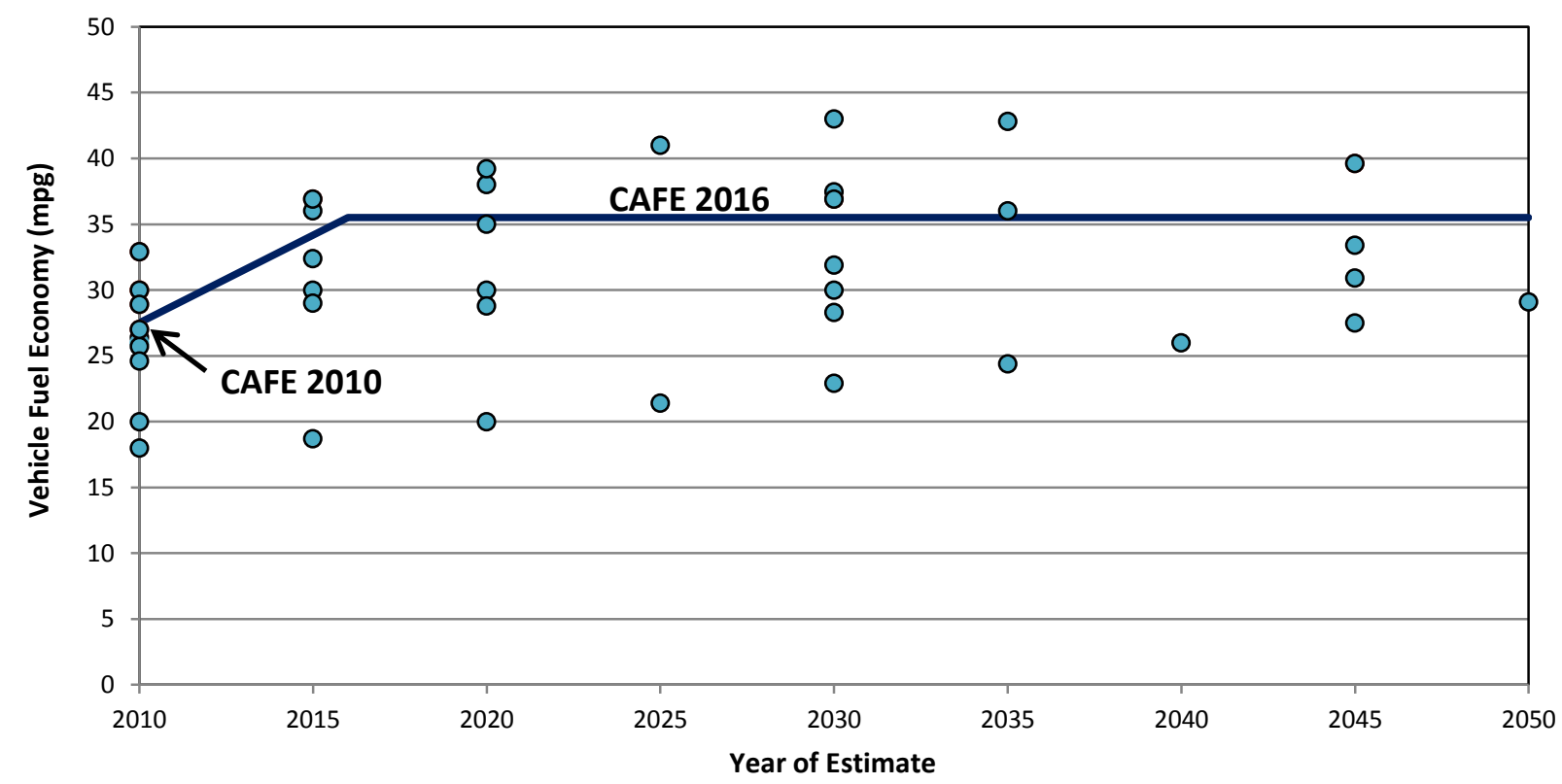

Figure 36: Projected conventional vehicle fuel economy out to 2050 with the current and 2016 CAFE standards marked

In order to calculate the improvement in oil displacement achievable with a PEV, it is necessary for the baseline fuel economy of an ICE to be specified. Within this category there are several ways of calculating this baseline value:

- Using the standard EPA test cycles

- Using the newer five-cycle EPA fuel economy tests

- Using "real world" driving data

- Making assumptions about driving style/driving conditions

- Using 2007 EPA results but adjust them by a factor to more accurately depict "real world" driving habits 
The values in Figure 37 represent any conventional vehicle mileage given for any year, broken down by individual study. The range here is from $18 \mathrm{mpg}$, given by CalCars, to $42.8 \mathrm{mpg}$ given by MIT 2035. Fuel economy has a significant impact on the results of any oil displacement analyses. For example, an LDV with a fuel economy average of $42.8 \mathrm{mpg}$ uses $42 \%$ of the fuel that a vehicle getting $18 \mathrm{mpg}$ uses. Results can be skewed drastically depending on the number used. The lines drawn across the graph represent the current CAFE standard of $27.5 \mathrm{mpg}$ and the future CAFE standard of $35.5 \mathrm{mpg}$. Most vehicles surpass current CAFE standards, but approximately two-thirds of the vehicles fail to meet the 2016 standard.

\section{ICE Fuel Economy Values for All Studies and All Timeframes}

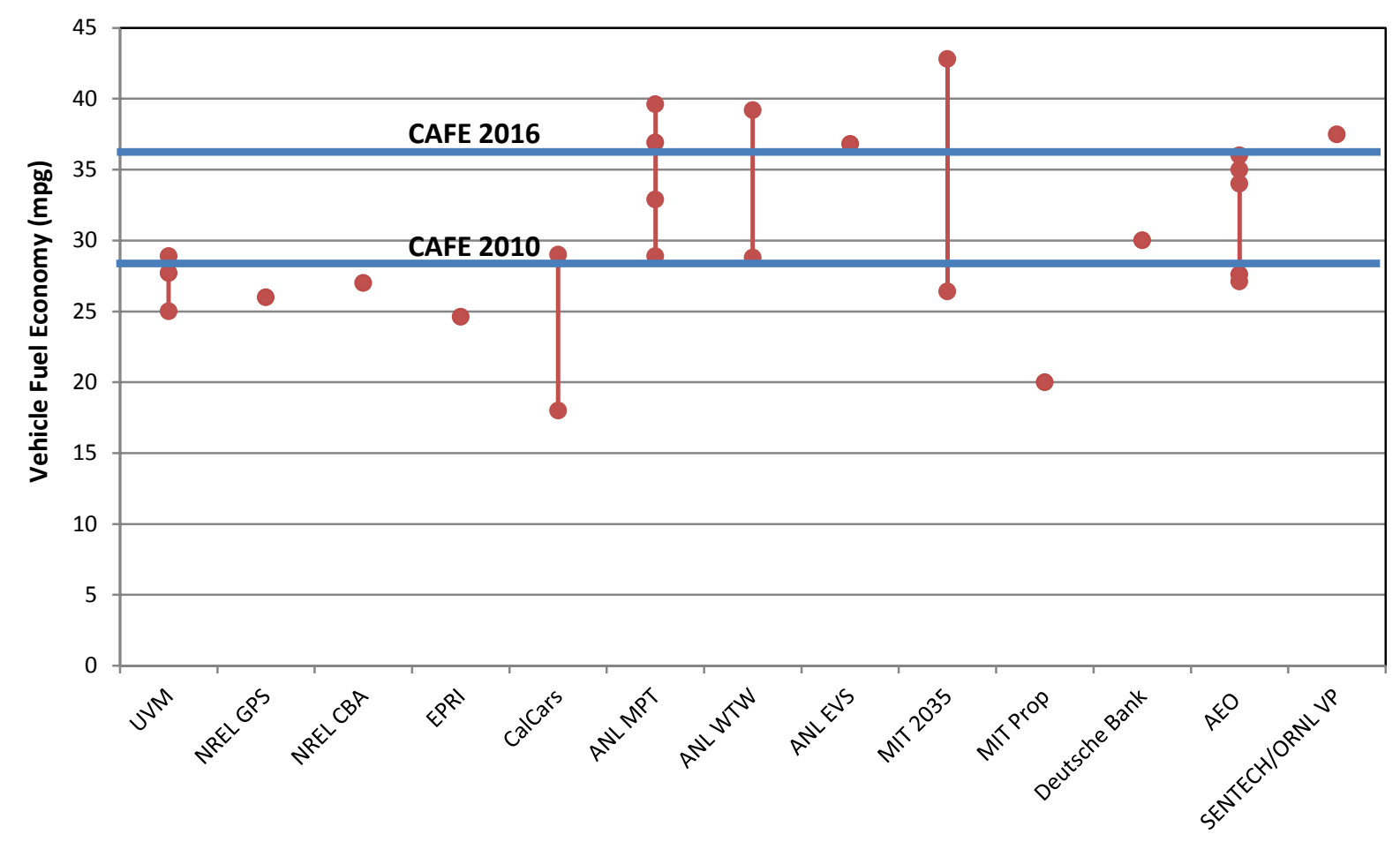

Figure 37: Graph of the fuel economy values used for conventional vehicles, broken down by study

\subsubsection{Vehicle Mass/Weight}

Oil displacement projections also depend on the makeup of the vehicle being investigated. Most studies reviewed in this comparative study focus on LDVs that are approximately 8,000 lbs. or lighter. The ANL MPT study provides mass values and fuel use for mid-size and crossover sports utility vehicles (SUV) as well, but the bulk of its analysis focuses on the mid-size sedan. A vehicle's mass/weight is a critical factor in the fuel economy and thus the oil displacement a vehicle will be able to achieve. The more weight an engine has to move, the less impactful its oil displacement will be. EPRI/NRDC also lists mass values for larger vehicles up to $19,500 \mathrm{lbs}$., but only provides their fuel economies. All scenarios and analyses made use of the LDV category ranging from $0-6,000 \mathrm{lbs}$. Table 65 provides a breakdown of vehicle mass/weight data by publication. 
Table 65: Listing of the types of mass/weight values provided from the reports examined in this chapter

\section{Vehicle Mass/Weight Data}

\begin{tabular}{|c|c|c|c|c|c|c|c|}
\hline \multirow{2}{*}{ Study } & \multirow{2}{*}{$\begin{array}{l}\text { Mass/Weight } \\
\text { Value Provided }\end{array}$} & \multicolumn{6}{|c|}{ Vehicle Type for Each Weight Value } \\
\hline & & CV & HEV & PHEV10 & PHEV20 & PHEV30 & PHEV40 \\
\hline ANL WTW & $\begin{array}{l}\text { Estimate from } \\
\text { graph }\end{array}$ & & $x$ & $x$ & $X$ & $x$ & $X$ \\
\hline$E C$ & $\begin{array}{l}\text { Less than } 3,855 \mathrm{~kg} \\
(8,500 \mathrm{lbs})\end{array}$ & $x$ & $x$ & & & & $x$ \\
\hline NREL GPS & Exact value & $x$ & $X$ & & $x$ & & $x$ \\
\hline $\begin{array}{l}\text { SENTECH/ORNL } \\
\text { VP }\end{array}$ & Exact value in 2030 & $X$ & $x$ & & & $x$ & \\
\hline CalCars & $\begin{array}{l}\text { Less than } 2,721 \mathrm{~kg} \\
(6,000 \mathrm{lbs})\end{array}$ & $x$ & & & $x$ & $x$ & $x$ \\
\hline \multirow{2}{*}{ EPRI } & Exact value & $x$ & $x$ & & & & \\
\hline & Exact value in 2030 & & & $x$ & & & \\
\hline ANL MPT & Glider mass only & $x$ & $x$ & $x$ & & & $X$ \\
\hline
\end{tabular}

Improvements have been made in vehicle performance, but these have not gone towards raising fuel economy. Some reports included in this comparative study forecast weight reductions in the future. For example, SENTECH/ORNL VP calculates that a $30 \%$ reduction in glider mass from a standard ICE in 2030 will lower gasoline consumption $8.1 \%$, and a $45 \%$ reduction in glider mass will decrease gas consumption by $12.8 \%$. The general rule of thumb for vehicle mass is that a $10 \%$ mass reduction will cause a $7 \%$ increase in fuel economy. The EPRI and SENTECH/ORNL VP studies are the only two which provide fuel economy values for variations of mass in a conventional vehicle. Figure 38 depicts these results. The SENTECH/ORNL VP study does not provide these values directly, but lists annual mileage and liquid fuel consumption data from which fuel economy values were calculated. No other vehicle fuel economy and mass ranges are provided in these studies. 


\section{Fuel Economy as a Function of Conventional Vehicle Mass}

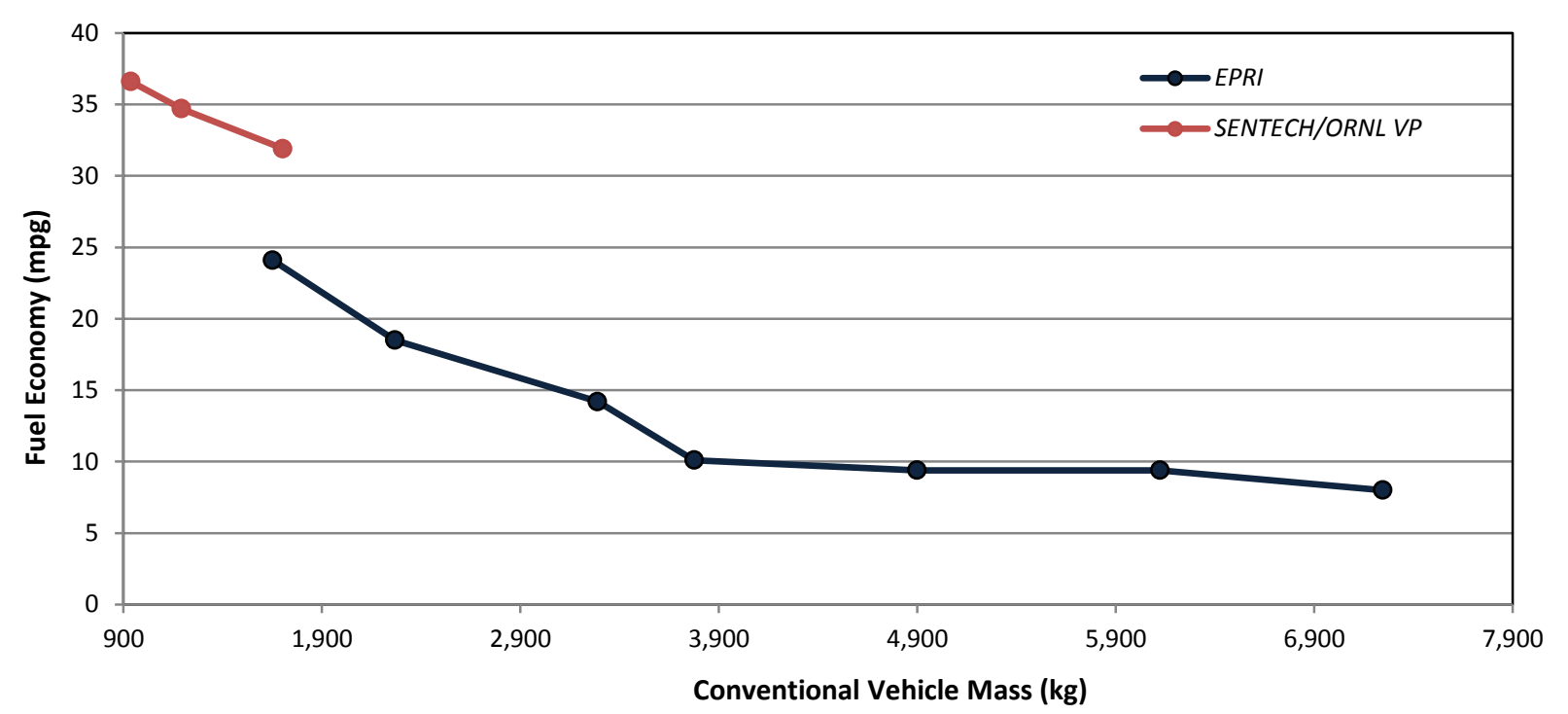

Figure 38: Variation in conventional vehicle fuel economy with mass

\subsection{HEV}

\subsubsection{Fuel Economy}

Like conventional vehicles, fuel economy estimates for HEVs also cover a wide range, as seen in Figure 39. The lowest mileage given for an HEV is 35.9 miles per gallon of gasoline; the highest is 75.9 miles per gallon. Best case estimates then use less than half the fuel of vehicles with the lower bound estimates, which just meet 2016 fuel economy standards. Figure 39 presents the gasoline displacement of an HEV with respect to a conventional vehicle along with the fuel economy value associated with that displacement. While the highest displacement percentage is due to the highest fuel efficiency, the rest of the data points do not show a distinct correlation between these two variables. The greatest forecasted fuel economy value for an HEV in any year is $75.9 \mathrm{mpg}$, but the remaining data points fall approximately within a $15 \mathrm{mpg}$ range from 38 to 55 miles per gallon.

Figure 40 represents how fuel economy varies as a function of mass. As shown in this figure, the majority of vehicles included in this section of the comparative study have a mass between 1,000 and 2,000 kg. Within this range, the fuel economy is quite diverse due to various vehicle characteristics, but it is clear that as vehicle mass increases, fuel economy decreases. According to the figure, fuel economy appears to flatten out at approximately $10 \mathrm{mpg}$ for conventional vehicles and $15 \mathrm{mpg}$ for HEVs for vehicles with masses exceeding $3,500 \mathrm{~kg}$. 


\section{Liquid Fuel Displaced by Replacing a CV with an HEV}

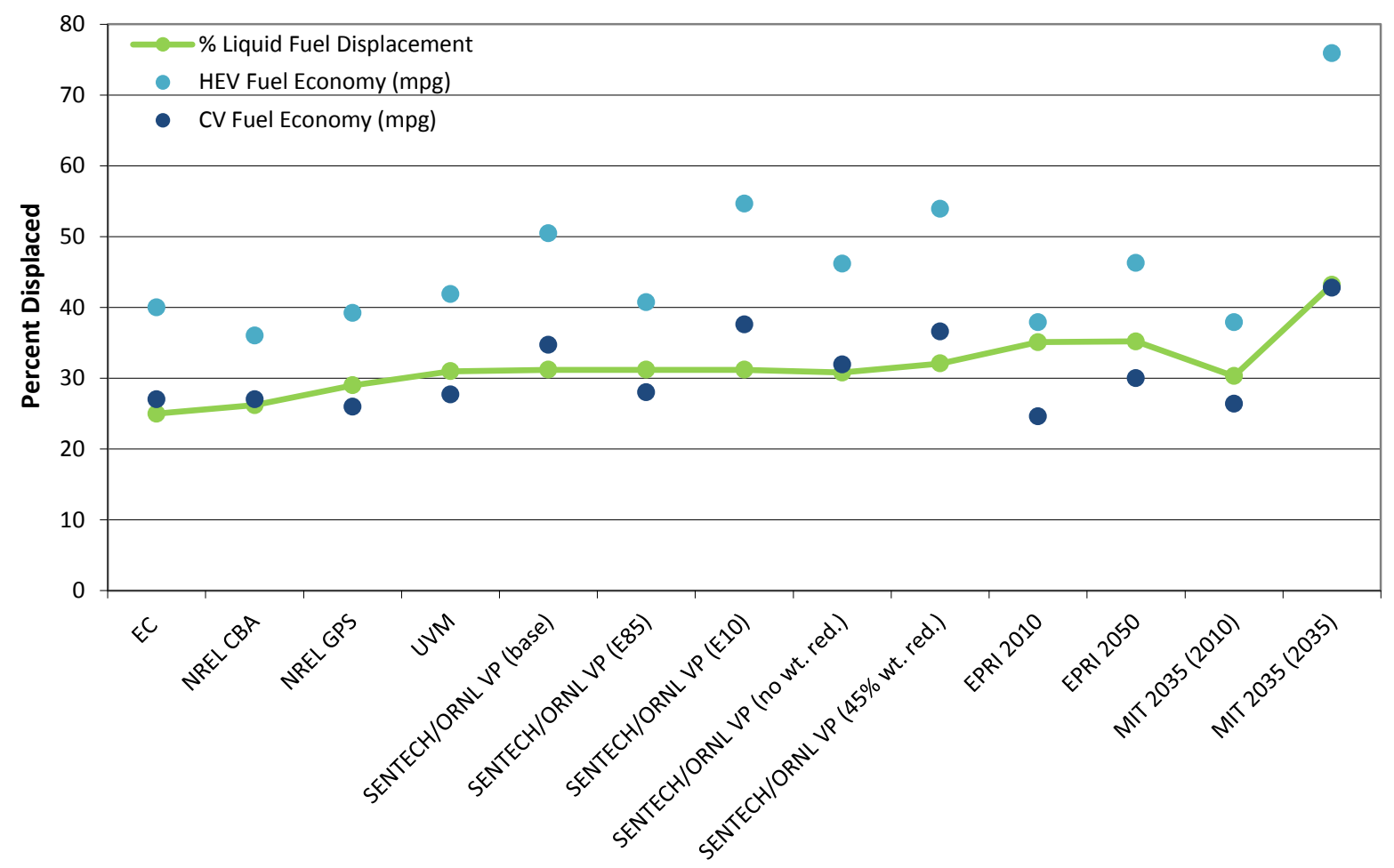

Figure 39: Gasoline displacement plotted with vehicle fuel economy

\section{Vehicle Fuel Economy as a Function of Mass}

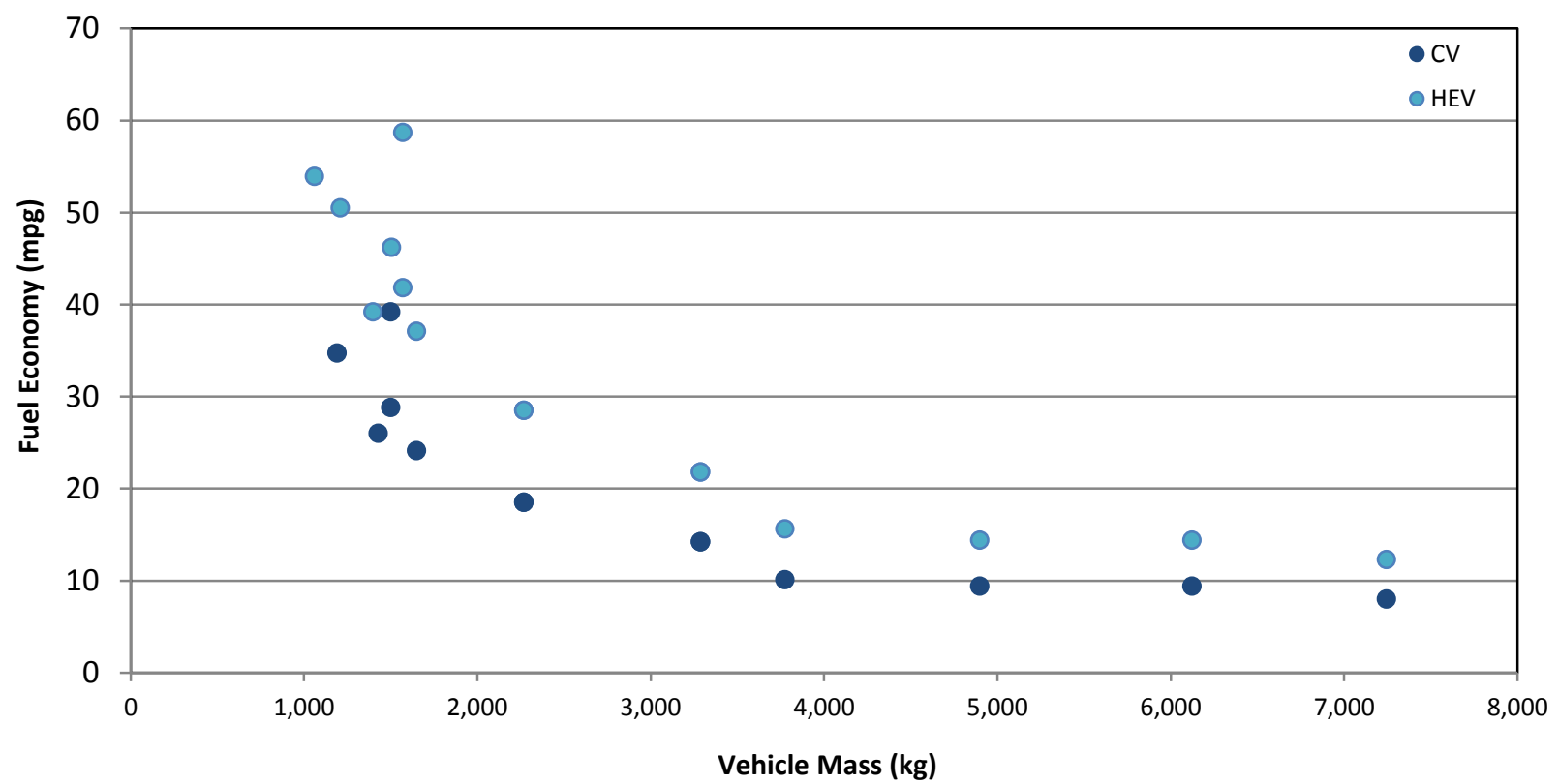

Figure 40: Vehicle fuel economy as a function of mass 


\subsubsection{Fuel Displacement Results}

Of the thirteen values shown in Figure 39, six are for a mileage of approximately 12,000; six used approximately 15,000; and one, the NREL GPS study, used 8,650 miles. All mileage estimates are annual except for the 8,650 mile estimate, which is the distance covered in a specific study. For those with around 15,000 miles (NREL CBA used 15,000, and the rest came from the SENTECH/ORNL VP study which lists three values for three different weight reduction amounts and assumed an annual mileage of 15,427), the volume of gasoline displaced per vehicle ranges only from 135.2 to 149 gallons. This equates to $6.76-$ 7.45 barrels of oil displaced per year. The six studies using an annual VMT figure of 12,000 miles (the UVM study uses 12,379) displace between 100 and 171.2 gallons of gasoline, or $5-8.56$ barrels of oil, per year per HEV on the road. The gasoline displacement for these scenarios is listed in Table 66. Results from these studies are given on an annual basis and a scaled VMT basis.

Table 66: Annual gasoline displacement by a single HEV from different reports

\begin{tabular}{|l|c|c|c|c|}
\hline \multicolumn{5}{|l}{ HEV Gasoline Displacement for Report Scenarios } \\
\hline Study Name & $\begin{array}{c}\text { Gallons of Gasoline } \\
\text { Displaced } \\
\text { per HEV per Year }\end{array}$ & Annual Mileage & $\begin{array}{c}\text { \% Fuel } \\
\text { Displaced per } \\
\text { HEV per Year }\end{array}$ & $\begin{array}{c}\text { Gallons of Gasoline } \\
\text { Displaced per } \\
\text { Thousand VMT }\end{array}$ \\
\hline EC & 100 & 12,000 & 25 & 8.3 \\
\hline NREL CBA & 148 & 15,000 & 26 & 9.87 \\
\hline NREL GPS & 96.5 & 8,650 & 33.7 & 11.16 \\
\hline SENTECH/ORNL VP & 138.4 & 15,427 & 31.2 & 8.97 \\
\hline UVM & 149 & 15,427 & 30.8 & 9.66 \\
\hline EPRI (2010) & 135.2 & 15,427 & 32.1 & 8.76 \\
\hline EPRI (2050) & 132.9 & 12,379 & 31 & 10.74 \\
\hline MIT 2035 & 171.2 & 12,000 & 35.1 & 14.27 \\
\hline
\end{tabular}

Putting the gasoline displacement results on equal footing shows that, regardless of the AER, an HEV will displace between eight and fourteen gallons of gasoline, or $0.4-0.7$ barrels of oil for every thousand miles the vehicle travels.

\subsection{PHEV}

\subsubsection{Fuel Economy}

A large range of fuel economy values has been measured and forecasted for PHEVs. The values identified for this comparative study range from a minimum of $51 \mathrm{mpg}$ to a maximum of $205 \mathrm{mpg}$. In Figure 41, the two reports with fuel economy values for an AER of 10, 20,30 and 40 (the ANL EVS and the 
SENTECH/ORNL VP studies) show strongly linear results. MIT's two studies result in similar fuel economy values, as well as NREL's two studies.

\section{Comparison of PHEV Fuel Economies as a Function of AER}

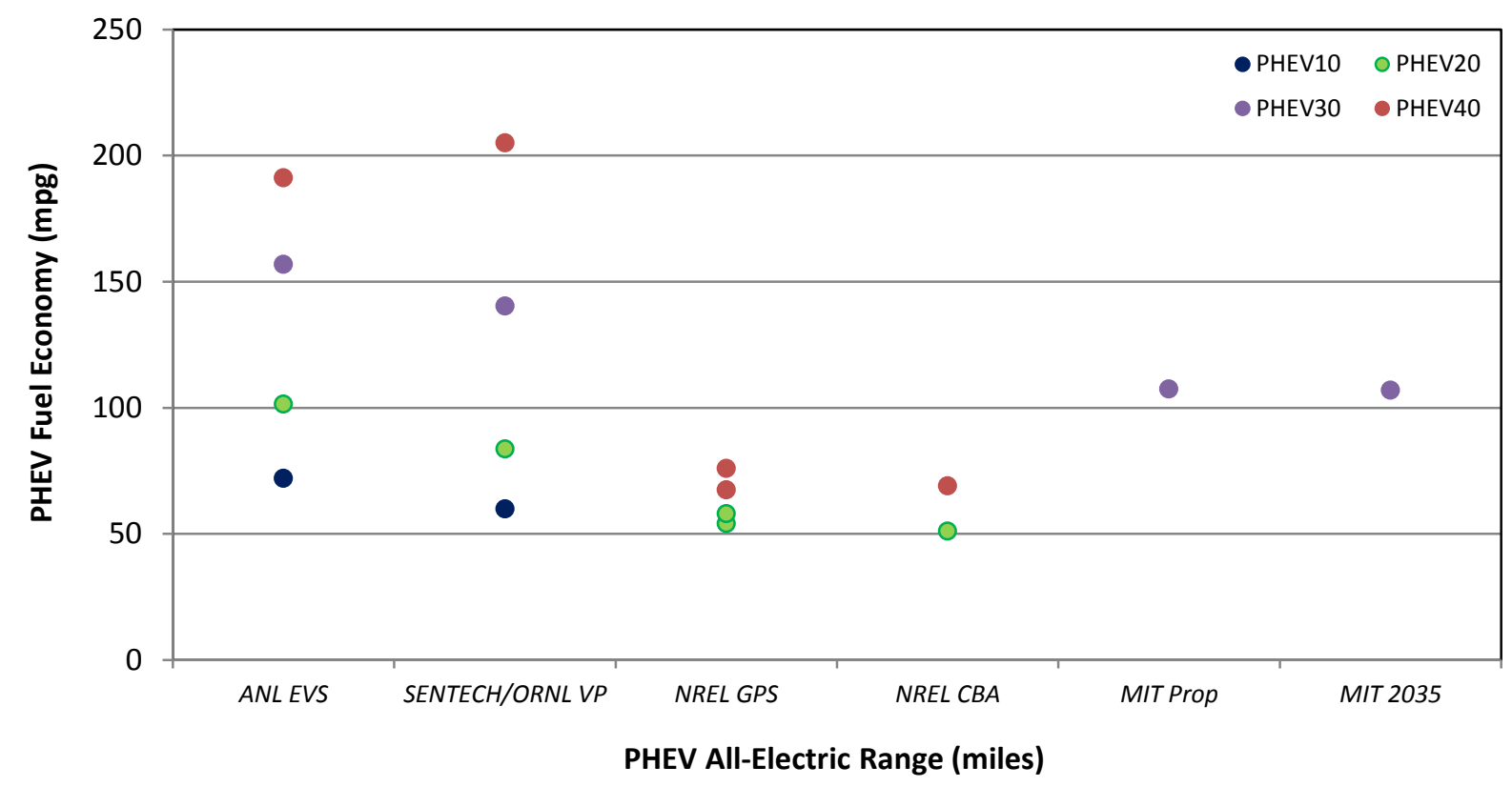

Figure 41: PHEV fuel economy by study

While the fuel economies shown for all AERs vary, the range for PHEV40s is especially large. Reviewing the different assumption choices for these studies did not provide any enlightenment into why this would be the case. Three of the four studies evaluate PHEV fuel economy for the present-day. Considering drivetrains, two use a parallel system and two a series system, but they do not correlate with the differences in fuel economy. Drive cycle and drive strategy are also possible sources of discrepancy. However, the reports using real world data, ANL EVS and NREL GPS, do not arrive at similar values. Modeling software is another possible cause: NREL GPS uses the ADVISOR program and SENTECH/ORNL's analysis uses the PSAT software. Software results are compared to see if any definitive trend exists between the two model simulations. As section 5.4.8 shows, model trends for a PHEV30 run counter to the results in Figure 41 for a PHEV40.

\subsubsection{All-Electric Range}

As Figure 42 depicts, identical AERs do not necessarily align with gasoline displacement across the reports reviewed in this comparative study. No clear trend is discernible among the analyses either. Dividing these values by their rated AER fails to provide a clear picture of the fuel economy to be gained by selecting a specific electric range. Looking at these values on an absolute scale of gallons of gasoline displaced versus distance travelled, seen in Figure 43, provides little additional insight. 


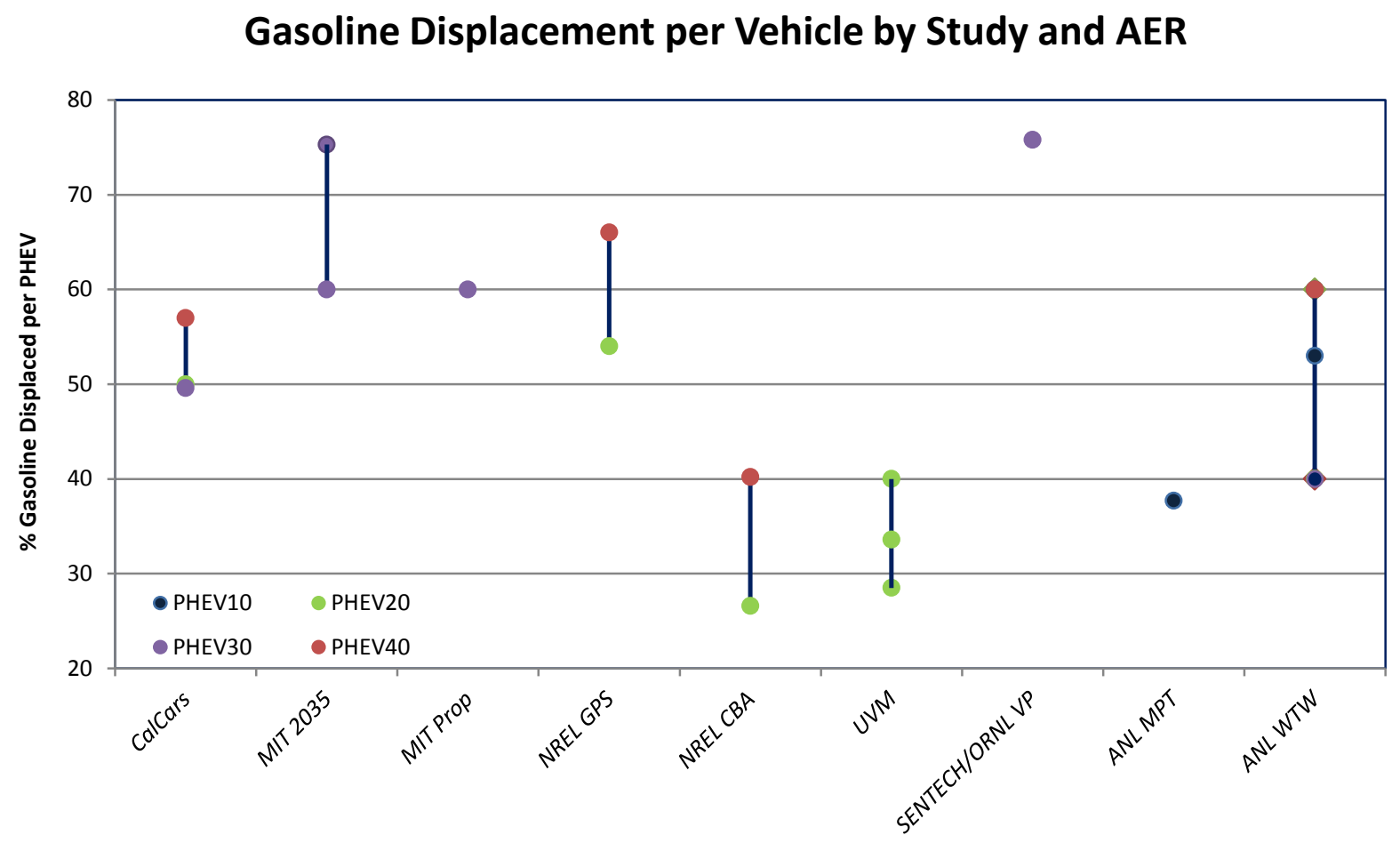

Figure 42: Percent gasoline displaced by one PHEV compared to a single conventional vehicle as a function of its AER

\section{Gasoline Displacement as a Function of VMT}

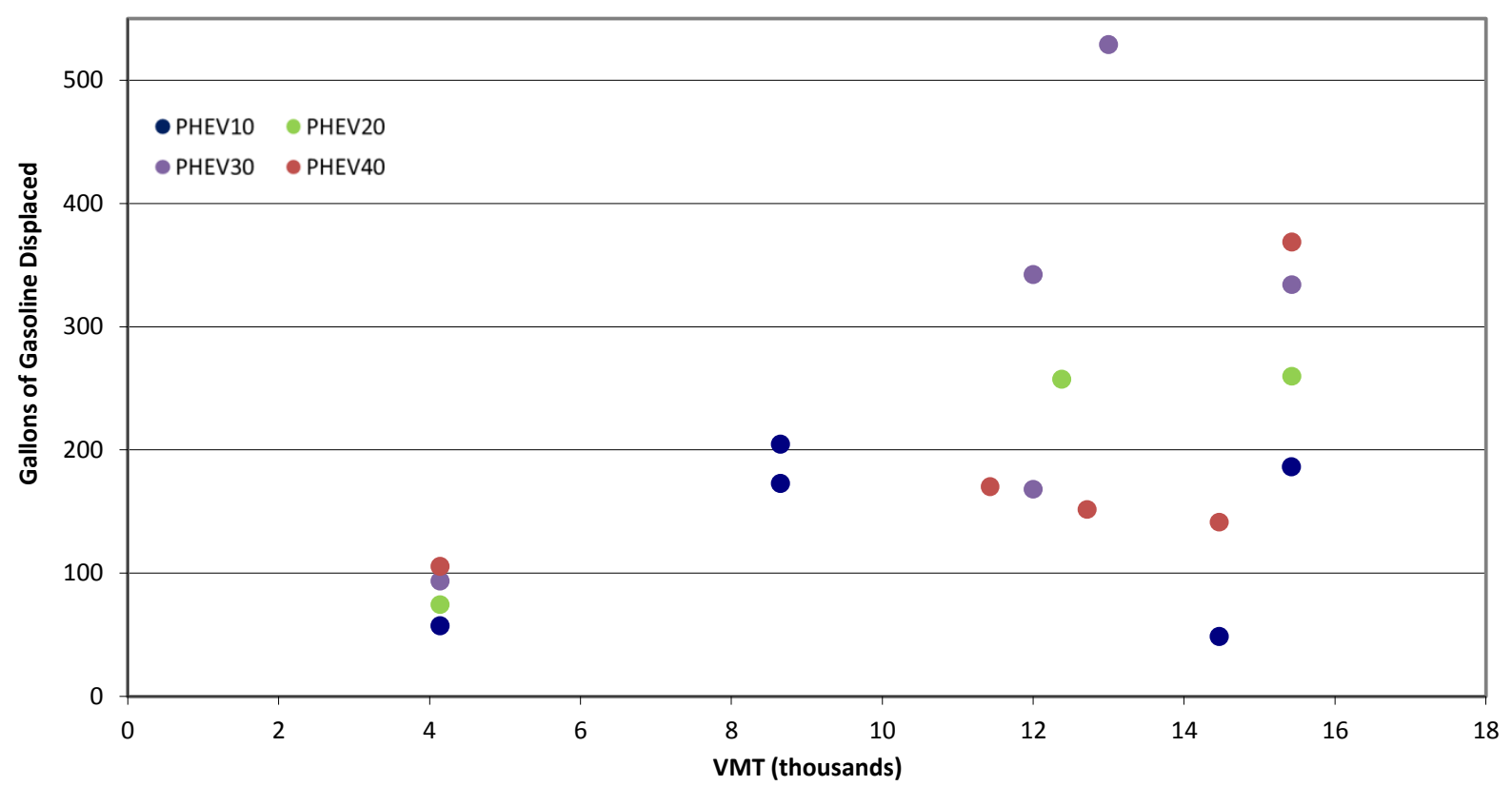

Figure 43: Gasoline displaced per PHEV as a function of VMT 


\subsubsection{Battery Capacity}

The amount of energy available in the electric motor of a PHEV determines its AER and through that the vehicle fuel efficiency. Data taken from the ANL EVS analysis portrays a linear relationship between battery power and the amount of gasoline fuel the battery is capable of displacing, as shown in Figure 44.

\section{Gasoline Displacement as a Function of Total Battery Power}

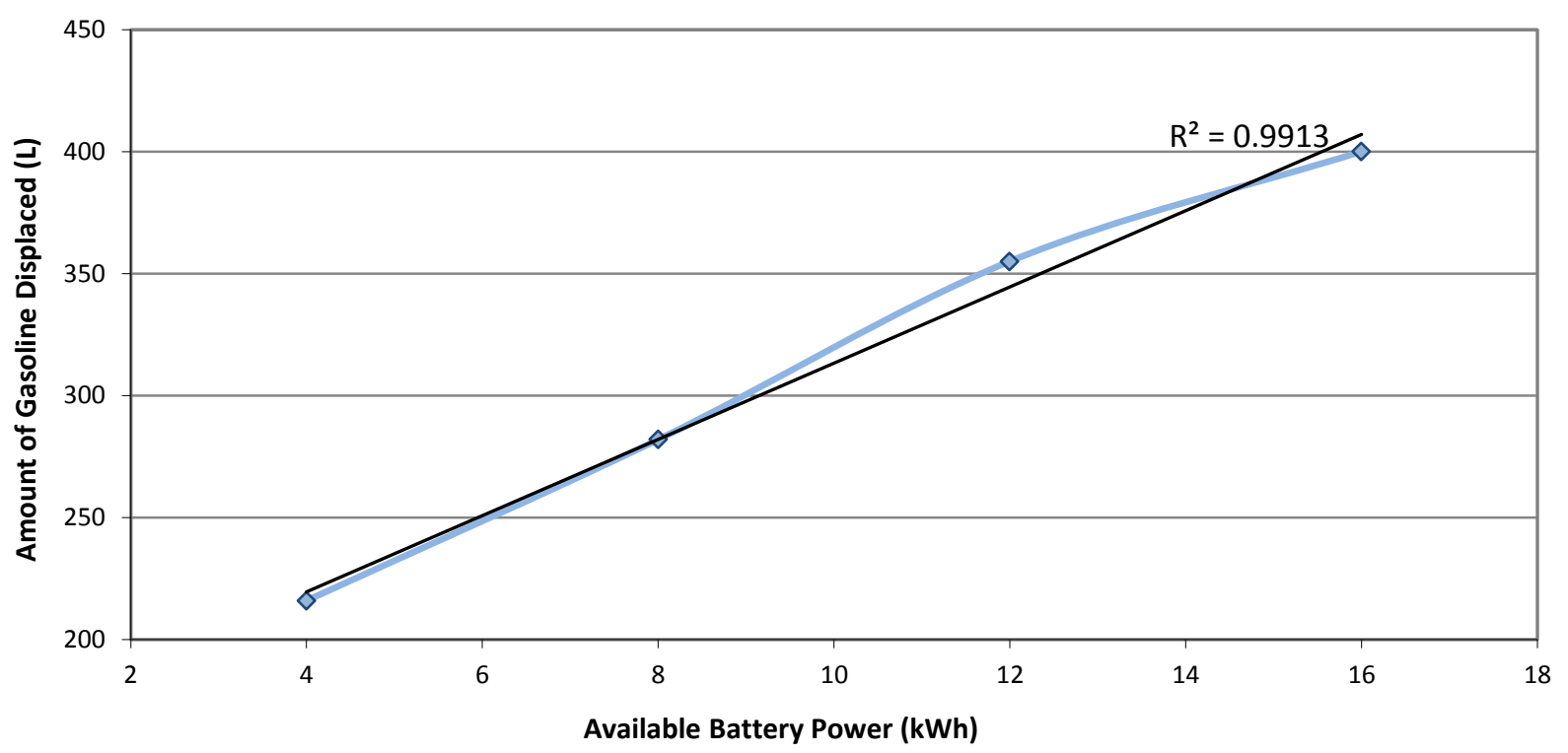

Figure 44: Correlation between battery power and fuel displacement from ANL EVS

\subsubsection{Utility Factor}

A utility factor represents the percentage of vehicle miles which are traveled on electricity, and is sometimes defined in an effort to more aptly describe a PHEV's gasoline displacement capability. Only the EPRI and MIT Prop studies quoted an overall utility factor; these values ranged from 0.12 to 0.66 . ANL WTW lists utility factors for CD and CS mode separately, but does not list the percentage of miles traveled in each operating mode and therefore cannot be directly compared to the utility factors listed in the other two studies.

\subsubsection{Vehicle Mass}

With PHEVs not yet on the road, estimating their performance involves a great deal of uncertainty, as does estimating the effects of other vehicle properties on performance. The SENTECH/ORNL VP report is the only one which provided more than one mass value for its PHEV. Figure 45 depicts the change in fuel economy for a PHEV30 in 2030 for three different vehicle masses as well as for a conventional vehicle and $\mathrm{HEV}$. As seen in this graph, the performance of the PHEV30 is much more sensitive to additional weight than the HEV and conventional vehicle. 


\section{SENTECH/ORNL VP Vehicle Fuel Economy as a Function of Mass}

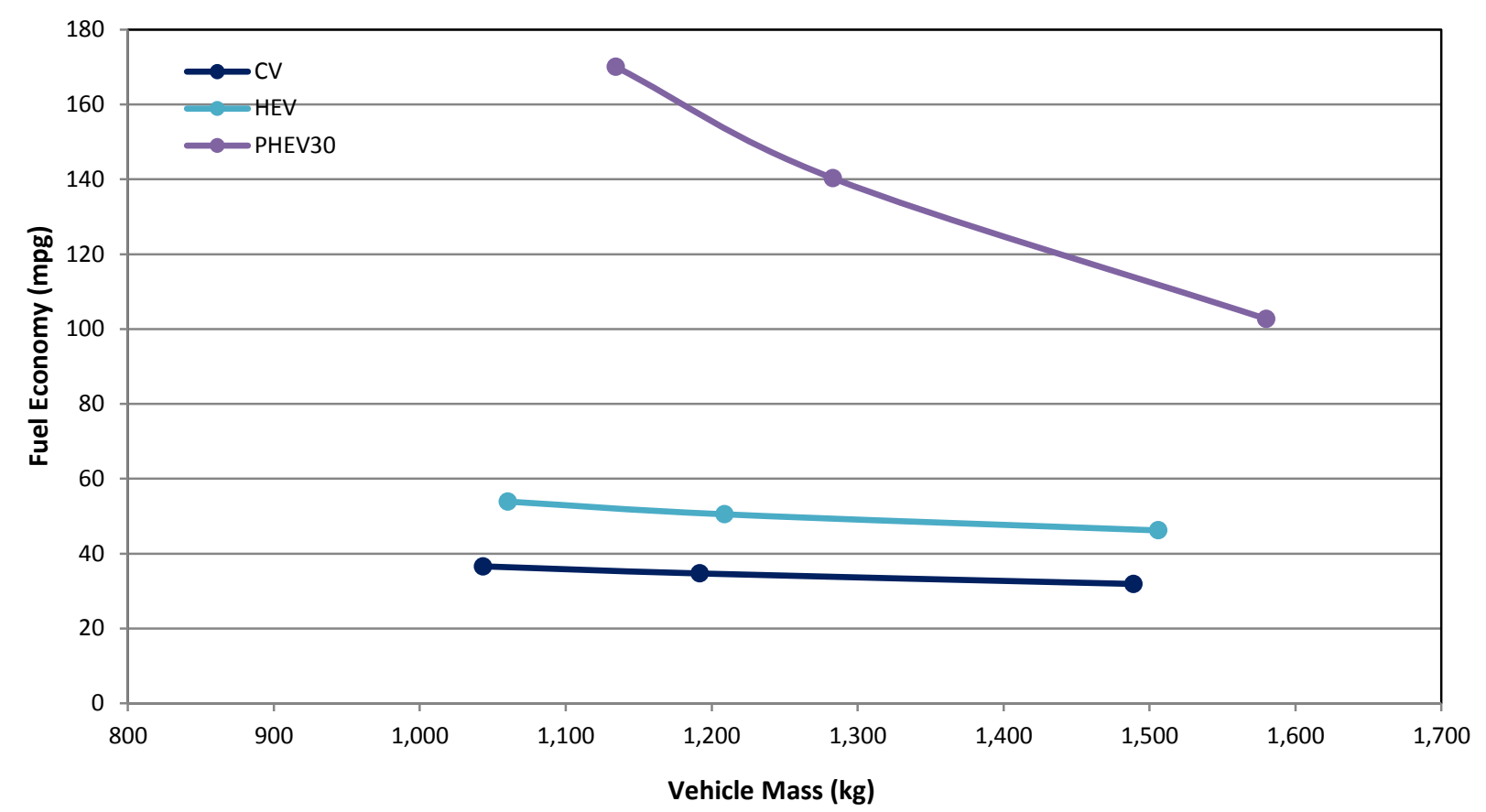

Figure 45: SENTECH/ORNL VP provides information to calculate fuel economy for three different vehicle masses and three different vehicle types

Estimating the effect of vehicle mass on future fuel economy required assumptions on PHEV performance, future vehicle mass, future battery efficiency, and future battery mass. SENTECH/ORNL VP utilizes the modeling software PSAT to calculate these variables as accurately as possible to obtain fuel economy values, but future estimates will inherently contain a number of unknowns. However, these fuel economy values provide a good picture of the likely overall effect of vehicle mass on vehicle performance.

\subsubsection{Drivetrain}

A more concrete factor that must be considered when estimating oil displacement potential is the anatomy of the PHEV's drivetrain. Three main drivetrain configurations have emerged for PHEVs in the reports investigated for this study: series, parallel and power-split. A series configuration runs solely on electricity before switching to a CS mode of operation once the battery is depleted. A parallel PHEV, on the other hand, can be powered by the battery or the engine at any time. PHEVs in a power-split configuration utilize two electric motors plus an ICE; the ICE can provide torque independently or in addition to the larger electric motor. Which of these three systems will be preferred on the commercial market is yet to be seen. Table 67 identifies which reports assume different PHEV drivetrain configurations. 
Table 67: List of PHEV drivetrain configurations where defined

\section{Gasoline Displacement for Report Scenarios}

\begin{tabular}{|l|c|c|}
\hline Study Name & AER $(\mathrm{mi})$ & $\begin{array}{c}\text { Drivetrain } \\
\text { Configuration }\end{array}$ \\
\hline ANL WTW & $10,20,30,40$ & Power-split / Series \\
\hline ANL EVS & $10,20,30,40$ & Power-split / Series \\
\hline NREL GPS & 20,40 & Parallel \\
\hline SENTECH/ORNL VP & $10,20,30,40$ & Parallel \\
\hline
\end{tabular}

The gasoline displacement results for specified drivetrains are plotted below in Figure 46. The ANL WTW data could not be plotted on this graph because the report did not provide any mileage from which to derive gasoline displacement.

\section{Gallons of Gasoline Displaced per 1,000 Miles Driven}

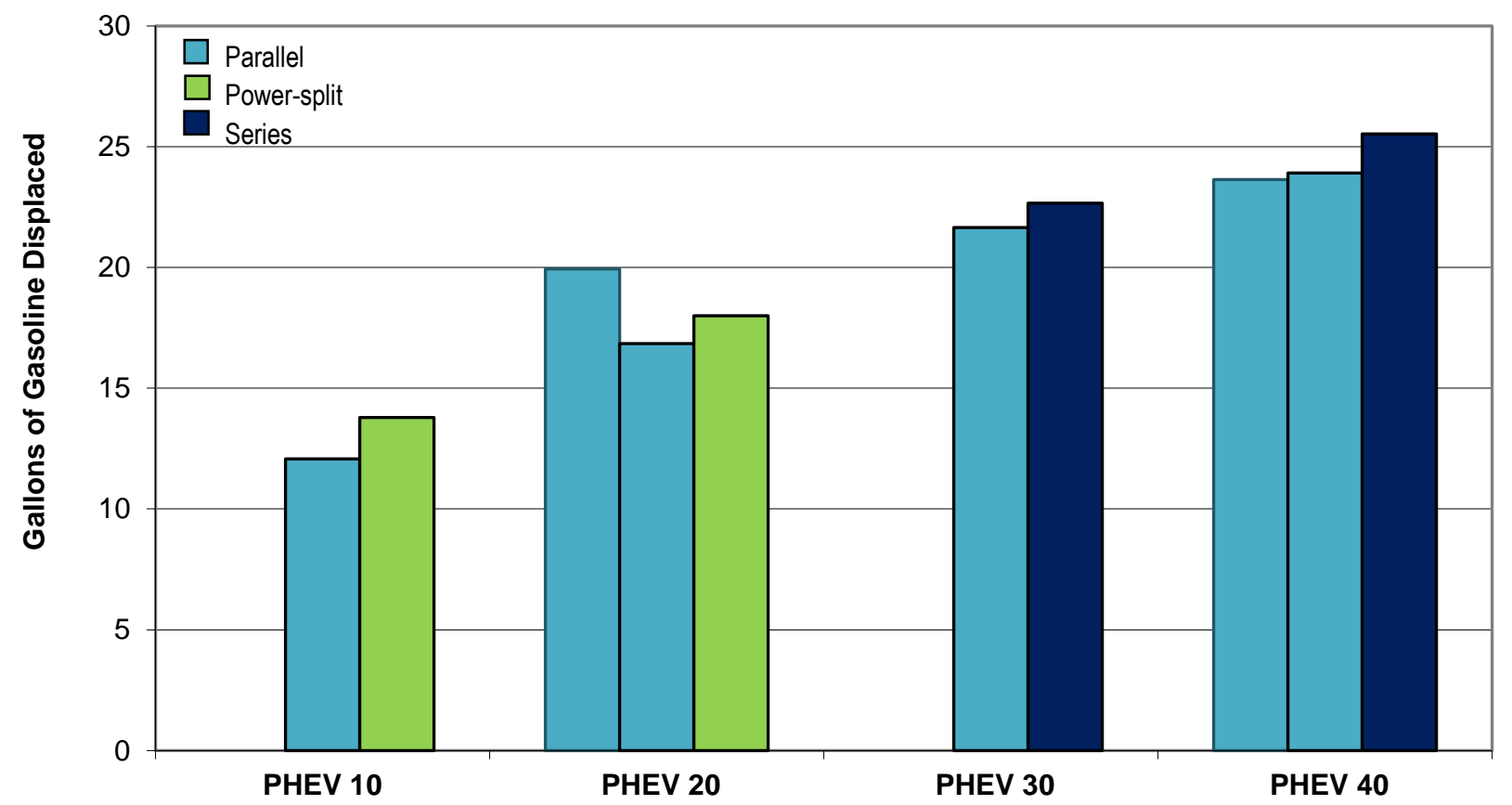

Figure 46: Gasoline displacement as a function of AER and drivetrain configuration

\subsubsection{Drive Mode}

Assumptions made for drive mode greatly affect the scenario results, because whether the PHEV operates in CD mode, CS mode, or a blended mode of operation affects the extent to which a PHEV displaces the oil use of its conventional counterpart. Running in a blended mode, the plug-in hybrid combines the use of the battery power and engine power to obtain the peak efficiency for each. However, within the reports 
reviewed for this chapter, the most popular driving strategy appears to be to run in CD mode until a minimum SOC is reached and then switch to CS mode. The other control strategy specified is a blended $C D$ mode, meaning the engine engages for power demands above the capacity of the electric motor. Little elaboration is given on driving strategy because quantitative information on this driving aspect is scarce. However the breakdown of driving mode chosen for each study is listed in Table 68.

Table 68: Choice of driving strategy selected for each report

\begin{tabular}{|c|c|c|c|c|}
\hline Study Name & $\mathrm{CD} / \mathrm{CS}$ & Blended CD & Blended & Not Explicitly Given \\
\hline ANL WTW & $x$ & & & \\
\hline ANL EVS & $x$ & $x$ & $x$ & \\
\hline NREL GPS & $x$ & & & \\
\hline SENTECH/ORNL VP & & & $x$ & \\
\hline ANL MPT & & $x$ & & \\
\hline MIT 2035 & & & & $x$ \\
\hline CalCars & & & & $x$ \\
\hline EPRI & & & & $x$ \\
\hline MIT Prop & $x$ & & & \\
\hline UVM & $x$ & & & \\
\hline NREL CBA & & & & $x$ \\
\hline$E C$ & & & & $x$ \\
\hline
\end{tabular}

\subsubsection{Modeling Software}

With future scenarios especially, modeling software is often utilized to forecast the impact that PHEVs will have on oil displacement. Each modeling program used in reports reviewed for this study is briefly described before comparing the displacement results calculated from these models.

- PSAT, or the Powertrain System Analysis Toolkit, developed by ANL, creates vehicle models which simulate fuel economy and vehicle performance. A variety of inputs such as driving cycle and energy management strategy can be applied to more accurately simulate battery charge/discharge profiles and corresponding fuel use.

- ADVISOR, or ADvanced Vehlcle SimulatOR, is a modeling program developed by the NREL which simulates vehicle design and can assess fuel consumption and performance of advanced technology vehicles, conventional vehicles, and PEVs with a variety of drivetrain configurations.

- MOBILE6, or the Mobile Source Emission Factor Model, developed by EPA, contains data on VMT for the mainland United States in 28 vehicle classifications, allowing energy use to be customized for each vehicle category. 
- $\quad$ NEMS, or the National Energy Modeling System, was developed by EIA and constructs integrated modeling scenarios of the future U.S. LDV fleet.

- EPPA, or the Emissions Prediction and Policy Analysis (EPPA) model, was developed by the MIT Joint Program on the Science and Policy of Global Change. It utilizes a recursive-dynamic general equilibrium model of the world economy starting with a base year of 1997. The model is solved recursively every five years starting in 2000. This model implements data from the Global Trade Analysis Project (GTAP).

The two programs used most often are PSAT and ADVISOR with each used in three different reports, or half of the 12 reports reviewed in this comparative study. MOBILE6 and EPPA are each used in a single report. All programs used in different studies are listed below in Table 69.

Table 69: List of various modeling programs used to calculate oil displacement

\section{Modeling Software Used in Each Report}

\begin{tabular}{|c|c|c|}
\hline PSAT & ADVISOR & Other (MOBILE6, EPPA) \\
\hline ANL WTW & NREL GPS & MIT Prop \\
\hline SENTECH/ORNL VP & MIT 2035 & EPRI \\
\hline ANL MPT & UVM & \\
\hline
\end{tabular}

To check for consistency within each modeling program, the gasoline displacement results are compared for the ADVISOR and PSAT studies in Figure 47. As the figure suggests, neither model seems to lend itself to a particular result.

\section{Barrels of Oil Displaced per 1000 Miles Driven}

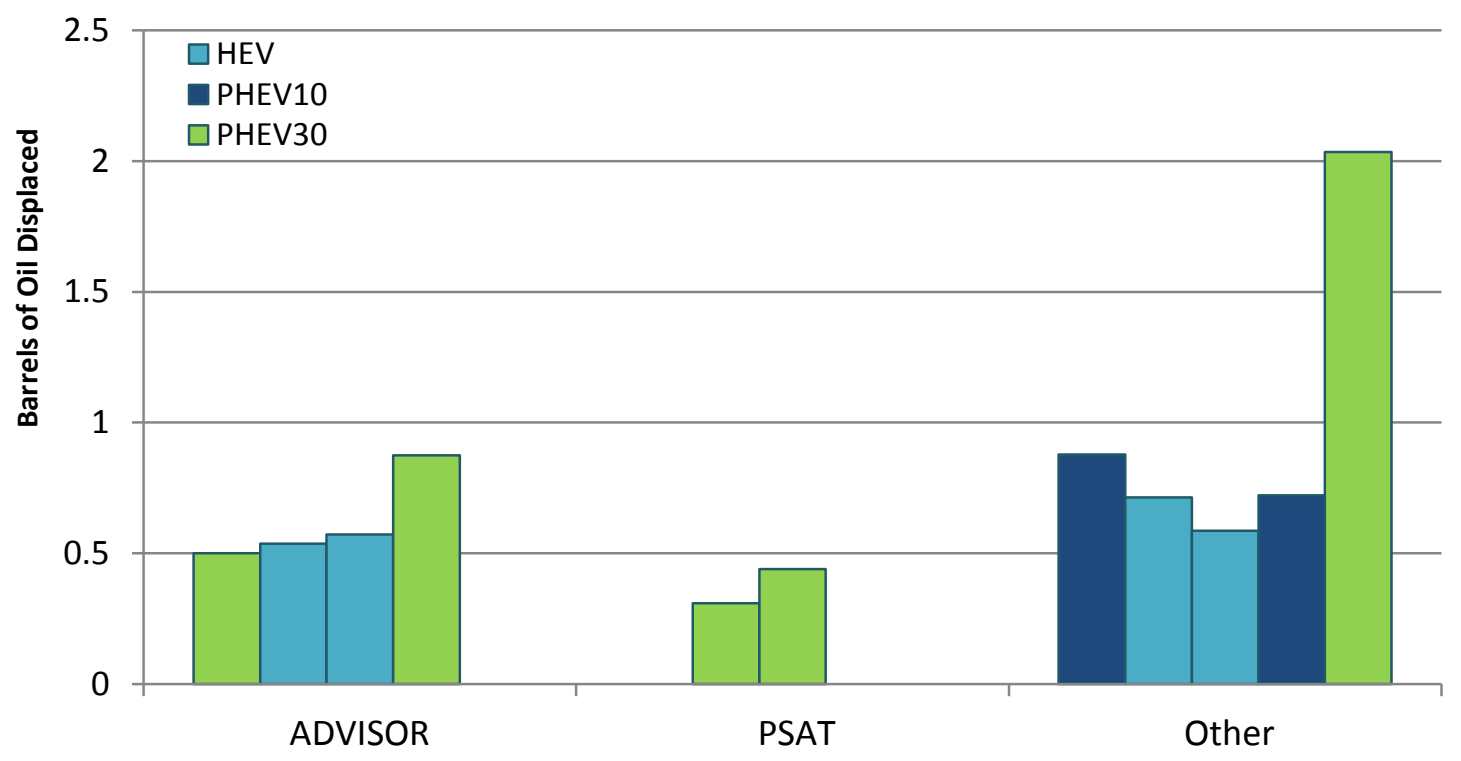

Figure 47: Gasoline displacement with respect to the modeling software implemented in the analysis 


\subsubsection{Qualitative Factors}

To compare a PHEV to a conventional vehicle, the distance it can travel solely on electricity, or AER, is key to determining the vehicle's fuel economy. PHEV's fuel economy is closely related to its AER in that the two are affected by many of the same attributes. Each vehicle is given a rated AER, but its true AER also depends on a number of more nebulous factors. Most apparent are the driving habits of the owner including his/her aggressiveness in speed, acceleration, deceleration, and accessory use; the distance traveled between charging events; whether the miles the PHEV travels are city or highway miles; the climate and the terrain. These factors can decrease or increase the miles driven on electricity for a given vehicle configuration. Recharging a PHEV before it has fully depleting its battery will boost its gasoline displacement. Aggressive driving puts a drain on the battery, shortens the vehicle's AER and ultimately lowers the PHEV's effectiveness in displacing gasoline fuel consumption.

\subsubsection{Fuel Displacement Results}

Figure 48 groups these values by the PHEV AER and plots the displacement per thousand vehicle miles traveled. This shows the PHEV20 to have the closest agreement in displacement results among studies and the PHEV30 to have the least agreement. The large variation in gasoline displacement for the PHEV30 appears to correspond with a variation in timeframe. MIT Prop sets up scenarios for the year 2100, at which time technology will have progressed from its present status, which is represented by the ANL EVS and UVM studies, and from its status in 2030 and 2035, the values portrayed by the SENTECH/ORNL VP study and the MIT 2035 study. The two PHEV30 values depicted for the MIT 2035 report correspond to its predictions for the present day and in 2035, with displacement increasing over time.

\section{Gallons of Gasoline Displaced by One PHEV per 1,000 Miles Driven}

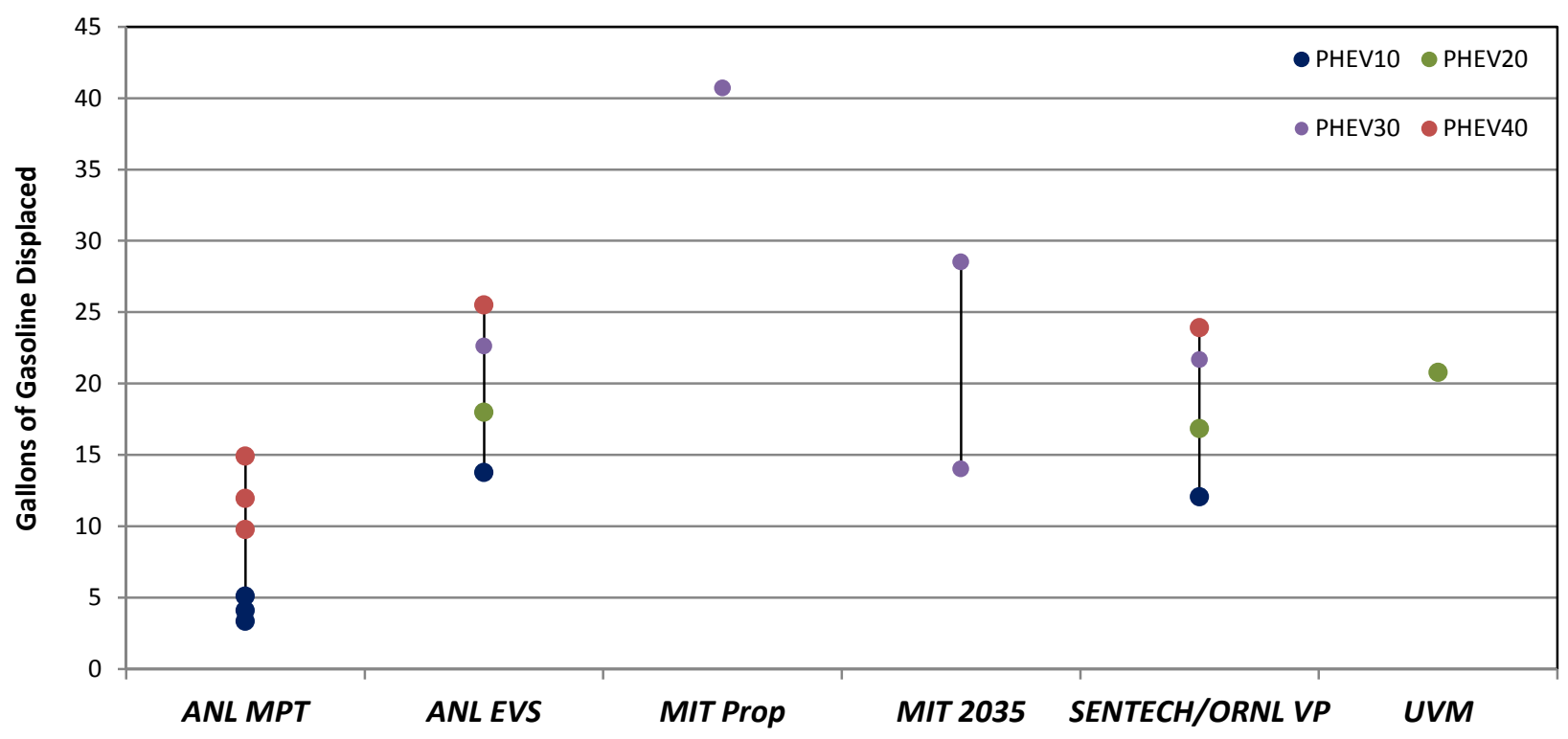

Figure 48: PHEV gasoline displacement per thousand miles driven per vehicle relative to a conventional vehicle 
It is important to understand that the effectiveness of a PHEV's oil displacement is relative to the vehicle it is replacing. Each organization that estimates oil displacement in their study must define a baseline vehicle (usually an ICE or other conventional vehicle), so the future maturity level for these vehicles is critical for making fair comparisons among vehicles.

The data shown throughout this chapter all show the effectiveness of PHEVs to reduce fuel consumption. One aspect not explicitly covered in the reports used in this chapter is the performance of PHEVs relative to each other. For example, how much greater is the fuel displacement of a PHEV40 versus a PHEV10? Comparing values within the three studies that specifically list PHEV10 and PHEV40 fuel use shows that between 1.8 and 3.0 PHEV10s are needed to displace the same amount of gasoline as one PHEV40.

Looking at oil displacement on an annual scale, Figure 49 portrays the barrels of oil displaced by HEVs and PHEVs. This graph can be viewed in two ways: one, it can be seen as the displacement of one PHEV over the course of a year, or two, as the displacement of 1 million PHEVs over the course of the year, if the barrels of oil values are assumed to be in millions.

\section{Oil Displacement per Year as a Function of AER}

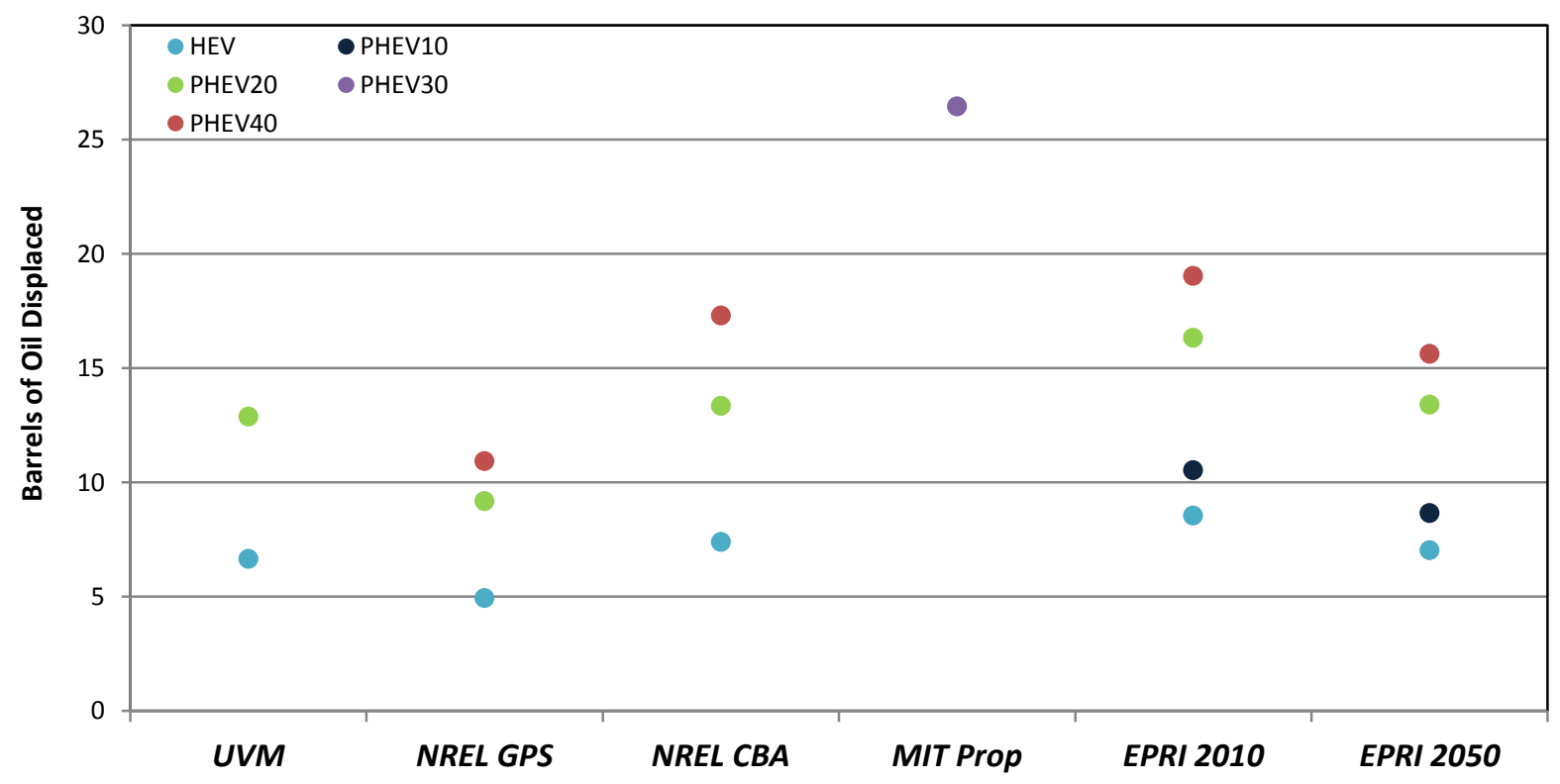

Figure 49: Annual oil displacement for per vehicle, broken down by publication relative to a conventional vehicle

An annual comparison does not put all the oil displacement numbers on the same scale however. To do this, the same data was used to calculate the amount of oil displaced for every thousand miles traveled. The results are depicted in Figure 50 and show oil displacement on an absolute scale. 


\section{Oil Dispacement per 1,000 Miles Driven}

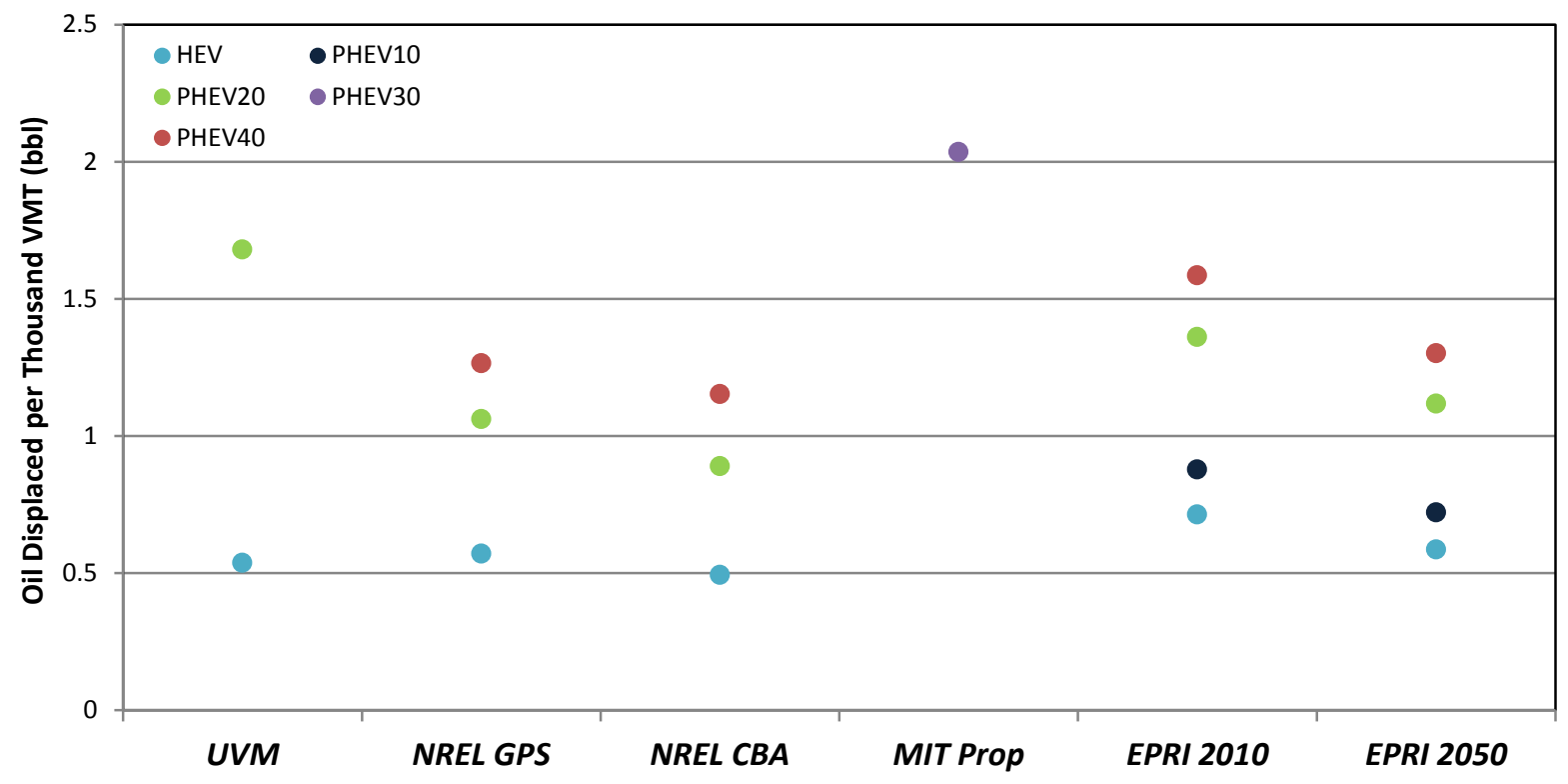

Figure 50: Oil displacement per thousand VMT

As with Figure 49, the data in the graph above can be viewed two separate ways: as the oil displacement of one vehicle over one thousand miles of travel; or the displacement of 1 million vehicles over 1,000 miles of travel, with the barrels of oil displaced then representing millions of barrels. Even with a uniform VMT, none of the AERs show consistent results across studies. Only the HEV, which is already being manufactured, shows consistent results.

\subsubsection{Number of PHEVs on the Road}

From a national fleet perspective, PHEV adoption rate has the greatest impact on the total oil displaced by PHEVs and other electric vehicle technologies. Unfortunately, with PEVs just making their mass-market debut, the number of variables involved is too great to estimate any specific vehicle volume. As concluded in Chapter 4, one of the largest factors in determining market penetration rate of PHEVs will be the price of gasoline. Other determinants include implemented climate policies, or lack thereof; the upfront cost of buying a PHEV versus a conventional vehicle; the available AER on PHEVs; the ability of the electric grid to handle large numbers of vehicles when plugged in; the length of time required to recharge a vehicle; and consumer preferences. Since several of these factors are interrelated, the uncertainty increases.

While already commercially available, the EC cites HEVs as comprising less than $1 \%$ of the current light duty fleet, or less than 2.5 million vehicles. In addition, EIA estimates that all grid-enabled vehicles will compose less than $1.5 \%$ of LDVs in 2030 , equating to approximately 4.3 million vehicles. The drawback to HEVs is that their benefits are inherently limited by a dependence on gasoline fuel. All studies reviewed for this report predict that the number of PHEVs on the road will increase, but whether that number will increase to over 200 million vehicles, or only half a million vehicles by 2035 remains to be seen. 


\subsection{Conclusions}

To sum up the results of this chapter, the fuel economy of a conventional gasoline vehicle in 2030 is projected to range between 23 and $37 \mathrm{mpg}$, and the fuel economy of a PHEV is predicted to be between 40 and $205 \mathrm{mpg}$. The rated AER of a PHEV does not appear to restrict predictions on its gasoline displacement to any significant degree within the analyses reviewed due to varying powertrain architectures. The mileage for conventional vehicles shows a general downward trend in fuel economy as the mass of the vehicle increases, and the projections for the mass and possible mileage of PHEVs in the SENTECH/ORNL VP study show this trend magnified for PHEVs. There is no apparent trend within the results in regard to the software utilized in the studies, such as PSAT and ADVISOR, in comparison to studies that base their results on future fuel economy standards.

For the studies reviewed here, PHEVs are forecast to displace anywhere from $24 \%$ to $90 \%$ of the oil used by a conventional vehicle, but most estimates put their displacement potential between $30 \%$ and $60 \%$ relative to a conventional vehicle. Oil displacement calculations begin with a single vehicle's gasoline reduction over a comparable conventional vehicle, but the overall amount of oil displaced by a certain vehicle type (e.g., PHEV fleet) ultimately depends on the number of that vehicle model on the road. With PHEV penetration rate projections in 2030 ranging from 1 million to almost 207 million units, the range of potential oil displacement is very broad and difficult to pinpoint. 


\section{Overall Conclusions}

The overall future of electric vehicle technologies is still uncertain and subject to great debate by the scientific community. National laboratories, universities, market analysis firms, and others have published reports discussing the future of electric vehicle technologies especially regarding their associated GHG emissions, annual market penetration rate, and oil displacement potential. This comparative study attempts to present an unbiased review of different reports that discusses the future of the electric vehicle technologies with respect to these major categories. While this study investigates all types of electric vehicle technologies (PHEVs, HEVs, and BEVs), a primary focus is placed on PHEVs.

\subsection{Comparison Constraints}

As explained throughout the report, the vast differences in approaches among the 31 reports investigated create a challenge when attempting to compare "apples-to-apples." The inconsistencies in assumption categories across the different studies further weaken the ability to compare one report to another. Therefore, the accuracy of the comparative analysis is constrained by five variables: 1) variation in the assumptions addressed, 2) variation in the year of the assumptions, 3) variation in the type of vehicle, 4) hidden assumptions, and 5) ambiguous assumptions.

- Variation in the assumption categories addressed: Very rarely do two studies address the same set of assumption categories. For example, when addressing the vehicle price assumption, in their report "Prospects for Plug-in Hybrid Electric Vehicles in the United States and Japan: A General Equilibrium Analysis," MIT addresses the vehicle price in terms of the vehicle mark-up as a percentage, while UMTRI addresses the vehicle price in terms of price premium as a dollar amount in their report entitled "Market Models for Predicting PHEV Adoption and Diffusion." Comparing percentages to dollars would require secondary assumptions to be made, potentially weakening the analysis. This dilemma is also seen with fuel prices where some organizations present the price in gallons while others make their assumptions for the price of oil in barrels.

- Variation in the year of the assumptions: Characteristics of electric vehicle technologies (e.g., vehicle cost, fuel economy) will not remain stagnant through the next few decades. Therefore, when different studies investigate the same vehicles for different timeframes, a fair comparison cannot easily be made. For example, a comparison of MIT's report "On the Road in 2035," which analyzes PHEVs in 2035, to EPRI/NRDC's report "Environmental Assessment of Plug-In Hybrid Electric Vehicles, Volume 1: Nationwide Greenhouse Gas Emissions," which analyzes PHEVs in 2050, will surely have some caveats. To eliminate this variation and compare the multiple data sets, secondary assumptions would have to be made regarding inflation rates and technology advancements that could have distorted the accuracy of the analysis.

- Variation in the type of vehicle: Often studies generalize their assumptions among the different types of vehicles addressed and group two or more vehicle powertrains into a single forecast. This is the case in Deloitte's report entitled "Gaining Traction: A customer view of electric vehicle mass adoption in the U.S. automotive market" where an average price is assumed for both the BEV and the PHEVs collectively. Deloitte assumes the vehicle price (valid for both PHEVs and BEVs) to be $\$ 25,000$ for their most aggressive scenario, so it not clear how to compare. Since other studies may discuss the vehicle price only for PHEVs, comparing Deloitte's vehicle price versus other vehicle price may not be accurate.

- Hidden assumptions: Only information available in published reports is used in this comparative analysis. Most of the published reports do not document the full extent of model inputs used to 
generate each PHEV annual market penetration forecast, even though they may have taken them into account during their analyses. Instead, they usually highlight key assumptions used. As a result, assuming values for assumptions that exist but just hidden could distort the accuracy of the analysis.

- Ambiguous or immeasurable assumptions: In addition to hidden assumptions, some reports are ambiguous in their assumptions. For example, certain reports suggest that PHEV technology development will be "accelerated" as a result of advancements made in hybrid technology. Other reports may assume that lithium-ion battery costs will be "reduced." Both assumptions are qualitatively explained and are viable within their own report's context. However, neither assumption provides a ground for comparison because of the immeasurability of the assumptions.

Therefore, as displayed in Figure 51, a full comparative analysis across the 31 studies would likely be distorted due to the five main comparison constraints. Requiring an "apples-to-apples" comparative study would force the project team to make compounding assumptions in order to bring the studies on the same ground. Hence, the project team chose to present a breakdown of the assumptions supporting the scenarios and the data points presented earlier in this comparative study, and to perform comparisons only when a strong comparison could be made.

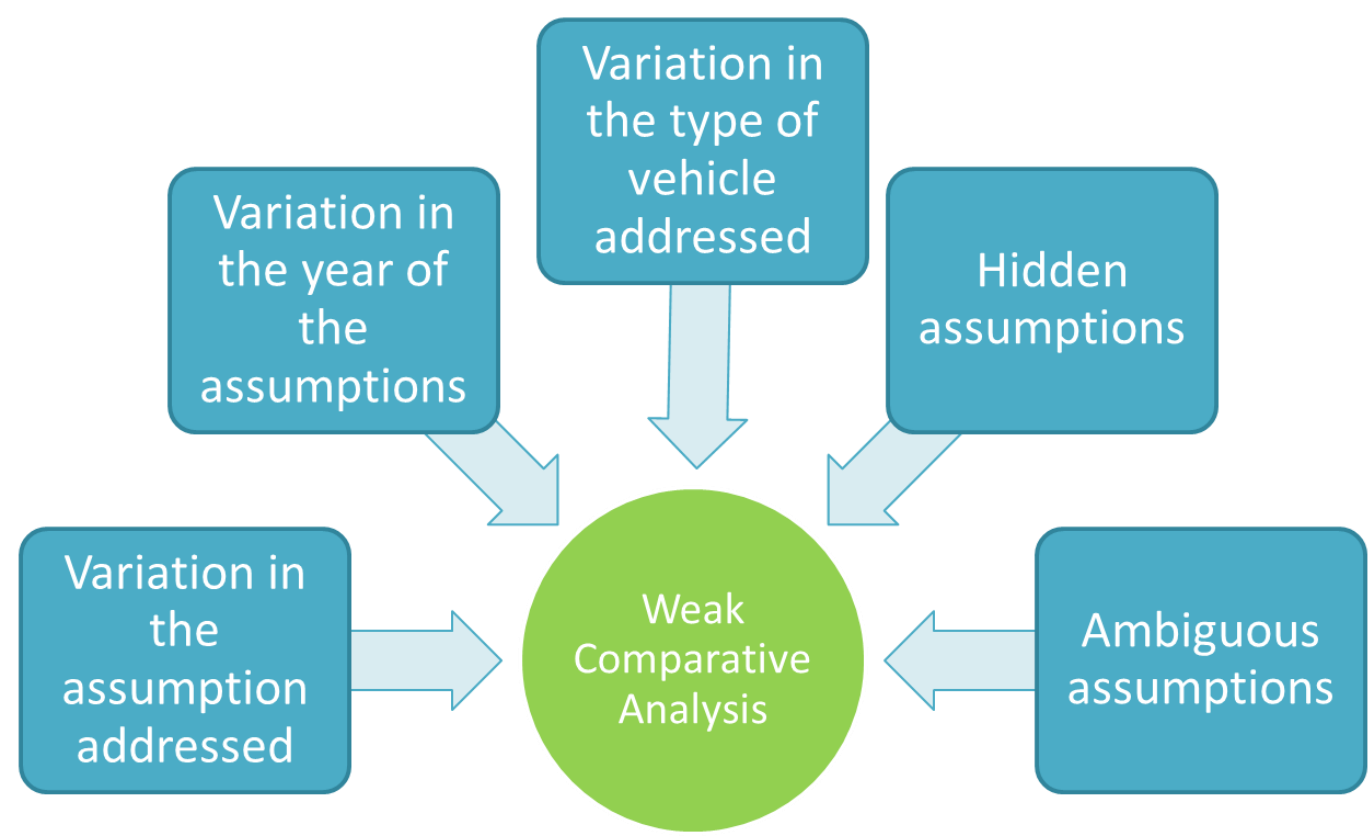

Figure 51: Comparison Constraints 


\subsection{Major Areas of Focus}

\subsubsection{GHG Emissions}

With regards to the baseline conventional and alternative vehicle technologies, the data points suggest overall agreement among the major studies. Of course, small discrepancies in the data exist, which can likely be attributed to the different models used to calculate emissions and the assumptions made on "average" electricity generation mixes, fuel blends, etc. Even though no two reports use the exact same assumptions or present identical results, none can be deemed "right" or "wrong." Each group clearly defines their assumptions and methods for arriving at their results. Ultimately, it appears that each report is generally reaching similar conclusions, just building different scenarios to demonstrate them.

When the various electricity generation mixes for each report are investigated, the results are initially scattered. However, an overall trend can be seen that relates the emissions value to the carbon intensity of the electricity generation mix being used, assuming fuel blend and AER are held constant. Generally speaking, the carbon intensity levels of the key inputs (electricity generation and fuel blend) have the greatest impacts on the resultant GHG emissions. Similarly, when investigating the various fuel blends used across studies, the carbon intensity of the fuel blend appears to be directly related to the vehicle emissions.

\subsubsection{Annual Market Penetration}

The PEV annual market penetration outlook is highly diverse across the reports reviewed in this comparative study. This is especially true for PHEVs in 2050 where the annual market penetration ranges from $0 \%$ to almost $90 \%$. The variation in the PHEV annual market penetration forecasts could be partly justified by studies using different assumptions, which the project team breaks down for each scenario provided in the reports reviewed. BEVs have the most conservative annual market penetration forecast in that beyond 2020, BEVs maintain 0\% annual market penetration for scenarios that only investigate BEVs. $\mathrm{HEV}$ annual market penetration is relatively consistent across most studies forecasting a range between $10 \%$ and $50 \%$ throughout the timeframe 2020 to 2050.

\subsubsection{Oil Displacement}

Although single PEVs are capable of displacing a large percentage of oil relative to a conventional vehicle, they are unlikely to make a significant contribution to fleet-wide petroleum displacement until production ramps up into the millions. As such, many critical factors that will affect their ability to displace petroleum, such as future conventional fuel economy, PHEV AER, and the ease of recharging are still unknowns. However, most studies agree that with PHEVs as a significant portion of the light vehicle fleet, imported petroleum consumption can be drastically reduced. RAND Corporation asserts that 10 million PHEV40s on the road could displace $1.8-2.9$ billion gallons of gasoline per year. Using EIA's conversion factor of 20 gallons of gasoline per barrel of petroleum, this translates 90 to 145 million barrels of oil per year that could be displaced by 10 million PHEV40s.

Regardless of the level of penetration that PHEVs reach within the market, the reports reviewed in this comparative study project that a PHEV will be capable of displacing anywhere from approximately $25 \%$ of a conventional vehicle's fuel consumption up to approximately $90 \%$. The majority of studies place this number between $30 \%$ and $60 \%$, but with so many variables unknown, the true benefits of PHEVs cannot be conclusively established. 


\subsection{Final Thoughts}

As demonstrated in the body of this study, numerous factors affect future projections of GHG emissions, annual market penetration rates, and oil displacement. Since each individual factor adds a new layer of uncertainty it is near impossible to accurately predict what the future holds for electric vehicle technologies. With this large amount of assumptions that must be made by each organization's assessment, it is easy to understand why such a wide range of possible projections is seen in the collection of reports investigated in this comparative study.

In order to account for the unknown variables, such as the cost of oil, government intervention, and technological breakthroughs, many of the authors included extensive sensitivity analyses within their reports to capture a wide range of potential scenarios. The project team anticipates that the scientific community will continuously incorporate future data into their models and projections to more accurately estimate the future of electric vehicle technologies. As the industry matures, it is anticipated that the wide range of possibilities will narrow to provide a more consistent picture of the future of vehicle technologies. 


\section{References}

Axsen, J. et al., 2010, Plug-In Hybrid Vehicle GHG Impacts in California: Integrating Consumer-Informed Recharge Profiles with an Electricity-Dispatch Model, University of California-Davis.

Balducci, P., 2008, Plug-in Hybrid Electric Vehicle Annual Market Penetration Scenarios, Pacific Northwest National Laboratory, Report\# PNNL-17441, September.

Bandivadekar, A., et al., 2008, On the Road in 2035 - Reducing Transportation's Petroleum Consumption and GHG Emissions, Massachusetts Institute of Technology, Repor\# LFEE 2008-05 RP, July.

Book, Michael, et al., 2009, The Comeback of the Electric Car?,The Boston Consulting Group.

Deloitte Consulting LLP, 2010, Gaining Traction: A customer view of electric vehicle mass adoption in the U.S. automotive market.

Deutsche Bank, 2008, Electric Cars: Plugged In, Deutsche Bank Securities Inc., June.

Dowds, J., and P. Hines, 2009, A Review of Results from Plug-in Hybrid Electric Vehicle Impact Studies, The Institute of Electrical and Electronics Engineers.

Electric Power Research Institute and Natural Resources Defense Council, 2007, Environmental Assessment of Plug-In Hybrid Electric Vehicles, Volume 1: Nationwide Greenhouse Gas Emissions, EPRI Repor\#\# 1015325, July.

Electrification Coalition, 2009, Electrification Roadmap: Revolutionizing Transportation and Achieving Energy Security, November.

Elgowainy, A., et al., 2010, Well-to-Wheels Analysis of Energy Use and Greenhouse Gas Emissions of Plug-in Hybrid Electric Vehicles, Argonne National Laboratory, Report\# ANL/ESD/10-1, June.

Energy Information Administration, 2009, Annual Energy Outlook 2010 Early Release Overview, U.S. Department of Energy, Washington, D.C., December.

Environmental Protection Agency, 2010, Analysis of the Transportation Sector: Greenhouse Gas and Oil Reduction Scenarios, February.

Genung (Sikes), K., et al. Plug-In Hybrid Electric Vehicle Value Proposition Study: Interim Report: Phase 1 Scenario Evaluation, Oak Ridge National Laboratory/Sentech, Inc., January 2009. ORNL/TM2008/076.

Gonder, J., et al., 2007, Using GPS Travel Data to Assess the Real World Driving Energy Use of Plug-in Hybrid Electric Vehicles, National Renewable Energy Laboratory, Presented at the Transportation Research Board 86 th Annual Meeting, January.

Gremban, R., 2009, Displacement of Petroleum \& $\mathrm{CO}_{2}$ Reductions from Super-Optimistic Business-asUsual Mass Production of Light Vehicle PHEVs, CalCars. 
Hadley, S., 2006, Impact of Plug-in Hybrid Vehicles on the Electric Grid, Oak Ridge National Laboratory, Report\# ORNL/TM-2006/554, October.

JD Power and Associates, 2010, Drive Green 2020: More Hope Than Reality?: A Special Report by J.D. Power and Associates, November.

Jessup, P., 2007, Plug-In Hybrids: Prospects and Progress, Toronto Atmospheric Fund.

Karbowski, Dominik; Haliburton C.; Rousseau, A., 2008, Impact of Component Size on Plug-In Hybrid Energy Consumption Using Global Optimization, Argonne National Laboratory.

Karplus, V.; Paltsev, S.; Reilly, J., 2009, Prospects for Plug-In Hybrid Electric Vehicles in the United States and Japan: A General Equilibrium Analysis, MIT Joint Program on the Science and Policy of Global Change, April.

Kintner-Meyer, M., K. Schneider, and R. Pratt, 2006, Impacts Assessment of Plug-In Hybrid Vehicles on Electric Utilities and Regional U.S. Power Grids, Pacific Northwest National Laboratory, Paper commissioned by the U.S. Department of Energy.

Letendre, S., 2008, Plug-In Hybrid Vehicles and the Vermont Grid: A Scoping Analysis, Scoping Analysis. Burlington: The University of Vermont.

McManus, W., and R. Senter, Jr., 2009, Market Models for Predicting PHEV Adoption and Diffusion, The University of Michigan Transportation Research Institute, Report\# UMTRI-2009-37, July.

National Research Council, 2010, Transitions to Alternative Transportation Technologies - Plug-in Hybrid Electric Vehicles, The National Academies Press, Washington D.C.

The Obama-Biden Transition Project. Agenda: Energy and Environment. Energy Plan Overview, "Get 1 Million Plug-In Hybrid Cars on the Road by 2015." 2009

Energy Independence and Security Act of 2007 (EISA). Pub. L. 110-140. § 131.

Pesaran, A., and T. Markel, 2007, Battery Requirements and Cost-Benefit Analysis for Plug-In Hybrid Vehicles, National Renewable Energy Laboratory, Presented at the 24th International Battery Seminar \& Exhibition.

Plotkin, S., and K. Singh, 2009, Multi-Path Transportation Future Study: Vehicle Characterization and Scenario Analyses, Argonne National Laboratory, Report\# ANL/ESD/09-5, December.

Roland Berger Strategy Consultants, 2010, Powertrain 2020 Li-ion Batteries - The Next Bubble Ahead?, February.

Rousseau, A., et al., 2009, Impact of Real World Drive Cycles on PHEV Fuel Efficiency and Cost for Different Powertrain and Battery Characteristics, Argonne National Laboratory, presented at AABC 2009.

Samaras, C., 2010, Environmental, Security, and Economic Issues of Electricity as a Transportation Fuel, RAND Corporation, Presentation made on March 15. 
Samaras, C. and K. Meisterling, 2007, Life Cycle Assessment of Greenhouse Gas Emissions from Plug-in Hybrid Vehicles: Implications for Policy, Published in Environmental Science Technology, 2008, 42, 3170-3176, Carnegie Mellon University, August.

Sikes, K., et al., 2010, Plug-In Hybrid Electric Vehicle Market Introduction Study: Final Report. ORNL/TM2009/019. Oak Ridge National Laboratory/Sentech, Inc. January.

United States. Environmental Protection Agency. "Dynamometer Driver's Aid." June 2010.

United States. Environmental Protection Agency. Energy Information Administration. Frequently Asked Questions. Sept. 2010.

United States. Environmental Protection Agency. National Highway Traffic Safety Administration. "Notice of Upcoming Joint Rulemaking to Establish 2017 and Later Model Year Light Duty Vehicle GHG Emissions and CAFE Standards." Sept. 2009. 
Appendix

Total projected light-duty vehicle sales in the United States according to the Oak Ridge National Laboratory MA ${ }^{3} T$ Model

\begin{tabular}{|l|l|}
\hline Year & Sales (Thousands) \\
\hline 2012 & 14,851 \\
\hline 2013 & 15,654 \\
\hline 2014 & 16,216 \\
\hline 2015 & 16,576 \\
\hline 2016 & 16,581 \\
\hline 2017 & 16,802 \\
\hline 2018 & 16,967 \\
\hline 2019 & 17,140 \\
\hline 2020 & 17,279 \\
\hline 2021 & 17,203 \\
\hline 2022 & 17,191 \\
\hline 2023 & 17,384 \\
\hline 2024 & 17,674 \\
\hline 2025 & 18,022 \\
\hline 2026 & 18,253 \\
\hline 2027 & 18,367 \\
\hline 2028 & 18,457 \\
\hline 2029 & 18,563 \\
\hline 2030 & 18,800 \\
\hline 2031 & 18,962 \\
\hline & \\
\hline
\end{tabular}

\begin{tabular}{|l|l|}
\hline Year (cont'd) & Sales (Thousands) \\
\hline 2032 & 19,125 \\
\hline 2033 & 19,290 \\
\hline 2034 & 19,458 \\
\hline 2035 & 19,627 \\
\hline 2036 & 19,797 \\
\hline 2037 & 19,970 \\
\hline 2038 & 20,145 \\
\hline 2039 & 20,322 \\
\hline 2040 & 20,500 \\
\hline 2041 & 20,681 \\
\hline 2042 & 20,863 \\
\hline 2043 & 21,048 \\
\hline 2044 & 21,235 \\
\hline 2045 & 21,424 \\
\hline 2046 & 21,615 \\
\hline 2047 & 21,808 \\
\hline 2048 & 22,003 \\
\hline 2049 & 22,201 \\
\hline 2050 & 22,400 \\
\hline
\end{tabular}

